ANDRE GINGRICH

\title{
6. Wohnarchitektur im südwestlichen Saudi Arabien: Lokale Zeugnisse historischer Interaktionen mit Nachbarn, Herrschern und Fremden
}

\subsection{EINLEITUNG}

Die vorliegende Untersuchung befaßt sich mit der vorindustriellen Wohnarchitektur der südwestlichen Provinzen Saudi Arabiens. Ausgehend vom Erhebungszeitraum Anfang der 80er Jahre werden vier architektonische Haupttypen unterschieden. Dies sind der städtische Küstenstil am Roten Meer, die Hütten der Küstenebenen und der östlichen Oasen, weiters die innerarabische Lehmbauweise am Rande des Najd, und schließlich die südwestliche defensive Hochbauweise (mit zwei Subtypen und ihren jeweils drei Varianten).

Der methodischen Aufgabenstellung entsprechend legt die Untersuchung besonderen Wert auf die räumliche Dimension, ohne deshalb die zeitliche und kulturhistorische Seite zu vernachlässigen. Jeder der vier Haupttypen von regionaler Architektur ist dabei in besonderer Weise mit bestimmten sozio-ökonomischen Strukturen und Nachbarregionen stärker verbunden als mit anderen.

Der städtische Küstenstil verweist auf die Dynamik des internationalen Handels am Roten Meer und im Indischen Ozean, an deren anderen Küsten er in ähnlichen Varianten ebenfalls auftritt. Die sozialen Träger dieses Typus sind Kaufleute, Gelehrte und Beamte, daneben aber auch Fischer und früher Taucher.

Die Hütten der Küstenebenen und östlichen Oasen sind charakteristisch für das einfache ländliche Leben am Rande der Steppe. Dörfliche Gelehrte, Parzellenbauern, Handwerkerfamilien, aber auch semitribale und kleinere Verbände und Gruppen ehemaliger Sklaven sind die sozialen Träger dieses Typus, der in vielfältiger Weise auf die Nachbarschaft Ostafrikas verweist.

Die innerarabische Lehmbauweise am Rande des Najd wiederum ist geprägt vom dortigen Wechselspiel zwischen Oasenbauern und nomadischen Gruppen. Dieser Typus ist der südwestlichste Ausläufer von Formen, deren Hauptverbreitungsgebiete im Zentrum der Arabischen Halbinsel liegen.

Damit sind drei der vier traditionellen architektonischen Haupttypen dieser Region eingebunden in große, überregionale Zusammenhänge - nämlich die Küsten am Roten Meer und am Indischen Ozean, die ostafrikanischen Binnenländer, und die Steppen und Oasen Innerarabiens.

Der vierte Typus, die südwestliche defensive Hochbauweise, ist ebenfalls Teil eines überregionalen kulturellen Zusammenhanges, der durch das alte, bäuerliche Erbe Südwestarabiens definiert wird. Zugleich aber ist die Hochbauweise stärker als die drei ande- 
ren Typen durch eine Vielzahl lokaler Besonderheiten charakterisiert, denen die Untersuchung erstmals systematisch nachgeht. Die tribale bäuerliche Bevölkerung dieser Berggebiete - hauptsächlich jene des 'Asīr und des südlichen Hijāz - sind die eigentlichen sozialen Träger dieses architektonischen Typus, der unter den Vieren der bedeutendste ist und die absolute Bevölkerungsmehrheit im saudischen Südwesten beherbergt.

Ich habe mich bei der Dokumentation, Analyse und Interpretation des vorliegenden Datenmaterials neben meinen eigenen Erhebungen (1980-82 und - im nördlichen Khawlān - 1986) auf drei weitere, außerordentlich wichtige Datensätze stützen können: Dies sind erstens die von Walter Dostal 1979 erhobenen und 1983 publizierten Materialien des „Preliminary Report" zum jetzt vorliegenden Werk, zweitens ein von Claudia Kickinger verdienstvollerweise angelegtes Archiv solcher älterer Quellen, die in westlichen Sprachen publiziert worden sind, und drittens die umfangreichen Photoarchive von Mauger Thierry und insbesondere von Pascal und Marie Maréchaux (Paris). Für hilfreiche Hinweise, Ratschläge und Hilfestellungen bei der Ausarbeitung dieser Untersuchung danke ich weiters Gebhard Fartaček, Sylvia Haas und Johann Heiß.

Völlig verzichtet habe ich auf die Untersuchung der modernen Veränderungsprozesse, die bereits zur Erhebungszeit einsetzten, und die Architektur im saudischen Südwesten seither weitgehend umgestaltet haben. Es schien mir wichtiger (und, ich kann es nicht leugnen, auch interessanter) dem Reichtum und der Vielfalt der vorindustriellen Architektur mein Hauptaugenmerk zu schenken. Aber auch die modernen Veränderungen selbst lassen sich erst verstehen, wenn die sozio-kulturellen Grundlagen und historischen Voraussetzungen identifiziert sind, in welche die modernen Transformationen hinein intervenieren. Um diese sozio-kulturellen Grundlagen und Voraussetzungen, um die technischen, konstruktiven, sozialen und ästhetischen Eigenschaften der vorindustriellen Wohnarchitektur im saudischen Südwesten geht es in den folgenden Ausführungen.

\subsection{DER KÜSTENSTIL IN AL-QUNFUDHA}

Die kleine und relativ junge Hafenstadt al-Qunfudha bietet Beispiele an Architektur und Lebensstil, die bis vor wenigen Jahrzehnten für die Küstengebiete des Roten Meeres typisch waren, und darüber hinaus auch für die angrenzenden Küstenstreifen am Indischen Ozean. Die hier untersuchten Architekturbestände von al-Qunfudha lagen Anfang der 1980er Jahre (dem ethnographischen Präsens) nur mehr in letzten, größtenteils verfallenen Restformen vor. Diese Untersuchung ist daher bereits eine historische Retrospektive: Die alten Hausbestände der Erhebungszeit sind zum Zeitpunkt der Publikation nahezu völlig verschwunden und durch moderne Stadtarchitektur ersetzt worden.

Der Standort dieser Siedlung am Roten Meer ist durch zwei Faktoren geprägt - erstens durch das Zusammentreffen mehrerer Verkehrs- und Handelsrouten bei einem natürlichen Hafen, und zweitens durch die Versorgung mit Trinkwasser.

Der Seeweg galt schon in früher islamischer Zeit als bevorzugte Reiseroute für Händler und Pilger. ${ }^{1}$ Parallel dazu verläuft zu Land die bedeutende Küstenroute von Jidda nach dem Jemen. Auf diese beiden historischen Nord-Süd-Verbindungen stoßen im Umland der Siedlung die Mündungsgebiete mehrerer Wadis, die ungefähr in Ost-West-Richtung

\footnotetext{
1 King und Lewcock 1978 (1984): 209.
} 
die Berggebiete des südlichen Hijāaz zum Meer hin entwässern. Dies sind (in ihrer ungefähr parallelen Abfolge von Norden nach Süden) das W. Aḥsiba, das W. Lūma, das W. Ghamīm, und als größtes das W. Qanūna. Die bedeutenden Regenfluten aus dem Hochland bewirken für die Mündungsgebiete dieser Wadis wesentlich höhere Grundwasserspiegel als im flachen Hinterland der Küste mit seinem ariden Klima. Mehrere Brunnen für Trinkwasser sind für die Mündung des W. Qanūna belegt. ${ }^{2}$ Zugleich sind diese Wadis die entscheidenden Verkehrsrouten, die das bäuerliche Hinterland der Tihāma und des Hijāz mit der Küste verbinden.

Kleine Sandinseln und -bänke vor dem Mündungsgebiet des W. Qanūna bilden einen geschützten, natürlichen Hafen, der allerdings nur beschränkt nutzbar ist: Der niedrige Wasserstand in einem breiten Streifen vor der Küste, und davor zahlreiche Korallenbänke haben den Hafen nur für kleine und flache Boote zugänglich gemacht; größere Schiffe mußten stets auf See ankern. ${ }^{3}$

Die historische Rolle von al-Qunfudha war die eines staatlichen Garnisons- und Nachschubortes an der Küste, weiters jene eines „port of trade “4 für das bäuerliche Hinterland der Tihāma und des Hịjāz (insbesondere für die Ghāmid-Föderation im südlichen Ḥijāz), und schließlich die einer Pilgerstation auf dem Weg zu den heiligen Stätten des Islam. Die beschränkte Kapazität seines Hafens und die geringe Bedeutung seines Hinterlandes im Vergleich zum Jemen oder zu al-Haramayn (Mekka und Medina) haben al-Qunfudha aber nie zu einer Küstenstadt von erstrangiger Bedeutung werden lassen; es stand Zeit seines Bestehens im Schatten wichtigerer Häfen wie Jidda, al-Ḥudayda, oder al-Mukha. Dennoch hat al-Qunfudha in den letzten drei, vier Jahrhunderten für diesen Abschnitt der Ostküste des Roten Meeres die Rolle eines wichtigen Küstenortes eingenommen. Ähnlich wie weiter südlich Jīzān (Jāzān) für die Tihāma des 'As̄̄r ist al-Qunfudha also für den südlichen Hijāz und die davor liegende Küstenebene der wichtigste Hafenort. Sein Status als sekundärer und später nahezu vergessener Hafen hat zunächst manche Modernisierung des 20. Jh. verzögert, was ältere Bausubstanz noch längere Zeit bestehen ließ.

Wie alle anderen Hafenstädte am Roten Meer ist al-Qunfudha jenem heißen, schwülfeuchten Klima ausgesetzt, das für den schmalen, 10-15 km breiten Streifen längs der Küste charakteristisch ist. ${ }^{5}$ Die gesundheitlichen Auswirkungen dieses Klimas scheinen die Einwohnerzahl der Siedlung bis in das 20. Jh. ebenfalls recht niedrig gehalten zu haben; europäische Besucher berichten für al-Qunfudha von Fieber, Ruhr, Skorbut und Cholera. ${ }^{6}$ Heiße, feuchte Südwinde herrschen zumeist vor, daher sind die südlichen Stadtteile klimatisch benachteiligt: Die ärmeren und sozial unterprivilegierten Gruppen der Stadtbevölkerung siedeln dementsprechend eher im Süd- und Südostteil. Im Nordteil von al-Qunfudha, und damit den kühleren Nordwinden zugewendet, liegen rund um die Hafenanlage die Verwaltungsgebäude, Markt- oder Geschäftshäuser und die (größtenteils verfallenen) Wohnhäuser der wohlhabendeneren Teile der Stadtbevölkerung. Diese grundsätzliche Gliederung des Siedlungsmusters entlang einer Nord-Südostachse entspricht den Beob-

\footnotetext{
2 Rüppel 1838: 178.

3 Niebuhr: 375; Rochet D’Héricourt 1841: 351; Rüppel 1838: 178; Thesiger 1947: 197; Philby 1952 (1976): 691-693.

4 cf. dazu die Ausführungen von Dostal in diesem Band.

5 Talib 1984: 67; Abdulfattah 1981: 27, 33-34, Karten 2, 3.

${ }^{6}$ Combes und Tamisier 1838, IV: 35; Philby 1952 (1976): 691-93.
} 
achtungen von Philby Ende der 30er Jahre. ${ }^{7}$ Diese Siedlungsstruktur findet eine ihrer entscheidenden Ausdrucksformen in der unterschiedlichen Verteilung von Haustypen im Stadtgebiet.

Die dominante Hausform in den Ost- und Südostteilen der Stadt ist die Stroh- und Holzhütte ('ushsha) mit kegelförmigem oder Giebeldach über kreisförmigem oder rechteckigem Grundriß. Diese 'ushsha ist die typische Hausform der ebenen und hügeligen Tihāma, und wird im dortigen Zusammenhang näher erörtert.

Nur an der Küste verbreitet ist hingegen jener Konstruktionstypus, der im nördlichen Teil von al-Qunfudha dominiert, aber vereinzelt auch im Süd- und Südostteil auftritt. Dies sind die typischen Korallenstein-Gebäude der Küste. Da und dort treten in al-Qunfudha auch gemauerte Ziegelbauten auf. Beide Hausformen sind ein- oder mehrgeschoßig über rechteckigem Grundriß mit flachem Dach gebaut. Die Bauweise und Nutzung dieser Gebäudetypen ist hier näher zu untersuchen.

\subsubsection{BAUMATERIAL UND SEIN SOZIALER KonTEXT}

Auf dem Festland gibt die natürliche Umwelt des Küstengebietes nur eine äußerst beschränkte Auswahl an Baumaterialien vor. Ungebrannter Lehm erweist sich durch die hohe Luftfeuchtigkeit, durch Insekten und Fluten als wenig geeignetes Baumaterial für das Küstengebiet, und geeignete Steinvorkommen sind in diesen sandigen, flachen Teilen der Tihāma einfach nicht ausreichend vorhanden. Damit bleiben Holz und andere Vegetabilien als ausreichend vorhandene Baumaterialien für die Wohnbedürfnisse der breiten Bevölkerungsmehrheit der Küstenebene; sie werden für die billigere und einfachere Konstruktion der 'ushash genutzt.

Die typischen Steingebäude der Küstenstädte (Abb. 30, 31) setzen hingegen einen wesentlich höheren Aufwand zur Beschaffung der Baumaterialien voraus. Ziegel und Korallensteine sind das Ergebnis komplexer Arbeitsprozesse. In al-Qunfudha sind diese Baumaterialien nach Auskunft älterer Gewährsleute nur für zwei Gruppen zugänglich gewesen: Das waren vor allem reiche Geschäftsleute, Händler und hohe Beamte, die genügend Geld besaßen, um diese Baumaterialien zu kaufen oder ihre Beschaffung in Auftrag zu geben. Darüber hinaus verwendeten die Taucher und ihre Familien Korallensteine auch für die Errichtung ihrer eigenen Wohnhäuser. Darauf gehen vereinzelte Steingebäude in den östlichen und südöstlichen Teilen der Stadt zurück.

Von vornherein verweist die Existenz von Gebäuden aus Ziegel oder Korallenstein an der Küste daher auf größeres Geldvermögen und Handelskapital, und auf komplexe Arbeitsorganisation. Die Ziegel konnten nicht örtlich hergestellt, sondern mußten auf dem Seeweg herangebracht werden. Da der seichte Hafen den Transport schwerer Materialien sehr umständlich machte, sind Ziegelbauten in al-Qunfudha dementsprechend selten.

Das nächstgelegene örtliche Rohmaterial für Steinbauten lag vor der Küste unter der Meeresoberfläche. Der Abbau dieser Korallenaggregate wird heutzutage nicht mehr betrieben und konnte ebenso wie der Bauprozeß der Häuser nur mehr teilweise aus der mündlichen Überlieferung rekonstruiert werden:

\footnotetext{
7 Philby 1952 (1976), a. a. O.
} 
Als Umschlagplatz des Handels und als Pilgerstation lagen die ökonomischen Schwerpunkte für al-Qunfudha vorwiegend im Bereich der Dienstleistungen, der Verwaltung und der Güterzirkulation. Die örtliche Produktion war demgegenüber von untergeordneter Bedeutung und dabei auf die Reichtümer des Meeres konzentriert: Salz wurde bis in die 60er Jahre in einigen Dörfern um al-Qunfudha gewonnen, indem man Meerwasser einfach in flachen Gefäßen verdunsten ließ. ${ }^{8}$ Fischerei, Perlentauchen und der Abbau von Korallenaggregaten verlangen den Einsatz von Booten. Die Konstruktion und Reparatur derartiger flacher Holzsegelboote (sambūk) ist bis heute ein wesentlicher Erwerbszweig bestimmter Handwerkergruppen von al-Qunfudha geblieben. Der Sambūk-Typus ist einbis zweimastig, hat einen oder zwei Anker, und kann bis zu maximal 15 t Last und sieben bis acht Mann Besatzung aufnehmen. Er entspricht somit ungefähr jenen Formen, die Weisl in den 20er Jahren erwähnte. ${ }^{9}$ Diese Boote dienen heute allerdings nur mehr der Fischerei und sind dementsprechend kleiner.

Der Abbau der Korallensteine war also eingebunden in ein weites Umfeld von beruflichen Kenntnissen und Spezialisierungen der unteren sozialen Schichten der Stadtbevölkerung, die mit Booten unterwegs, und über wie unter Wasser tätig waren. Während die Fischerei nur Bewohner der Stadt und ihres unmittelbaren Umlandes versorgte (Fischnahrung wird von den Bauern des Hinterlandes als unrein verachtet), diente das Tauchen nach Perlen und Korallenstein sowohl den Bedürfnissen der reichen Stadtbevölkerung wie jenen des Fernhandels und war dementsprechend angesehen.

Perlentauchen wurde vor al-Qunfudha bis in die 50er Jahre betrieben, als es durch übermächtige Konkurrenz am Weltmarkt zum Erliegen kam. ${ }^{10}$ Abbau von Korallenstein galt demgegenüber jedoch als rohere und weniger angesehene Arbeit. Die Spezialisten konnten manchmal zwar aus denselben Familien wie die Perlentaucher kommen, in der Regel wurde aber beides nicht von derselben Person betrieben. Das Perlentauchen war nicht nur eine Frage der körperlichen Verfassung und der Erfahrung, sondern auch des Glücks und des Mutes. Der Abbau von Korallenstein konnte auch von älteren Männern betrieben werden, er erbrachte ein niedrigeres, aber beständiges Einkommen, und er erfolgte in größeren Arbeitsgruppen auf mehreren Booten.

Die höheren Korallenbänke erlaubten, daß der Abbau manchmal sogar in seichtem Gewässer durchgeführt werden konnte, sodaß die Spezialisten sich zumindest zum Atmen stehend aufrichten konnten. Diese Abbauorte waren daher bevorzugt, weil sie leichteres und sichereres Arbeiten ermöglichten. In den letzten Jahrzehnten vor dem Niedergang dieses Berufszweiges scheinen derartige Abbaustellen aber bereits rar gewesen zu sein; durch die hohe Nachfrage vor Ort und im Export waren die günstigen Abbaustellen bereits erschöpft. Bei tieferen Abbaustellen wechselten jeweils zwei Zweiergruppen von Tauchern einander ab, wobei oft sechs oder acht Männer an einer Stelle unter Wasser tätig waren, während die anderen in den Booten die Netze bedienten und schlichteten. Die abgebauten Materialien wurden an Land gebracht, dort grob zugeschlagen und dann an den Händler oder Bauherrn weitergeliefert. Korallenstein (farūsh, mashāl) wurde nicht kontinuierlich abgebaut, sondern man erfüllte die Aufträge nur in größeren zeitlichen Abstän-

\footnotetext{
8 ef. auch Philby 1952 (1976): 700.

9 Weisl 1927: 292.

10 King 1986: 60 führt das Beispiel eines reichen Perlenhändlers an, der noch in den 20er Jahren eine der schönsten Moscheen der Küstenregion auf den Farasān-Inseln von Jīzān errichten ließ.
} 
den bei ruhiger See. Die Bereitstellung von geeignetem Material lag auch hier - wie bei den Auftragsarbeiten im tribalen Bergland - in der Verantwortung des Bauherrn. Ob dieser die Korallensteine nun in al-Qunfudha direkt von den Tauchern bezog, oder ob er anderswo durch Händler beliefert wurde - in jedem Fall durfte das Material bei Baubeginn noch nicht zu ausgetrocknet sein. Dann wird der Korallenstein nämlich zu spröde, er bricht und bröselt zu leicht und kann nicht mehr kontrolliert bearbeitet werden. Außerdem beginnen sich im ausgetrockneten Material Termiten und andere Insekten rasch einzunisten, was die Wohnqualität später erheblich beeinträchtigen kann. ${ }^{11}$ Diese Materialeigenschaften sind ebenfalls dafür maßgeblich, daß die Taucher den Korallenstein nicht auf Vorrat abbauten und lagerten, sondern jeweils die aktuellen Aufträge von Bauherrn oder Händlern abwarteten. Im übrigen entspricht diese Form von Auftragsarbeit zwischen Kunden und Produzenten dem generellen Muster der Region für derartige Wirtschaftsbeziehungen, die hier selbst unter den Bedingungen der florierenden Geldökonomie von al-Qunfudha fortbestanden. ${ }^{12}$

Die wesentlichen Baumaterialien für die Korallenhäuser von al-Qunfudha waren also der mashāl und weiters Holz, sowie Binde- und Abdeckmaterialien (Kalk, Mörtel, Gips). Von diesen zusätzlichen Materialien war keines örtlich vorhanden. Die kräftigen Holzstämme für Deckenbalken und Türen wurden aus dem Hijāa und der hügeligen Tihāma bezogen; das Holz für die Gestaltung von Fassaden und Innentüren stammte manchmal sogar aus Südostasien und Afrika; ${ }^{13}$ die Binde- und Abdeckmaterialien mußte man größtenteils ebenso über den Seeweg importieren. Auch für die Bereitstellung dieser Materialien war der Bauherr gegenüber den Handwerkern verantwortlich, er beauftragte einen der örtlichen Händler mit ihrer Beschaffung, die dann vorwiegend über Jidda verlief.

Die direkt am Hausbau beschäftigten Arbeitskräfte gliederten sich in die zwei sozialen Gruppen der mobilen Dekorateure (von Holz- und Korallenstein) und des Bautrupps. Dieser Bautrupp war eine der örtlichen Arbeitsgruppen; es waren stets einige Verwandte und Nachbarn der städtischen Mittel- und Unterschicht, die für derartige Anlässe regelmäßig zusammenarbeiteten, aber ansonsten anderen Tätigkeiten (etwa der Fischerei oder dem Korallensteinabbau) nachgingen. Der Bau eines Korallensteinhauses war in al-Qunfudha eine seltene Angelegenheit; vor Ort konnte man von diesem Handwerk alleine nicht leben, und andere Küstenstädte hatten ihre eigenen Bautrupps. Die Dekorateure kamen hingegen von weither; diese Spezialisten für Holz- oder Steindekor waren berühmte Fachleute aus der jemenitischen Tihāma oder aus Jidda ${ }^{14}$, deren kurzfristiges Engagement vor Ort sehr teuer kam und daher nur bei wenigen Prestigebauten erfolgte. Nebenbei verweist dieser Umstand darauf, daß traditionelle Architektur in der Dritten Welt keineswegs immer „anonym“ ist, sondern wie im vorliegenden Fall von namhaft bekannten Fachleuten hergestellt sein kann.

Der Bau derartiger Korallensteinhäuser fand also in einem sozialen Ambiente statt, das geprägt war von überregional tätigen Kunsthandwerkern, von weitgereisten Bauherrn und von Fernhändlern für importierte Rohmaterialien - im Rahmen eines städti-

11 Nankivell, 1985a: 58 berichtet Ähnliches für die Korallenstein-Gebäude der jemenitischen Tihāma.

12 Gingrich 1983a: 253-287 und 1983b: 107-113.

13 Talib 1984: 67-77.

14 Auch für die Moschee von 'Umm Farasān berichtet King 1986: 65 den Einsatz derartiger Kunsthandwerker. 
schen port of trade, der stets mit fernen Staatszentralen verbunden war. Ein derartiges soziales Ambiente macht erst den internationalen Charakter des Küstenstils verständlich, der auch für die Architektur von al-Qunfudha markant ist.

\subsubsection{KonstruKtION UND IHRE ERFORDERNISSE}

Die Kunsthandwerker waren ausschließlich für die von ihnen dekorierten Elemente zuständig, alle anderen Arbeiten wurden vom Bautrupp besorgt. Zusammen mit dem Leiter des Bautrupps koordinierte der Bauherr das Gesamtgeschehen, aber anders als beim ländlichen Hausbau waren diese wohlhabenden Bauherrn von al-Qunfudha nicht am praktischen Arbeitsablauf beteiligt, und noch weniger waren dies ihre Familien.

Der Korallenstein wurde an der Baustelle in seine endgültige Form zu einfachen Quadern behauen und geglättet. Nur für manche ebenerdige Gebäude der ärmeren Stadtteile wurde auf das Glätten der Oberfläche und Kanten verzichtet. Beim Bau breiter Stützmauern hingegen wurden nur die Frontseiten der Steine poliert und geglättet; die Unebenheiten gewährleisteten eine bessere Verstrebung der Rückseiten mit der Mauerfüllung. Die Mauern ebenerdiger Gebäude wurden oft trocken verlegt, ansonsten verwendete man schon für Fundament und Grundmauern Mörtel. In Abständen von mehreren Steinreihen wurden horizontale Holzlatten zueinander versetzt eingemauert, welche stabilisieren und Spannungen im spröden Mauerwerk abfangen. ${ }^{15}$

Die als Wohnhäuser genutzten Korallensteingebäude sind im Norden der Stadt meist mehrgeschoßig, allerdings haben sie im Unterschied zu jenen von Jidda (Abb. 35) selten mehr als zwei Stockwerke. Zur Stützung der Decke dienen Steinsäulen; Innenwände hat man vermieden, um die Luftzirkulation nicht zu beeinträchtigen. Die Verwendung derartiger Steinsäulen für Decken mit Spannweiten, die durch die Länge der hölzernen Dekkenbalken beschränkt sind, ist auch aus Jidda bekannt. ${ }^{16}$ Zugleich haben diese steinernen Stützsäulen als Konstruktionsprinzip der städtischen Wohnarchitektur am Roten Meer ihre Parallele (und wohl ihre kulturhistorischen Vorläufer) in den hölzernen Stützpfeilern der tribalen Bauernhäuser des Hijāz. Ebenerdige Korallensteinhäuser sind oft nur durch Holz- und Lattenwände im Inneren weiter unterteilt, wobei jedes Abteil Zugang zu zwei Fensteröffnungen in den Windrichtungen hat. Mehrgeschoßige Häuser haben pro Geschoß meist nur zwei Räume, die dann durch das Stiegenhaus im Inneren getrennt sind. Auch derartige Stiegenhäuser haben ihre tribalen Parallelen, und zwar im Bergland des 'Asīr und im Jemen.

In diesem Stiegenhaus, über den Haupteingängen oder auch im großen Empfangssaal eines solchen nobleren Wohnhauses können zuweilen echte Bögen errichtet sein, die man in al-Qunfudha ansonsten nur in Moscheen und Palästen (Abb. 30, 34) antrifft. Das Konstruktionselement des echten Bogens mit Schlußstein ist ein spezifisches Merkmal der städtischen Architektur dieser Region, das sie von jener des ländlichen und tribalen Hinterlandes eindeutig unterscheidet. In stilisierter Form als Relief sind einfache oder dreiteilige Bögen zugleich die häufigsten Motive des Steindekors; sie sind im Inneren und an der Fassade stets über den Tür- und Fensteröffnungen konzentriert. ${ }^{17}$

\footnotetext{
15 King 1986: 56.

16 Talib 1984: 73; Pesca 1974: passim.

17 Philby 1952 (1976): 673, fig. 63 mit Mauerzinnen.
} 
Damit lassen sich echte und Reliefbögen im Korallensteinbau als typische Merkmale dieses Küstenstils identifizieren.

Die verfallenen und nicht getünchten Beispiele dekorierter Wohnhäuser von al-Qunfudha belegen überdies, daß der Fassadendekor tatsächlich in das Korallenaggregat hineingearbeitet ist, und nicht bloß von außen applizierte Gipsformen darstellt, wie manche Autoren meinen. In den Korallensteingebäuden von al-Qunfudha ist Gipsdekor nur in den repräsentativsten Innenräumen angebracht. Die Fassadenseiten der Wohn- und Amtshäuser aus Korallenaggregat sind nur manchmal mit einer Mörtel- und Gipsschichte versehen, und zwar eher bei Außenmauern aus grob behauenem Stein. Die Wände der Innenräume schließlich sind bei allen Steinbauten der Küste zum Schutz vor Insekten und vor der Hitze mit einer Gipsschicht bedeckt. Eine vollständige Umhüllung der Außenseiten mit einer doppelten Gipsschicht ist jedoch bloß für die Ziegelbauten des Küstenstils typisch. Die mit Mörtel verlegten Ziegelwände dieser in al-Qunfudha selteneren Hausformen würden dem feucht-heißen Klima ohne diese Umhüllung nicht widerstehen, deren äußere Schichte dekoriert sein kann. Die weißen Ziegelhäuser der Küste sind insgesamt wesentlich einfacher als die Korallensteingebäude gebaut (Abb. 37, 38). Die Gemeinsamkeiten zwischen beiden Hausformen liegen in der mehrgeschoßigen Konstruktion mit Stützpfeilern für die Decken im Inneren, im fallweisen Auftreten des echten Bogens, und schließlich in der Dachkonstruktion.

In beiden Formen ist um das flache, leicht geneigte Dach eine Brüstung hochgezogen, welche die Dachterrasse zu einem geschützten Aufenthaltsort macht. Die Brüstungen können bei Ziegelbauten an den Ecken erhöht und mit Zinnen geschmückt sein (Abb. 39). Kleine Öffnungen mit herausragenden Rinnen sorgen für den Abfluß von Regenwasser. Diese Dachterrassen sind kühle abendliche Aufenthaltsorte und Schlafstätten. ${ }^{18}$ Angesichts der ganzjährig vorherrschenden schwülen Hitze ist die Ermöglichung von Luftzirkulation und kühlen Innentemperaturen in den Wohnhäusern ein grundlegendes Konstruktionsprinzip. Alles, was die Kühlung der Innenräume fördert, wird in der Bauweise und Einrichtung genutzt. Die mehrgeschoßigen Wohnhäuser des Küstenstils sind als Einzelbauten errichtet. Direkte $\mathrm{Zu}$ - und Anbauten werden vermieden; ein zusätzliches Haus derselben Familiengruppe wird etwas abgesetzt errichtet und gegebenenfalls durch eine Mauer verbunden (Abb. 31). Dadurch können mehrere Wohngebäude in einem weiten Hofareal zusammengeschlossen sein, was dem Leben der Frauen und Kinder mehr Spielraum ermöglicht. Den typischen Innenhof, der für die städtische Architektur Nordostarabiens und von Teilen des südwestarabischen Hochlandes charakteristisch ist, ${ }^{19}$ gibt es im Küstenstil allerdings nicht. Er würde hier die Luftzirkulation nur behindern. Die Exponiertheit der vier Fassadenwände durch ihre Distanz zu Nachbarhäusern ist eine offenkundige, klimabedingte Parallele zur Bauweise der Tihāma-Hütte; dies macht das Haus von jeder Seite her für die kleinste Brise zugänglich und minimiert das Potential für stehende Luft im Inneren. Die Hochbauweise erhöht natürlich per se die Exponiertheit gegenüber Luftzügen; der Besitz eines mehrstöckigen Wohnhauses in Nordlage war daher ein erstrebenswertes und prestigeträchtiges Zeichen für eine entschieden angenehmere Lebensqualität als im Rest der Stadt (Taf. XXXIII).

\footnotetext{
18 Philby 1952 (1976): 691.

19 Niewöhner 1977: 177-204; Nippa 1991: 81.
} 
Im Inneren sind pro Stockwerk aus demselben Grund höchstens zwei Räume angelegt. Damit hat jeder Raum Zugang zu mindestens einer Fassadenseite. In diesen Stadthäusern sind die Empfangs- und Aufenthaltsräume im Erdgeschoß eingerichtet (Stallungen wie in der ländlichen Architektur gibt es natürlich nicht); die Schlafräume (līwān) sind nach Geschlechtern getrennt in den kühleren oberen Geschoßen untergebracht.

Die primäre Gestaltungsnotwendigkeit eines erträglichen Innenklimas durch Luftventilation der Wohnhäuser hat einem weiteren, wesentlichen Konstruktionselement seinen funktionalen Anlaß geboten. Dieses Grundprinzip von „transparenten Fassaden“ ist durch große Fensteröffnungen gelöst, die in vielfältigen Formen von hölzernen Vorbauten, Balkonen, Fenstergittern und -läden gestaltet sind. Der Sammelbegriff für derartige Fassadengestaltung durch hölzerne Fensterverbauungen ist „mushrabīya“; der Begriff bezeichnet zugleich das charakteristische Element innerhalb dieser Formenvielfalt, nämlich den Balkonvorbau (Abb. 30).

Dies ist das sichtbarste und bekannteste Element der Wohnarchitektur des Küstenstils. Die mushrabiya ist „a protected bay window with decorative wooden screens as enclosures “ ${ }^{20}$ die Fensterblenden können auch durch Läden ersetzt sein. Seltener findet man in al-Qunfudha offene Holzbalkone; für diese wie für das bay window ist auch der Ausdruck rawshān (pl. rawāshin) gebräuchlich. Offene Fenstergitter und verschließbare Fensterläden werden (wie auch in anderen Landesteilen) als nāfidha (pl. nawāfidhu) bezeichnet. Im Inneren der Wohnhäuser werden in den Zimmern vor diesen diversen Fensteröffnungen mit Wasser gefüllte Tongefäße aufgestellt, um die Lufttemperatur durch die Verdunstungskühlung zusätzlich zu senken. Dieses „getrunken werden“ des Kühlwassers soll den Fensterverbauungen ihren Namen verliehen haben.

Auf einfache, aber effektive Weise wird damit das zentrale Problem der Luftzirkulation mit den spezifischen Mitteln des städtischen Lebensstils gelöst: Derartige große Fensteröffnungen wären unter den Bedingungen von Fehde und Blutrache, wie sie etwa in der tribalen Gesellschaft des 'Asīr und Hijāz vorgeherrscht haben, ein militärisches Risiko. Die Verbreitung der mushrabiya setzt ein stabiles Mindestmaß an Frieden voraus, der im staatlich kontrollierten Stadtgebiet am ehesten gegeben ist. Zugleich verlangt die Moral der Geschlechtertrennung und der Ehre hier explizit die Absonderung der familiären und weiblichen Lebenswelt von der männlichen Öffentlichkeit. Man hat die mushrabiya daher als architektonisches Pendant zur Verschleierung der muslimischen Frau bezeichnet: Sie erlaubt zu sehen, ohne gesehen zu werden. ${ }^{21}$

\subsubsection{LOKALE SOZIALE VARIATIONEN}

Korallensteinbauten des Küstenstils treten in der verbliebenen Bausubstanz von alQunfudha im wesentlichen in vier Gebäudetypen auf: Moscheen, Verwaltungs- und Regierungsgebäude, Wohnhäuser und Marktbauten.

Die alte Hauptmoschee von al-Qunfudha ist bei G. King beschrieben; ${ }^{22}$ sie wird im Zusammenhang mit der Stadtgeschichte noch näher erörtert.

\footnotetext{
20 Talib 1984 1984a: 68.

21 Bonnenenfant 1987b: 123.

22 King 1986: 55-56.
} 
Der architektonischen Schönheit zu Ehren Gottes im Rang am nächsten standen im Stadtbild die Amts- und Wohngebäude der Regierungsvertreter ${ }^{23}$ von denen die meisten zur Erhebungszeit allerdings bereits durch Neubauten ersetzt waren. Daran schlossen nach Ausstattung, Dekor und Konstruktion die mehrgeschoßigen Wohn- und Lagerhäuser der reichsten Geschäftsleute an (Abb. 32). Einfache zwei- und dreigeschoßige Wohnhäuser mit wenig Fassadendekor waren ebenfalls noch im nördlichen Regierungs- und Handelsviertel vertreten; die ebenerdigen, außen undekorierten Korallensteinhäuser finden sich hingegen auch im Ost- und Südostteil der Stadt. Einige darunter haben ebenfalls wooden bay windows, die hier meist durch Steinsockel am Straßenniveau abgestützt sind (Abb. 31). Diese bescheideneren und vereinfachten, aber zahlenmäßig häufigeren Formen von bay windows sind volkstümliche Varianten des prestigeträchtigeren Vorbildes, das die Wohnhäuser der Oberschichte im Norden von al-Qunfudha abgeben. Sie sind der manifeste Ausdruck dafür, daß sich quer durch die Hierarchie der verschiedenen sozialen Schichten und Abstammungsgruppen die Normen und Wertmaßstäbe der führenden Kräfte dieses port of trade durchgesetzt und als städtischer Lebensstil verallgemeinert haben.

Ebenerdig wie diese Wohnhäuser sind auch die Marktbauten in der Nähe des Hafens (Abb. 29). Sie sind als einziger Gebäudetypus zeilenförmig aneinander gereiht und bilden ein geschlossenes Areal abseits der Wohnhäuser. ${ }^{24}$ Darin entspricht diese Anlage dem allgemeinen Muster arabischer Stadtmärkte. ${ }^{25}$ Die Marktbauten sind zweckorientiert errichtet und daher fensterlos, sie umschließen jeweils einen einzigen Raum, ein großes Flügeltor schützt vor Diebstahl und kann als Auslage auch weit geöffnet werden. Einige Frontfassaden dieser Marktbauten sind sogar dekoriert, was auf den wohlhabenden Status ihrer Eigentümer verweist. Diese Bauten dienen als Verkaufs- und Lagerräume. Die Nähe des Marktareals zu Hafen und Verwaltungssitz erleichtert sowohl den Transport wie die Kontrolle staatlicher Abgaben. Mit diesen Bezügen zu Staatsmacht und Fernhandel stellt das Marktareal das eigentliche Kernstück dieser Hafenstadt dar.

Moscheen, Verwaltungs- und Regierungsgebäude, Wohnhäuser und Marktbauten von al-Qunfudha drücken zugleich die soziale Bedeutung der lokalen Führungsschichte aus Gelehrte, Beamte und Fernhändler haben diese Gebäude errichten lassen und in ihnen gewirkt. Die Mehrheit der Stadtbevölkerung, also Geschäftsleute, Handwerker, Straßenhändler, Fischer, Taucher und Bootsfahrer leben hingegen in den ebenerdigen Steinbauten und vor allem in den 'ushash.

Die Architektur von al-Qunfudha vereint damit zweierlei Einflüsse zu einer komplexen sozialen Synthese. Von den einfachen Korallensteinbauten abgesehen, dominieren in den Vierteln der städtischen Unter- und Mittelschichten (im Ost- und Südteil der Stadt) die Strohhütten, ein Typus von Lokalarchitektur, der aus dem benachbarten ländlichen Raum stammt. Übernahme der bäuerlichen Bauweise der Tihāma, oder simplifizierte Variation jener anderen Bauweise, welche von der städtischen Oberschicht getragen ist diese beiden alternativen Orientierungen charakterisieren die Architektur der Unter- und Mittelschichten von al-Qunfudha.

\footnotetext{
23 Philby 1952 (1976): 691-93.

24 Mauger 1993: 15, wonach die Marktanlagen (in den urbanen Bereichen der Tih!ma) nur an einem Tag in der Woche geöffnet sind.

25 Dostal 1983d: 241-275; Wirth 1975/76: 203-260, 6-46.
} 
Der eigentliche, typisch städtische Baustil ist also jener der Oberschicht mit ihren überregionalen und internationalen Verbindungen. Dieser Baustil der Oberschicht ist keine lokale Tradition von al-Qunfudha; vielmehr ist er allen größeren und mittelgroßen Hafenorten längs des Roten Meeres bis in die 80er Jahre des 20. Jh. gemeinsam.

Dieser internationale Küstenstil ist durch die Kombination von mehreren architektonischen Einzelelementen charakterisiert, denen diese Untersuchung bereits begegnet ist. Es sind

1. die Verwendung von vorgefertigtem, festem Baumaterial (Korallenaggregate, Ziegel, selten: Basalt ${ }^{26}$ ), aber nicht von natürlichem Fels. Die Bereitstellung dieser festen Baumaterialien setzt komplexe Arbeitsspezialisierung und Geldwirtschaft voraus;

2. die Konstruktion als Einzelbauten über rechteckigem Grundriß mit mehreren Geschoßen und wenigen Räumen pro Geschoß; eine Dachterrasse mit Brüstung bei Abwesenheit von Innenhofanlagen;

3. die Vermeidung von Innenwänden und die Verwendung von Stützpfeilern; die Abdekkung der Fassadeninnenseiten (bei Ziegelbauten immer auch der Außenseiten) mit Gips;

4. Gipsdekor innen und nur bei Ziegelbauten auch außen, Steindekor auf Korallenfassaden; fallweises Auftreten des echten Bogens; große Fensteröffnungen mit holzdekorierter mushrabìya.

Alleinstehende, mehrgeschoßige und rechteckige Häuser aus Ziegel oder Korallenstein, die durch transparente Fassaden und möglichst offene Innenräume die Luftzirkulation fördern und mit Dekor, echten Bögen und mushrabīya urbanes Wissen und Lebensgefühl vermitteln - das sind in Kürze die architektonischen Hauptelemente des Küstenstils.

\subsubsection{Regionale VARIANTEN}

In dieser allgemeinen, aber typischen Kombination ist der Küstenstil für zahlreiche Städte am Roten Meer belegt und dokumentiert - darunter für al-Waj und Yanbū ${ }^{c},{ }^{27}$ Jidda, ${ }^{28}$ Jīzān, ${ }^{29}$ und schließlich für die eritreischen, ostafrikanischen und vor allem die jemenitischen Küstenstädte am Roten Meer, wie Suwākin, ${ }^{30}$ Massāwa, Kilwa, und im Jemen al-Luhayya, al-Hudayda und al-Mukha. ${ }^{31}$ Man hat daher schon frühzeitig von einem „Red Sea Style“ in der Architektur gesprochen. ${ }^{32}$ Die gemeinsame Assoziierung von bestimmten Kulturelementen längs der arabischen und ostafrikanischen Küsten ist ein seit langem

26 Lehm ist als Baumaterial der Wohnarchitektur an der Küste meines Wissens nur für al-Līth nördlich von al-Qunfudha belegt (Philby 1952: 705 f.); Basalt tritt lokal begrenzt im mittleren Abschnitt bei den Lavafeldern nordöstlich von al-Qaḥma bis Maḥāil auf; cf. Abdulfattah 1978: Karte 4 und Thesiger 1947: 193f.; Mauger 1993: 103.

27 G. und P. Bonnenfant 1987: 5.

28 Pesce 1974; Talib 1984: 66-77.

29 King 1986: 60, 65, $67 \mathrm{f}$.

30 Greenlow 1976: passim.

31 Für den Jemen sei hier auf die Arbeiten von Varanda 1982, S. und Hirschi 1983 und den von Stone 1985 herausgegebenen Band verwiesen; zu Kilwa cf. Denyer 1978: 36 f., 194.

32 Matthews 1953: 60-68 und 1955: 12-112. 
bekanntes ethnographisches Faktum, ${ }^{33}$ das seine wesentlichen Impulse dem arabisch dominierten Fernhandel und dem Einfluß des Islam verdankte. ${ }^{34}$

In den Küstenstädten Arabiens am Indischen Ozean dominierte in der vorindustriellen Architektur gleichfalls noch der Korallenstein, allerdings herrschen dort bereits andere Stilelemente und Bauformen vor, ${ }^{35}$ sodaß zwischen einem „Roten Meerstil“ im engeren Sinn und einem „arabisch-ostafrikanisch-indisch-persischen Küstenstil“ im weiteren Sinn zu unterscheiden wäre.

Aber auch im südwestlichen Küstengebiet des heutigen Saudi Arabien treten deutliche Variationen auf. Ziegelbauten, die in al-Qunfudha noch die Ausnahme darstellen, werden nach Süden hin in den großen Orten wie 'Umm Farāsan oder im älteren (heute verschwundenen) Teil von Jīzān etwas häufiger, ${ }^{36}$ und generell sind Korallensteinbauten fast ausschließlich auf die größeren Küstenorte konzentriert. Sofern es in den kleineren Küstenorten überhaupt feste Bauten gibt, so sind sie dort meist aus Ziegel - wie in al-Lith (wo neben Ziegel- auch Lehmbauten auftreten), al-Birk, Halī oder Qạ̣ma. ${ }^{37}$ Doch auch der in den Lavagebieten zwischen Mahā’il, al-Birk und Qạ̣ma reichlich vorhandene Basalt wird häufig zum Hausbau verwendet. ${ }^{38}$ Von der Küste weg zum Landesinneren hin bricht die Verbreitung von Korallenstein als Baumaterial dann überhaupt abrupt ab; er kommt also fast nur an der Küstenlinie selbst zum Einsatz. In den nächsten größeren Orten und Marktflecken landeinwärts, wie Mahā'il, Makhwā, oder Sūq Khamīs al-Baḥr, Șabyā, al-Darb oder Abū 'Arīsh dominiert in der mehrgeschoßigen, festen Architektur bereits der Ziegelbau (Abb. 37, 38, 39). ${ }^{39}$ Diese quasi-urbanen Bauten der flachen Tihāma im Landesinneren sind nach den angeführten vier Merkmalgruppen aber noch als periphere Ausprägungen des Küstenstils anzusehen, ähnlich wie im viel eindeutigeren Fall der jemenitischen Städte in der flachen Tihāma.40

Im ethnographischen Präsens der frühen 80er Jahre, also vor der endgültigen Durchsetzung industrieller Stahlbetonarchitektur in den Küstenstädten, weist die Verbreitung des Küstenstils folglich eine deutliche Differenzierung nach Material und Stilelementen auf. Tabelle 1 gibt für diese Differenzierung einen Überblick von Wohnbauten aus festem Baumaterial, also ohne Berücksichtigung von Marktgebäuden und von Gebäuden mit primär militärisch-administrativer oder sakraler Funktion.

Damit wird deutlich, daß die mehrgeschoßigen Bauten aus Korallenstein (1A) bloß die auffälligste und prestigeträchtigste, internationale Variante eines Küstenstils darstellen, der zugleich mehrere weniger spektakuläre, lokale Formen umfaßt. Diese sind in den mittleren Orten der Küstenlinie (Form 1B) und in den Binnengebieten der Küstenebene (Form 2A und 2B) unter den Bauten aus festem Material dominant.

Von den soeben für al-Qunfudha identifizierten vier Merkmalen des „internationalen Red Sea Style" (mehrgeschoßige Formen von 1A) treffen nur drei Merkmalsgruppen auch

33 Hirschberg 1931: 269-273.

${ }^{34}$ Lewcock 1976: passim.

35 King und Lewcock 1984: 209.

36 King 1986: 60, 72.

37 Thesiger 1947: 193f.; Philby 1952: 705f., 679 f., 674 f. und eigene Erhebungen.

38 Thesiger 1947: 193f.; Mauger 1993: 103.

39 ibid. eigene Erhebungen, und zu Șabyā cf. Forbes 1923: 274 und Thesiger 1947: 194 und 196f., wonach die Ziegelbauten im neuen Teil von Șabyā auf Gründungen der Idrīsī zurückgehen.

40 Nankivell 1985: 57-71; Ehrlich 1985: 58, 65-71. 
auf diese einfachen, „volkstümlichen“ anderen Formen zu: sie sind ebenfalls mit vorgefertigtem Baumaterial, rechteckigem Grundriß und Dachterrasse ausgestattet. Die Distanz zu Nachbarhäusern wird gewahrt, Innenwände werden auch hier vermieden, und Stützpfeiler können auch bei diesen Formen vorkommen. Große Fensteröffnungen und Verputz der Innen- und Außenwände verweisen ebenfalls auf urbane, friedliche Lebensbedingungen. Allerdings sind diese Gebäude niedriger, und bei diesen Formen fehlen generell die Elemente des echten Bogens und der mushrabīya. Abgesehen von den Häusern reicher Kaufleute, die oft mit einer Gipsstukkatur ausgestattet sind, ${ }^{41}$ fehlt jede andere nennenswerte Dekorausstattung. Diese populären, niedrigen semi-urbanen Formen des Küstenstils werden auch „arḍī“ (ebenerdig) genannt ${ }^{42}$ und setzen die Existenz von kleineren Garnisonen oder Polizeistationen in ihrer Nähe voraus. Daher treten sie bei kleineren oder mittleren Hafen- oder Marktorten entlang der, oder am Ausgangspunkt von größeren Handelsrouten der Region auf (Karte 8).

Tab. 1: Hauptformen des Küstenstils in der saudischen Tihāma

\begin{tabular}{|l|l|l|}
\hline $\begin{array}{l}\text { Wohngebäude aus festem } \\
\text { Material }\end{array}$ & Größere Orte (A) & Mittlere Orte (B) \\
\hline Küstenlinie (1) & $\begin{array}{l}\text { Material: Korallenstein (häufig), } \\
\text { Ziegel (seltener) } \\
\text { Geschoße: 1 (häufiger), 3-4 (seltener) }\end{array}$ & $\begin{array}{l}\text { Material: Ziegel (häufig), } \\
\text { Korallen (selten), Lehm und } \\
\text { Basalt (lokal) } \\
\text { Geschoße: 1-2 Form 1A }\end{array}$ \\
\hline $\begin{array}{l}\text { Binnengebiet der } \\
\text { Küstenebene (2) }\end{array}$ & $\begin{array}{l}\text { Material: Ziegel (häufiger), Basalt } \\
\text { (lokal) Form 1B } \\
\text { Geschoße: 2 (häufiger), 1 (seltener) } \\
\text { Form 2A }\end{array}$ & $\begin{array}{l}\text { Material: Ziegel (häufig), } \\
\text { Basalt (lokal) } \\
\text { Geschoße: 1 vorwiegend } \\
\text { Form 2B }\end{array}$ \\
\hline
\end{tabular}

Nicht dem Küstenstil zuzurechnen ist hingegen die traditionelle Architektur der Städte im Hijāz, also von al-Ḥaramayn (Mekka und Medina) und von al-Ṭā’if, auch wenn es auf den ersten Blick diesen Anschein haben mag: Die äußere Erscheinung der städtischen Wohnarchitektur im Hijāz ist nämlich ebenso von der dekorierten mushrabīya geprägt wie jene der Küstenstädte. Dies belegt allerdings bloß, daß die Städte des Hijāz neben vielen anderen auch immer wieder architektonische Impulse von der Küste erfahren, und Einzelelemente von dort übernommen haben. In al-Ṭà if ist die mushrabīya überdies heute wie schon in der ersten Hälfte des 19. Jh. nur für die (im traditionellen Stil errichteten) Wohnhäuser wohlhabender Persönlichkeiten charakteristisch, und selbst dort sind Luftlöcher als Aussparung in Ziegelwänden ebenso häufig (Abb. 36). Auch aus klimatischen Gründen ist diese Einrichtung zur Luftzirkulation in allen übrigen Wohnhäusern von alTầ if dominant. ${ }^{43}$

\footnotetext{
41 Mauger 1993: 15.

42 Prochazka 1978: 118 (The Tihāma) gibt den Begriff Șabl, pl. Șubūl an: "Square or rectangular hut with flat roof: Sabl, pl. Subul." Die von Thesiger (1947: 194) verwendete Bezeichnung 'Ardhi villages ist geographisch gemeint. Vgl. dazu Thesiger (1947: 190): "... and the escarpment itself is known as the 'Ardhi, while in the south of Abha it is called the Hibata."

43 Tamisier 1840, I: 283f. und eigene Erhebung.
} 
Neben der mushrabīya gibt es auch Überschneidungen von anderen Stilelementen der städtischen Wohnarchitektur zwischen der Küste und dem Hochland, etwa hinsichtlich der Stützpfeiler oder der echten Bögen. Diese verweisen allerdings nicht nur auf direkte architektonische Beeinflussung der Ḥijāz-Städte durch jene der Küste (oder umgekehrt), als vielmehr auf die gemeinsame Übernahme von anderen Einflüssen - im Fall des echten Bogen seitens der kulturhistorischen Vorläufer der Islamischen Architektur, und im Fall der Stützpfeiler seitens der ländlich-tribalen Architektur des Hịjāz.

Bei allen Ähnlichkeiten des städtischen Wohnbaus, die in einer gemeinsamen Islamischen Tradition für Nachbarregionen selbstverständlich sind, ist die Stadtarchitektur des Hijāz folglich doch geprägt durch andere Baumaterialien, unterschiedliche klimatische Herausforderungen und eine stärkere Durchsetzung mit Einflüssen aus Inner- und NordArabien, vor allem aber aus dem bäuerlichen Hochland selbst.

Die Unterschiede und Gemeinsamkeiten zwischen der städtischen Wohnarchitektur des Küstenstils zu jener des Hijāz unterstreichen also, daß der „Rote Meerstil“ (in seinen internationalen und lokalen Formen) eine Kombination aus mehreren Elementen darstellt, die jeweils ihre eigene historische Dimension haben. Die heute so prägende mushrabìya etwa, die alle anderen Elementen der Wohnarchitektur spektakulär in den Schatten stellt, ist ein relativ rezentes Stilphänomen an der Südostküste des Roten Meeres.

\subsubsection{Historische Dimensionen}

Guillemette und Paul Bonnenfant haben demonstriert, daß die mushrabīya ursprünglich in Kairo und Unterägypten heimisch war, wo sie erst ab dem 17. Jh. weitere Verbreitung erlangte. Von dort fand sie zu Beginn des 19. Jh. ihren Weg nach Jidda und al-Țā'if. Von diesen beiden Städten aus eroberte die mushrabìya danach als architektonische Mode bis zur Jahrhundertwende alle anderen größeren Häfen im ägyptisch-türkischen Einflußbereich am Roten Meer. Von al-Ḥudayda gelangte sie vermutlich erst Mitte des 19. Jh. bis San ${ }^{c}{ }^{a} \cdot{ }^{44}$ Dieses jüngste Element des internationalen Küstenstils ist also ein Ergebnis der Veränderungen des 19. Jh., mit seiner ägyptisch-türkischen und dann türkischen Vorherrschaft über das Rote Meer, und parallel dazu der zunehmenden Ausdehnung von Weltmarkt und Transportwesen. ${ }^{45}$

In al-Qunfudha selbst dürfte die mushrabiya erst im letzten Viertel des 19. Jh. Verbreitung gefunden haben, also nach der Eröffnung des Suezkanals. Ein Vergleich von rawshān-Dekor aus Jidda, al-Ṭā'if und al-Qunfudha (Abb. 30, 35, 36) verdeutlicht, wie sehr al-Qunfudha den beiden anderen Städten schon um die Jahrhundertwende in Bedeutung, Prestige und Wohlstand nachgestanden haben muß. Das relativ geringe Alter, mit dem die mushrabiya als Einzelelement in al-Qunfudha vertreten ist, wirft insgesamt die Frage nach dem historischen Hintergrund des Küstenstils in dieser Stadt auf, und damit nach ihrer geschichtlichen Entwicklung.

44 Bonnenfant 1987: 168; für al-Ṭa if cf. Tamisier 1840, I: 283; Mermier 1993: 246 zitiert einen jemenitischen Text, der die mushrabīya in Șan 'ẩ für 1858 belegt.

45 Die relativ rezente Entwicklungs- und Verbreitungsgeschichte der mushrabīya baut allerdings auf der wesentlich älteren Tradition von Holzdekor in der Architektur des Islamischen Orients auf. Beispiele dafür sind dekorierte Holzfriese aus dem Ägypten des frühen 9. und 10. Jh. (Musée du Louvre, Arts d'Islam, Salle 2, obj. 2, 3, 7 und 9). 
Das W. Qanūna, in dessen Mündungsgebiet das heutige al-Qunfudha liegt, dürfte in der Antike schon Plinius gekannt haben, aber ein Ort dieses Namens scheint weder den antiken noch den mittelalterlichen arabischen Autoren bekannt gewesen zu sein. Jedenfalls findet sich das auffällige Toponym ${ }^{46}$ weder in den ansonsten sehr genauen Beschreibungen Südwestarabiens und der Küste bei al-Hamdānī im 10. Jh. noch bei Ibon al-Mujāwir im frühen 13. Jh. ${ }^{47}$ Der Hafenort dürfte also erst im ausgehenden Mittelalter oder der beginnenden Neuzeit gegründet worden sein, was angesichts der Versandung mancher älterer Häfen am Roten Meer keine Ausnahme wäre. ${ }^{48}$

Im Mittelalter kam noch al-Līth und Halī (die nächstgelegenen größeren Küstenorte nördlich und südlich des heutigen al-Qunfudha) in diesem Abschnitt der Tihāma größere Bedeutung zu, die sie heute verloren haben. ${ }^{49}$ Im späten Mittelalter scheint also ein Prozeß einzusetzen, in dessen Verlauf die Stellung dieser beiden Küstenorte allmählich zurückgedrängt und in ihrer Bedeutung durch al-Qunfudha abgelöst wurde.

Erste Erwähnung findet der Hafenort verschiedenen Quellen zufolge zur Zeit der Rasūliden-Herrschaft im Jemen, die im Spätmittelalter Wirtschaft und Handel auch am Roten Meer belebte. Nach einer Zeit des Niedergangs, die mit dem portugiesischen Zugriff auf die Meere um Arabien in Zusammenhang gebracht wird, etablierten sich die Osmanen im Gegenzug erstmals auch in al-Qunfudha, das von der Mitte des 16. Jh. bis etwa 1630 als türkische Nachschubstation erwähnt wird. ${ }^{50}$ Der ältere Einfluß der Sharîfen von Mekka auf den Tihāma-Abschnitt um al-Qunfudha wurde von den Osmanen nominell bestätigt.

Die Quellen des 18. und frühen 19. Jh. deuten darauf hin, daß sich aus jener Periode der frühen Geschichte von al-Qunfudha später keine architektonischen Zeugnisse des Küstenstils erhalten hatten. Dies muß allerdings nicht bedeuten, daß er zwischen dem 14 . und dem frühen 17. Jh. nicht schon erste lokale Ausformungen in al-Qunfudha durchlaufen haben könnte, da die Korallensteinbauweise für andere Orte Ostafrikas und der Roten Meerküste bereits für das 15. Jh. belegt sind. Die Zeit der politischen Unruhen nach

46 Qunfudh heißt porcupine fish, mit dem Attribut baḥrī auch: sea urchin; qunfudh oder qunfadh hingegen bezeichnet „an elevated place abounding with trees" (Lane); cf. auch Gingrich 2005 und Heiss in diesem Band S. 520.

47 al-Hamdān̄̄ (ed. Müller); Ibn al-Mujāwir (ed. Loefgren); Grohmann and Bosworth in EI². Die Küstenorte und Tihāma-Wadis werden von al-Hamdānī mit seiner üblichen Genauigkeit aufgezählt. Er führt dabei auch (188) das W. Qanūna an, aber nicht das heute an dessen Mündung gelegene al-Qunfudha (das auch in anderen mittelalterlichen arabischen Beschreibungen nicht aufscheint). Für das W. Qanūna führt al-Hamdānī bloß den Ort al-Juwainīya an, der auch al-Qanāt heiße.

Eine Bucht dieses Namens (, waterway', ,canal') mit wenigen Hütten in der Nähe liegt unmittelbar im Süden des heutigen al-Qunfudha. Sie diente bereits Philby (1952, 1976: 691) als Lagerplatz, und ebenso 1981/82 dem österreichisch-saudischen Team.

48 Ein ähnlicher Fall ist an der Tihāma-Küste des 'Asīr mit Jīzān gegeben, das im Mittelalter gegenüber dem großen Hafenort 'Aththar vor Baysh praktisch bedeutungslos war, und es erst nach dessen Versandung am Beginn der Neuzeit ablöste (Forrer 1942: 48f., Fußnote 1mit Anmerkungen; Rentz 1965: 516-518).

49 Al-Lìth wird seit dem 7. Jh. mehrfach von arabischen Historikern erwähnt (Forrer 1942: 53, Fußnote 1 mit Anmerkungen). Das Gebiet um Ḥalī wird bei al-Hamdānī (ed. Müller: 129) als Sitz der Führung der B. Ḥirām von den Kināna genannt. Der Ort trägt den lokalen Namen Makhshūsh und umfaßt einen jüngeren, südlichen Teil (Ḥalī 'l-jadīd), der von Ḥudhayl und niederen Statusgruppen bewohnt ist. Zum anderen leben im alten, nördlichen Ortsteil Ḥalī 'l-qadīm bis heute Kināna (Philby 1952: 686).

50 Aloshban 1987: 73 f., 80 unter Berufung auf Arbeiten von al-Faqih al-`Aqī̄ì und weitere Quellen, die mir nicht zugänglich waren. 
dem Niedergang der ersten Türkenherrschaft, und die Vergänglichkeit des Baumaterials könnten also auch das Verschwinden einer derartigen, hypothetischen ersten Phase des Küstenstils in al-Qunfudha bewirkt haben. In jedem Fall scheint al-Qunfudha im 18. Jh. dann bloß die kleinen Dimensionen eines einfachen Hafenortes gehabt zu haben.

Je nachdem, ob es eine derartige, hypothetische frühere Phase des Küstenstils in alQunfudha vor dem 18. Jh. gegeben hat, stellt dann diese baugeschichtliche Zeit eines kleinen Hafenortes im 18. Jh. entweder eine vor- oder eine „zwischen“-staatliche Periode dar. Dem kleinen, unbefestigten Hafenort der vor- oder zwischenstaatlichen Periode der ersten Hälfte des 18. Jh. kann mit einiger Sicherheit bereits die Funktion eines tribalen "port of trade" zugewiesen werden.

Diese Funktion, die al-Qunfudha noch heute für die Ghāmid-Stämme der Hijāz-Berge einnimmt (cf. Dostal in diesem Band) geriet allerdings mit den verstärkten Staatseinflüssen des späten 18. und des 19. Jh. auf den Hafenort zunehmend in den Hintergrund.

Erst aus den Beschreibungen von Carsten Niebuhr (1761) und James Bruce (1769) ergibt sich ein recht konkretes Bild. Im ausgehenden 18. Jh. war in al-Qunfudha im Gegensatz zu Mekka, Madīna und al-Ṭā̉if keine türkische Garnison stationiert. Die Gebietsgrenze des Sharīfen lag weiter südlich bei Ḥalī. Ein Gouverneur und Soldaten des Sharīfen sorgten aber auch in al-Qunfudha bereits für die Besteuerung und Verzollung von Handelsgütern wie jemenitischem Kaffee, die auf Schiffen nach Jidda gebracht wurden. Der Gouverneurssitz war damals in einem Wehrturm auf einer Insel vor der Küste untergebracht. ${ }^{51}$ Die eigentliche Siedlung war bereits recht groß und bestand aus etwa 200 Tihāma-Hütten. Selbst die Wohnstätte des Gouverneurs war bloß eine solche Konstruktion, nur im Inneren hob sie sich durch eine Ziegelwand von den anderen Behausungen ab. ${ }^{52}$ Südwestlich des Ankerplatzes lag 1/4 Meile entfernt jenes Kastell, dessen Nachfolgebau wohl noch 1832 auf Rupert Kirk's Ölgemälde der Stadt abgebildet ist. ${ }^{53}$

Das Warenangebot bestand nach Bruce aus Fisch, Butter, Milch und Ziegenfleisch; darüber hinaus kann eine beschränkte Bedeutung des Sklavenhandels angenommen werden. ${ }^{54}$

Aus diesen Quellen ergibt sich, daß der seichte, nur für leichte Boote nutzbare Ankerplatz von wenigen Amtsgebäuden (Kastell und Wehrturm auf der Insel) bewacht war; beim Hafen dürfte auch der damals noch unbefestigte Marktplatz gelegen sein. Die Gärten der Siedlung lagen hingegen landeinwärts. Dies bedeutet, daß sie natürlich nicht im sandigen Küsten- und Mündungsteil gelegen sein können, sondern im fruchtbareren Teil rund um die Süßwasserbrunnen. Diesem von der Küste deutlich abgesetzten Standort landeinwärts lag daher auch der Großteil der Wohnhütten nahe, was auch durch Kirk's Abbildung (trotz der inzwischen eingetretenen historischen Veränderungen) noch bestätigt wird.

Im ausgehenden 18. Jh. bietet al-Qunfudha daher ein Stadtbild und Siedlungsmuster, das sich sehr deutlich von den späteren und heutigen Gegebenheiten unterscheidet: Die Siedlung ist in zwei Teile gegliedert. Der Garten- und Wohnteil liegt landeinwärts bei den

\footnotetext{
51 Niebuhr 1772 (1969): 358 und Karte.

52 Bruce 1790-91: 344-47.

53 King 1986: 55.

54 Rüppel spricht für die späten $20 \mathrm{er}$ und frühen $30 \mathrm{er}$ Jahre des 19 . Jh. davon, daß die Bedeutung des Sklavenhandels in al-Qunfudha gesunken sei; Rüppel 1838: 177-179; cf. auch Toledano 1982: 27, 37.
} 
Brunnen und ist damit vor Angriffen vom Meer aus zusätzlich geschützt; dieser Teil besteht ausschließlich aus 'ushash. Der Verwaltungs- und Hafenteil an der Küste besteht hingegen aus dem Ankerplatz, einer freien Marktfläche und den beiden staatlichen Gebäuden: Wehrturm und Kastell dienen eindeutig militärischen Zwecken; neben der Gouverneurswohnung sind dies die beiden einzigen Gebäude aus festem Baumaterial.

Diese Zweiteilung des Siedlungsmusters von al-Qunfudha gemäß einer Ost-West-Gliederung am Ende des 18. Jh. entspricht im wesentlichen jener, die heute größere Fischerdörfer am Roten Meer aufweisen - eine Polizeistation und einige Läden liegen bei der Bootsanlegestelle; die Wohnhütten liegen davon abgesetzt bei den Gärten und den nächsten Brunnen landeinwärts. Für al-Līth wird im 19. und 20. Jh. der Fortbestand einer derartigen Zweiteilung berichtet, ${ }^{55}$ und das große Fischerdorf al-Birk im Süden weist noch heute ein ähnliches Muster auf. Schließlich ist in diesem Zusammenhang auch das ältere, heute verschwundene Siedlungsmuster von Jīzān zu erwähnen, das noch in der ersten Hälfte des 20. Jh. in Restelementen fortbestand. Im Jīzān der 20er Jahre des 20. Jh. lebte die Mehrheit der Bevölkerung in Holzhütten; die wenigen mehrstöckigen Gebäude aus Korallenstein waren die Wohnhäuser von Kaufleuten und Ashrāf, die Moschee, Fort und Kastell, Amtsgebäude und Palasthäuser von Regierungsvertretern. ${ }^{56}$ Aus klimatisch-gesundheitlichen Gründen, wegen der Trinkwasserversorgung und auf Grund der größeren militärischen Bedrohung an der flachen, offenen Küste liegen die historischen Standorte größerer Dorfsiedlungen in der Küstenregion des Roten Meeres also meist landeinwärts. Die abgesonderte Lage des Marktplatzes entspricht den praktischen Erfordernissen und zugleich dem generellen Ordnungsprinzip südwestarabischer Märkte.

Das nach der Ost-West-Richtung zweigegliederte Siedlungsmuster des späten 18. Jh., als al-Qunfudha einer gewissen staatlichen Kontrolle unterlag, dürfte daher kontinuierlich auf dem Siedlungsmuster der vorangegangenen vor- oder zwischenstaatlichen Phase aufgebaut haben. Die Anlage von al-Qunfudha als tribaler „port of trade“ in der ersten Hälfte des 18. Jh. hätte demnach jener des heutigen „port of trade“ der Zahrān in Dawqa entsprochen, und sich am Ende des 18. Jh., in der ersten Phase staatlicher Kontrolle, noch nicht grundsätzlich geändert.

Die Weiterentwicklung von einem staatlich kontrollierten Küstendorf mit alter OstWest-Gliederung zur städtischen Siedlung mit allmählicher Hinwendung zu einer Dominanz der Nord-Süd-Gliederung dürfte sich in al-Qunfudha erst in den ersten Jahrzehnten des 19. Jh. vollzogen haben. Dies wurzelt in den militärisch-politischen Veränderungen dieser Zeit.

Diese waren bestimmt von wachsendem Einfluß des „Unitarianismus “ der sogenannten „wahhabitischen“ Strömung des Islam, und damit verbunden vom Aufstieg des ersten saudischen Staates. Dessen Truppen drangen 1803 erstmals in den Hijāz vor, ${ }^{57}$ das einige Jahre unter die Oberhoheit des mit den „Wahhabiten“ verbündeten Emir von 'Asīr (Abū Nuqta) geriet. Dessen expansive Einfälle in die Tihāma brachten die Sharīfen von Abū 'Arīsh in schwere Bedrängnis, deren Einfluß zeitweilig bis al-Qunfudha gereicht hatte. ${ }^{58}$

\footnotetext{
55 Combes und Tamisier 1838, IV: 33; Philby 1952 (1976): 470-472, 705; für al-Birk cf. auch Weisl 1927: 292.

56 King 1986: 14; Forbes 1923: 271 f.; Weisl 1927: 257, $280 \mathrm{f}$.

57 Burckhardt 1829: 453 und 1831, II: $190 \mathrm{f}$.

58 Burckhardt 1831, II: 202 und 274-77.
} 
Im Gegenzug gelang es dem ägyptisch-türkischen Heer unter Muḥammad 'Alī nach wechselhaftem Kriegsverlauf, die saudischen Truppen zwischen 1811 und 1819 aus dem Hịāāz und der Küste wieder abzudrängen. ${ }^{59} 1814$ wurde al-Qunfudha wieder von türkischen Truppen eingenommen und verblieb bis in die 40er Jahre unter turko-ägyptischer Herrschaft, die danach bis zum Ende des 1 . Weltkrieges von den Osmanen abgelöst wurde. ${ }^{60}$

Aus dem frühen 19. Jh., der Periode saudisch-ägyptisch-türkischer Kämpfe, liegt eine Beschreibung der damaligen Befestigungsanlagen der Stadt vor. Der Italiener Giovanni Finati nahm 1814, im Dienst der Armee des Muhammad 'Alī, an der ersten Belagerung von al-Qunfudha teil, das von saudischen Truppen gehalten wurde. In seinen war journals berichtet Finati vom al-Qunfudha des Jahres 1814:

"It is but a small village in itself, situated close to the water's edge; but its principal point of strength consists in the appendage of a fort or castle, placed at one of its extremities, which, though constructed of mud only, and weak and crumbling in appearance, was yet solidly built, and calculated to make a stout defense; it was also well garrisoned, for great number of Wahhabis, driven out from other places, had fled hither for refuge. (...) the village (...) was not tenable, and when it was perceived that we were gaining ground, and had even gotten some footing within it, at a sudden signal all retreated at once into the castle (...). Though we took all advantages of ground, and brought our cannon into full play, yet the whole fabric being of earth, or of unbaked brick', the balls only sunk into the walls and bastions, without further destroying them; and when, by order of our Bey-commandant, we approached for an assault, those within found means of directing a fire upon us, from their matchlocks and small field pieces, through loop-holes scarcely perceptible, so as to do great execution among us, without our being able to do the smallest upon them in return ..." 61

Finati's eindrucksvolle Schilderung belegt zum einen den Heroismus der saudischen Truppen jener Zeit. Darüber hinaus zeugt sie von den militärtechnischen Vorzügen des damaligen Forts der Stadt, das aus Lehmziegeln errichtet gewesen zu sein scheint: Offenbar war das Kastell des späten 18. Jh. um 1814 von den saudischen Truppen ausgebaut, und vielleicht auch mit zusätzlichen Elementen des Najd-Stils versehen worden.

Auf die Kämpfe des frühen 19. Jh. folgte die erwähnte Periode relativer Konsolidierung unter turko-ägyptischer Kontrolle. Aus dieser Zeit, der ersten Hälfte des 19. Jh., liegen einige weitere Hinweise und Beschreibungen von al-Qunfudha vor. Die Grenze lag nun erneut im Süden bei Halī ${ }^{62}$ und die Siedlung stand wiederum unter der formalen Herrschaft der Sharïfen von Mekka. Sie war aber nun von einer starken türkischen Garnison belegt. E. Rüppel, der al-Qunfudha 1827 und 1831 besuchte, berichtet über die Stationierung von 150 türkischen Reitern und von Artillerie. ${ }^{63} \mathrm{Nach}$ ihm hatte der Ort 1200 Einwohner. Im Vergleich zum ausgehenden 18. Jh. hatte sich auch der örtliche Handel wesentlich ausgeweitet. Die Quellen führen im Warenangebot von al-Qunfudha nun Getreide, Hirse, Salz, Butter und Datteln an ${ }^{64}$ aber auch Granatäpfel und Schafe ${ }^{65}$ werden als regionale Landeserzeugnisse für den Fernhandel angeboten. Ob dazu auch die in dem Be-

\footnotetext{
59 King 1986: 14.

60 ibid. und Burckhardt 1831, II: 274-77; Rüppel 1838: 179; Peters 1994: 219.

61 Peters 1994: 313f.

62 Burckhardt 1829: 453.

63 Rüppel 1838: 177-79 und ibid für 1831: um saudisch-'`asīrische Streifzüge abzuhalten, mußte „der Pascha fortwährend mit schweren Kosten ein Truppencorps in al-Qunfida oder einem Lager der Umgebung unterhalten".

64 Galinier and Ferret 1843: 111.

65 Rüppel 1838: 177-179.
} 
richt erwähnten Rosinen, Trauben und Stoffe zählten, ${ }^{66}$ oder ob diese - was wahrscheinlicher ist - Importware repräsentierten, bleibt offen. Der Fernhandel versorgte das Hinterland von al-Qunfudha mit allen „Luxusbedürfnissen“, wie Rüppel schreibt, darunter auch mit abessynischen Sklaven und mit Waffen. ${ }^{67}$

Obwohl der Handel Anfang der 30er Jahre des 19. Jh. durch die Kriegsfolgen und die Willkür der türkischen Truppen stagnierte, ${ }^{68}$ macht diese Aufstellung doch den qualitativen Unterschied zum ausgehenden 18. Jh. deutlich. Das tribale und ländliche Hinterland war nun mit einer ganzen Palette von Agrarprodukten an den „port of trade“ angeschlossen (wobei lokaler Kaffee noch nicht erwähnt ist), und es bezog strategische und Luxusgüter von dort. Dies zeigt zum einen erhebliche Umwandlungsprozesse in der Struktur des bäuerlichen und tribalen Hinterlandes an; zum anderen verdeutlicht es den geänderten Stellenwert der Stadt selbst. Die meisten Handelsströme von und nach al-Qunfudha verliefen über Jidda, ${ }^{69}$ was die staatliche Kontrolle besser gewährleistete. Vor allem aber hatte sich in al-Qunfudha selbst eine entscheidende städtebauliche Veränderung vollzogen: Das Marktareal beim Hafen war nun im Viereck von einer 15 Fuß hohen Steinmauer umgeben. Sie war mit mehreren eckigen Türmen und Kanonen bewehrt und im Norden, Süden und Westen mit Toren versehen. Innerhalb des Mauergevierts lagen vorwiegend einstöckige Magazine und Läden mit flachen Dächern aus Stein (wakālāt), aber auch einige 'ushash, die außerhalb der Mauern weiter dominierten. ${ }^{70}$

Neben dem Gouverneurssitz und dem Kastell, die schon Ende des 18. Jh. als Steinbauten bestanden hatten, und drei ebenerdigen, geweißten Wohnhäusern war somit im ersten Drittel des 19. Jh. ein befestigtes Marktareal aus Stein als wesentliche Neuerung hinzugekommen, wie neben den Reiseberichten auch Kirk's Gemälde belegt. Staatlicher Schutz für, und Kontrolle des port of trade initiierten somit die Ausdehnung der Konstruktion mit festen Baumaterialien. Der Aufschwung des Welthandels und die Veränderungen der politischen und militärischen Verhältnisse waren die externen Stimuli, welche dafür den Ausschlag gaben. Der Ausbau dieser Befestigungsanlagen direkt an der Küstenlinie darf als entscheidende Voraussetzung dafür angesehen werden, daß sich in den folgenden Jahrzehnten auch die Siedlungsstruktur zum Nord-West-Muster hin verschob: Ab nun bot die Küstenlinie als Wohnstandort mehr wirtschaftliche Anreize (durch den Ausbau des Handels) und zugleich verbesserten militärischen Schutz.

Eine ähnliche Entwicklung zeichnet sich für diese Periode auch für al-Qaḥma ab, das auf halbem Weg zwischen den beiden Haupthäfen Jīzān und al-Qunfudha liegt und durch seine Lage westlich von Abhā eine gewisse Bedeutung erlangte (die allerdings nie an jene dieser beiden Haupthäfen heranreichte). Noch 1937 war al-Qahma in vier Viertel gegliedert, die zusammen eine vorherrschende Nord-Süd-Gliederung bildeten. Im Norden lag das Marktareal (bei einem der zwei Ankerplätze), umgeben von mehreren gemauerten Häusern. Südlich davon stand das Zollhaus, an das östlich das Wohnviertel Mishwat al-

\footnotetext{
${ }^{66}$ King 1986: 55 (Kirk's Gemälde); Rüppel 1838: 177-197; Combes und Tamisier 1838, IV: 34-36; Tamisier 1840, I: 271-272.

67 Rüppel 1838.

68 Philby 1952 (1976): $673 \mathrm{f}$.

${ }^{69}$ Für Abū 'Arīsh notiert Tamisier (I, 1840: 385) etwa in derselben Epoche ein ebenerdiges Marktareal, dort allerdings aus Ziegeln gemauert.

70 Rutter 1928; I: 71, zit. nach King 1986: 56. Rutter's Arbeit selbst war mir leider nicht zugänglich.
} 
Jār anschloß. Daran wiederum südlich und westlich zum Meer hin schloß das administrative und kommerzielle Zentrum 'Anaqa an, wo die Residenz des Amīr, ein Zollhaus und der Hafendamm (für den zweiten Ankerplatz) lagen. Bezeichnenderweise landeinwärts lag das ärmere Wohnviertel al-'Arq, mit einer Moschee und einer Mehrheit von 'ushash. ${ }^{71}$

Auch hier sind die wenigen Häuser aus festem Material die Residenz, das Zollhaus, Gebäude im Marktbereich und die Moschee, während die Mehrheit der Bevölkerung in 'ushash lebt. Eine ältere Ost-West-Gliederung, die im Zug der politisch-militärischen Interventionen ab dem frühen 19. Jh. durch eine jüngere Nord-Süd-Gliederung schrittweise überlagert wurde, läßt sich aus Philby's Beschreibung analog zu al-Qunfudha daher auch für al-Qahma rekonstruieren.

Im Fall von al-Qunfudha ist es darüber hinaus möglich, die kulturhistorische Rekonstruktion von Architektur und Stadtbild einen Schritt weiter zu führen. Die konsultierten Quellen erlauben nämlich, die ältesten Gebäudekomplexe zu identifizieren, welche in alQunfudha zum Zeitpunkt der Erhebung (Dezember 1981 und Februar 1982) noch erhalten waren. Dies ist erstens nach Anlage und Konstruktion das heutige (1981, 1982) Marktareal, das dem bei Rüppel 1827 und Kirk 1832 dokumentierten entspricht (Abb. 30). ${ }^{72}$ Auch einige Gebäude darunter könnten durchaus 160 Jahre alt sein, was sich aber nicht im einzelnen nachweisen ließ.

Dies ist jedoch möglich für den zweiten Gebäudekomplex, nämlich die alte Moschee der Stadt (Abb. 33). Sie ist identisch mit jener, die in der Bildmitte auf Kirk's Gemälde zu sehen ist. Damals war sie die einzige Moschee der Stadt und lag außerhalb des Marktgebietes, also wie heute weit landeinwärts, im Zentrum des ältesten Wohngebietes, das weiterhin ausschließlich aus 'ushash bestand. Die Moschee wurde in den 20er Jahren beschrieben als „square and sqat, some fifty feet in height, and the top is surmounted by a little round tower “. ${ }^{73}$ Wie die jüngeren Moscheen hat sie „a walled north “. ${ }^{74}$ Das breite Minarett mit seinem runden, glockenartigen Aufsatz unterscheidet sich deutlich von anderen Formen der Region und ist nach King entweder eine rein lokale Schöpfung aus al-Qunfudha, oder es geht ebenfalls auf äußere Einflüsse zurück, die sich in der Region aber nicht weiter durchsetzen.

King gibt als eine Möglichkeit für derartige externe stilistische Stimuli auf diesen Moscheebau nordafrikanischen (also wohl: Idrisi-) Einfluß an. Ergänzend dazu möchte ich auch auf die Möglichkeit eines südasiatischen oder südarabischen Elementes hinweisen. Indische und hadramitische Händlerkolonien sind für die Küstenorte bereits in jener Zeit belegt, und sie bilden auch im 20. Jh. einen wichtigen Sektor der Kaufmannschaft von alQunfudha. ${ }^{75}$ Aus dem Umstand, daß diese älteste Moschee von al-Qunfudha bereits aus Korallenstein erbaut war, läßt sich der historische Hintergrund jenes ethnographischen Küstenstils bestimmen, den die Erhebung am Beispiel der Stadt dokumentiert: In dieser

\footnotetext{
71 Philby 1952 (1976): 674.

72 King 1986: 56; Tamisier 1840, I: 387 (für Abū `Arīsh im Jahre 1834); Philby 1952 (1976): 691-693. Bei King's eigenem Besuch im Mai 1984 war die hier erstmals abgebildete Moschee bereits abgerissen; seine detaillierte Beschreibung beruht auf Photomaterialien von Prochazka.

73 Rutter 1928, I: 71, zit. nach King 1986: 56.

74 King 1986: 56.

75 King 1986: 56; Tamisier 1840, I: 387 (für Abū 'Arīsh im Jahr 1834); Philby 1952 (1976): 691-693; eigene Erhebungen.
} 
Ausformung von 1982, die mittlerweile selbst wieder verschwunden ist, wurzeln die Anfänge des „internationalen“ Küstenstils im ausgehenden 18. und den ersten Jahrzehnten des 19. Jh. In einer für Hafenorte typischen, zweigeteilten dörflichen Siedlung etablierte sich diese rezente Form des Küstenstils also zunächst über mehrgeschoßige Militär- und Verwaltungsgebäude am Meer. Er setzte sich einige Jahrzehnte später über die befestigte Marktanlage fort, die ebenfalls am Hafen liegt, und weitet sich offenbar erst in dieser zweiten Phase über die alte Moschee und wenige andere Gebäude landeinwärts auch auf das ältere, im Osten gelegene Wohnviertel aus. Bezeichnenderweise waren diese steinernen Markt- und Wohngebäude im Unterschied zu Moschee und Militärgebäude zunächst noch ebenerdig: Die mehrgeschoßige Bauweise griff auf die profanen und zivilen Bauten erst in der folgenden dritten Phase über.

Für das ausgehende 18. und frühe 19. Jh. lassen diese Ergebnisse zugleich eine Schlußfolgerung zu, welche für die Untersuchung der 'ushash-Architektur von Bedeutung ist: Die Diskrepanz zwischen zwei unterschiedlichen Rhythmen der Architektur- und Siedlungsgeschichte an der Küste gewinnt in dieser Periode zunehmende Bedeutung. Während die größeren und mittleren Hafenorte einem primär durch externe Stimuli bedingten, dynamischen Veränderungsprozeß unterliegen, bewahrt die ländliche, dünn besiedelte Küstenregion in ungleich höherem Ausmaß ihr althergebrachtes architektonisches Erscheinungsbild. 1761 sah Niebuhr zwischen Jidda und Abū Arīsh außer al-Qunfudha an der Küste „nur Ankerplätze, die aus ein paar Hütten“ bestanden, und er wußte diese „Hütten“ nördlich von Abū 'Arīsh klar von den „Dörfern“ südlich davon zu unterscheiden. ${ }^{76}$ Siebzig Jahre später, also nach Einsetzen der großen Militäraktionen, welche den ersten großen städtebaulichen Wandel von al-Qunfudha einleiteten, bietet die Küste abseits der größeren Häfen jedoch im wesentlichen noch immer das gleiche Bild: Combes und Tamisier etwa sprechen von den kleinen Dörfern südlich von Halī, die hauptsächlich aus Strohhütten bestünden. ${ }^{77}$ Die ${ }^{c}$ ushāsh-Architektur der ländlichen Tihāma wird in ihrer Form und Konstruktion offenbar kaum, oder nur viel langsamer von jenen internationalen Veränderungen erfaßt, welche ab der Wende vom 18. zum 19. Jh. al-Qunfudha, al-Qahma und Jīzān durchdringen.

Diese Diskrepanz vertiefte sich in der zweiten Hälfte des 19. Jh. um ein Vielfaches. Diese Periode markiert die dritte Phase der Baugeschichte von al-Qunfudha, in der sein Küstenstil schließlich jene dauerhafte Ausformung erhielt, die ihn dann etwa einhundert Jahre lang kennzeichnete: Diese dritte Phase seiner endgültigen Ausgestaltung war geprägt von einer relativ stabilisierten osmanischen Kontrolle über die Region, bei wachsender Einflußnahme europäischer Mächte, vor allem Englands. ${ }^{78}$ Damit einher ging eine bedeutende Steigerung des Handelsverkehrs durch das Rote Meer, insbesondere nach der Eröffnung des Suez-Kanals. Daraus ergab sich auch für al-Qunfudha die Möglichkeit einer intensivierten kommerziellen Vermittlung zwischen bäuerlichen und tribalen Gebieten in seinem Hinterland sowie zu Jidda und dem Weltmarkt. Der regelmäßige Verkauf von lokalem Kaffee aus dem südlichen Hịjāz (vor allem aus dem Gebiet des J. Shadā’) an Händler in al-Qunfudha scheint sich erst in dieser Periode etabliert zu haben, und der - unter westlichem Druck - immer stärker eingeschränkte Sklavenhandel aus Ostafrika fand in

\footnotetext{
76 Niebuhr 1774: $63 \mathrm{f}$.

77 Combes and Tamisier 1838, IV: 42.

78 Cornwallis 1976: 25-28; Toledano 1982: 129-135, 219-224.
} 
al-Qunfudha einen seiner letzten, wichtigen Umschlagsorte. ${ }^{79}$ Eine parallele Entwicklung in kleinerem Maßstab dürfte nach meiner Rekonstruktion auch al-Qaḥma durchlaufen haben.

In dieser Phase (deren Ende wohl mit dem Beginn des 1. Weltkrieges anzusetzen ist) vollziehen sich jene drei städtebaulichen Veränderungen, welche die Reisenden des 20. Jh. beschreiben, ${ }^{80}$ und deren Überreste diese Erhebung Anfang der 80er Jahre noch vorfand (Tab. 2 und 3).

Die drei Veränderungen der zweiten Hälfte des 19. Jh. sind:

- Die Ausweitung der Korallensteinkonstruktionen auf die Wohnviertel von al-Qunfudha nach der nun dominierenden Nord-Süd-Gliederung: Dies erfolgte sowohl durch Errichtung von ebenerdigen (Süden) wie auch von mehrgeschoßigen Bauten (Norden). Letztere waren Wohnhäuser der ansäßigen Händler (darunter ein größerer Anteil von hadramitischer und indischer Herkunft) und der Gelehrten. Ihre Errichtung folgte wohl dem Beispiel von Jidda und jenem der örtlichen Verwaltungsbauten; die Höhe dieser neuen Wohnhäuser hielt sich aber in bescheideneren Grenzen und überstieg selten drei Geschoße.

- Durch die erhöhte administrative und kommerzielle Bedeutung siedelten sich auch Angehörige der Unter- und Mittelschichten an, wodurch die Anzahl der Tihāma-Hütten (im Südteil der Stadt) ebenfalls stieg. Beide Prozesse mündeten in der allmählichen Auflösung der traditionellen Zweiteilung des Ortes; der bis dahin räumlich getrennte Hafen-(Markt-, Verwaltungs-)Teil und das Wohnviertel verschmolzen zu einem zusammenhängenden, kleinen Stadtareal.

- Zusammen mit der Errichtung von mehrgeschoßigen Wohnhäusern wohlhabender Kaufleute und Händler wurde von Jidda die mushrabìya, und speziell das screened bay window in vereinfachter Form übernommen. Dem architektonischen Beispiel dieser Oberschicht-Häuser wurde bei der Konstruktion ebenerdiger Korallenstein-Bauten mit einfacheren Mitteln gefolgt.

Diese kleine Hafenstadt war für den internationalen Handel am Roten Meer zweifellos nur ein Nebenschauplatz. Für die Bevölkerung der angrenzenden Tihāma und des Hijāāz stellte al-Qunfudha jedoch den internationalen Hafen schlechthin dar - in einem solchen Ausmaß, daß W. Thesinger noch 1947 als übliche Lokalbezeichnung „al-Bandar“ (der Hafen) für al-Qunfudha angibt. ${ }^{81}$ Und Ende der 30er Jahre vermerkt Philby nicht ohne Erstaunen, wieviele lokale Produkte über al-Qunfudha exportiert wurden - darunter auch solche, die in früheren Aufzählungen noch nicht erwähnt worden waren, wie Felle und Häute, Sesam, Feigen, Honig und Kaffee. ${ }^{82}$

\footnotetext{
${ }^{79}$ Die hier konsultierten Quellen erwähnen lokalen Kaffee im Warenangebot von al-Qunfudha erst für das 20. Jh.

${ }^{80}$ Einen bibliographischen Überblick zur rezenten Reiseliteratur über al-Qunfudha geben Grohmann und Bosworth s. v. in $\mathrm{EI}^{2}$.

81 Thesiger 1947: 197.

82 Philby 1952 (1976): 195, 691-693.
} 
Tab. 2: Hauptphasen der Entwicklung von Küstenstil und Siedlungsanlage in al-Qunfudha ab Mitte 18. Jh.

\begin{tabular}{|l|l|l|}
\hline Entwicklung & Elemente des Küstenstils & Siedlungsanlage \\
\hline $\begin{array}{l}\text { Phase 1: } \\
\text { 2. Hälfte des 18. Jh. }\end{array}$ & $\begin{array}{l}\text { Erste Bauten aus festem Material: } \\
\text { Kastell, Wehrturm }\end{array}$ & $\begin{array}{l}\text { Zweiteilung zwischen geschütztem Hafen } \\
\text { (Westen: Anlegestelle, Markt, Militär- und } \\
\text { Verwaltungsbauten) und Wohnquartieren } \\
\text { (Osten: landeinwärts, nur Hütten) }\end{array}$ \\
\hline $\begin{array}{l}\text { Phase 2: } \\
\text { 1. Hälfte des 19. Jh. }\end{array}$ & $\begin{array}{l}\text { Meitere feste Bauten: befestigte } \\
\text { ne; alte Moschee und ebenerdige } \\
\text { Wohnhäuser }\end{array}$ & $\begin{array}{l}\text { Zweiteilung mit stark befestigtem Hafen; } \\
\text { ausgebaute Wohnquartiere mit ersten fe- } \\
\text { sten Bauten }\end{array}$ \\
$\begin{array}{l}\text { Phase 3: } \\
\text { 2. Hälfte des 19. Jh. }\end{array}$ & $\begin{array}{l}\text { erste mehrgeschoßige Wohnhäu- } \\
\text { ser; die vornehmsten mit mushra- } \\
\text { bīya }\end{array}$ & $\begin{array}{l}\text { Verschmelzung von Wohn- und Hafenvier- } \\
\text { tel durch Neubauten an der Küstenlinie in } \\
\text { Nord-Süd-Ausrichtung; Erhöhung der Zahl } \\
\text { von Hütten, ebenerdigen und mehrgescho- } \\
\text { Bigen Wohnhäusern, Moscheen }\end{array}$ \\
\hline
\end{tabular}

Der architektonische Küstenstil des Roten Meeres hat mit der bescheidenen Lokalausformung von al-Qunfudha also mehrere Entwicklungsschübe durchlaufen, und er weist an diesem Ort ein relativ junges Alter auf. Ob dieser rezenten Baugeschichte am selben Ort eine frühere Phase (14.-17. Jh.) von internationalem oder lokalem Küstenstil vorausging oder ob eher eine ausschließliche 'ushash-Tradition vorherrschte, das ist ungewiß. Das bedeutet allerdings nicht, daß die Korallenstein-Bauweise per se an diesen Küsten ebenso rezent wäre. Vielmehr liegen von anderen Hafenorten dafür weitaus ältere Belege vor als bei al-Qunfudha. Schon 1508 notierte Lodovico di Varthema, daß sich in Jīzān hauptsächlich runde ,Korbhütten“ (also 'ushash) befanden, daneben aber auch „einige quadratische Häuser aus Stein " und ein altes Fort, das in Trümmern lag. ${ }^{83}$ Angesichts der Tatsache, daß die Korallensteinbauweise auch für Ostafrika ${ }^{84}$ spätestens seit dem 15. Jh. nachgewiesen ist, besteht kaum ein Zweifel daran, daß jene Steinhäuser im Jīzān des frühen 16. Jh. ebenfalls aus Korallenstein oder -geröll errichtet waren.

Der internationale Red Sea Küstenstil hat sich also bereits lange vor seiner letzten, mit der mushrabìya verbundenen Phase über mehrere Perioden und von verschiedenen Ein-

${ }^{83}$ Di Varthema 1888: 61.

${ }^{84}$ Die ostafrikanische Küste beherbergt mehrere hundert Moscheen, die zwischen dem 12. und dem 19. Jh. dort errichtet wurden. Ein entscheidender Stimulus für die Herausbildung dieser ostafrikanischen „Muslim Swahili civilization" war bekanntlich durch die Islamisierung und den Fernhandel von Arabien aus gegeben.

Neben anderen historischen Bauwerken in Mogadishu, Mombasa und auf Zanzibar gilt die Great Mosque in Kilwa (Tanzania) als bekanntestes Beispiel dieses Architekturstils. Sie datiert bereits aus dem 12. Jh., die meisten erhaltenen älteren Teile stammen allerdings aus dem 15. Jh. Ihr miḥrāb, die Bögen und Säulen sind aus bearbeitetem Korallenstein, die Mauern aus Korallenschotter und Lehmmörtel (Denyer 1978: 36, 37, 194).

Hier ist weniger bedeutsam, daß der arabische Einfluß auf die tanzanische Küste historisch vorwiegend aus 'Umān stammte (Scholz 1990: 16-21). Entscheidend ist die Tatsache, daß die Korallensteinarchitektur von den mobilen, internationalen Kunsthandwerkern bereits in dieser Epoche des Spätmittelalters und der Frühzeit an der Küste des Roten Meeres beherrscht wurde - wo es wenig anderes festes Baumaterial gab. 
flußorten aus entwickelt (Tab. 3). Das Beispiel von al-Qunfudha legt aber nahe, daß seine Durchsetzung auch anderswo über dieselben Gebäudeformen verlief, und mithilfe derselben sozialen Institutionen und ihrer Akteure, welche diese Gebäude repräsentierten nämlich Garnison, Markt und Moschee.

Tab. 3: Relative Chronologie des Küstenstils nach Gebäudefunktionen

\begin{tabular}{|l|l|}
\hline Phase 1 & 1. Militäreinrichtungen \\
\hline Phase 2 & $\begin{array}{l}\text { 2. Marktanlage } \\
\text { Moschee } \\
\text { ebenerdige Wohnhäuser }\end{array}$ \\
\hline Phase 3 & $\begin{array}{l}\text { 3. mehrgeschoßige Wohnhäuser mit mushrabīya } \\
\text { 4. ebenerdige Wohnhäuser mit rawshān }\end{array}$ \\
\hline
\end{tabular}

Die für al-Qunfudha identifizierten drei rezenten architektonischen Entwicklungsphasen repräsentieren eine Dynamik, die insgesamt wohl nur für die betreffenden 140 Jahre charakteristisch ist. Davor, in früheren Perioden und an anderen Orten der Küste, war die Entwicklung der Korallensteinbauweise vermutlich langsamer verlaufen. Aber diese drei rezenten Phasen, welche die vor- oder zwischenstaatliche Phase eines tribalen „port of trade “ im frühen 18. Jh. ablösten, repräsentieren die Herausbildung eines völlig neuen Stadtkerns. Die genannte, rezente Dynamik der Stadtarchitektur drückt die historischen Veränderungen aus, denen dieser „port of trade “ durch externe Einflüsse in ungleich höherem Maße ausgesetzt war, als das bäuerliche und tribale Hinterland. Der Wandel der Stadtarchitektur von al-Qunfudha zeigt daher wie ein Gradmesser die Transformation der Beziehungen an, welche sich zwischen der Lokalkultur der Tihāma und des südlichen Hijāz und ihrer weiteren sozialen Umgebung entfaltet haben.

Die klare räumliche Begrenzung dieses architektonischen Stils auf das unmittelbare Küstengebiet und auf einige wenige Zentren im flachen Hinterland belegt aber zugleich, wie beschränkt und peripher diese Außenbeziehungen lange Zeit für die Bauerndörfer und Stammesgesellschaften der Küstenebene und des Berglandes geblieben sind. Nur ganz wenige Einzelelemente, wie die Konstruktion von Holzbalkonen, sind vom Küstenstil ausgehend in manche Teile der Hijāz-Architektur übernommen worden. Das wechselhafte und diskontinuierliche Schicksal der Küstenarchitektur kontrastiert daher recht deutlich zur etwas stärkeren historischen Kontinuität, welche die Bauweise der Tihāma, des Najd-Randes und der südwestlichen Berggebiete auszeichnet.

\subsection{HÜTTEN DER SÜDWESTLICHEN EBENEN UND OASEN: DIE 'USHASH-ARCHITEKTUR}

\subsubsection{GRUNDEigenschaften}

Der hier zu erörternde Typus von Architektur tritt in einer Vielzahl von Variationen auf, und das hat ihm in der Literatur auch eine Vielzahl von teilweise ungenauen Bezeichnungen eingetragen. Diese einfachen Hütten sind als Tihāma straw huts bezeichnet worden, obwohl sie nicht nur in der Tihāma auftreten, sondern auch an der Küste und am Ostabhang der Sarāt, also auch im Übergangsgebiet zum Najd. Sie sind auch nicht vorwie- 
gend aus Stroh oder Schilf konstruiert, wie die andere Bezeichnung „reed huts “ suggeriert. Und auch der Terminus „beehive hut" charakterisiert nur eine bestimmte Variation der Bauweise, aber nicht die Grundeigenschaften dieses Typs. ${ }^{85}$

Gemeinsam sind diesen Variationsformen einige wenige, grundlegende Eigenschaften, die sie von den anderen Architekturtypen des südwestlichen (Saudi-) Arabien unterscheiden. Erstens sind diese Konstruktionen aus primär lokal verfügbaren vegetabilen Material errichtet - also aus festen Baumstämmen und Zweigen, und weiters aus flexiblen Ästen, Gräsern, Stroh, Schilf oder Blättern, die mit Schnüren verbunden sind. Zweitens sind diese Bauten stets ebenerdig, haben aber kein Flachdach, sondern ein aufstrebendes Dach (Kuppel-, Kegel-, Zelt- oder Satteldach), ${ }^{86}$ wobei im häufigeren Fall die Höhe der Hütte etwas größer als ihr Durchmesser ist. Und drittens haben diese Formen üblicherweise keine Fensteröffnungen und nur eine Türe (Abb. 40, 42).

Diese drei Material- und Konstruktionseigenschaften sind hier mit „Hütte“ gemeint, der lokale Terminus dafür ist 'ushsha, pl. 'ushash oder ' $\bar{a}$ 'ishash. Gelegentlich wird 'ushsha auch als abschätziger Begriff von den Bewohnern der Stein-, Lehm- oder Ziegelbauten gebraucht, während die Bewohner der 'ushash darauf insistieren, daß ihr Haus ebenso ein "bayt" sei wie jene anderen Wohnquartiere. Hinter diesen terminologischen Dissonanzen verbergen sich jedoch eher Fragen, die den sozialen Status der Bewohner dieser Hütten betreffen. Ein Großteil von ihnen, wenn auch keineswegs alle, gehören solchen sozialen Schichten an, die eine abhängige, untergeordnete oder verachtete Position im traditionellen Sozialgefüge des Südwestens einnahmen. Die negative Bewertung von außen gilt also eher dem sozialen Status eines Großteils der Bewohner dieser Hütten, und weniger direkt ihrer Architektur. Auch von den Bewohnern selbst ist mir kein anderer Terminus als „bayt" oder „'ushsha“" genannt worden. ${ }^{87}$

Diese ebenerdigen Hütten aus vegetabilem Material werden im Prinzip auf sehr ähnliche Weise errichtet; nämlich in vier aufeinanderfolgenden Arbeitsphasen. Die erste Bauphase besteht in der Anlage von Fundament und Boden. Die überwiegende Mehrzahl der Hütten, auch jene in Städten und größeren Marktorten, wird als Einzelbauten und nicht als Anbau zu anderen Hütten errichtet. Diese isolierte Anlage von Fundament und Grundriß ermöglicht die Luftzufuhr von allen Seiten her und stellt eine zweckmäßige, klimatisch bedingte und kulturhistorisch wohl ältere Parallele zur Hausanlage des Küstenstils dar.

85 Abdulfattah 1981: 93; Mauger 1993: 55; Nankivell 1985a: 57; Schmidt 1940: 966 und Philby 1952: passim, z. B. S. 685 in der Reihenfolge der erwähnten Bezeichnungen. Cf. weiters für die Tihāma bei alQawz Prochazka 1978: 118 „Squared hut with domed roof: 'Uššah pl. 'Ušš;" hingegen Prockazka 1978: 115 „Enclosure for animals outside the house: 'Iššah pl. 'Išaš (...)“. Wehr 1977: 552 nennt 'ushsha, pl. 'ushash, 'ishash als Hütte, Laube.

${ }^{86}$ Feest und Janata 1989: 114.

87 Auch Abdulfattah und Philby machen dieselbe Angabe; nur Thesiger führt den Terminus „khadur“ an (1947: 190), und nach ihm auch King 1976: 28. Der Begriff „khadur“ könnte sich bei Thesiger aber auch auf die „Bayt Ḥassāf“ beziehen, cf. auch Anm. 117 und Text. Prochazka (1978: 118) führt zum Tihāma-Marktort von al-Qawz als zwei gesonderte Kategorien (neben „ushsha“) noch „jundub“ für Längshütte und „sabl“ für flache vierkantige Hütte (eine etwas zweifelhafte Kategorie) an. Mit 'ushsha bezeichnet man in al-Qawz demnach, laut Prochazka, nur eine „squared hut with domed roof“. Mir wurde demgegenüber ' ushsha auch in al-Qawz als genereller Begriff für alle Varianten von Hütten genannt. 
Entsprechend dem kreisrunden, quadratischen oder rechteckigen Grundriß werden Sand und Erde ausgehoben. Der Durchmesser runder Grundrisse beträgt zwischen 3, 5 und $6 \mathrm{~m}$, die diagonalen Ausmaße langer, rechteckiger Hütten können bis zu $10 \mathrm{~m}$ betragen. Der Aushub selbst kann bis zu einem Meter tief sein, wenn der Bau einer stabilen, über viele Jahre hinweg nutzbaren 'ushsha vorgesehen ist, und Lage oder Bodenqualität es erfordern. ${ }^{88}$ Derartige tiefere Fundamente können mit flachen Steinen ausgelegt sein; für kurzfristigere Nutzung oder bei günstigeren Standorten genügt ein niedrigerer Aushub. Der Aushub wird mit einem Gemisch aus Lehm, Häcksel und Rindermist (ținn) gefüllt, das man danach zum Boden ('arșa) stampft, glättet und an den Rändern hochzieht. Dieser hervorragende Rand des Hüttenbodens stellt einen gewissen Schutz für das Innere der 'ushsha vor Kleintieren, Sand und Regenwasser dar. ${ }^{89}$

Die zweite Bauphase umfaßt dann die Errichtung einer zylindrischen Wand (jidūn) oder von vier Wänden. Bei rechteckigem Grundriß beginnt man mit der Errichtung der Eckpfeiler, bei runden Hütten mit dem Mittelpfeiler. Entlang der Außenwand werden in das Fundament stabile Holzbündel oder Baumstämme (ḥarija, pl. ḥarāij) als Träger des Gesamtgerüstes in regelmäßigen Abständen voneinander eingelassen. Zwei dieser Holzbündel oder Stämme stehen in größerer Nähe zur Türöffnung, deren Stock gleichfalls in das Fundament versenkt wird (Taf. XXXIV). Zwischen diesen stabileren, tragenden Holzbündeln oder -stämmen der Außenwand werden dicht nebeneinander gleich hohe (ca. 2 m), längliche Bündel (jarīda, pl. jarā’id) aus Reisig, Hölzern oder Schilf in den Rand des Fundaments versenkt. Wenn Wand und Dach direkt ineinander übergehen sollen, benützt man für die Errichtung der Wände keine Stämme. Dann befinden sich unter diesen Holzbündeln zumindest einige, die wesentlich länger sind. Alle diese Bündel sind mit Palmblatt- oder Hanfseilen (habl, hubūl) verschnürt, und sie werden damit auch untereinander und mit den Stämmen fixiert. Als Baumaterial dienen Palmstämme, Stämme und Zweige des miswāk-Baumes, und die Hölzer und Zweige der fundhub-, markh- und sallam-Sträucher. ${ }^{90}$ Die Verschnürung von Bündeln und Stämmen ergibt eine einheitliche Wandfläche, an welche außen noch eine Schicht aus gebündeltem oder geflochtenem Heu oder Stroh appliziert werden kann.

In der dritten Bauphase erfolgt die Dachkonstruktion. Bei rundem oder quadratischem Grundriß ist dafür ein einzelner Stütz- und Schnürpfeiler (da'ma’, siyāl) im Zentrum errichtet. Zur Abstützung des Dachfirstes von rechteckigen Hütten stellt man hingegen zwei derartige Pfeiler mit Gabelung auf. Sie sind massiver als die Stämme der Außenwand, aber aus demselben Holz oder aus der Zizyphus-Art nabaq, ebenso wie der leichtere Firstbalken. Die Spitzen der hohen Bündel der Außenwand werden am First oder an der Spitze des Stützpfeilers festgebunden, und desgleichen alle anderen Lagen von Dachhölzern und Zweigbündeln, die man mit der Wand verschnürt. Die unter Spannung fixierte Biegung der an der Spitze des Mittelpfeilers angeschnürten, langen Wandbündel ergibt eine konvexe Form; wo man hingegen das Dach (sumr, sumūr) als eigenen Aufsatz (ohne Wandbündel) baut, entsteht eine gerade Dachfläche. Das ist bei Wandverstärkung durch mehrere Baumstämme und bei Hirsestroh- und Palmblattdächern der Fall. Die Stämme der Außenwände, der Stützpfeiler und die daran fixierte innere Dachla-

\footnotetext{
88 cf. auch Nankivell 1985a: 57; Ehrlich 1985: 87.

89 cf. auch Philby 1952: 460 f., 638.

90 cf. auch Tamisier 1840: 385-387.
} 
ge erinnern im Rohbau an Käfige. ${ }^{91}$ Auf die inneren Dachlagen werden weitere Schichten von Bündeln (murkh, murūkh) aus Zweigen, Stroh, Palmblättern und Gräsern aufgeschnürt. Das gesamte Dach ist letztlich außen noch durch eine Verschnürung (mannīna) zusammengehalten, die in zwei oder mehreren Linien parallel zum Dachansatz verläuft, oder aber in vielen parallelen Linien Dachansatz und Dachspitze verbindet. ${ }^{92}$ In jedem Fall ist die Verschnürung an First oder Spitze verknotet.

Die abschließende Bauphase besteht in der Gestaltung der Innenwände. Zwischen die Stämme und Bündel werden Kräuter und Pflanzen gesteckt. Sie sollen die Geruchsqualität erhöhen und auch gegen die Insektenplage wirken. Die hölzernen Innenwände werden vom Boden bis hoch in das Dach hinauf mit țin (Lehm) oder einem Lehm-Dung-Gemisch (ribda) verputzt, auf den bei langfristig genutzten Hütten oft mit Kalk versetzte Tonerde aufgetragen wird. Auch die Außenseite kann in seltenen Fällen rund um die Türöffnung auf diese Weise verputzt werden. Licht und Luft fallen primär durch die niedrige Tür ein; in allen Fällen ist die Abzugsöffnung im Dach (quțra) wesentlich: Sie liegt bei quadratischen oder runden Hütten beim oder um den höchsten Dachpunkt, an der Spitze des Pfeilers; in rechteckigen Hütten liegen zwei davon in Giebelnähe.

Die Wandoberfläche im Inneren der Hütten ist meist schmucklos; weitere Bemalungen des Verputzes sind äußerst selten; waagrecht herausragende Haken dienen zum Aufhängen des Hausrats an den Wänden. ${ }^{93}$

Dieses Aufhängen von Matten, Körben oder Kalebassen im Inneren hat vor allem den funktionalen Zweck, den knappen Bodenraum freizuhalten und den Hausrat vor Sand und Insekten zu schützen. In den Fällen, in denen eine Familie eine eigene Hütte für ihre Frauen, oder - in einer rechteckigen Hütte - einen eigenen Frauenraum eingerichtet hat, sind die Gegenstände der Frauen dort gesondert aufgehängt. Rechteckige, längliche 'ushash können mit Binsenwänden in mehrere Räume unterteilt sein; die Mehrheit alter Hütten ist jedoch einräumig.

Das wesentliche Möbelstück dieser Hüttenräume sind die hochgestellten Bett-Couchen ( $\mathrm{q}^{c} \bar{a} \mathrm{da}$ ), deren Flächen aus Hanfseilen verflochten und gespannt sind. Sie dienen als Ablage, Arbeitsfläche, aber vor allem als Sitzstelle. ${ }^{94}$ Als Betten (sarīr) werden manchmal eigene Möbel verwendet, die der qa ${ }^{c} \bar{a} d a$ gleichen, aber keine Rücken- und Armstütze haben. Pölster und Teppiche fehlen in den Hütten fast völlig; die qa āàda ist demgegenüber luftiger und durch ihre Höhe besser vor Sand und Ungeziefer geschützt. Tagsüber sind die Bett-Couchen im Inneren der Hütten längs der Wand aufgestellt; abends und nachts werden sie - außer in den kurzen Regenzeiten des Jahres - im Freien aufgestellt, wo man sich dann unterhält, ißt und schläft.

Die hier identifizierten drei Grundeigenschaften und vier Bauphasen sind allen Variationen von 'ushash im wesentlichen gemeinsam, sie sind deren größter gemeinsamer Nenner. Neben der Hüttenbauweise sind auch einzelne andere Elemente der 'ushash-Architektur im weiteren Sinn zuzurechnen; sie stehen aber nicht im Zentrum dieser mit Wohnarchitektur befaßten Untersuchung. Erwähnenswert sind einerseits einfache Arbeitseinrichtungen wie Sonnenschirme (bei den Feldern), Viehgatter und Gartenhecken bäuerli-

\footnotetext{
91 Rüppel 1838: 177-179.

92 cf. auch Nankivell 1985b: 60, 62; Philby 1952: 460f.; Mauger 1993: 102f.; Maréchaux 1998: 89.

93 Thesiger 1947: 192; Mauger 1993: $106 \mathrm{f}$.

${ }^{94}$ Ehrlich 1985: 100; Philby 1952: 638; Mauger 1993: 106 f.
} 
cher Haushalte, oder die gemeinsamen Sonnenschirme der kleinen Händler auf den Wochenmärkten der Tihāma (Abb. 43). Andererseits sind der ' ushshah-Architektur auch die einfachen Gebetsplätze der Tihāma zuzurechnen. Sie bestehen in der Regel nur aus einem mihhrab, der als überdachter, halbkreisförmiger Windschirm nach der Qibla orientiert ist (Abb. 44).

An den Material- und Konstruktionseigenschaften der Wohnarchitektur sind ihre wesentlichsten ökologischen und sozialen Dimensionen bereits deutlich geworden: Die 'ushash sind aus Materialien errichtet, die örtlich verfügbar sind und prinzipiell ohne spezialisierten und komplexen Arbeitseinsatz beschafft werden können. Meistens suchen, fällen und bearbeiten die Männer unter den zukünftigen Bewohnern selbst die größeren Stämme und Zweige; die Frauen sammeln Äste und Strauchwerk, und sie schnüren die Holz-, Stroh- und Grasbündel. An der Küste fehlt es allerdings oft an lokalen Holzvorkommen; hier wie in den größeren Markt- oder Stadtzentren des Landesinneren kann man aber lokales Holz von spezialisierten Händlern auf den Wochenmärkten zu günstigen Preisen kaufen. Beim Hausbau sind dann die Männer für die eigentliche Konstruktion zuständig, während die Frauen den țīn anrichten und anbringen. Die Materialien beschaffen die Bewohner also zumeist selbst, und ihre 'ushash errichten sie immer selbst.

Diese vorwiegend auf unspezialisierter Lokalarbeit beruhende Bauweise ist daher nach den Begriffen der Geldökonomie „billig“; Bewohner der Küste, der Oasen und der flachen Tihāma verfügten traditionell über entsprechend geringe Geldvermögen zur Beschaffung anderer Materialien als jener, die eben als einzige lokal für den Hausbau vorhanden sind.

Die Konstruktion der 'ushash ist vor allem auf die Schaffung schattiger, kühler Räume ausgerichtet - die Hütten „atmen“ Rauch und heiße Luft über die Abzugslöcher aus, und sie lassen kühlere Luft in der Nacht durch die Türöffnung herein, die man tagsüber dann mit Matten verhängt. ${ }^{95}$ Dementsprechend sind die Hütten primär als Aufbewahrungsorte, und nur nachmittags als Aufenthaltsräume im eigentlichen Sinn genutzt. Die Abende und Nächte verbringt man auf der qa ${ }^{c} \bar{a} d a$ meist im Freien, und den größten Teil der Tage auf den Feldern, Weiden, Märkten oder in Läden. Die poröse Wand- und Dachkonstruktion verstärkt den Effekt der kontinuierlichen Luftzirkulation, und ebenso die auffällige vertikale Orientierung mit hohen Dachspitzen, die zugleich schon aus der Ferne markante Orientierungen im flachen Terrain abgeben. ${ }^{96}$

Der hochgezogene Rand des Fundaments, die Wandaufhängung des Hausrats und die mobilen, hohen Bett-Couchen sind weitere Abstimmungen auf eine Umwelt und ein Klima, die von Sand, Hitze und geringem Niederschlag geprägt sind. In den sporadischen Regenzeiten wird als provisorischer Schutz oft noch eine Zeltplane über das Dach gelegt (Abb. 55). All diese Eigenschaften veranlassen die Bewohner der Tihāma zur auch mir gegenüber häufig geäußerten Meinung, daß das Wohnen in 'ushash generell kühler, gesünder und sauberer sei, als in vielen älteren Ziegel- oder Korallensteinbauten ${ }^{97}$

In sozialer Hinsicht fehlt den 'ushash (ebenso wie der Wohnarchitektur des Küstenstils) ein Aspekt, der für die Bauten des Hochlandes grundlegend ist: Die Hütten der Ebenen sind keine Wehrbauten; von gewissen, noch zu erörternden Ausnahmen und Mischty-

\footnotetext{
95 Talib 1984: 79; Philby 1952: 685-687.

96 Ehrlich 1985: 95.

97 cf. auch Philby 1952: 673.
} 
pen abgesehen, fehlt den Hüttenkonstruktionen also nahezu jegliche militärtechnische Einrichtung. Im Küstenstil drückt dies die Friedensordnung des dort unmittelbar gegebenen Staatseinflusses aus, und als Märkte sind die großen Häfen nach tribalen Gesichtspunkten ohnedies Orte des Friedens. Die „Wehrlosigkeit“ der ländlichen 'ushsha hingegen ist durch andere Ursachen bedingt. Dafür ist das Zusammenwirken mehrerer Faktoren verantwortlich. Das Material der Hütten ist als Schutz vor Feuerwaffen von vornherein nicht sehr geeignet; aber Fehden und andere Kampfhandlungen unterlagen historisch in dieser Region auch einer Reihe von sozialen und politischen Einschränkungen. Konkurrenz um lokale Ressourcen konnte nicht allzu ausgeprägt sein, da zumindest die HijāzTihāma wenig wirtschaftliches Potential bot und die Bevölkerungsdichte daher relativ niedrig war. Die leichte Zugänglichkeit der gesamten Küstenebene (und auch der Oasen im Osten) von außen förderte andererseits den Einfluß überlokaler, staatlicher Verwaltungen und von staatlicher Militärkontrolle, die ihre eigenständigen architektonischen Spuren hinterließ. Dies sind die erwähnten Befestigungsanlagen der Küstenstädte, und ebenso Garnisonseinrichtungen und einzelne Wohnbauten in den größeren Marktorten der Ebene, insbesondere entlang der Hauptrouten zum Berg- und Hochland. Eine wichtige Linie derartiger Befestigungen verband Ende des 19. Jh. al-Qunfudha mit Abhā und verlief über die beiden großen Tihāma-Märkte Khamīs al-Qawz und Maḥāyil durch das W. Tayya an die Shifā unterhalb von Abhā (Karte 8); eine zweite Route ging von bei der Küste al-Qaḥma ostwärts, um sich beim W. Tayya mit der ersten zu verbinden bzw. von ihr abzuzweigen. Eine dritte Route schließlich verband spätestens zu Beginn des 20. Jh. al-Qunfudha, über al-Majārida und die 'Aqaba Sinān, mit der Garnison von al-Namāṣ im Hochland. Die historische Militär- und Defensivarchitektur der Küstenebene lag entlang dieser Routen und manifestiert sich in separierten, spezialisierten Gebäuden - und diese sind aus festem Material konstruierte Staats- und Markteinrichtungen. Dieser, auf wenige Orte konzentrierte, architektonische Ausdruck von Regierungseinfluß und staatlicher Militärmacht wird örtlich von den erwähnten, einfachen Lokalformen des Küstenstils (den Formen 1B, 2A und 2B in Tab. 1) begleitet. All dem steht die flächendeckende, nicht auf Konflikt ausgerichtete, volkstümliche Architektur der 'ushash gegenüber.

Diese 'ushash-Architektur wird gleichzeitig von der sozialen Tatsache mitgeprägt, daß ein Großteil ihrer Bewohner tatsächlich waffenlos ist: Den Handwerkergruppen (Töpfer, Flechter) und kleinen Gemeinden von Parzellenbauern ist eine sozial untergeordnete und abhängige Stellung zugewiesen, die sie auch unter pre-modernen Verhältnissen nicht zum Tragen von Waffen berechtigte. Dasselbe gilt für die Pächter und Landarbeiter der südlichen Tihāma um Baysh, Abū 'Arīsh, Șabyā und Jīzān, ${ }^{98}$ und für die 'ushash-Bewohner am Ostrand des Najd, die oft ehemaligen Sklavenfamilien entstammen. Andere Siedlungen und Gebiete, wie etwa das W. Ahsibā nördlich von al-Qunfudha, sind hingegen fast ausschließlich von Ashrāf bewohnt - also von Nachfahren des Propheten, denen ihr privilegierter Status als Männer des Friedens ebenfalls Beschränkungen im Tragen von Waffen auferlegte..$^{99}$

Ein effektiveres staatliches Gewaltmonopol, und ein hoher sozialer Anteil von nichttribalen Statusgruppen, die normalerweise keine Waffen trugen - dies sind also die we-

98 Abdulfattah 1981: 88f.

${ }^{99} \mathrm{Zu}$ den Ashrāf des W. Ahsibā cf. Philby 1952: 698; Philby 1947: 188. 
sentlichen historischen Faktoren für die Abwesenheit von Defensiveinrichtungen in der 'ushash-Architektur.

\subsubsection{Regionale Verbreitungsgebiete}

Nachdem die großen Gemeinsamkeiten dieses Typs behandelt worden sind, können nun seine regionalen Variationsformen erörtert werden.

Im Vergleich zum Küstenstil und zur Wohnarchitektur aus Stein oder Lehm entlang der Sarāt repräsentieren die 'ushash im saudi-arabischen Südwesten den Typus mit der flächenmäßig weitaus größten Verbreitung. Die Hütten treten überall im breiten Band des flachen Tieflandes auf, das sich zwischen der Uferlinie des Roten Meeres im Westen und dem hügeligen und gebirgigen Vorland des Hijāz im Osten erstreckt; darüber hinaus finden sich 'ushash auch in einzelnen Oasen am Ostrand der Sarāt zum Najd hin.

Die Verbreitung von 'ushash-Architektur erstreckt sich überdies von Nordwesten nach Südosten weit über das Untersuchungsgebiet hinaus. Nach Nordwesten hin treten 'ushash in der Küstenebene vor dem nördlichen Hijāz auf, und nach Südwesten hin prägen sie gleichfalls die ländlichen Siedlungen der jemenitischen Tihāma. ${ }^{100}$

Diesem flächenmäßig sehr ausgedehnten Verbreitungsgebiet steht eine relativ niedrige Bevölkerungsdichte in diesen ariden und in manchen Teilen - nach vorindustriellen Kriterien - agroklimatisch benachteiligten Gebieten gegenüber: Trotz der räumlichen Bedeutung dieses Architekturtyps lebt also nur ein relativ geringer Anteil der Bevölkerung des Südwestens in den 'ushash.

Innerhalb ihres gesamten Verbreitungsgebietes sind die 'ushash jeweils auf die günstigsten Lebensräume konzentriert - also auf die kleinen Oasen im Osten, und im Westen auf die flood plains und Wādīs der Tihāma. Diese Wādīs und flood plains entwässern die Sarāt periodisch zum Roten Meer hin; Böden und Randpartien sind dementsprechend nutzbar für Viehzucht und landwirtschaftliche Zwecke. Darüber hinaus sind die flood valleys die geeignetsten Reise- und Handelsverbindungen zwischen der Sarāt und der Küste. Entlang dieser ungefähr von Ost nach West verlaufenden Wādīs und in deren Mündungsgebieten an der Küste ist daher der Großteil der 'ushash-Siedlungen konzentriert. Von Nord nach Süd handelt es sich um die ungefähr parallel verlaufenden Wādīs al-Dawqa, Qarha, Nawān, Aḥsiba, Lūma, Qanūna, Yabā, Ḥalī, 'Amq, 'Arik, Nahab, Rīm, 'Itwad, Bayḍ, Baysh, Șabyā und Jìzān. In den fruchtbaren Mündungsgebieten dieser Wādīs liegen an der Küste die meisten der bereits erwähnten Hafen- und Fischerorte, wie al-Lïth, alDawqa, al-Qunfudha, Ḥalī, al-Birk, Qaḥma, al-Shuqayq und Jīzān mit ihrem hohen Anteil an 'ushash-Architektur, der hier teilweise in Kombination mit dem spezifischen Küstenstil auftritt oder früher auftrat. Dieselbe Kombination ist auch für die Architektur der Farasān-Inselgruppe vor Jīzan belegt. ${ }^{101}$

Landeinwärts hinter der Küstenlinie ist die Bevölkerungsdichte im Mündungsgebiet der großen Wādīs am höchsten, und dementsprechend ausgeprägt ist hier auch das Auftreten der 'ushash-Architektur. Nach Osten hin nimmt die Aridität dann auch entlang der Wādīs zu, die Nutzflächen für Landwirtschaft und Viehzucht werden knapper und unergiebiger, und daher ist die ländliche Bevölkerungsdichte in diesem anschließenden, fla-

100 Abdulfattah 1981: 93; Nankivell 1985a: 57-59.

101 cf. Abdulfattah 1981: Karte 6 (ohne Erwähnung des Küstenstils!); King 1986: 60. 
chen Mittelteil der Tihāma im Norden deutlich, im Süden ein wenig niedriger. Im Vergleich zum breiten Mündungsgebiet der Wādīs mit höherer Bevölkerungsdichte verengen sich daher tendenziell im flachen Mittelteil ${ }^{102}$ und trichterförmig die Siedlungsgebiete mit 'ushash-Architektur (Karte 9).

Zugleich liegen in diesem flachen Mittelteil der Tihāma die großen Marktorte oder Städte des Flachlandes mit ihren einfachen Formen des Küstenstils. In der Hijāz-Tihāma waren diese Orte „Garnisonsmärkte" und dienten oft als Verwaltungssitz und Befestigungen der jeweiligen, historischen Staatsorgane - al-Qawz, Khamīs Ḥarb, Maḥāyil, Khamīs al-Baḥr oder al-Darb. In der 'Asīr-Tihāma hingegen handelt es sich um weit größere, stadtähnliche Siedlungen wie Abū 'Arīsh, Baysh oder Șabyā. In all diesen Orten ist der Küstenstil nochmals durch einfache Ziegelbauweise vertreten.

Östlich des flachen Mittelteils der Tihāma beginnt, teils hinter vorgelagerten niedrigen Bergrücken, die hügelige und gebirgige Tihāma, die vereinzelt von hohen isolierten Bergstöcken durchsetzt ist. Die dicht besiedelten Höhenzüge dieser Gebirgs-Tihāma sind durchgängiges Verbreitungsgebiet der tribalen Steinarchitektur. Die niedrigen Tallagen und Wādī-Sohlen der Gebirgs-Tihāma stellen hingegen das Gebiet der Übergangs- und Mischformen zwischen 'ushash- und Steinarchitektur dar. Entsprechend dieser naturräumlichen Gliederung läßt sich idealtypisch in Tab. 4 die Verbreitung der 'ushash-Architektur im West-Ost-Profil darstellen.

Tab. 4: Verbreitung von 'ushash-Architektur im West-Ost-Profil Südwest-Saudi Arabiens

\begin{tabular}{|c|c|c|c|c|}
\hline Küstenlinie & Mündungsgebiet & $\begin{array}{l}\text { Flacher } \\
\text { Mittelteil }\end{array}$ & $\begin{array}{l}\text { Tallagen der } \\
\text { Gebirgstihāma }\end{array}$ & $\begin{array}{l}\text { Oasen am } \\
\text { Ostabhang der } \\
\text { sarāt }\end{array}$ \\
\hline $\begin{array}{l}\text { In kleinen Kü- } \\
\text { stenorten do- } \\
\text { minant, in grö- } \\
\text { ßeren Häfen } \\
\text { gemeinsam } \\
\text { mit dem Kü- } \\
\text { stenstil }\end{array}$ & $\begin{array}{l}\text { hauptsächliches } \\
\text { Verbreitungsgebiet }\end{array}$ & $\begin{array}{l}\text { dominant, paral- } \\
\text { lel zum einfachen } \\
\text { Küstenstil der } \\
\text { größeren Markt- } \\
\text { und Verwal- } \\
\text { tungszentren } \\
\text { bzw. (im Süden) } \\
\text { der Städte }\end{array}$ & $\begin{array}{l}\text { Misch- und } \\
\text { Übergangsformen } \\
\text { zur Steinarchitek- } \\
\text { tur der Sarāt }\end{array}$ & $\begin{array}{l}\text { Punktuelles } \\
\text { Auftreten, ge- } \\
\text { meinsam mit } \\
\text { der dominanten } \\
\text { Lehmarchitek- } \\
\text { tur }\end{array}$ \\
\hline
\end{tabular}

Diese Gliederung der Verbreitung von 'ushash-Architektur zeigt, daß sie einerseits in bestimmten Gebieten als die einzige Bauform auftreten kann - insofern ist sie die typische Bauweise der Mündungsgebiete und flood plains der Tihāma. Andererseits ist die 'ushash-Architektur die einzige Bauform des Südwestens, die auch gemeinsam mit allen anderen Grundtypen der traditionellen Architektur dieser Gesamtregion auftritt: Mit dem Küstenstil der Hafenstädte am Roten Meer, mit der tribalen Steinarchitektur der Gebirgs-Tihāma, und mit der Lehmarchitektur der östlichen Oasen. Die 'ushash-Architektur ist ein eigenständiger Typus der Region, und zugleich ist sie die marginale Begleiterscheinung zu allen anderen Architekturtypen des Südwestens.

Auf diese grundsätzliche Gliederung im Ost-West-Profil wirkt eine bereits angesprochene, naturräumliche Modifikation entlang der Nord(-West)-, Süd(-Ost)-Achse ein, wel-

102 ibid. Karte 4. 
che für die Siedlungs- und die Variationsformen der 'ushash bedeutsam ist. Die Tihāma des südlichen Ḥijāz ist im Vergleich zur Tihāma des 'Asīr (Provinz Jīzān) landwirtschaftlich wesentlich ärmer und insgesamt weitaus dünner besiedelt. Dies ist primär durch die unterschiedlichen Formen der natürlichen Wasserversorgung bedingt. Der Steilabhang der Sarāt ist im südlichen Hijāz kaum unterbrochen, und ihm sind nur wenige isolierte Bergstöcke vorgelagert. Die Regenfluten gehen daher reißender ab, werden kaum gebremst und sind schwerer zu kontrollieren. Überdies geht die Hauptmasse der Niederschläge nur zu einer Jahresperiode ab, nämlich als Winterregen. ${ }^{103}$

Reißende Flutmassen und seltenere Jahresniederschlagszeiten bedingen, daß in der Tihāma des südlichen Hijāz nur kleinere und verletzlichere Anlagen zur landwirtschaftlichen Flutnutzung unter vormodernen Verhältnissen möglich waren, die dem örtlichen Bauern auch gehörten. Die Übergangsgebiete zwischen den parallelen Wādī-Läufen hingegen sind bis heute ausgedehnte Steppen- und Wüstenzonen mit dem lokalen Namen alKhabt. Dies trifft etwa für die Gebiete zwischen W. Aḥsiba, Lūma und Qanūna zu, oder für die flachen Mittelteile der Tihāma südlich des W. Ḥalī. In diesen Mittelteilen der Tihāma des südlichen Hijāaz dominieren daher Kleinstweiler (3 bis 6 'ushash) und Einzelhäuser von Ashrāf, Handwerkern und Bauern entlang der Wādīs, und weiters die 'ushash von halbnomadischen Gruppen in den Steppengebieten zwischen den Wādīs.

Die Tihāma des 'Asīr weist demgegenüber ein höheres landwirtschaftliches Potential auf, dessen sich Staatsorgane und auch Großgrundbesitzer in der Geschichte schon frühzeitig bemächtigt zu haben scheinen: Direkte, lokale Staatskontrolle ist für ,al-Mikhlāf alSulaymāniyya“ jedenfalls schon mindestens seit dem 11. Jh. belegt. ${ }^{104}$ Die stärkere Gliederung und Unterbrechung der Sarāt, und das Auftreten zahlreicher vorgelagerter TihāmaBergmassive zügeln und bremsen den Flutabgang hier nachhaltiger. Die schwächeren Niederschläge werden hier um die stärkeren Ausläufer der Monsunregen im Frühjahr und Sommer ergänzt, wodurch Fluten und Niederschläge auch gleichmäßiger im Jahr verteilt sind.

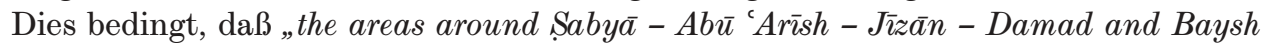
constitute almost a continously extended, settled area, without, or with only very few, spaces for nomads among them ". ${ }^{105}$ Die weitaus höhere Bevölkerungsdichte und kontinuierliches Staatsinteresse an dieser Region haben in diesem Abschnitt der Tihāma somit auch im Binnenland zur Entstehung größerer stadtähnlicher Zentren beigetragen, die in der Geschichte wiederholt zum Ausgangspunkt regionalstaatlicher Ansprüche wurden. ${ }^{106}$ Die Existenz derartiger Zentren wie Abū 'Ar̄̄sh oder Șabyā im Mittelteil der 'Asīr-Tihāma stellt eine Parallele zu ähnlich gelegenen Städten der jemenitischen Tihāma (Bayt al-Faqīh, Bājil, Zabīd) dar, und unterscheidet beide von den „Garnisonsmärkten“ der Tihāma des Hijāz und auch des nördlichen 'Asīr.

Unterschiedliche landwirtschaftliche und siedlungsgeschichtliche Akzente gliedern die Tihāma des Südwestens somit in einen nördlichen und einen südlichen Abschnitt, die hier vereinfacht als „Hijāza-Tihāma“ und „Asīr-Tihāma“ bezeichnet werden. Das Übergangsgebiet zwischen beiden Abschnitten der Küstenebenen verläuft etwa zwischen dem

103 Abdulfattah 1981: 33-46 und Karte 4.

104 Rentz 1965: 516-518; einen Überblick zur frühneuzeitlichen Geschichte der Region gibt Tuchscherer 1985/I: 45-63; cf. auch Abdulfattah 1981: 57-67, 88 f.

105 Abdulfattah 1981: 88.

106 Tuchscherer 1985: 56-62; Baldry 1975: 76-107. 
W. Tayya und al-Birk; er überschneidet sich daher größtenteils mit dem öden, vulkanischen Basalt-Gebiet der Harrah südöstlich von Maḥāyil. ${ }^{107}$ Für die 'ushash-Architektur ergeben sich aus dieser Differenzierung vor allem Unterschiede in den Siedlungslagen der Mündungsgebiete und des flachen Mittelteils der Tihāma (Tab. 5).

Tab. 5: Siedlungsunterschiede der 'ushash-Architektur im Nord- und Südteil der Tihāma Südwest-Saudi Arabiens

\begin{tabular}{|l|l|}
\hline Gliederung & Mündungsgebiete und flache Mittelteile der Tihāma \\
\hline Nordteil (Tihāma des südlichen Ḥijāz) & $\begin{array}{l}\text { Größere Dorfsiedlungen im Mündungsgebiet; Garnisons- } \\
\text { märkte im Mittelteil; ausgeprägte Formen von Halbnomadi- } \\
\text { mus }\end{array}$ \\
\hline Südteil (Tihāma des `As̄̄r, Jīzān) & $\begin{array}{l}\text { Kompakte Dorfsiedlungen im zusammenhängenden Sied- } \\
\text { lungsgebiet; wenige Formen von Halbnomadismus; städtische } \\
\text { Zentren im Mittelteil }\end{array}$ \\
\hline
\end{tabular}

Aus der dargelegten Gliederung nach dem West-Ost-Profil und gemäß dem Nord- und Südabschnitt der Tihāma ergeben sich also unterschiedliche soziale und kulturelle Rahmenbedingungen der 'ushash-Architektur, die für die Ausprägungen ihrer Variationsformen mitverantwortlich sind. Es wäre aber verfehlt, diese Variationsformen einseitig als bloß ökologisch determiniert zu begreifen. Die unterschiedlichen agroklimatischen und demographischen Voraussetzungen sind in langfristigen historischen Prozessen durch soziale, politische und religiöse Faktoren strukturiert worden, denen für die Ausprägung der Variationen in der 'ushash-Architektur daher ihr eigenständiges Gewicht zukommt.

Diese Variationsformen sind zunächst nach den drei großen Verbreitungszonen ('AsīrTihāma, Hijāz-Tihāma, Najd-Rand östlich der Sarāt) zu erfassen. In allen drei Zonen zumindest vertreten, dies sei vorausgeschickt, ist eine Grundform: Mit der Darstellung der drei Grundeigenschaften und vier Konstruktionsphasen der 'ushash ist nämlich nicht nur der gemeinsame Nenner aller Varianten benannt worden. Diese Eigenschaften charakterisieren zugleich die häufigste, „prototypische“ Variation, nämlich die 'ushsha mit kreisrundem Grundriß und abgesetztem, geradlinigem Kegeldach.

Diese „runde Hütte“ ist die dominante Form im Mündungsgebiet des nördlichen und südlichen Tihāma-Abschnittes. Sie ist auch die dominante Form in den mittleren TihāmaTeilen im Norden, und sie stellt für die größere Hälfte der 'ushash-Wohnhäuser in den südlichen flood-plains die Grundform dar. Am Najd-Rand ist sie hingegen nur selten anzutreffen. ${ }^{108}$

\subsubsection{1. 'ushash der 'Asīr-Tihāma}

Die Bewohner der 'ushash im Süden der Tihāma sind ebenso Handwerker, Familien von Ashrāf, wie vor allem von nicht-tribalen Pächtern und Parzellenbauern (fallāḥīn). In den südlichen flood plains bilden neben den runden Hütten die 'ushash mit rechteckigem (selten mit quadratischem) Grundriß die andere Hauptform der Wohnhütten; diese Formen sind hier besonders häufig. ${ }^{109}$

107 Thesiger 1947: 193f.; Abdulfattah 1981: Karte 4.

108 Philby 1952: passim, 572, und 641, fig. 59 für composite (prototypische) und beehive forms.

109 Tamisier 1840, I: 385-387; Weisl 1927: 257. 
Im Siedlungszusammenhang, den die Mündungsgebiete und Mittelteile der Tihāma im Süden bilden, treten zusätzliche, charakteristische Attribute der ' ushash-Architektur hinzu. Dies sind Umzäunungen der Hütten und Hüttenanlagen, und die etwas großzügigere Ausgestaltung mancher Innenräume. Diese beiden charakteristischen Attribute der südlichen Tihāma-Abschnitte treten sowohl bei 'ushash mit rechteckigem wie mit rundem Grundriß auf.

In der 'Asīr-Tihāma gruppieren die Umzäunungen meist mehrere 'ushash zusammen in einer Hofanlage ('Arīsh, 'Arä'ish). Diese Form wird nach Norden hin (etwa bis al-Darb) und an der Küste etwas häufiger und nimmt nach Südosten, zum 'Asīr-Hochland hin, etwas ab.

Die umzäunte Hofanlage von mehreren 'ushash ist also typisch für die südliche saudische Tihāma. ${ }^{110}$ Die Umzäunungen sind aus Stroh-, Zweig- oder Reisigbündeln verfertigt. Sie sind meistens mannshoch und haben ein verschließbares Tor, das in den weiten Hof führt. In seinem Inneren befinden sich normalerweise mehr als eine 'ushsha; die Hütten stehen in der Nähe des Zaunes (zarība) oder sind in diesen eingebaut, sodaß ihre Türöffnung ins Hofinnere gerichtet ist (Taf. XXXV). Bei den einzelnen Hütten sind in der Hofanlage oft kleine Gärten eingerichtet; in einem Hofwinkel liegt häufig auch ein Gehege für Kleinvieh. Innerhalb einer derartigen Hofanlage können sich bis zu 6 oder 7 'ushash befinden, deren männliche Bewohner meist demselben Familienverband angehören.

Schon die Diskussion über die Grundeigenschaften der 'ushsha hat gezeigt, daß ihre Bewohner den Großteil von Nacht und Tag eigentlich außerhalb der Hütten verbringen. Die Anlage der umzäunten Höfe gestaltet also einen geschützten Raum für einen Großteil dieses unumgänglichen Alltags im Freien. Die Zaun- und Palisadenanlagen haben daher sowohl eine gewisse militärische, wie vor allem eine sozio-religiöse Bedeutung.

Zum einen stellen die Zäune eine bescheidene militärische Defensiveinrichtung angesichts von Diebstahl, Überfällen, Fehden und Kriegshandlungen dar: Sie bieten einen etwas besseren Schutz für die an sich unbewehrten 'ushash, für das dort verwahrte Eigentum und Vieh, wie auch für die Bewohner. Die wechselvolle politisch-militärische Staatsgeschichte des südlichen Tihāma-Abschnittes, die höhere Bevölkerungsdichte und die deutlich akzentuierteren Reichtumsunterschiede zwischen den Einwohnern sind die Hauptfaktoren, welche diese eigentumsrechtliche und militärische Schutzeinrichtung förderten.

Darüber hinaus erfüllt die Umzäunung aber einen zweiten, mindestens ebenso wichtigen Zweck. Die 'ushash hinter den Umzäunungen sind im Prinzip nicht einräumig angelegt, sondern zweiräumig. Es kann sich dabei entweder um eine Hütte mit rechteckigem Grundriß als architektonische Residenzeinheit handeln, in der zwei Räume durch eine leichte Innenwand unterteilt sind. Oder aber zwei einräumige Hütten mit rundem oder quadratischem Grundriß bilden zusammen eine derartige minimale Residenzeinheit für eine Familie innerhalb der Gesamtanlage, indem diese beiden Hütten nahe beieinander errichtet sind. In beiden Fällen sind die Innenräume dieser Hütten nach Geschlechtern getrennt. Diese Geschlechtertrennung der Innenräume geht in der südlichen Tihāma Saudi Arabiens Hand in Hand mit der Umzäunung ganzer Gruppen dieser Hütten zu Hofanlagen: Die Abschirmung mittels der Umzäunung nach außen hin ist also stets kombi-

110 Thesiger 1947: 192. 
niert mit der geschlechtsspezifischen Raumaufteilung im Inneren der Hütten. Die Umzäunung ist daher architektonischer Bestandteil einer allgemeinen Geschlechterordnung des Raumes, welche gemeinsam mit der spezifischen Geschlechtersegregation der 'ushash-Räume auftritt. In dieser Hinsicht schafft die Umzäunung ebenfalls einen „geschützten Raum", aber im Sinne der hierarchischen Trennung der Geschlechter und ferner entsprechend einer offiziellen Moral, die Männern einen privilegierten Zugang zur sogenannten „Öffentlichkeit“ gewährt, während sie Frauen die Domäne der sogenannten „häuslichen Privatheit" zuweist.

Die Umzäunung schirmt einen Innenhof vor den Blicken Fremder und Außenstehender ab, in dem sich ein großer Teil des weiblichen Alltags unter freiem Himmel abspielt. Die Frauen und Mädchen der verschiedenen Haushalte, die in einer solchen Hofanlage zusammengeschlossen sind, können sich hier frei bewegen, der Hausarbeit nachgehen, und zu Besuch kommen. Nur wenn fremde Männer den Hof betreten, die sich dann rasch in die Männerräume der 'ushash zu begeben haben, ziehen sich auch die Frauen und Mädchen etwas vom Hofgeschehen zurück.

Die praktische Nutzung dieser architektonischen Raumgliederung zeigt also, daß ihre Definition in männliche „öffentlichkeit" und weibliche „Privatheit" ein ideologisches Konstrukt ist, auch wenn es sich hierbei nicht bloß um ein gängiges wissenschaftliches Stereotyp, sondern vor allem um indigene Kategorien handelt (al-'āmm, al-khāṣṣ). Die erwachsenen Männer haben ebensosehr eine Sphäre des Rückzugs, nämlich die der Männerräume der 'ushash, wie die Frauen Zugang zu Sphären der Mobilität und der Außenbeziehungen haben - nämlich zu den Frauen ihres eigenen Hofes, und zu jenen von anderen Höfen, die sie besuchen.

Tatsächlich ist hier nicht der Gegensatz zwischen „öffentlich“ und „privat“ wesentlich, sondern die Tatsache, daß die sozialen Räume der Geschlechter weitgehend "getrennt" sind. Im Siedlungsbereich halten sich die Frauen und Mädchen primär in ihren eigenen und anderen Innenhöfen auf, die Männer hingegen vor allem auf der Straße (Läden, Kaffeehäuser) und in ihren eigenen 'ushash-Räumen. Die landwirtschaftlichen Arbeiten erfordern darüber hinaus die Anwesenheit beider Geschlechter außerhalb der Siedlungen.

Die materielle und soziale Getrenntheit der geschlechtsspezifischen Räume in der Siedlung ist somit entscheidend; erst diese Perspektive erlaubt die Feststellung, daß der männliche soziale Raum wesentlich ausgedehnter ist als jener der Frauen. Umzäunungen und geschlechtsspezifische Anordnung der 'ushash-Räume akzentuieren somit die rituelle Meidung und Segregation der Geschlechter. Dies erfolgt in einer hierarchischen Form, die den Männern außerhalb der Zäune mehr Mobilität zugesteht, als den Frauen ihrerseits in den vielen Innenhöfen zukommt. Das Prinzip der geschlechtsspezifischen Trennung und hierarchischen Anordnung der sozialen Räume in Siedlungsmuster und Architektur ist selbstverständlich nicht nur für den Südabschnitt der saudischen Tihāma typisch, sondern für viele Bereiche des Islamischen Orients. Im Vergleich zur städtischen Lebensform bietet die Umzäunung der ' ushash aber für die davon betroffenen Frauen eine Reihe von Erleichterungen. Diese Frauen können sich tagsüber und nachts im Freien aufhalten, ohne fortwährend auf fremde Blicke achten zu müssen; sie haben weiters eine Vielzahl von unaufwendigen sozialen Interaktionsmöglichkeiten mit anderen Frauen. Die nahezu unbeschränkte weibliche Mobilität innerhalb und zwischen den Innenhöfen und das dichte, alltägliche Interaktionsnetz mit anderen Frauen verweisen damit auf eine Zwischenstellung, die dieser Form von Geschlechtersegregation innerhalb der Tihāma zu- 
kommt: Sie ist wesentlich weniger restriktiv als in den städtischen Zentren an der Küste und im Binnenland, aber deutlich ausgeprägter als in den übrigen ländlichen Regionen der Tihāma (Tab. 6).

Tab. 6: Abschirmung weiblicher Lebenswelt durch die Tihāma-Architektur

\begin{tabular}{|l|l|l|}
\hline Stadthäuser des Küstenstils & $\begin{array}{l}\text { Getrennte 'ushash-Räume in den } \\
\text { Hofanlagen der 'Asīr-Tihāma }\end{array}$ & $\begin{array}{l}\text { 'ushash ohne Umzäunung (üb- } \\
\text { rige, flache Tihāma) }\end{array}$ \\
\hline minimale räumliche Mobilität & eingeschränkte räumliche Mobilität & maximale räumliche Mobilität \\
\hline
\end{tabular}

Die strukturelle Mittelposition zwischen der restriktiven Ausprägung der Hafen- und Binnenstadtarchitektur einerseits und der Dorfarchitektur in der Tihāma andererseits erlaubt, diese Hofanlagen mit geschlechtsspezifischen 'ushash-Räumen als Einfluß der Stadtkultur auf das ländliche Umland zu interpretieren. Sie treten in der saudischen Tihāma nahezu ausschließlich im südlichen Abschnitt auf, also im dicht besiedelten Umfeld der dortigen, typischen Städte des Binnenlandes mit ihren kontinuierlichen politischen und theologischen Traditionen. Und es ist wohl kein Zufall, daß der lokale Terminus für derartige umzäunte Hofanlagen auch einer der historisch bedeutsamsten stadtähnlichen Siedlungen der Region seinen Namen gegeben hat: Abū 'Arīsh ist benannt nach diesem Terminus, 'arīsh. pl. 'arā’ish. ${ }^{111}$

Der hier angesprochene Zusammenhang zwischen 'arā'ish und städtischem Kultureinfluß wird deutlich unterstrichen durch die Tatsache, daß er seine konsequente räumliche Fortsetzung jenseits der heutigen Staatsgrenze in der jemenitischen Tihāma findet. Die dort gegebene, ausgeprägte Existenz von städtischen Zentren an der Küste wie im Binnenteil der Tihāma, auf die bereits hingewiesen wurde, korreliert ebenfalls durchgängig mit dem Auftreten von 'arā'ish und geschlechtsspezifisch getrennten Räumen bei der 'ushash-Architektur im Umland und am Rande dieser städtischen Zentren. All dies steht im Einklang mit dem periodischen Einfluß, der in der Islamischen Geschichte von Zabīd vor allem auf die 'Asīr-Tihāma ausging, und umgekehrt von Abū 'Arīsh fallweise auch auf die Tihama des Jemen. ${ }^{112}$

In einer anderen Hinsicht unterscheidet sich die 'ushash-Architektur der städtischen 'Asīr-Tihāma allerdings graduell von jener der jemenitischen Küstenebene. Die bewundernswerte künstlerische Formenvielfalt der Fassaden von jemenitischen Stroh- und Holzhütten findet eine etwas geringere Entsprechung in der Gestaltung der ' ushash um Șabyā oder Abū 'Arīsh. In dieser Hinsicht muß von einer graduellen künstlerischen und ästhetischen Verflachung gesprochen werden, die vom jemenitischen Süden aus nach Norden hin immer deutlicher wird. Die dekorative Ausstrahlung, die das Erbe der alten islamischen Stadtzentren in der jemenitischen Tihāma auf die dortige 'ushash-Architektur ausübt, nimmt also nach Norden hin markant ab.

Die kunstvollen Dachverschnürungen, geschnitzte Holztüren und andere Außendekorationen der jemenitischen Tihāma-Hütten setzen sich in der 'Asīr-Tihāma nur teilweise

111 Forbes 1923: 274; Philby 1952: 572. Ich habe ‘arā’ish in der Ḥijāz-Tihāma nirgendwo feststellen können, und auch Philby und Rüppel erwähnen sie für diese Region nur je ein Mal, und zwar bezeichnenderweise für Küstenorte, nämlich al-Lïth (Philby 1952: 705 f.) und al-Qunfudha (Rüppel 1838: 177 f.).

112 Rentz 1965: 516-518; Burckhardt 1831, II: 202. 
fort; hier sind aber auch viele 'ushash auf dieselbe schlichte Weise konstruiert wie in der Tihāma des Hijijāz. ${ }^{113}$

In der Innenausstattung unterscheiden sich die Hütten der 'Asīr-Tihāma hingegen deutlicher von den 'ushash im Nordabschnitt. Diese elaborierte Gestaltung der Innenräume stellt eine Verbreitungsform der prächtigen Innenausstattungen dar, die manche stadtnahe und städtische Hütten der jemenitischen Tihāma auszeichnet. ${ }^{114}$ Zugleich verweisen manche dieser farbenfrohen Innenräume auch auf Parallelen in der Steinarchitektur des 'Asīr (cf. Abschnitt 5.2.4. dieses Beitrags).

Diese ästhetische Ausgestaltung der 'ushash-Innenräume hat daher eine regionale Komponente (sie ist in der 'Asīr-Tihāma schwächer ausgeprägt als in der Jemen-Tihāma, aber stärker als in der Hijāz-Tihāma). Zugleich repräsentiert sie aber ähnlich wie in der Jemen-Tihāma eine soziale Komponente. Auch in der 'Asīr-Tihāma haben unterschiedlicher sozialer Status und wirtschaftliche Differenzierung Reichtumsunterschiede hervorgebracht, die in der ästhetischen und symbolischen Gestaltung der 'ushash-Innenwände manchmal prestigeträchtig zur Schau gestellt wurden.

Die ästhetische Ausgestaltung der 'ushash-Innenräume ist in dieser Form also eine regional-kulturelle und soziale Besonderheit der 'Asīr-Tihāma, welche wiederum nach geschlechtsspezifischen Gesichtspunkten ungleich verteilt ist. Rekapitulieren wir diese kurz. Es ist gezeigt worden, daß innerhalb der umzäunten 'arā'ish die eigene 'ushsha (oder der eigene 'ushsha-Raum) der wichtigste Aufenthaltsort der Männer ist, während das gesamte übrige Hofareal die bevorzugte Domäne der Frauen und Kinder darstellt.

Die Geschlechterordnung des Raumes innerhalb und durch die 'arā'ish bedingt, daß die männlichen Gastgeber und ihre Besucher sich hier nicht ohne weiteres im Freien vor der Hütte aufhalten können: Dies würde dem Meidungsgebot zwischen den Geschlechtern tendenziell widersprechen. Im Gegensatz zum Normalfall der Hijāz-Tihāma sind die männlichen 'ushash-Räume der 'arā'ish also veritable Aufenthaltsräume für derartige, punktuelle Anlässe. Dieser Männerraum dient auch als Empfangs- und Gastraum für andere männliche Besucher und ist bei entsprechendem Status (ähnlich den Empfangsräumen der tribalen 'Asīr-Architektur, cf. 5.3.4.) mit Pflanzen- und Erdfarben bemalt, ${ }^{115}$ mit kunstvoll gearbeiteten Matten und Körben behängt, durch kleine Holzmöbel mit Perlmuttintarsien geschmückt, ${ }^{116}$ und mit schön gearbeiteten, zur Schau gestellten Waffen ausgestattet. Bis auf die hier seltene Form der Innenbemalung sind diese Elemente allerdings ohne direkten Bezug zur Architektur; mit diesen Objekten wird das Prestige und die etwas verfeinerte Wohnkultur zum Ausdruck gebracht, welche die männlichen Angehörigen der semi-urbanen Oberschicht in diesem Teil der Tihāma auszeichnet. Diese Personengruppe erweist sich daher als der eigentliche soziale Träger des städtischen Kultureinflusses auf die Anlage der 'ushash und 'arā'ish.

Der umzäunte 'arīsh, die Geschlechtertrennung der Hütten-Räume, und der verfeinerte Innendekor mancher Männerräume lassen sich damit als die wesentlichen Variationsformen der 'ushash-Architektur in der 'Asīr-Tihāma identifizieren. Hinzu kommen die etwas häufigere Verbreitung von 'ushash mit rechteckigem Grundriß. Der Einfluß der

113 Nankivell 1985a: 57, 1985b: 60, 61; Ehrlich 1985: 84, 85, 93, 110; Philby 1952: 480, 638, 643.

114 Nankivell 1985a: 57, 1985b: 61.

115 Forbes 1923: $271 \mathrm{f}$.

116 Tamisier 1840, I: 385-387. 
hier gegebenen Stadtnähe und die Bezüge zur anschließenden jemenitischen Tihāma sind als jene Faktoren qualifiziert worden, die diese südliche Variationsform der 'ushash-Architektur beeinflussen.

Abschließend sei noch eine Sonderform der 'ushash Architektur in der 'Asīr-Tihāma erwähnt, die Mauger als „bayt khassāf" bezeichnet. ${ }^{117}$ Unter diesem Begriff werden mobile zeltähnliche Behausungen subsumiert, die saisonal an verschiedenen Plätzen errichtet werden. Ihr Verbreitungsgebiet erstreckt sich vom Wādī Dala' (südlich von Abha, in der heutigen Provinz 'Asīr) bis in das Lavagebiet zwischen al-Birk und al-Shuqayq unweit der Küste.

Die Bewohner des bayt khassāf (Untergruppen der Rabi a, Bani Mughayd, Manjaha) sind nomadisierende Viehzüchter. ${ }^{118}$ Die Grundeigenschaften dieser Behausungen bestehen darin, daß sie verhältnismäßig einfach abzubauen, zu transportieren und wieder von neuem zu errichten sind. ${ }^{119}$ Dies kommt bereits in der Bezeichnung „bayt khassāf" zum Ausdruck: Der Wurzel kh-s-f liegt die Bedeutung „verschwinden, versinken, niedersinken, untergehen“ zugrunde. ${ }^{120}$ Khasaf al-bayt bedeutet also etwa „das Haus zum Niedersinken bringen" (um es anderswo wieder zu errichten). Demnach leitet sich die Bezeichnung „,bayt khassāf“ davon ab, daß diese Behausungen immer wieder „zum Verschwinden gebracht“ bzw. „zum Niedersinken gebracht“ werden, da es sich eben um mobile Behausungen handelt. Darüber hinaus liegt der Wurzel kh-s-f noch eine weitere Bedeutung zugrunde: Khasf bedeutet „Minderwertigkeit, Niedrigkeit, Schande“. Rajul khāsif bezeichnet einen armen - und deshalb schlanken - Mann. Demnach könnte der Begriff „bayt khassāf" auch auf die Bewohner dieser mobilen Behausungen verweisen und als „Armenhütte" übersetzt werden.

Die Konstruktion dieser Hüttenform besteht aus einem parallel angeordneten Gerippe von Holzstangen, deren Durchmesser zwischen 3 und $5 \mathrm{~cm}$ variieren kann. Der Abstand zwischen den einzelnen Holzstangen beträgt etwa $10 \mathrm{~cm}$, in manchen Fällen bis zu $20 \mathrm{~cm} .{ }^{121}$ Das Gerüst ist mit Seilen (mannīna) ${ }^{122}$ fixiert, wobei Dach und Wand aus einer Konstruktion bestehen. In der Mitte verläuft ein etwas dickerer Dachfirst, welcher mit mehreren vertikalen Stangen abgestützt ist. Halbkreisförmige Stangen, die vom Boden zum First und wiederum zum Boden verlaufen, konstituieren den äußeren Rand dieses „Kuppelzeltes“ und tragen die parallel angeordneten Holzstangen. Sie sind ebenso wie die vertikal verlaufenden geraden Stangen, die den Dachfirst tragen, im Untergrund fest verankert. Der Boden ('arșah) ${ }^{123}$ besteht in der Regel aus gestampfter Erde bzw. aus Lehm.

Das gesamte Holzgerüst ist mit Stoffbahnen und Matten bedeckt. ${ }^{124}$ Sie werden in der Regeln „nach Maß“ angefertigt und können dabei sehr unterschiedlich beschaffen sein. Als Grundmaterial dienen meist die Fasern der Dawmpalme (dawm) ${ }^{125}$ die oft zu langen

117 Der folgende Abschnitt stützt sich primär auf die Veröffentlichung von Mauger (1993) und nicht auf eigene Datenerhebung; ich danke Gebhard Fartaček (ÖAW) für die entsprechende Zusammenstellung.

118 Thesiger 1947: 193f.; Cornwallis 1976: 25, 58; Mauger 1993: 47, 117.

119 Mauger 1993: $98 \mathrm{f}$.

120 Wehr 1977: 215.

121 Mauger 1993: 88, $96 \mathrm{f} ., 116 \mathrm{f}$.

122 Prochazka 1978: 118.

123 Prochazka 1978: 118.

124 Diese Tatsache findet in der Bezeichnung „house of mats“ (Mauger 1993: 47, 73) ihre Entsprechung.

125 Mauger 1993: 47. 
Stoffbahnen gewebt oder geflochten werden und unterschiedliche Motive aufweisen können. Doch auch geflochtene Schilfmatten sowie maschinell hergestellte Zeltplanen werden manchmal verwendet.

Die Konstruktion gewährleistet eine hervorragende Luftzirkulation, was den klimatischen Bedingungen dieser Gegend sehr entgegenkommt: Sie bietet Schutz gegen jedes Wetter. ${ }^{126}$ Der zweite Vorteil dieser Behausungen besteht zweifelsohne darin, daß sie relativ schnell errichtet und einfach zu transportieren sind. Somit handelt es sich beim bayt khassāf um eine extrem mobile Sonderform (in materieller, aber nicht konstruktiver Hinsicht) der 'ushash-Architektur, welche in hohem Maß sowohl dem Klima dieser Gegend als auch der speziellen Wirtschaftsform (nomadisierende Viehzucht) angepaßt ist. In konstruktiver Hinsicht (jedoch nicht dem Material nach) sind die Parallelen des bayt khassāf zum nomadischen Zelt Innerarabiens nicht von der Hand zu weisen.

Einem Hinweis von Mauger zufolge ${ }^{127}$ wird im Lavagebiet zwischen al-Birk und al-Shuqayq, also im Gebiet der Manjaha, das bayt khassāf zunehmend durch einfache Blockhäuser ersetzt. Dies ist wohl ein Ausdruck davon, daß der traditionelle Nomadismus im Gebiet der Lavawüste allmählich durch größere Seßhaftigkeit in benachbarten Gebieten abgelöst wird.

\subsubsection{2. 'ushash der Hijō̄z-Tihāma}

Abgesehen von der zuletzt erwähnten Sonderform des bayt khassāf im Lavagebiet präsentiert die südliche Tihāma ansonsten, wie soeben gezeigt, eine relativ kompakte, einheitliche Variation der 'ushash-Architektur. Einzelhütten ohne 'arīsh sind hier relativ selten. Die äußere Form der 'ushsha unterscheidet sich bloß danach, ob es sich jeweils um Längshütten oder um solche mit rundem Grundriß handelt. Die Längshütten, bei Prochazka (1978: 118) auch als ,jundub, pl. janādib“ angegeben, treten häufiger im Umfeld größerer Siedlungen auf; Rundhütten kommen hingegen überall in der Hijāz-Tihāma vor. Nur nach Osten hin, im Übergangsgebiet zur tribalen Steinarchitektur, treten jene Mischformen auf, die auch im entsprechenden Teil des nördlichen Abschnitts gegeben sind.

Demgegenüber bietet die 'ushash-Architektur der viel dünner besiedelten Hijāaz-Tihāma eine weit größere Variationsbreite.

Wie schon erwähnt, herrschen runde Einzelhütten im flachen Mittelteil und um das Mündungsgebiet der Wādīs vor (Abb. 45). Die Bewohner dieser Architektur sind meist Familien von Einzelbauern mit losem Bezug zu semitribalen und kleineren tribalen Verbänden, ${ }^{128}$ wie den Zubayd und B. Zayd im W. Lūma und W. Qanūna, oder den Kināna im W. Halī. ${ }^{129}$ Dies sind zumeist „Pflug'-Bauern, ${ }^{130}$ die Hirse oder Sesam anbauen und in der

126 Mauger 1993: 88, 117.

127 Mauger 1993: 103.

128 Unter semitribalen Gruppen verstehe ich solche kleinen, wenige Dörfer umfassenden Bevölkerungsgruppen, die sich zwar selbst als „Stamm“ (qabīla) bezeichnen, die aber von den Bergstämmen nicht als ebenbürtig angesehen und behandelt werden. Der entscheidende Aspekt der rechtlichen Souveränität über das eigene Territorium ist in diesen Fällen stark eingeschränkt. Das später erörterte Beispiel der 'Abādil etwa zeigt, daß deren Sommerweiden zum Territorium der Ḥijāz-Stämme zählen.

${ }^{129}$ Die B. Zayd werden ihrerseits dem größeren Verband der Ḥarb zugerechnet, cf. dazu auch Philby 1952: 691-693 und 686 . 
Nähe ihrer Hütten oft winzige Gärten angelegt haben. Das Kleinvieh wird in kleinen Gattern bei der Hütte über Nacht gehalten, und tagsüber auf die offenen Weidegebiete geführt, die nördlich und südlich der Flutbetten beginnen. Auffällig ist in den etwas fruchtbareren Gebieten der hohe Anteil von Buckelrindern (mit eigenen Gehegen) an der örtlichen Viehzucht, der - wie die gesamte 'ushash-Architektur selbst - auf parallele Phänomene auf der anderen Seite des Roten Meeres verweist, aber auch Entsprechungen im Bergland hat.

Noch explizitere Bezüge zu Afrika repräsentieren einzelne Handwerkerfamilien, etwa jene der Siedlung al-Maghāriba. Diese Āl Maghārib („Leute aus dem Westen“, also hier: aus Afrika) sind nicht nur vom Standpunkt der physischen Anthropologie afrikanischer Herkunft, wie viele Bevölkerungsteile der Tihāma. Sie sind darüber hinaus eine der wenigen unter diesen Gruppen, die sich explizit als eingewanderte, „freie Afrikaner" definieren und genealogisch ableiten, was zugleich ihre höhere Selbsteinschätzung gegenüber ehemaligen Sklaven afrikanischer Herkunft betont (Abb. 47). Dieser bezeichnende Fall belegt daher die lebendige Fortdauer von wechselseitigen Einflüssen auf die Lokalkulturen zu beiden Seiten des Roten Meeres.

Die Ansiedlung dieser Töpferfamilien umfaßt eine Reihe von runden 'ushash desselben „Prototyps“, der in der gesamten Tihāma verbreitet ist. Sie sind auch hier die einräumige Wohneinheit für einen Töpferhaushalt. Die einzigen Besonderheiten sind durch die Berufsspezialisierung bedingt: Die Handwerkerhaushalte besitzen kein Land oder Vieh, weshalb hier auch das Viehgatter fehlt. Dafür gibt es hier einige zusätzliche Hütten (aus Wellblech oder als geräumige 'ushash), in der mehrere Familien jeweils ihre Arbeitsmaterialien und Produktlager untergebracht haben (Abb. 46). Im Schatten dieser Arbeitshütten wird auch gemeinsam gearbeitet.

Neben den seßhaften, semitribalen oder tribalen Bauern und den handwerklichen Vollspezialisten gibt es in den flachen Mittelteilen der Hijāāz-Tihāma noch eine weitere Subsistenzweise, mit eigenen Konsequenzen auf die Variation der 'ushash-Architektur. Dies sind die erwähnten Formen des Halbnomadismus. ${ }^{131}$

Im Übergangsgebiet zwischen den größeren Wādīs der nördlichen Tihāma reicht die Bodenqualität für regelmäßige landwirtschaftliche Aktivitäten nach traditionellen Anbaumethoden nicht mehr aus. In diesen ariden, teilweise sandigen Steppenzonen (alKhabt) hat sich daher eine spezifische Form von „pulsatory nomadism “ entwickelt. ${ }^{132}$ Die Viehhaltung dieser kleinen, aber zahlreichen Gruppen von Tihāma-Bewohnern umfaßt vor allem Schafe und Ziegen, aber auch größere Kamel-, Esel- und Rinderbestände. Während der kühleren Jahreszeit halten sich die Halbnomaden in den arideren Gebieten des flachen Mittelteils der Tihāma auf, wo die Weiden zu dieser Jahreszeit ihren günstigsten Futterbestand bieten. Im späten Frühjahr werden die Herden dann auf die Sommerweiden nach Osten getrieben, wo die etwas feuchteren Weiden der beginnenden Gebirgs-Tihāma liegen.

In den Gebieten dieser beiden Weidezonen hat jede Gruppe ihre konstanten Standorte und Weidenutzungsrechte, die vertraglich mit den jeweils nächstgelegenen Bauern fixiert

\footnotetext{
130 Tatsächlich arbeiten diese Bauern nicht mit dem Pflug, sondern mit der Arl.

131 Abdulfattah 1981: map 4 und p. 56 spricht in diesem Zusammenhang etwas irreführend von „intermittent and occasional rainfed farming".

132 Johnson 1969: passim.
} 
sind. Mit den Vertragspartnern der westlichen Weidegründe, also den Bauern an den Rändern der Tihāma-Wādīs ergibt sich daraus ein reziprokes Beistandverhältnis. Halbnomaden, wie etwa die $\overline{\mathrm{Al}}{ }^{\mathrm{C}} \mathrm{Aba} d i l$ südlich des W. Aḥsiba, haben also ebenfalls halbtribalen Status, einige andere unter ihnen gehören sogar denselben losen kleineren tribalen Verbänden (etwa den Ḥarb) an. Gegenüber den tribalen Bauern, zu deren Stammesgebieten die östlichen Weidegründe an den Tieflagen der Gebirgs-Tihāma meist zählen, nehmen die Halbnomaden hingegen den Vertragsstatus eines nicht souveränen Verbandes ein, der in einer asymmetrischen Abhängigkeit zu seinen dortigen Partnern (meist den Ghāmid oder Zahrān) steht. Die Berg-Tihāma ist von semitribalen Bauerndörfern (meist in den hügeligen Lagen) und tribalen Agrarverbänden (eher am Steilhang und in den höheren Lagen) besiedelt; letztere sind meist die Vertragspartner der Halbnomaden für die Nutzung der Ostweiden. Heutzutage leisten die Halbnomaden Geldabgaben an die tribalen Bauern der Gebirgs-Tihāma; vor der endgültigen Etablierung des saudischen Staates in dieser Region waren sie bei Bedarf zu einseitigem Beistand in größeren Fehden verpflichtet und wurden auch „mawālī" genannt.

Die mehrjährig stabilen Standorte der westlichen Winter- und der östlichen Sommerweiden erlauben den Halbnomaden die Errichtung von permanenten Gehegen und Viehgattern, die daher das äußere, materielle und architektonische Zeichen dieser vertraglichen Bindungen und Pendelbewegungen darstellen. Diese Viehgatter sind im Mittelteil der Tihāma aus stabilen Holzzäunen errichtet, im Ostteil sind sie hingegen aus Stein.

Anders als ihre stabilen Gehege und Viehgatter sind die Behausungen der Halbnomaden hingegen semi-permanent. Im Gegensatz zur vorherrschenden, nomadischen Wohnform des traditionellen Najd in Innerarabien leben diese Gruppen der Tihāma nicht in Zelten, sondern ebenfalls in 'ushash. Anders als das „zeltähnliche“ bayt khassāf in der 'Asīr-Tihāma ist diese nomadische Hütte der Hijā̄z-Tihāma also eine reguläre Variante der 'ushash-Architektur: Auf den westlichen Winterweiden werden diese sehr leicht gebauten, niedrige Hütten errichtet, welche die einfachste Variationsform der 'ushash-Architektur in der Tihāma darstellen. Sie sind stets rund, um den größeren Aufwand zu vermeiden, den die Bereitstellung und Versenkung von vier Eckstämmen bedeutet, und sie bestehen ausschließlich aus flexiblem Material. Die langen Zweige oder dünnen, langen Bündel sind am höchsten Punkt kreuzweise übereinander gelegt und verschnürt; sie bilden also eine Kuppel. Beide Enden dieser Zweige stecken im Sand; dies und die leichte Bauweise machen einen Mittelpfeiler überflüssig. Dementsprechend seicht ist auch das Fundament dieser Hütten, das nur die Wand aus Reisigbündeln und Zweigen fixieren muß. Die ganze, recht fragile Konstruktion dieser „Kuppeldachhütte“133 reicht einem Bewohner in aufrechter Haltung kaum bis zur Schulter; die geringe Höhe vermeidet zu großen Widerstand (Abb. 48). Diese Hütten dienen - außer bei Regenfällen oder Sandstür-

133 Zur terminologischen Klarstellung: P. W. Schmidt, den Andrews in seinem Beitrag über ethnologische Architekturforschung (1994) bestätigend zitiert, setzte diese Form der Kuppeldachhütte (ohne Stützpfeiler) mit dem Begriff der Bienenkorbhütte (diese hat einen Stützpfeiler) irrtümlich gleich. Philby hingegen verwendet „Bienenkorbhütte“ im Prinzip korrekt als eine Form mit Stützpfeiler. Neben seiner terminologischen Verwirrung ordnete Schmidt diese Form überdies, gemäß seinem theoretischen Dogma, einer „urkulturlichen“ Entwicklungsstufe zu (1940: 966). Die vorliegende Analyse hingegen verortet diese Hüttenform im halbnomadischen Kontext, welcher die Existenz von Bodenbau voraussetzt. 
men - sehr selten als Aufenthaltsräume, sondern meist nur der Aufbewahrung. Geschlafen wird nachts auch nur außerhalb der ' ushash im Freien, und tagsüber ist man auf der Weide, beim Holzsammeln oder auf den Märkten beschäftigt.

Die Konstruktionsweise dieser Hütten der Halbnomaden entspricht also (bis auf den Stützpfeiler) den genannten Grundeigenschaften der 'ushash-Architektur, ist aber speziell darauf ausgerichtet, daß man sie nach einem Halbjahr auf der Winterweide wieder aufgibt. In der Zeit der Abwesenheit verfallen die Hütten zumeist.

Allerdings sind diese Tihāma-Bewohner eben keine Vollnomaden. Wenn es möglich ist, betreiben sie in Ergänzung zur dominanten Viehzucht auch fallweise Bodenbau. Im Winter als jener Jahreszeit in der es am ehesten manchmal regnet, halten sie sich im Flachteil der Tihāma auf. Daher wird der ergänzende, fallweise Bodenbau nur dort betrieben, aber nicht auf den Sommerweiden der unteren Gebirgs-Tihāma. Der Bodenbau wird bei diesen Halbnomaden also in Abhängigkeit vom Zyklus der Viehzucht betrieben, und nicht umgekehrt.

Die Standorte und Weiden der Halbnomaden liegen abseits der großen Wādīs und daher ist ihr Bodenbau nicht an der Wasserzufuhr durch Flut oder Brunnen orientiert, sondern auf den spärlichen direkten Niederschlag angewiesen. In den wenigen Jahren, in denen es in der Tihāma ausreichend regnet, bleibt ein Teil der Haushalte auf den Westweiden, um sich versuchsweise um Bodenbau zu kümmern. Der andere Teil der Gruppe spaltet sich ab und zieht mit den Herden auf die Sommerweide; dorthin folgt der Rest der Gruppe nach der Ernte (oder nach dem gescheiterten Anbauversuch) nach.

Die mobile Lebensweise, die gegebene Bodenqualität, und die nicht auf Zugvieh ausgerichtete Tierhaltung bedingen, daß die hier betriebene Art von Bodenbestellung kein Akkerbau (mit Furchenziehung durch Arl und Zugvieh) sein kann. Wenn die Chancen auf eine erfolgreiche Ernte gegeben sind, wendet man hier eine einfache - aber meines Wissens auf der Arabischen Halbinsel seltene - Form von slash-and-burn-Technik an. Gestrüpp und Gräser werden gemeinsam niedergebrannt, die Asche wird dann zusammen mit reichlich Rinder- und Kameldung auf kleine, mit der Ziehhacke gezogene Felder verteilt. ${ }^{134}$ Das benötigte Saatgut wird von den agrarischen Vertragspartnern erworben und mit dem Grabstock in die Saatlöcher gesteckt. Danach wartet man ab, ob die Aussaat gedeiht.

Für diesen vor Ort verbleibenden Teil von fallweisen Bodenbauern ist es daher wichtig, daß der „herdenführende“ Teil solange noch auf den Westweiden bleibt, bis genügend Dungmist zur Verfügung steht, aber dann abzieht, um die Aussaat durch Abweidung nicht zu zerstören. Die Konsequenz für die Architektur der Halbnomaden besteht zu den seltenen, ,agrarischen“ Winterzeiten nur aus zweierlei: Während der Regen werden die 'ushash mit Tüchern und Planen zusätzlich abgedeckt, und während der Reife und Erntezeit werden sie repariert und stabilisiert.

Auch in einigen Dörfern von seßhaften Bauernfamilien, die im Übergangsgebiet zur Steppe liegen, wie etwa der Siedlung Da'shīsh, beruht der Bodenbau hauptsächlich auf dieser einfachen Form von slash-and-burn-Technik, wobei die Wasserzufuhr dann häufiger durch Brunnenbewässerung ergänzt werden kann. Die 'ushash dieser Dörfer sind allerdings nach der üblichen, prototypischen Rundbauweise errichtet. Je tiefer man also

134 Philby 1952: 698; Abdulfattah 1981: 56. 
vom Rand der großen Wādīs nach Norden oder Süden in die Steppenzonen zwischen diesen Wādīs gelangt, desto deutlicher verändern sich Subsistenzweise und Architektur (Tab. 7). Es handelt sich insgesamt um eine Übergangszone zwischen halbnomadischer Lebensform mit provisorischen, niedrigen Kuppeldach-'ushash am ariden Ende, und seßhaftem Arlanbau mit vieljährigen und prototypischen 'ushash am fruchtbaren Beginn des Übergangsgebietes. Bei den Extremen dieses Übergangsgebietes hat sich die Bedeutung der Subsistenzgrundlagen umgekehrt. Im einen Fall stützt und ergänzt die Viehhaltung die Landwirtschaft, im anderen Fall ergänzt der Bodenbau fallweise die Viehhaltung der Halbnomaden, deren Architektur dementsprechend variiert.

Tab. 7: Subsistenz und 'ushash-Architektur im Mittelteil der Hijāz-Tihāma

\begin{tabular}{|c|c|c|c|}
\hline Naturraum & Flutbett - Ufergebiet & Übergang zur Steppe & Steppengebiet \\
\hline Beispiel & Dörfer um Khamīs al-Qawz & Da'shīsh & Lager der 'Abādil \\
\hline Subsistenz & Ackerbau (Arl und Zugvieh) & $\begin{array}{l}\text { slash-and-burn-Bodenbau, } \\
\text { ergänzt um Viehhaltung }\end{array}$ & $\begin{array}{l}\text { Viehhaltung, ergänzt um } \\
\text { slash-and-burn-Bodenbau } \\
\text { mit Grabstock }\end{array}$ \\
\hline Architektur & $\begin{array}{l}\text { seßhafte Bauernfamilien, } \\
\text { vieljährige 'ushash (Proto- } \\
\text { typ) }\end{array}$ & $\begin{array}{l}\text { seßhafte Bauernfamilien, } \\
\text { mehrjährige ‘ushash (Pro- } \\
\text { totyp) }\end{array}$ & $\begin{array}{l}\text { Winterlager von Halbnoma- } \\
\text { den, provisorische Kuppel- } \\
\text { dach-'ushash }\end{array}$ \\
\hline
\end{tabular}

Die offenkundige Schlichtheit der Architektur und Lebensführung dieser Halbnomaden sollte nicht den Blick auf ihre Bedeutung verstellen. Es handelt sich nicht nur um seltene Sonderformen der materiellen Kultur Südwestarabiens, sondern um mehr. Die Halbnomaden der Hijāz-Tihāma stellen einen ethnographischen Beleg en miniature für das dar, was Anthropologie und Archäologie über die Grundlagen und Ursprünge des Nomadismus lehren. ${ }^{135}$ Man wird in der Interpretation kaum fehlgehen, daß auch diese Halbnomaden aus einer gemischtwirtschaftlichen Landwirtschaft (entlang der Flußbetten der Tihāma-Wādīs) heraus in aridere Steppengebiete hinein marginalisiert worden sind. Darauf verweist schon die gemeinsame Zugehörigkeit zu denselben Verbänden. Und ebenso teilen diese Gruppen mit anderen halbnomadischen und nomadischen Verbänden der Alten Welt die grundlegenden Eigenschaften der permanenten Interdependenz mit ihrem seßhaften Umland. ${ }^{136}$

Diese Interdependenz manifestiert sich im konkreten Fall auch in der Architektur der Standorte an den sommerlichen Ostweiden, in den Tieflagen der Berg-Tihāma.

Es wurde schon darauf hingewiesen, daß dort permanente Viehgatter aus Stein errichtet sind. Diese sind also aus demselben Material wie die Architektur der tribalen und halbtribalen Bauern in der Berg-Tihāma. Zugleich ist der Grundriß dieser Viehgatter rund, wie jener der 'ushash; die Steinarchitektur des tribalen Berglandes im südlichen Ḥijāz kennt hingegen fast keine runden Formen. ${ }^{137}$

Nicht alle dieser runden Steinmauerungen werden als Viehgatter genutzt. Einige darunter werden für die Dauer der Sommerweide auch als Wohnräume herangezogen und

135 cf. dazu Grjasnow; Dostal 1983a: 125-158 und Khazanov 1984: 85-118.

136 Dostal 1974b: 206-212.

137 Dies ist einer der Unterschiede zur tribalen Hochbauweise des 'Asīr, wo zumindest runde Wehrtürme häufiger auftreten; cf. Abschnitt 5 dieser Arbeit. 
dafür gereinigt, repariert und mit einem einfachen Kegeldach aus Zweigen- und Reisigbündeln versehen, das an einem Mittelpfeiler verschnürt und abgestützt ist. Diese Sommerquartiere der Halbnomaden sind eine direkte Erweiterung des Prinzips ihrer Viehgatter und zugleich sind sie einfache Variationen der Wohnhütten ihrer seßhaften, semitribalen Nachbarn, den Bewohnern der Berg-Tihāma.

Stein ist hier das leichter verfügbare Baumaterial, es schützt vor den deutlichen Temperaturschwankungen der Berg-Tihāma und vor Fehden, und es übersteht die Winterfluten. Daß die Wände der Viehgatter, der Sommer-Wohnquartiere der Halbnomaden, und ebenso der Wohnhäuser der umliegenden, seßhaften Bevölkerung in den Tieflagen der Berg-Tihāma alle aus Stein sind, ist also durch praktische Erfordernisse bedingt. Der runde Grundriß hingegen ist nicht das Ergebnis pragmatischer Faktoren, sondern ein soziokulturelles Symbol: Es markiert im gegebenen Zusammenhang den halbtribalen Status seiner Bewohner, der dem tribalen Status des Hochlandes untergeordnet ist.

Damit ist eine weitere Variationsform der 'ushash-Architektur zu erörtern - die Misch- und Übergangsformen zur Steinarchitektur der Sarāt (Karte 9).

Diese Übergangsform ist charakterisiert durch runden Grundriß, ein Kegeldach aus Holz, Zweigen und Stroh und weist auch einen hölzernen Mittelpfosten auf. Sie entspricht mit diesen Konstruktionseigenschaften der 'ushash, aber die Steinbauweise der Außenwand und einige weitere Attribute entsprechen zugleich der tribalen Bauweise des hohen, eigentlichen Berglandes in der östlichen Nachbarschaft.

Alleine schon diese Bauweise würde es erlauben, von semitribaler Architektur zu sprechen. Hinzu kommt noch, daß auch die Bewohner dieser Mischarchitektur in sozialer Hinsicht als semitribale Gruppen anzusprechen sind. Dies gilt allerdings auch für manche der erwähnten seßhaften und halbnomadischen Gruppen aus dem Mittelteil der Tihāma, deren Bauweise nicht Mischform, sondern Variation der eigentlichen 'ushash-Architektur darstellt. Bei weitem nicht alle semitribalen Verbände der Tihāma leben also in diesen Mischformen, aber wo sie auftreten, dort sind sie, bis auf einige Handwerkergruppen, bezeichnend für die Ansiedlung von semitribalen Verbänden. Von der Ausnahme der Handwerkergruppen abgesehen, ist der Zusammenhang zwischen diesen Mischformen der 'ushashArchitektur und semitribalen Sozialverbänden zwar eindeutig, aber nicht eineindeutig.

Die Mischformen treten fast nur im dörflichen Siedlungsverband auf, höchst selten sieht man sie als Einzelbauten. Diese Dörfer sind ein charakteristisches Element der Kulturlandschaft in der hügeligen Tihāma, wo sie an den Kuppen niedriger Erhebungen oder in unteren Teilen der steilen Hügel angelegt sind. Die Mischformen sind etwas häufiger im Ostteil der Ḥijāz-Tihāma vertreten, kommen aber auch am Rande des 'Asīr vor.

Beispiele für derartige Mischformen bieten für den Westteil der Hijāz-Tihāma die Architektur bei al-Qunfudha, und im Osten jene von al-Tawq bei Mikhwā (nahe des Steilabhanges, Abb. 49), für den Ostteil der 'Asīr-Tihāma schließlich jene von am Qurūna (am Oberlauf des W. Tayya). Unter den hier ausgewählten Beispielen stellen jene von al-Tawq und von am Qurūna die einfacheren Mischformen dar. Sie haben teilweise sehr niedrige Steinwände von bloß einem halben Meter Höhe, auf den die Kegeldächer aus șidr- und athl-Holz ruhen. Die Stärke der Steinwände bei diesen Mischformen gestattet, daß man viel stärkere Dachbalken verwendet als beim Prototyp der 'ushsha. Ihre Festigkeit und stabile Abstützung auf der Mauerkrone erlaubt, daß die Balken einander auch an der Kegelspitze selbst abstützen können. Daher entfällt selbst bei niedrigen Wänden aus Stein bei den Mischformen manchmal die Notwendigkeit, einen Mittelpfeiler zu errichten (Taf. 
XXXVI). In den kleinen Ansiedlungen von am Qurūna und al-Tawq sind die Mehrheit der Wohnhäuser in dieser spezifischen Mischform errichtet; daneben gibt es auch einige „prototypische" 'ushash und weiters einige Mischformen mit Mittelpfeiler.

In al-Tawq haben einige Mischformen mit höheren Steinwänden auch Fensteröffnungen (Taf. XXXVI). Diese Öffnungen sind in der „prototypischen“ Form natürlich nicht möglich; auch die Terminologie der Fenster und der verwendeten Steinformen verweist bereits auf die tribale Bergarchitektur aus Stein.

Die Anlage von am Qurūna ist eine Streusiedlung von Flechtern, Töpfern und anderen Handwerkerfamilien, die sich in einem Schutzverhältnis zu jenem kleinen Stamm befinden, der die Region und den Eintritt des W. Tayya in die hügelige Tihāma dominiert, den Āl Mūsā. Die Handwerkersiedlung heißt daher auch Tayyat al-Sun' $\bar{a}$; die Wohnhäuser sind von den Bewohnern selbst errichtet.

Auch in al-Tawq, in der Hijāz-Tihāma, sind die Wohnhäuser ohne Hinzuziehen von Spezialisten durch die Bewohner selbst errichtet. Die Siedlung ist hier in Form eines groBen Kreises um einen zentralen Platz errichtet, auf den die Türöffnungen der Hütten blikken. Dies verweist auf eine kollektive Anlage der ganzen Siedlung gemäß gemeinsamer Absprachen; das Ergebnis gewährleistet Offenheit und Kommunikation untereinander und eine gewisse gemeinsame Abschirmung nach außen. Die Einwohner dieser Siedlung im W. al-Ḥumrā' gehören den Āl Jumayn an, die sich als ehemalige, seßhaft gewordene Nomaden bezeichnen und jetzt als abhängige Klientel einem der beiden großen Verbände des südlichen Hịjāz angehören, nämlich den Ghāmid. Die Architektur dieser Āl Jumayn unterstreicht durch Mischform, Terminologie und Siedlungsanlage diese sozialen, semitribalen Bezüge zur Sarāt.

Gegenüber diesen beiden kleinen Siedlungen mit niedrigen Steinwänden repräsentiert die Dorfsiedlung von Șurayḥāt die elaborierteste Ausprägung von architektonischen Mischformen in der Tihāma.

Șurayḥāt ist das Hauptdorf der Banī İsā, einem etwas größeren tribalen Verband von seßhaften Ackerbauern, welche die flachen Kuppen mehrerer Hügelketten entlang des W. al-Jāra besiedeln, einem Zufluß des W. Qanūna.

Das Gebiet der B. İsā ist das am weitesten westlich gelegene Verbreitungsgebiet der architektonischen Mischform, das hier inselartig in den Bereich der Mittelläufe der Tihāma-Wādīs hineinreicht, wo ansonsten bereits überall die „reinen“ 'ushash-Bauten dominieren (Karte 9). Die Hügelketten der B. İsā sind die fruchtbaren Südwest-Ausläufer einiger niedriger (und ansonsten meist unfruchtbarer), der Berg-Tihāma vorgelagerter Rükken, wie dem J. Maswada.

Surayhāt ist fast als „Straßendorf“ anzusprechen; die Häuser liegen zu beiden Seiten eines Mittelweges, den die Längskuppe des Hügels vorgibt (Abb. 50). Ganz wenige Bauten sind hier "prototypische“ 'ushash, die man aber bloß als Geräteschuppen oder Magazine nutzt.

Die gebräuchlicheren Wohnhäuser sind hier bestimmte Mischformen, die allesamt sehr solide, mannshohe Steinwände aufweisen. Dies erlaubt auch die Verwendung von massiven Dachbalken; ihre Ausmaße und ihr Gewicht (Abb. 52) steht jenem der horizontalen Dachbalken in der tribalen Bergarchitektur um nichts nach. Hier gewährleistet die Stärke der Mauerkronen und die Statik der Schrägbalken ebenfalls, daß man keinen mittleren Stützpfeiler benötigt. Diese frei schwebenden Kegeldächer sind auch ästhetisch sehr ansprechend gearbeitet und ergeben, im Inneren von unten betrachtet, einen charakteri- 
stischen, sternförmigen Anblick (Abb. 51). Die Innenseiten der Wände und Dächer sind hier nicht mit țīn verputzt; die Isolierung reicht auch ohne diesen Zusatz aus und ist auBen durch Strohbündel erhöht.

Diese normalen Wohnhäuser von Șurayhạt verfügen über einige Zusatzeinrichtungen, welche die defensive, militärische Funktionalität der Steinmauern erhöhen. Dies sind einfach dekorierte, verschließbare Holztüren in hölzernen oder steinernen Türstöcken, und weiters in den Steinmauern ausgesparte Schießscharten (barj, burūj). Sie befinden sich neben den Türen in Schulterhöhe, und im gesamten Mauerkreis knapp über dem Erdboden (Abb. 52). Zwei kleine, steinerne Wach- und Wehrtürme sichern die militärischen Qualitäten der Siedlung weiter ab.

Nicht nur in der Konstruktion, der klimabezogenen Isolierkraft und den Defensiveigenschaften sind die Bezüge dieser Mischform zur Hochlandarchitektur bereits unübersehbar. Auch der Außendekor weist dieselben Affinitäten auf: Von außen präsentieren die gemeinschaftlichen Familienbauten und die Männerhütten dem Näherkommenden den Schnitzdekor der Türstöcke und Holztüren und die bescheidenen Verzierungen mit weiBem Marmorstein (marw) in den Mauern.

Eingeschoßigkeit und Einräumigkeit, runder Grundriß und Kegeldach - diese Eigenschaften teilt die Mischform von Șurayḥāt noch mit der Konstruktionsweise der 'ushash. Alle anderen Eigenschaften (dicke Steinwände mit Schießscharten und Holztüren, freie Raumüberspannung mit festen Balken, Außendekor in Stein und Holz) sind hingegen schon charakteristische Eigenschaften der tribalen Hochlandarchitektur.

Diese wesentlich aufwendigere Bauweise als jene der prototypischen 'ushash erfordert eine komplexere Arbeitsorganisation, für die in Șurayhāt ein eigener Halbspezialist zuständig ist. Der örtliche „muhandis“ ist zugleich auch Bauer; er übernimmt aber im Dorf und in dessen näherer Umgebung alle wesentlichen Wohnbauaufträge. Dies betrifft die Bearbeitung der Baustoffe in Stein und Holz sowie den eigentlichen Hausbau am Ort; die Baustoffe selbst müssen von der Familie des Bauherrn bereitgestellt werden.

Die differenziertere Sozialorganisation der B. Isā äußert sich in ihrer Architektur nicht nur anhand der halbspezialisierten Fertigung dieser Wohnhäuser und in der Existenz von eigenen 'ushash für ihre Gerätschaften. Es wurde bereits kurz angedeutet, daß sich hier auch die Geschlechtertrennung in der Wohnarchitektur wiederfindet, der wir bei den bisher diskutierten Variationsformen von 'ushash-Architektur in der Hijāz-Tihāma noch nirgendwo begegnet sind. Etwa ein Drittel der Wohneinheiten von Șurayhāt sind paarweise angelegt; mit einer einräumigen Mischform-' ushash der Männer direkt neben jener der Frauen. Diese geschlechtsspezifische Trennung der Wohnhäuser wird von einigen Besonderheiten begleitet, welche auf die soziale Rolle der Frau verweisen: Die Frauen-'ushash sind nicht immer mit Steindekor verziert und sie haben auch keine Schießscharten. In einigen Fällen ist der offene Raum zwischen Männer- und Frauen-'ushash mit Holz und Stroh zu einem Sonnen- und Regenschutz überdacht; der darunterliegende Platz dient als Koch- und Arbeitsstelle der Frauen (Abb. 53). Kleine Kräuter- und Gemüsegärten, die mit einer niedrigen Steinmauer umgeben sind, ergänzen die Wohnanlagen. Șurayḥāt repräsentiert damit zwar eine architektonisch fixierte Form der Geschlechterordnung des Wohnraumes, aber diese ist schwächer ausgeprägt als in der 'Asīr-Tihāma. Keine einzige Wohnanlage ist von einer 'arīsh umzäunt; der Raum außerhalb der 'ushash ist also nicht architektonisch für die Geschlechter geteilt, und die Frauenhäuser sind ebenso auf die Dorfgasse hin gewendet wie jene der Männer. Allerdings dienen diese 
Wohnhäuser von Șurayhāat - wie ihre geräumige und stabile Bauweise bereits bezeugt - in weit höherem Maß als Schlaf- und Aufenthaltsräume als die Frauen-'ushash der 'Asīr-Tihāma. Dies bedingt für jene Minderheit von Fällen einer „paarweisen“ 'ushash-Anlage die stärkere soziale Bindung der betreffenden Frauen an ihre segregierten häuslichen Räume.

$\mathrm{Zu}$ berücksichtigen ist weiters, daß für den Bau und die Instandhaltung eines derartigen Hauses der muhandis zu entschädigen ist. Dies und die etwas komfortablere Inneneinrichtung des besagten Drittels von „paarweisen“ Wohneinheiten belegen, daß es sich bei den Eigentümern um den wohlhabenderen Teil der Dorffamilien handelt, die sich ein eigenes Haus für ihre Frauen als etwas Erstrebenswertes und Angesehenes leisten können. Die architektonische Geschlechtertrennung markiert also sozialen Aufstieg, und sie setzt sich in der Hierarchie von Status und Reichtum auch von oben nach unten durch was letztlich wiederum eine Parallele zur 'Asīr-Tihāma und zu den verbleibenden Beispielen des Nordens darstellt.

Die architektonische Markierung der Geschlechtersegregation ist zugleich Teil einer allgemeineren Hierarchisierung, die in dieser dörflichen Gesellschaft noch eine weitere Dimension hat. Im mittleren Teil von Șurayḥāt steht das einzige Wohnhaus, das nicht im 'ushash-Stil erbaut ist. Es handelt sich um ein ebenerdiges, mehrräumiges Steingebäude mit rechteckigem Grundriß, flachem Dach und mehreren Fenstern. Im Prinzip entspricht dieses flache Steingebäude völlig den einfachsten Formen der Steinarchitektur im tribalen Bergland (Abb. 50).

Was aber dort den unteren Durchschnittswert der tribalen Volksarchitektur charakterisiert, markiert hier in der hügeligen Hijāz-Tihāma die Spitze der sozialen Hierarchie: Das Steingebäude ist der Wohnsitz des Vorstandes ('arīfa) von Șurayḥāt, der zugleich Oberhaupt des Gesamtverbandes der B. Īsā ist. Sein Haus umfaßt links von der Eingangstür die Aufenthalts- und Schlafräume der Frauen, nach rechts öffnet sich ein größerer Aufenthalts- und Gastraum für männliche Besucher (mufraj). Hier werden Gäste des Dorfes empfangen oder Probleme des Dorfes und des Stammes beraten.

Dieser zentrale Steinbau von Șurayḥāt trägt also dem größeren Raumbedarf Rechnung, der sich aus den sozialen Anforderungen an die dörfliche und tribale Zentralinstanz ergibt: Regelmäßiger, und oftmals zahlreicher Besuch verlangt einen großen Gastraum. Dieses „öffentliche“ Haus ist zugleich das Haus des ersten Mannes im Dorf und muß daher auch seinem besonderen Status entsprechen. Die Segregation der weiblichen Räumlichkeiten ist hier ebenfalls gegeben, aber sie ist in denselben Gebäudekomplex integriert.

Die Integration getrennter Frauenräume in ein und dasselbe Gebäude, in dem sich auch der Männer- und Gastraum befindet, ist ein weitverbreitetes Prinzip der südwestarabischen Architektur. Es tritt sowohl in den Städten der Küste wie auch des Hochlandes auf, und ebenso in der tribalen Architektur der Bergregionen. In Șurayḥāt ist es eindeutig an die Steinbauweise gebunden, und an die soziale Spitzenposition der Lokalgesellschaft.

Im Hauptort eines der bedeutendsten tribalen Verbände der Ḥijāz-Tihāma verbindet sich also eine komplexere Sozialstruktur mit mehreren Elementen dörflicher Architektur dieser Region. Für die Sozialstruktur lassen sich arbeitsteilige Halbspezialisten von bäuerlichen Haushalten unterscheiden. Unter den Spezialisten sind der muhandis und als Führungsposition der 'arīfa identifiziert worden; die bäuerlichen Haushalte schließlich sind in eine Mehrheit von weniger reichen und in eine Minderheit von wohlhabenderen 
Residenzeinheiten differenziert worden. In den Familien dieser wohlhabenderen Haushalte und jener des 'arîfa ist die Segregation der Frauen weitaus deutlicher ausgeprägt als im Rest der Dorfbevölkerung.

Hinzu kommt eine agroklimatisch günstige Subsistenzgrundlage auf einem Territorium, das im Nordosten bereits an jenes der Ghāmid grenzt, also eines tribalen Hauptverbandes im südlichen Hijāz. Tribale Nachbarschaft, komplexe innere Sozialorganisation auf bäuerlicher Grundlage, und nicht zuletzt der eigene genealogische Bezug auf einem prestigeträchtigen Ahnennamen - diese Eigenschaften zeigen einen tribalen Tihāma-Verband an, der sich in sozialer Hinsicht nur mehr geringfügig von den Stammesgruppen des Hijjāz unterscheidet.

In architektonischer Hinsicht offenbart die Haus- und Dorfanlage von Șurayḥāt ebenfalls ein vielfältiges Bild. Grundelemente der 'ushash-Architektur (runder Grundriß, Kegeldach über einräumigem Erdgeschoß) sind mit solchen der tribalen Bauweise des Hijāz kombiniert (Steinmauern mit Schießscharten, überspannende Dachbalken), und von überregionalen Prinzipien der Geschlechtersegregation überlagert, die sich in der Architektur von der Spitze der dörflichen Sozialhierarchie weg etabliert haben. Architekturelemente der 'ushash, der tribalen Hijāz-Bauweise, und die überregionale Norm der geschlechtlichen Ordnung des Raumes sind hier also zu einem komplexen, architektonischen Ganzen verschmolzen, das selbst wieder Hauptelement einer breiteren Palette dörflicher Architektur ist. Die „paarweise Mischform“, in der die drei genannten Einflüsse kombiniert sind, koexistiert in Surayhāat mit (wenigen) Formen der prototypischen 'ushsha, (häufigen) Beispielen „einzelner Mischformen“ und einem Exemplar von Steinbau.

Damit offenbart sich in Șurayḥāt ein Nebeneinander architektonischer Formen, das einer klaren Hierarchie der sozialen Funktionen und Positionen entspricht (Tab. 8). Die prototypische 'ushash-Form ist hier bloß für einige pragmatische Funktionen marginalisiert, und die Mischformen dominieren. Dabei kann sich eine Minderheit die paarweise Mischform leisten; als eigentliches, erstrebenswertes Ideal gilt hingegen bereits der Steinbau. Die mindere Bewertung der prototypischen 'ushsha, die in den Städten und Stammesgebieten vorherrscht, ist auch in dieser Randregion der Tihāma aus praktischen (klimatischen, militärischen) und aus moralisch-politischen und sozialen Gründen Realität geworden.

Tab. 8: Hierarchie der Konstruktionsformen in Șurayḥāt, östliche Ḥijāz-Tihāma

\begin{tabular}{|l|l|l|l|l|}
\hline Konstruktion & $\begin{array}{l}\text { prototypische } \\
\text { cushash }\end{array}$ & Mischform, Einzelbau & $\begin{array}{l}\text { paarweise } \\
\text { Mischform }\end{array}$ & Steinbau \\
\hline Soziale Nutzung & $\begin{array}{l}\text { Geräteschuppen, } \\
\text { Magazine }\end{array}$ & $\begin{array}{l}\text { normale Wohneinheit } \\
\text { einer Dorffamilie }\end{array}$ & $\begin{array}{l}\text { nach Geschlech- } \\
\text { tern getrennte } \\
\text { Wohneinheit } \\
\text { wohlhabender } \\
\text { Familien }\end{array}$ & $\begin{array}{l}\text { Repräsentations- } \\
\text { raum des 'arīfa }\end{array}$ \\
\hline
\end{tabular}

In dieser Komplexität stellt Șurayḥāt einen allerdings bezeichnenden Sonderfall der Architektur der Mischformen im besonderen, und der 'ushash-Architektur der Hijāz-Tihāma im allgemeinen dar. Er belegt erstens, daß die Möglichkeiten für Defensiveinrichtungen mit der Einführung von Stein als Baumaterial deutlich zunehmen, was meist die 
Existenz semitribaler Gruppen anzeigt (aber nicht umgekehrt). Zweitens belegt dieser Sonderfall die Durchsetzung der architektonischen Geschlechtertrennung über soziale Hierarchien von oben nach unten. Und drittens belegt er, daß die Minderbewertung der 'ushash nicht bloß von Außenstehenden der Tihāma zugeordnet wird, sondern auch von Teilen ihrer Lokalbevölkerung selbst vertreten wird - von jenen nämlich, die sich architektonisch und sozial davon etwas abheben können.

Wenn Șurayḥāt einen prägnanten Fall des Übergangs zur tribalen Steinarchitektur der Berggebiete darstellt, so verweisen die verbleibenden Fälle hingegen auf Übergangsformen zur quasi-urbanen Kultur in der Küstenebene. Dazu kehren wir von den Mischformen ein letztes Mal zurück zur eigentlichen 'ushash-Bauweise.

Im Mittelteil der Tihāma treten die „paarweisen“ Anlagen von 'ushash-Wohneinheiten nur vereinzelt auf. In konzentrierter, dominanter Häufigkeit sah ich sie nur im Wādī Aḥsibā'. Sein Mittelteil ist Wohngebiet einer seßhaften, bäuerlichen Ashrāf-Gruppe, der 'Abādila. ${ }^{138}$ Diese Zugehörigkeit zu den Nachfahren des Propheten ist zugleich der ausschlaggebende Faktor für Geschlechtersegregation in Form von zwei getrennten 'ushash pro Wohneinheit. Sie wird materiell möglich durch die größere Wohlhabenheit der Ashrāf, und sie ist moralisch geboten durch ihre intensivere Bindung an die städtischen und schriftlichen Traditionen.

Vom Sonderfall Șurayḥāt abgesehen, haben alle anderen bisher erörterten Fallbeispiele belegt, daß die Geschlechtersegregation mithilfe der Architektur im mittleren und östlichen Teil der Hijāz-Tihāma kein bedeutender Faktor ist, und dies in deutlichem Unterschied zur 'Asīr-Tihāma. Ihre Dominanz in den beiden Fällen der dörflichen Oberschicht von Surayhāt und im Fall dieser Ashrāf-Ansiedlungen des W. Aḥsibā’ zeigen, daß die räumliche und architektonische Geschlechtersegregation in diesem Teil der Tihāma bloß von den wohlhabenden und theologisch gebildeten Schichten praktiziert wird. Daher stellt sie im Mittel- und Ostteil der Hijāa-Tihāma bloß eine schichtenspezifische, eher marginale Variationsform der 'ushash-Architektur dar.

$\mathrm{Zu}$ den Küstenorten im Westen hin nehmen jedoch sowohl die „paarweisen“ "ushash zu, wie auch die 'ushash mit rechteckigem Grundriß (Abb. 53, 54). Beide Arten von Wohneinheiten sind insgesamt geräumiger, und sehen eigene Frauenräume vor - einmal in Form einer zweiten Hütte, und das andere Mal als gesondertes Abteil derselben Hütte. Das höhere Maß an Wohlhabenheit im Mündungsgebiet der Wādīs und der intensivere Einfluß der nahen Häfen bewirken die größere Verbreitung dieser Variationsformen. Auf eine ähnliche, wenn auch weitaus schwächer ausgeprägte Weise wie die 'arīsh-Anlagen im Umfeld der Steinarchitektur des einfachen Küstenstils von Șabyā oder Abū 'Arīsh im Süden zeigt die 'ushash-Architektur im Umfeld um Ḥalī, al-Qunfudha oder al-Līth im Norden also quasiurbane Variationsformen. Eine darunter ist im Mittel- und Ostteil der südlichen Tihāma nur schichtspezifische Variationsform (die „paarweise“ Wohneinheit); die andere davon tritt in besonderer Häufigkeit ansonsten nur im quasi-urbanen Umfeld der südlichen Tihāma-Städte auf (die rechteckige 'ushsha). Diese Form hat neben größerer Geräumigkeit und getrenntgeschlechtlichen Abteilungen noch eine weitere Eigenschaft. Ihr Grundriß entspricht dem der Häuser aus Ziegel, Lehm oder Korallenstein: Er ist ebenfalls rechteckig.

138 Philby 1952: 692-695 (nicht zu verwechseln mit den semitribalen, halbnomadischen Āl 'Abādil im Khabt) und Thesiger 1947: 188, 191. 


\subsubsection{3. 'ushash der östlichen Oasen}

Dies wird abgestützt durch die Tatsache, daß die rechteckigen Variationsformen auch unter den 'ushash in den Oasen am Ostrand der Sarāt besonders häufig sind (Abb. 55). In den Oasen östlich des Hijāza, wie etwa in al-'Aqīq, aber auch im Najrān der späten 30er Jahre, stellten die 'ushash-Bauten gegenüber der dominanten Lehmarchitektur nur eine Minderheit dar. ${ }^{139}$ Am Beispiel von al-'Aqīq wird auf diese architektonische Situation in Zusammenhang mit der Lehmarchitektur noch näher eingegangen. Ihre Hütten aus Palmstämmen und -zweigen sind fast durchwegs von rechteckigem Grundriß, was zweifellos mitbedingt ist durch das Vorherrschen von unflexiblen Palmstämmen als Bauholz im Nahbereich der Oasen. Zugleich aber stellen die häufigen rechteckigen Grundrisse dieser 'ushash eine soziale und konstruktive Anpassung dar, nämlich an die dominanten Lehmbauten der Oase.

Zusätzlich zu ihrem generellen Vorteil der größeren Geräumigkeit interpretiere ich also das häufigere Auftreten dieser vierwandigen 'ushsha-Form in der Nähe größerer Oasen und quasi-urbaner Zentren als volkstümliche, stilistische Angleichung und Annäherung an die feste, vierkantige Bauweise.

\subsubsection{Analyse und Zusammenfassung}

Zuletzt wurde gezeigt, daß sich im schmalen Umland von quasi-urbanen Zentren und Oasen zu beiden Seiten des Hijāz eine größere Konzentration der 'ushash-Variationen mit rechteckigem Grundriß als Übergangsform identifizieren läßt. Neben den Mischformen mit tribaler Architektur am Ostrand der Tihāma ist dies eine weitere Übergangsform innerhalb des Gesamtspektrums der 'ushash-Architektur im Norden des saudi arabischen Südwestens.

Damit können die Verbreitungsgebiete und Variationsformen der ' ushash-Architektur zusammengefaßt werden. Gehen wir nochmals von den drei hauptsächlich zu unterscheidenden Verbreitungsgebieten innerhalb des saudi arabischen Südwestens aus - dem Südabschnitt der Tihāma, ihrem Nordabschnitt und schließlich den Oasen am Ostrand der Sarāt.

Im Südabschnitt, und nur dort, dominiert der umzäunte 'arīsh. Die hier vorherrschende 'ushash-Variationsformen sind etwa zu gleichen Anteilen die 'ushash mit rechteckigem und jene mit rundem Grundriß bei „paarweiser“ Anlage. In der Hijā̄z-Tihāma sind am Ostrand die Misch- und Übergangsformen zur tribalen Steinarchitektur besonders häufig vertreten. Im Mittelteil ist die 'ushash-Architektur durch Formen mit rundem und viereckigem Grundriß charakterisiert, daneben treten dort die provisorischen 'ushash der Halbnomaden und vereinzelt die „paarweisen“ Anlagen der Rundformen auf. Im Mündungsgebiet der Wādīs und in den Küstenorten sind diese paarweisen Anlagen und 'ushash mit rechteckigem Grundriß häufiger als die Einzelbauten mit rundem oder quadratischem Grundriß. Die Variationsform mit rechteckigem Grundriß prägt auch die 'ushash-Architektur in den Oasen östlich der Sarāt, wo sie aber insgesamt von untergeordneter Bedeutung ist.

139 Philby 1952: 228. 
Die 'ushash repräsentieren einen eigenständigen Typus von Architektur, für den drei Grundeigenschaften und vier wesentliche Bauphasen als charakteristisch identifiziert wurden. Diesen entspricht die runde, zusammengesetzte Hütte mit aufgesetztem Kegeldach als die „prototypische“ und häufigste Form. Ausgehend von der Untersuchung der verschiedenen Variationsformen in ihrer regionalen Verteilung kann nun weiter differenziert werden nach Grundriß und Dachform, nach dem Aufriß und nach den Konstruktionselementen.

'ushash mit rundem Grundriß treten in allen drei Verbreitungsgebieten auf - als dominante Form im Mittelteil der Ḥijāz-Tihāma und in ihrem Ostteil als Mischform, als quantitativ ebenbürtige Form im Südteil der Tihāma und in den nördlichen Mündungsgebieten, und als sehr untergeordnete Form in den östlichen Oasen.

Diese „runden“ 'ushash haben nie ein Flachdach, sie haben nur in der halb-nomadischen Sonderform ein Kuppeldach, und ansonsten tragen sie durchwegs ein Kegeldach.

Mit quadratischem Grundriß sind 'ushash relativ selten in der 'Asīr-Tihāma und den Oasen der Ostabhänge vertreten; am Ostrand der Hijāz-Tihāma kommen sie überhaupt nicht vor. Etwas häufiger treten sie im Mündungsgebiet und im Mittelteil der Wādīs der Hijāz-Tihāma auf. Auch die 'ushash mit quadratischem Grundriß haben nie ein Flachdach; sie tragen ein Zeltdach mit Kanten, die durch die äußeren Strohbündel abgerundet sind. Die 'ushash mit rechteckigem Grundriß hingegen dominieren die Hüttenform in den östlichen Oasen und stellen erhebliche Anteile der Architektur in der 'Asīr-Tihāma und in den Mündungsgebieten der Ḥijāz-Tihāma; sie haben stets Satteldächer (Taf. XXXVII). ${ }^{140}$ Nach dem Grundriß besehen ist also die runde Form bei weitem dominant, die rechteckige ist häufig, die quadratische hingegen ist selten.

Im Aufriß betrachtet haben alle Variationsformen mit einer Ausnahme Mittelpfeiler die rechteckigen haben zwei, die quadratische und runde Form einen. Die Ausnahme ist die seminomadische Hütte. Diese ist zugleich die einzige Form, die

a) aus flexiblem Material so gebaut ist, daß beide Enden in der Erde versenkt sind. Die anderen Formen lassen sich danach unterscheiden, ob sie (vom Mittelpfeiler abgesehen)

b) nur aus flexiblem Material errichtet sind, von denen ein Ende im Fundament versenkt und das andere unter Spannung an der Spitze des Mittelpfeilers fixiert ist; oder ob sie c) aus festen und aus flexiblen Teilen zusammengesetzt sind.

Form a) ist die Kuppeldachhütte. Die Form b) kann nur auf rundem Grundriß errichtet werden; sie hat im Aufriß eine leicht konvexe Dachform und ist die eigentliche „beehive hut ". ${ }^{141}$ Form c) kann auf quadratischem, rechteckigem oder rundem Grundriß errichtet sein und umfaßt auch die Mischformen zur Steinarchitektur.

Aus diesen Differenzierungen ergeben sich einige ökologische und soziale Implikationen.

Die naturräumlichen Gegebenheiten der Tihāma und der Oasen am Ostrand der Sarāt bedingen erstens ein schwüles, heißes und niederschlagsarmes Klima. Zweitens sind in diesen Naturräumen bestimmte Baumaterialien verfügbarer als andere. Es ist nicht unmöglich, in der Tihāma mit Stein, Lehm oder Ziegeln zu bauen, aber die Bereitstellung

140 Feest und Janata 1989: 114

141 Denyer 1978: 135 (Nr. 8); cf. auch Philby 1952: 641, fig. 59. 
dieser festen Baumaterialien ist aufgrund ihrer Seltenheit im Mittel- und Küstenabschnitt arbeitsaufwendiger oder kostenintensiver. Vegetabile Baumaterialien sind für die sozial und ökonomisch niedrig situierte Mehrheitsbevölkerung der Küstenebene und für eine Minderheit in den östlichen Oasen also einfach verfügbarer. Und mit diesen Materialien lassen sich architektonische Abstimmungen auf das lokale Klima erzielen, die mit anderen Baumaterialien kaum, oder nur viel aufwendiger möglich sind.

Unter den Hüttenkonstruktionen kommt auch der Dominanz des runden Grundrisses eine ökologisch-konstruktionsmäßige Zweckorientiertheit zu. „Je mehr der Grundriß der Kreisform angenähert ist, desto kleiner ist der Umfang bei gleichbleibender Fläche. Rundbauten sind daher rechteckigen Bauten sowohl vom Standpunkt der Wärmeabgabe als auch im Hinblick auf ihre Materialökonomie überlegen. "142 Der runde Grundriß spart also Baumaterial ein, insbesondere feste Hölzer, und weiters bewahrt er die Innentemperatur des Hüttenraumes besser.

Viereckige (rechteckige und quadratische) Grundrisse weisen demgegenüber erstens innenarchitektonische Klimanachteile auf: Ihre größeren Wandflächen isolieren die Innentemperatur weniger gut, und insbesondere die Längshüttenkonstruktion erschwert zudem die Luftzirkulation. Zweitens erfordern 'ushash-Konstruktionen mit viereckigem Grundriß von vornherein wesentlich mehr Baumstämme und andere feste Hölzer für ihre Konstruktion: Dies gilt für ihre Eckpfeiler und Dachkanten, bei der Längshütte außerdem noch für den zweiten Pfeiler und den Dachgiebel.

Daher treten 'ushash mit rechteckigem Grundriß im Erhebungsgebiet nur dort auf, wo ihre Vorteile (mehr Raum) mehr zählen und ihre Nachteile weniger ins Gewicht fallen. Dies sind einerseits die Regionen mit größeren Lokalvorkommen an festen Baumstämmen - also die feuchten Mündungsgebiete in der Hijāz-Tihāma, die flood-plains in der 'Asīr-Tihāma und die Oasen im Osten. Der üppigere Bestand an Palmen ist dabei - aufgrund der aufwendigen Bearbeitung von Palmstämmen - weniger bedeutsam als der von anderen, allerdings weit weniger zahlreichen wildwachsenden Bäumen. Die größere Wohlhabenheit mancher Familien erlaubt überdies, daß man Bauholz da und dort auch am Markt erwirbt.

Der gemeinsame Vorteil von Hütten mit rechteckigem Grundriß ist ihre höhere Stabilität und Dauerhaftigkeit. Längshütten bieten überdies mehr Innenräume. Dementsprechend selten sind Hütten mit quadratischem Grundriß. Sie erlauben zwar eine bessere Luftzirkulation (durch die Spitze ihres Zeltdaches) und verlangen etwas weniger festes Baumaterial als Längshütten, aber wenn man sich schon eine Hütte mit viereckigem Grundriß leisten kann und will, dann geben die größeren Raummöglichkeiten meist den Ausschlag für die Längshütten.

Die Abwesenheit des Flachdaches in der Hüttenkonstruktion hat offensichtliche Gründe. Aufstrebende Dächer erhöhen im Innenraum das Emporsteigen von warmer Luft und Rauch, und sie geben aus der Ferne eine topographische Markierung im ebenen Raum ab. Überdies erleichtern sie das Abrinnen des seltenen Regenwassers.

Unter Berücksichtigung der Notwendigkeit, feste Hölzer einzusparen, repräsentieren alle auftretenden Dachformen nahezu eindeutige funktionale Zweckmäßigkeiten. Das Zeltdach kann nur über quadratischem Grundriß errichtet werden; Satteldächer sind nur

142 Feest und Janata 1989: 113. 
über rechteckigem Grundriß möglich; Kegel- und Kuppeldächer erheben sich nur über zylindrischen Wänden mit rundem Grundriß.

Ausschließlich mit flexiblen Materialien errichtet sind die Kuppeldachhütte der Halbnomaden und die Bienenkorbhütte, beide mit rundem Grundriß: Die Kuppeldachhütte ist auf die mobile Lebensführung und die Besonderheiten der Steppe ausgerichtet; die Bienenkorbhütte vereinigt alle Vorteile der Rundhütten mit Kegeldächern und spart feste Bauhölzer ein. Sie ist daher in den trockenen Teilen der Tihāma und heute unter ihren ärmsten Bewohnern die verbreitete Form.

Auch Hütten mit rundem Grundriß können aus festen und aus flexiblen Materialien errichtet sein; dies gilt für Wandverstärkungen aus Baumstämmen; das Kegeldach ist dann der verstärkten Wand mit eigener Traufe aufgelegt. Die Mischformen mit Steinwänden fallen ebenfalls in diese Kategorie. Hütten mit viereckigem Grundriß sind jedoch immer aus festen und flexiblen Formen zusammengesetzt.

Für die Hausanlage ergibt sich folgendes Bild: Der umzäunte 'arīsh tritt in der 'AsīrTihāma im wesentlichen nur mit Längshäusern und „zusammengesetzten“, paarweise angelegten Rundhütten auf, und mit keiner anderen 'ushash-Form. Diese beiden 'ushashFormen treten in den anderen Verbreitungsgebieten aber auch ohne 'arīsh auf. Die „paarweise“ Anlage schließlich tritt nur bei der „zusammengesetzten“ und der Bienenkorbform auf, die aber häufig auch als Einzelhütten vorkommen.

Aus diesen ökologischen, konstruktiven und sozialen Eigenschaften ergibt sich die regionale Verbreitung der einzelnen Variationsformen: Die seltenen Kuppeldach-Hütten nur in den Steppengebieten der Hijāz-Tihāma; die häufigen Bienenkorbhütten einzeln im Mittelteil der Hijā̄z-Tihāma und paarweise manchmal in ihrem Mündungsgebiet und im Mittelteil; die zusammengesetzte Rundhütte überall, aber vorwiegend paarweise in der 'Asīr-Tihāma und in den inneren Mündungsgebieten und Mittelteilen der Hijāz-Tihāma; die Mischformen, einzeln oder paarweise am Ostrand der gesamten Tihäma; die seltenen Hütten mit quadratischem Grundriß in der Hijāz-Tihāma und selten in jener des 'Asīr; und schließlich die Längshütte in der 'Asīr-Tihäma, den nördlichen Mündungsgebieten und den östlichen Oasen.

Mit Ausnahme der Mischformen erfüllt keine Hüttenform waffentechnische Funktionen; der umzäunte 'arīsh leistet dies im Süden nur in sehr beschränktem Maß. Die generelle Abwesenheit von Defensiveinrichtungen ist einerseits durch die Dominanz von flexiblen Baumaterialien bedingt. Zugleich entspricht sie dem nicht-tribalen, und oft sozial untergeordnetem Status vieler 'ushash-Bewohner; sie wird begleitet von der gesonderten Einrichtung staatlicher Garnisonsmärkte in der Hijāz-Tihāma, von Militärbauten der quasi-urbanen Siedlungen in der 'Asīr-Tihāma und in den Küstenstädten der Tihāma und von Lehmbauten der Oasenarchitektur.

In diesem sozialen Umfeld sind der 'arīsh und die Längshütte als ästhetische und soziale, und die paarweise Hüttenanlage als soziale Anpassung gegenüber den quasi-urbanen Siedlungen interpretiert worden. Die Kuppeldachhütte ist ausschließlich bei den seminomadischen Gruppen der Hijāz-Tihāma angetroffen worden.

Im Anschluß an diese ersten Zuordnungen kann vorsichtig versucht werden, die verbleibenden Korrelationen von Hüttenformen und Hausanlagen mit sozialen Gruppierungen anzusprechen. Die Bienenkorbhütten verweisen in der Regel auf geringen Wohlstand. In der Hijāā-Tihāma werden sie von ärmeren Bauern bewohnt, fallweise auch von Handwerkergruppen mit geringem Einkommen. Die zusammengesetzte Einzelhütte mit 
rundem Grundriß tritt am häufigsten in bäuerlichen Dorfverbänden der Hijāz-Tihāma auf, selten auch in den östlichen Oasen, und schließlich sind sie oft die Behausungen von Handwerkerfamilien (in diesem Fall manchmal mit rechteckigem Arbeits- und Geräteschuppen).

Schon die Beschreibung der 'ushash-Variationen hat ergeben, daß die drei Verbreitungsgebiete architektonisch sehr unterschiedlich gegliedert sind. Einer größeren Homogenität in der 'Asīr-Tihāma und in den östlichen Oasen steht die architektonische Heterogenität der Hijāaz-Tihāma gegenüber (Tab. 9).

Tab. 9: Verbreitungsgebiete der 'ushash-Variationen (Legende nach Tafel XXXVII, S. 663)

\begin{tabular}{|l|l|}
\hline Verbreitungsgebiet & 'ushash-Variationen \\
\hline 'Asīr-Tihāma & 5,3 ; selten 4 in C \\
\hline Oasen am Ostrand der Sarāt & 5, selten: $3 \mathrm{~B}$ \\
\hline Ḥijāz-Tihāma & $1 ; 2 \mathrm{~A}(\mathrm{~B}) ; 3 \mathrm{~A}, \mathrm{~B} ; 4 ; 5 \mathrm{~A}$ \\
\hline
\end{tabular}

Diese Polarisierung zwischen zwei homogenen und einem heterogenen Verbreitungsgebiet der 'ushash-Architektur steht in deutlichem Zusammenhang mit den jeweiligen Gegebenheiten des Naturraumes und der Sozialstruktur. Die spezifische Oasenwirtschaft des Ostens mit einheitlicher Brunnen- oder Flutbewässerung beschäftigt auch ehemalige Sklaven und abhängige Pächter - die dortigen 'ushash-Bewohner gehören fast durchwegs dieser einheitlichen sozialen Schicht an.

In den kompakt besiedelten Flutebenen der 'Asīr-Tihāma leben hauptsächlich „fallāhīn", die Bewohner der 'arīsh-Anlagen. Nur die reichere Oberschicht unter ihnen und die Angehörigen von Ashrāf-Linien verfügen über etwas kunstvoller ausgestattete Hütten. Ansonsten entspricht die 'arā'ish-Anlage dem kompakten, und für die 'Asīr-Tihāma typischen, breiten Stratum der fallahīn.

Diese äußere architektonische und stilistische Lebensform einer bestimmten sozialen Gruppierung ist verflochten mit der Staatskultur an der Küste, vor allem aber im Binnenland der 'Asīr-Tihāma, und weist darüber hinaus deutliche Bezüge und vereinfachte Beeinflussungen seitens der ' ushash-Architektur in der jemenitischen Tihāma auf.

In Abgrenzung zu diesen beiden homogenen Verbreitungsgebieten weist die dünnbesiedelte Hijāz-Tihāma nicht nur weitaus heterogenere architektonische Formen auf, sondern auch eine andere Sozialstruktur. Zum einen konzentriert sich der traditionelle Staatseinfluß hier nur auf einige Küstenorte und wenige „Garnisonsmärkte“ im Landesinneren, die sich kaum zu demographischen Ballungsräumen entwickeln konnten. Dies bedeutet, daß der vormoderne Staatseinfluß hier nur peripher geblieben ist und die nicht-staatlichen Sozialverhältnisse weniger intensiv durchdringen und zersetzen konnte.

Wie die heutige jemenitische Tihāma, so war auch die des Hijāz im Mittelalter noch größtenteils von Stammesgruppen und tribalen Teilverbänden besiedelt. ${ }^{143}$ Der im späten

$\overline{143}$ al-Hamdānī (Müller: 120) nennt für die Tihāma des Hịjāz etwa einen Teilverband der Jurhum bei Dawqa, die B. Ḥirām bei Ḥalī und seinem Hinterland, oder die Ḥarra; die beiden letztgenannten Gruppen gehören bereits den Kināna an; auch heute siedeln semitribale und kleine tribale Gruppen, 
Mittelalter und der Neuzeit dann offenbar einsetzende historische Prozeß einer „Detribalisierung"144 ist aber in der Tihāma des Hijāz auch im 20. Jh. offenkundig nicht so weit fortgeschritten wie in jener des 'Asīr oder in großen Teilen der jemenitischen Tihāma. Welche anderen Faktoren auch immer für diesen postulierten Prozeß einer Detribalisierung verantwortlich gewesen sind, dem Staatseinfluß kam dabei in jedem Fall eine gewichtige Rolle zu - sei es über die Organisation von Fernhandel und Militäranlagen, die Errichtung und Instandhaltung von großen Bewässerungsanlagen, oder die Förderung theologischer Zentren. All dies ist in der Hijāz-Tihāma durch den peripheren Staatseinfluß bis in das 20. Jh. kaum, oder in weniger intensivem Ausmaß möglich gewesen.

Die heterogene architektonische Formenvielfalt der Hijāz-Tihāma korrespondiert also mit einer uneinheitlichen Sozialstruktur, die sich aus einer Vielzahl verschiedenartiger Gruppen unterschiedlicher Größenordnung zusammensetzt: Bauern, die sich als „ehemalige Sklaven“ definieren und solche, die sich im Süden „fallaḥ̄n“ nennen, zählen dabei zu den kleineren Gruppen. Handwerker und andere Spezialisten (Flechter-, Töpfer-, Kalkbrenner-, Schmiede- und Holzsammlerfamilien), die ihre Herkunft teils aus Afrika, teils „aus der Sarāt“ ableiten, sind eine lose, größere Gruppe. Händler, deren Familien an der Küste leben, die aber ihren Zweitwohnsitz im Binnenland haben, zählen zu den wenigen wohlhabenden Bewohnern der Hịjāz-Tihāma. Den höchsten Status unter den 'ushash-Bewohnern dieses Verbreitungsgebietes haben zweifellos die Ashrāf inne, wie die erwähnte Gruppe der Abādila des W. Ahsiba. Sie sind größtenteils ebenfalls Bauern, umfassen aber auch kleine Anteile von Lokalgelehrten, die sich auf Rechtsbeistand und das Ausfertigen von Schriftstücken spezialisiert haben.

Den Hauptteil der Bevölkerung stellen jedoch die zahlreichen, losen semitribalen Verbände dar. Dies sind Arl- und Brandrodungsbauern mit relativ kompakten, kleinen Siedlungsgebieten, die an den Rändern in die Steppe übergehen - den Weidegründen der Halbnomaden, die etwa den gleichen sozialen Rang innehaben.

Die Sozialstruktur der Hijāz-Tihāma offenbart also ebenfalls eine größere Differenziertheit, und zwar sowohl in „vertikaler“ wie in „horizontaler“ Hinsicht. Horizontal etwa gleichrangig lebt hier auf getrennten Territorien eine Vielzahl von semitribalen Kleinverbänden, wie den Ḥarb-Gruppen, den B. Īsa, Zubayd und B. Zayd, oder Kināna, ${ }^{145}$ die somit durch Namen und Siedlungsgebiet voneinander unterschieden sind. Vertikal stehen dem Status und der Herkunft nach über diesen semitribalen Kleinverbänden die Ashrāf, und unter ihnen alle angeführten anderen Gruppen.

die sich als den Kināna zugehörig bezeichnen, um Ḥalī. Philby (1952: 686) erwähnt, daß der nördliche der beiden Siedlungsteile von Ḥalī als der ältere den Kināna zugehöre. Bei al-Hamdānī (Müller 1884-86: 120) wird eben dieser Ort bereits als Sitz der Führer der Kināna genannt. Zu den Kināna als Gruppe der Quraysh cf. die Angaben bei Peters 1994: 10-14.

Für die Tihāma des 'Asīr werden im Mittelalter zwar im Süden ebenfalls tribale Gruppen wie die heute verschwundenen Ḥakam genannt (bis Jāzān und Șabyā); nach Norden hin geht deren Gebiet aber schon zu jener Zeit in den mikhlāf 'Athr über (der „Bezirk“ im Hinterland der gleichnamigen, heute versandeten, bedeutenden Hafenstadt). Dieser mikhlāf reichte nach Norden bis zum W. Aramram, und in seinem Gebiet wird Baysh als eine der wenigen Ansiedlungen mit madīna, Stadt bezeichnet, wo bereits damals „mawālī“ (Klientel, Abhängige) der Quraysh lebten; cf. al-Hamdānī (Müller 1884-86): 54, 119, 170.

144 "Gingrich 1999: $208 \mathrm{f}$.

145 Die Angaben von Thesiger (1947: 191) und Abdulfattah (1981: Karte 5) zur räumlichen Gliederung dieser Verbände decken sich weitgehend mit meinen eigenen Daten. 
Es ist leicht, in dieser Gliederung die Parallelen zum tribalen Hochland der Sarāt zu erkennen. Hochrangige Gruppen der Nachfahren des Propheten gibt es hier wie dort. Was hier nur kleine, meist unbewaffnete, semitribale und mawali-Verbände des Mittelteils und Ostrandes der Tihāma sind, das sind dort die großen Hochlandstämme. Und was in der Sarāt die Minderheit der handwerklichen Berufsspezialisten von niederem Rang ist, dem entspricht in der Hijāzz-Tihāma ein wesentlich größerer Bevölkerungsanteil von ehemaligen Sklaven, eingewanderten afrikanischen oder Hochlandspezialisten, und von Händlern an der Küste. Hinzu kommen direkt an der Küste die Fischer, Bootsbauer und andere Lokalspezialisten.

Diesen Affinitäten in der Sozialstruktur der Hijā̄z-Tihāma entsprechen die Einflüsse der tribalen Hijāz-Architektur auf jene der vorgelagerten Küstenebene. Die Formenvielfalt der 'ushash-Architektur drückt also einerseits die heterogene Sozialstruktur des Verbreitungsgebietes aus, und andererseits deren Bezüge zum tribalen Hochland. Dies belegen die Mischformen am Ostrand der Sarāt und die einzelnen Steinbauten hochrangiger Persönlichkeiten. Die Architektur der Hijā̄z-Tihāma ist in ihrem Ostteil durchdrungen von Einflüssen der tribalen Architektur des Hochlandes.

Jedes der drei Verbreitungsgebiete von 'ushash-Architektur im saudi arabischen Südwesten trägt also die Spuren von Einflüssen seiner Nachbargebiete. Für die vierkantige 'ushash am Ostrand der Sarät wurde auf den Bezug zur Lehmarchitektur des Najd verwiesen. Die 'ushash-Anlagen der Tihäma sind an ihrem Ostrand in Gestalt der "Mischformen“ durchdrungen von Einflüssen der tribalen Steinbauweise der Sarät. Die 'ushash-Architektur der 'AsīrTihāma zeigt deutliche Einflüsse aus der benachbarten, nördlichen jemenitischen Tihāma. Beide Tihäma-Abschnitte sind letztlich von West nach Ost durch den Küstenstil durchsetzt und beeinflußt.

Dies war also zu Beginn dieses Kapitels mit dem Hinweis angedeutet worden, daß die 'ushash die unauffällige Begleiterscheinung aller anderen Architekturformen des Südwestens ist. Zugleich ist sie eine eigenständige Form, die im Prototypus der zusammengesetzten Hütte mit Kegeldach und in seiner fragileren Variante, der Bienenkorbhütte, am deutlichsten zum Ausdruck kommt.

Die Bezüge dieses Prototyps und auch der Bienenkorbhütte zur ostafrikanischen Architektur sind unübersehbar. Ähnliche Bauformen finden sich im Sudan und Eritrea ${ }^{146}$ oder in Kenia. Bevor man allerdings vorschnell diesen architektonischen Bezug zu Ostafrika herstellt, sind zwei Faktoren zu beachten. Erstens sind die klimatischen und geomorphologischen Voraussetzungen zu beiden Seiten des Roten Meeres sehr ähnlich, was der Architektur in beiden Regionen von vornherein dieselben Zwänge auferlegt und daher auch voneinander unabhängige, aber parallele Entwicklungsmöglichkeiten der Architektur miteinschließt. Und zweitens ist die Beeinflussung nachweislich nicht nur von einer Richtung zur anderen erfolgt; schon die frühesten historischen Belege zeigen eine wechselseitige Beeinflussung zwischen Ostafrika und der Arabischen Küste an; ${ }^{147}$ in der

146 Talib 1984: 100; Philby 1952: 456. 1974 habe ich im Zuge einer umfangreichen Erhebung auch die Hüttenformen der Flüchtlingsbevölkerung aus Eritrea und der lokalen Wohnbevölkerung um Kassala und Gedaref im Nordost-Sudan dokumentiert; Gingrich 1975: passim.

147 Constantini 1984: 41 hält dies bereits unter paleo-ethnobotanischen Gesichtspunkten fest; für Altsüdarabien cf. Müller 1987: 52-55 und darüber hinaus Raunig 1987: 411-420, jeweils mit weiterführender Literatur. 
Architektur ist der frühe, ostafrikanische Küstenstil sogar eindeutig aus arabisch-islamischen Impulsen ableitbar. ${ }^{148}$ Ähnliche 'ushash-Formen zu beiden Seiten des Roten Meeres sind also durchaus auch auf Einflüsse von der arabischen Küste nach Ostafrika hin zurückzuführen.

Bei prinzipieller Anerkennung der Koexistenz dieser beiden Möglichkeiten (voneinander unabhängige Parallelentwicklungen, und arabische Beeinflussung der ostafrikanischen Architektur) wäre es dennoch sehr einseitig, wollte man ausgerechnet die dritte, offenkundigste Möglichkeit ausschließen, die des afrikanischen Einflusses auf die arabische Küste.

Immerhin ist die Hüttenarchitektur in der materiellen Kultur riesiger ethnographischer Gebiete in Ost-, Zentral- und Westafrika verbreitet, und im Osten des Kontinents schließt praktisch kontinuierlich - bloß durch das Rote Meer unterbrochen - das vergleichsweise winzige südwestarabische Verbreitungsgebiet der Hüttenarchitektur an. Schon diese Größenordnungen und Kontinuitäten lassen eine Negierung der dritten Möglichkeit kaum zu. Überdies kann die Sozialstruktur der Hijāaz-Tihāma am Beispiel der freien Handwerker und der ehemaligen Sklaven afrikanischer Herkunft auf die letzten Phasen einer kontinuierlichen, wechselseitigen Beeinflussung verweisen, in deren Verlauf auch afrikanische Kulturelemente an die arabische Küste gelangt sind.

Die „prototypischen“ ' ushash-Formen der Tihāma sind nicht nur das Ergebnis ökologischer, klimatischer und konstruktiver Notwendigkeiten in einem gegebenen, sozialen und lokalen Kontext. Schon die Diskussion der Längshütte hat gezeigt, daß man in der lokalen Architektur aus kulturellen und sozialen Erfordernissen heraus bereit ist, bestimmte klimatische Nachteile in Kauf zu nehmen. Im Fall der Längshütte ist es das stilistische Vorbild der vierkantigen Form und das Gebot der Geschlechtersegregation, dessentwegen man die weitaus geringere Luftzirkulation in Kauf nimmt. Kulturelle und soziale Kräfte wählen also nicht nur aus den vorhandenen ökologischen und technischen Alternativen aus; sie können sich auch über manche ihrer Zwänge bis zu einem gewissen Grad hinwegsetzen.

Im Prinzip könnte die prototypische 'ushsha der Tihāma mit denselben Materialien und technischen Mitteln auch auf ganz andere Weise konstruiert werden. Eine verbreitete afrikanische Rundform mit Kegeldach etwa hat stets einen Durchmesser, der wesentlich größer ist als ihre Höhe. ${ }^{149}$ Diese Form hat den leichten Nachteil von etwas verminderter Luftzirkulation nach oben, aber dafür den Vorteil größerer Innenräume bei Wahrung der zylindrischen Wandform.

Diese, oder andere theoretisch denkbare und praktikable Formen treten in der Tihāma nicht auf, obwohl sie technisch und ökologisch ebenso sinnvoll wären wie etwa die Hütte mit rechteckigem Grundriß.

Die gegebenen 'ushash-Formen der Tihāma implizieren also nicht nur bedeutende ökologische und technische Notwendigkeiten, sondern auch kulturelle - hier stilistische und ästhetische - Faktoren. Unter den sinnvollen, ökologischen und technischen Alternativen hat die kulturelle Tradition in der Tihāma ausgerechnet jenen Prototyp ausgewählt, der auch innerhalb der gesamten, weiten Vielfalt afrikanischer Hüttenformen gerade im gegenüberliegenden Ostafrika besonders ausgeprägt ist.

148 siehe Abschnitt 2, Anm. 65.

149 In Ostafrika ist diese Hüttenform etwa für die Architektur der Kikuyu typisch; cf. Andersen 1978: 76, 80-86. 
Die zusammengesetzte Hütte mit Kegeldach ist für die sudanesische Küste und Eritrea nachgewiesen, ${ }^{150}$ und weiters für die Dörfer der Pokot in Kenia und viele Siedlungen der Galla. ${ }^{151}$ Die Bienenkorbhütte ist für die sudanesischen Dinka, die Dorze und Sidamo in Äthiopien und die Kamba in Kenia belegt. Sie hat ihre „main area of concentration on the upper basins of the Blue and White Niles und an der periphery of Lake Ngaw$z a$ “. .152

In diesem Zusammenhang ist die Tatsache immerhin bemerkenswert, daß die weitverbreitete Dominanz der zusammengesetzten Rundhütte mit hohem Kegeldach in der traditionellen Architektur Ostafrikas bei manchen - aber nicht bei allen - Völkern mit einer besonderen Bedeutung des Mittelpfeilers einhergeht: Bei einigen „hamitischen “ Gruppen, insbesondere den Galla und den ihnen kulturell nahestehenden Hadiya und Nandi hat dieser hohe Mittelpfeiler sakrale Bedeutung und markiert die Stelle von Opferhandlungen. ${ }^{153}$

Und schließlich sei an den auffälligen Umstand erinnert, daß die halbnomadischen Gruppen der Hijāā-Tihāma keine Zelte verwenden - im Unterschied zu den noch existierenden Halbnomaden und Nomaden am Ostrand der Sarāt und vor allem in Innerarabien - sondern Kuppeldachhütten. Der kulturelle Gehalt dieses Faktums wird ebenfalls deutlich, wenn man berücksichtigt, daß halbnomadische Gruppen Ostafrikas, wie etwa bestimmte Einheiten der Galla, ganz ähnliche Hütten bauen. ${ }^{54}$

Alle drei Variationen von Rundhütten der Tihāma sind also in weitaus größerer Dichte und Häufigkeit auch in Ostafrika vertreten - und zwar dort keineswegs nur unter den ähnlichen klimatisch-ökologischen Bedingungen der Küste am Roten Meer, sondern darüber hinaus auch in vielen anderen Regionen.

Diese Argumente und Belege erlauben meines Erachtens die folgende Schlußfolgerung: Die prototypische, runde 'ushash-Form der Tihäma ist ein seit langem etabliertes, afrikanisches Kulturelement an der arabischen Küste, das im Zuge der kontinuierlichen Wechselbeziehungen über das Rote Meer hinweg übernommen wurde und hier zu eigenständigen Variationsformen weiter entwickelt wurde. Als eigenständige Architekturform ist dies ein materielles Zeichen der spezifischen, marginalen Identität der Tihäma-Bewohner geworden. Arabien hat Afrika also nicht nur sehr viel gegeben, sondern auch von dort empfangen.

Aus diesen Darlegungen und den wenigen Erwähnungen von Reisenden lassen sich zum Abschluß noch einige historische Schlußfolgerungen zur 'ushash-Architektur ziehen.

150 Denyer 1978: 23, 132.

151 Andersen 1978: 14, 55. In den 30er Jahren des 19. Jh. berichten Combes und Tamisier (1838, IV: 38, 43) für den Tihāma-Abschnitt südlich von Ḥalī von der großen Anzahl schwarzer Sklaven, darunter von Galla-Sklaven. Da die Autoren auch das Galla-Gebiet selbst kennen, ist an dieser Aussage nicht zu zweifeln. Daraus kann sicher nicht auf eine exklusive und ursächliche Verwandtschaft zwischen den Hütten der ostafrikanischen Galla und den prototypischen Tihāma-'ushash Südwestarabiens geschlossen werden, zumal letztere schon lange vor dem frühen 19. Jh. in der Tihāma existierten. Der Hinweis von Combes und Tamisier stellt aber für eine relativ rezente Periode eindeutig klar, daß diese erzwungene Form von afrikanischen „Einflüssen“ unter anderem solche einschloß, die direkt aus Ostafrika und speziell dem Gebiet der Galla stammten.

152 Denyer 1978: 167.

153 Bereits P. W. Schmidt (1940: 967 und 1937, VII: 53, 85, 167, 449, 590 f.) hat aufgrund der älteren ethnographischen Literatur auf diesen systematischen Zusammenhang hingewiesen.

154 Andersen 1978: 36. 
Generell kann über das Verbreitungsgebiet der 'ushash-Architektur in der Tihāma zunächst gesagt werden, daß es im 19. und 20. Jh. zunehmend eingeschränkt worden ist und davor größere Teile der Küstenebene umfaßte als heute. Dies ist bedingt durch die Ausbreitung des Küstenstils im 19. und beginnenden 20. Jh., und durch das Vordringen der modernen Stadtbauweise in der zweiten Hälfte des 20. Jh. Das Beispiel des Küstenstils in al-Qunfudha hat belegt, wie hoch der Anteil der 'ushash-Architektur in diesem Ort noch Ende des 18. und Anfang des 19. Jh. war. Ebenso wird für Jīzān in der zweiten Hälfte des 18. Jh. berichtet, daß seine Häuser „aus Stroh und Schlamm“ errichtet sind; ${ }^{155}$ noch in den 20er Jahren dieses Jahrhunderts wohnten die meisten Einwohner von Jīzān in 'ushash. ${ }^{156}$ Auch die Städte und Garnisonsmärkte im Landesinneren bestanden im 19. und beginnenden 20. Jh. noch größtenteils aus 'ushash. ${ }^{157}$

Die Ausdehnung von Staats- und Stadtkultur hat in den letzten beiden Jahrhunderten die 'ushash-Architektur also teilweise von der Küste und den größeren Zentren im Landesinneren abgedrängt. Dieser Abdrängungsprozeß ist ein Ergebnis jener größeren städtischen Dynamik ab dem frühen 19. Jh., auf die bei der Analyse des Küstenstils verwiesen wurde.

Zweitens ergibt der interpretierte Zusammenhang zwischen Längshütten und Stadtkultur, daß auch die heutige Verbreitung dieser besonderen Variationsform auf eine rezentere Entwicklung zurückgeht. Das Längshaus mit seiner stilistischen und raumfunktionalen Anpassung an die feste Bauweise des Küstenstils wäre demnach als historisch etwas jüngere Reaktion der 'ushash-Architektur auf das Vordringen des Küstenstils zu verstehen. Philby erhielt in den 30er Jahren parallele Informationen, wonach in Jīzān früher die Bienenkorbhütten vorherrschend gewesen seien. ${ }^{158}$

Dies läßt auf eine zweiphasige, rezente Entwicklung der 'ushash-Architektur schlieBen, die zunächst ihre schrittweise Abdrängung von den Zentren an der Küste und im Binnenland der Küste einleitet, und als Reaktion darauf im verbleibenden Verbreitungsgebiet die Ausdehnung der Längshütte in Stadtnähe hervorbringt.

Zugleich muß hier an den Beharrungsfaktor erinnert werden, der für die Mehrheit der 'ushash-Formen im Gegensatz zur Dynamik des Küstenstils aus den Reiseberichten des späten 18. und frühen 19. Jh. abgeleitet wurde. Abdrängung durch, und sekundäre Anpassung an den Küstenstil gingen also einher mit Faktoren von architekturhistorischer Konstanz, durch welche die anderen, älteren Formen gleichzeitig bewahrt wurden.

Unter den verbleibenden Formen erscheint mir die quadratische Hütte etwas zu disfunktional und zu sehr an spezielle Voraussetzungen (den hohen Aufwand an Baumaterial) gebunden zu sein, um auf große historische Tiefe zurückblicken zu können. Die Kuppeldach-Hütte wiederum ist eine marginale Form, die hier eindeutig dem Halbnomadismus zugeordnet werden konnte. Damit aber handelt es sich um einen abgeleiteten und rezenteren Komplex, der auf älteren agrarischen Formen aufbaut und diese entwicklungslogisch voraussetzt. ${ }^{159}$

155 Bruce 1790-91: 352.

156 Forbes 1923: 271 f.; Weisl 1927: 257.

157 Thesiger 1947: 197; Tamisier 1840, I: 385-387.

158 Philby 1952: 476; ein früher Beleg für die Längshütte liegt Anfang des 19. Jh. durch Rüppel 1838: 177 für al-Qunfudha vor.

159 Diese Interpretation steht somit im Gegensatz zu Schmidt 1940: 967. 
Als jene beiden Typen, die weder disfunktionale und lokalspezifische Eigenschaften haben, noch von semiurbanen oder halbnomadischen Bezügen geprägt sind, verbleiben also die Bienenkorbhütte und die zusammengesetzte Rundhütte. Sie sind in der saudischen Tihāma deutlich mit agrarischer Subsistenz assoziiert und sie finden in den bisher zitierten historischen Quellen die häufigste Erwähnung.

Sie werden bereits vor etwa 500 Jahren zu Anfang des 16. Jh. von Lodovico di Varthema für Jīzān erwähnt, das schon zu seiner Zeit hauptsächlich aus runden Korbhütten in Pyramidenform errichtet war, ${ }^{160}$ und im Toponym Abu ' 'Arish ist zumindest der Name der charakteristischen Hofanlage, die im Süden mehrere solcher Hütten zusammenfaßt, lokal seit dem 13. Jh. nachgewiesen. ${ }^{161}$ Trotzdem diese bescheidenen Hütten in den von mir konsultierten älteren arabischen Quellen nicht ausdrücklich Erwähnung finden, erlaubt dies und Varthema's Hinweis am Beginn der Neuzeit die begründete Vermutung, daß diese Formen bereits im Mittelalter - und wohl noch viel früher - die Kulturlandschaft der Arabischen Küste vor Afrika geprägt haben.

\subsection{LEHMARCHITEKTUR AM RANDE DES NAJD}

Schon in den beiden vorangegangenen Abschnitten wurde die volkstümliche Architektur nach Kriterien differenziert, die nicht primär das Baumaterial berücksichtigt haben sondern auch die Verbreitung, und die vor allem von Stil- und Konstruktionselementen ausgingen. Die Identifizierung des „Küstenstils“ bezog Baumaterial (Korallenstein und Ziegel), Konstruktionselemente (Luftzirkulation, Stützpfeiler, fallweiser Hochbau) und Verbreitung (größere Hafenorte, Märkte und Städte der Küstenebene) als Kriterien heran. Ebensowenig reicht das vegetabile Baumaterial als Kriterium zur Charakterisierung der 'ushash-Architektur; auch hier müssen Konstruktionselemente (ebenerdig, aufstrebendes Dach), typische Formen (Grundriß, Materialverbindung) und hauptsächliche Verbreitungsgebiete zur Bestimmung herangezogen werden.

Die Notwendigkeit einer Kombination von mehreren grundlegenden Kriterien stellt sich noch deutlicher im nun folgenden Abschnitt. Dafür verlassen wir den Naturraum der Tihāma, der das Berg- und Hochland von Westen her begrenzt, und wenden uns den Randgebieten des Hijāz und 'Asīr im Osten zu. Diese östlichen, flachen Ausläufer des südwestarabischen Berglandes stellen das Übergangsgebiet zum innerarabischen Tafel- und Steppenland dar, dem Najd: Diese Ostabhänge des Berglandes gehen also über in den Südwestrand Innerarabiens. In diesem Randgebiet des Najd fanden nur wenige Erhebungen zum Studium der jeweiligen Verbreitungsgebiete von Architekturformen statt. Soweit hier auch die 'ushash-Architektur vertreten ist, wurde diese bereits im vorigen Abschnitt erörtert. Der folgende, kurze Abschnitt hat sich also nur mit den peripheren Ausprägungen eines anderen Architekturtypus zu befassen, dessen zentrales Verbreitungsgebiet im Nordosten liegt: Die traditionellen Bauten der östlichen Steppen- und Oasengebiete sind geprägt von der Lehmarchitektur des Najd.

160 di Varthema 1888: 61.

161 Beckingham 1960: 106. 
Im Unterschied zu Abdulfattah, aber in Übereinstimmung mit Philby und Lewcock ${ }^{162}$ erscheint es mir notwendig, die Lehmarchitektur des Najd klar von anderen südwestarabischen Bauweisen in Lehm zu unterscheiden. In den östlichen Randgebieten des Hijāāz und des nördlichen 'Asīr gehen die Verbreitungsgebiete der tribalen Steinarchitektur meist direkt in jene der Lehmbauweise des Najd über. Am Ostrand des zentralen und südlichen 'Asīr, und südöstlich davon im Nahbereich der Oase Najrān stoßen die Ausläufer der Najd-Architektur hingegen auf andere Formen von Lehmarchitektur.

Diese Lehmarchitektur von Najrān und Ost- ${ }^{\top}$ Asīr wird nochmals im fünften Abschnitt zu behandeln sein. Hier geht es nur darum, ihre Gemeinsamkeiten und Unterschiede zu jener des Najd festzustellen. Dabei zeigt sich, daß die beiden Kriterien von Konstruktion und Verbreitung in diesem Fall die Unterschiede markieren, während das Kriterium des Baumaterials eine der Gemeinsamkeiten zwischen den beiden Architekturformen anzeigt. Unterschieden wird hier also zwischen dem Großtypus der Najd-Architektur einerseits, deren marginale Südwestvariante hier zentrales Thema ist, und andererseits den Lehmbauten von Najrān als einem Subtypus der südwestarabischen Hochbauweise.

Zunächst sind beide „Stile“ angepaßt an die heiße, trockene Umwelt des östlichen Tafellandes. In beiden Fällen ist ein gestampftes Lehmgemisch das zentrale Baumaterial, das in Form von Ziegeln oder in Adobe-Technik, also mittels regelmäßig übereinander geschichteter Wulste über einem niedrigen Steinfundament, zu Wänden hochgezogen wird (Abb. 56); beiden „Stilen“ gemeinsam ist ferner das Flachdach über rechteckigem Grundriß.

Das Gemisch aus Lehm, Häcksel, Tiermist und Wasser ist (gegenüber Stein und Vegetabilien) nicht nur das etwas leichter verfügbare Baumaterial; Lehm „arbeitet“ mit den stärkeren Tag-Nacht-Schwankungen der Temperatur im Osten auch besser mit als etwa Stein. ${ }^{163}$ Allerdings ist er weniger widerstandsfähig gegenüber den seltenen, aber heftigen Regen und Fluten, die im südwestlichen Übergangsgebiet zum Bergland häufiger als im zentralen Innerarabien auftreten. Wie noch zu zeigen sein wird, ist die Präferenz für Lehm daher nicht überall in dieser Region eindeutig gewesen.

Die adobe-Technik ist in der ländlichen Architektur beider "Stile“ die absolut dominante Form. Im Najd-Stil trifft man darüber hinaus in der ländlichen Architektur häufig Häuser aus Lehmziegeln an, die nicht nur von Personen mit hohem Status genutzt werden. Derartige Häuser aus Lehmziegel scheinen hingegen im traditionellen, ländlichen Lehmstil von Najrān und dem östlichen 'Asīr völlig zu fehlen. ${ }^{164}$ Ferner sind beide Architekturformen auf ähnliche Weise eingegliedert in die Gesamtanlage der jeweiligen Oasen (Taf. XXXVIII): Die kleineren und größeren Siedlungen sind durchzogen und umgeben

162 Abdulfattah 1981: 96 f. spricht zwar im Text nur von „mud tower houses“ (und daher nicht von NajdArchitektur); seine Karte 6 faßt aber beide Formen undifferenziert unter einem Signum zusammen. Lewcock 1976: 18 führt diesbezüglich bereits für den Jemen eine deutlichere Differenzierung zwischen der Lehmarchitektur der „eastern desert zone " und jener des Hochlandes ein, obwohl diese Unterschiede im jemenitischen Osten nicht allzu ausgeprägt sind und dort keineswegs von Ausläufern des Najd-Stils berührt werden. Mit umso größerer Berechtigung ist diese Unterscheidung daher für die Architektur des saudischen Südwestens anzuwenden. Im Prinzip wurde dies bereits von Philby 1952: 130 gemacht: "So far as we are concerned on this journey Bisha was the last representative of the northern culture, though the market scene there, as I have suggested, had a recognisable tinge of the southern manner. Khamis Mushait was certainly the first of the 'Yamani' settlements in our path."

163 King 1986: 116.

164 Minosa 1983: passim; Philby 1952: 213-319, 224 (fig. 17), 321 (fig. 28). 
von Palmenhainen, die Sand abfangen und Schatten spenden. Die Einzelhäuser sind relativ nahe beieinander stehend so errichtet, daß für die dazwischen liegenden Gassen die Schattenwirkung der Wände ausgenutzt wird und die Sonneneinstrahlung minimiert werden kann. ${ }^{165}$ Kurzum, die Anlage der Lehmarchitektur ist in beiden Formen zusammen mit den Palmenoasen ausgerichtet auf die Schaffung eines stabilen, kühleren Mikroklimas.

Ausnahmen von dieser Oasen-Anlage gibt es in beiden Formen. Für den südwestlichen Bereich des Najd-Typus sind etwa für das Gebiet um Najī‘ a im W. Bīsha freistehende, bewehrte Einzelhöfe belegt, ${ }^{166}$ und auch im Ost-'Asīr um Khamīs Mushayt sind traditionelle Lehmgebäude fallweise als Einzelhöfe außerhalb der größeren Oasen errichtet. ${ }^{167}$ An diesen Einzelbauten fallen die Unterschiede zwischen beiden Formen bereits aus der Ferne klar auf; ansonsten bieten sie dem Näherkommenden zunächst ein ähnliches Bild - das von eng beieinander stehenden Lehmgebäuden inmitten von Oasenhainen.

Das offenkundigste, erste Kriterium der Unterscheidung zwischen dem Najd-Typus und der südwestarabischen Lehmbauweise ist bereits genannt - nämlich das ihrer regionalen Verbreitung. Die beiden Bauformen treten nur ganz selten gemeinsam in ein und derselben Siedlung oder Oase auf, normalerweise gehört ein ganzes Wādī entweder der einen oder der anderen „Stilrichtung“ an, und diese bilden darüber hinaus große, in sich zusammenhängende Zonen. Von Nordosten kommend, erstreckt sich das Verbreitungsgebiet der Najd-Architektur in seinem Südwesten also bis knapp nördlich von Khamīs Mushayț. Rund um diese letztgenannte Siedlung beginnt dann die Verbreitungszone der südwestarabischen Lehmbauweise, die sich nach Südosten hin von Oase zu Oase inselartig bis weit in das W. Najrān hinein fortsetzt und eine Variante der 'Asīr-Architektur darstellt.

Vor diesem Hintergrund lassen sich nun die wesentlichen konstruktiven Unterschiede zwischen der „südwestarabischen“ und der „innerarabischen“ Lehmarchitektur zusammenfassen.

Die innerarabische Lehmbauweise des Najd-Typus ist hier, in ihren ländlichem, südwestlichem Randgebiet, eindeutig geprägt von ebenerdigen, eingeschoßigen Bauten. ${ }^{168}$ Das Dach ist häufig auf Querbalken durch gitterartiges Geflecht von Palmzweigen abgedeckt, dem die Lehmschicht aufgetragen ist. Typisch sind außerdem die kleinen, dreiekkigen Fensteröffnungen in den Wänden (țāqa) und weiters die völlige Abwesenheit von Lehmbemalung oder Lehmdekor. Nicht selten ist an das Najd-Haus an einer oder zwei Seiten ein Hof angeschlossen, der ansonsten von einer hohen Lehmmauer umgeben ist.

Demgegenüber ist die südwestarabische Lehmbauweise durch die Dominanz von mehrgeschoßigen, hohen Bauten charakterisiert. Die Decken und Dächer müssen dementsprechend stabiler sein und sind aus Balken und festem Holz errichtet, deren größeres Gewicht durch tragende Innenwände aus Stein und Lehm, sowie im obersten Geschoß manchmal durch Holzpfeiler abgestützt wird. Rund um die tragende Innenwand führt in der Regel eine schmale Treppe nach oben. Die innerarabischen Steinsäulen sind hier also nicht vertreten. Die Außenwände des obersten Geschoßes haben viereckige Fensteröffnungen, darunter befinden sich hingegen nur schmale Schießscharten (burj/burūj). Auch

165 Talib 1984: 45-48.

166 Philby 1952: 32.

167 Dostal 1983c: 30-32, illustr. VII; Abdulfattah 1986: $96 \mathrm{f}$.

168 cf. Philby 1952: 37. 
die Dachterrasse kann zur Verteidigung genutzt werden, da die Außenwände sie als hohe Brüstung überragen. Außenhöfe sind in der südwestarabischen Lehmarchitektur Saudi Arabiens hingegen relativ selten. Diese Form ist jedoch durch üppigen Dekor in Lehmformen und Farben gekennzeichnet.

Diese charakteristischen Unterschiede zwischen südwestarabischer und innerarabischer Lehmbauweise sind in Tab. 10 nochmals zusammengestellt. Die südwestarabische Lehmbauweise kann daher als eine dekorreiche, mehrgeschoßige Wehrarchitektur bezeichnet werden. Trotz anderer Baumaterialien entsprechen diese konstruktiven Eigenschaften weitgehend der ansonsten vom Steinmaterial geprägten Bauweise des tribalen südwestarabischen Hochlandes, weshalb sie jenem Zusammenhang und Typus zuzuordnen ist. Die innerarabische Lehmbauweise ist hingegen als ebenerdige, dekorarme und karge Oasenarchitektur anzusprechen.

Tab. 10: Unterschiede zwischen innerarabischer und südwestarabischer Lehmbauweise

\begin{tabular}{|c|c|c|}
\hline Bauweise & $\begin{array}{l}\text { Innerarabische Lehmbauweise } \\
\text { (Südwestrand des Najd) }\end{array}$ & $\begin{array}{l}\text { Südwestarabische Lehmbauweise } \\
\text { (Ost-'Asīr und W. Najrān) }\end{array}$ \\
\hline $\begin{array}{l}\text { Geschoße } \\
\text { Dach und Stützung } \\
\text { Fensteröffnungen } \\
\text { Dekor } \\
\text { ummauerter Außenhof }\end{array}$ & $\begin{array}{l}\text { dominant erdgeschoßig } \\
\text { fragiles Dach und Steinsäulen, } \\
\text { Holzpfeiler } \\
\text { dreieckig } \\
\text { kaum Lehmdekor } \\
\text { häufig }\end{array}$ & $\begin{array}{l}\text { dominant mehrgeschoßig } \\
\text { feste Decken und befestigte } \\
\text { Dächer, tragende Innenwände } \\
\text { viereckig, Schießscharten } \\
\text { üppiger Lehmdekor } \\
\text { selten }\end{array}$ \\
\hline
\end{tabular}

Als Beispiel der innerarabischen Lehmbauweise kann hier die Architektur von al'Aqīq im Osten der heutigen Provinz al-Bāḥa näher dokumentiert werden (Taf. XXXIX, Abb. 56). Sie präsentiert alle Elemente der ländlichen Najd-Architektur mit ihrer typischen, kargen Schlichtheit.

Auffällig ist dabei bloß, daß die Termini für Herdstelle und Steinsäule jenen entsprechen, welche im benachbarten Hijāz für die dortigen, ganz anders gearteten Kocheinrichtungen und hölzernen Stützpfeiler verwendet werden; auch die Funktion und Bezeichnung der hölzernen Trennwand entspricht ähnlichen Formen im südlichen Hijāaz. Dies verweist auf die Tatsache, daß al- ${ }^{\circ}$ Aqīq mehrheitlich vom tribalen Verband der Ghāmid besiedelt wird, ebenso wie Teile des südlichen Hijāz. Die Grenzen der tribalen Siedlungsgebiete stimmen also nicht, jedenfalls nicht immer, mit jenen der Verbreitungsgebiete von Architekturformen überein: Ghamīd-Gruppen leben sowohl im südlichen Hijāz wie auch in der östlichen Oase al- ${ }^{` A q} \mathbf{1} q$; aber im Hijāz ist die tribale Steinarchitektur vorherrschend, während al-'Aqīq zum westlichsten Verbreitungsgebiet der innerarabischen Lehmbauweise zählt.

Aber auch im Hinblick auf die Geschichte dieser architektonischen „Stilzonen“ bietet al-`Aqīq bemerkenswerte Einblicke. Die heute (1982) gegebene Diskongruenz zwischen tribalem Siedlungsgebiet und architektonischem Stil hat nämlich ihrerseits markante historische Transformationen durchlaufen.

Unweit der heutigen Lehmhäuser von al-'Aqīq befinden sich außerhalb der Siedlung, auf einigen heute unbewohnten Anhöhen nördlich des Ortsteiles Jarrāb, die verfallenen Reste von Steinbauten (Abb. 57, Taf. XL). Diese Ruinen belegen frühere, ebenerdige wie mehrgeschoßige Wohnhäuser mit ebenerdigem Stall, dicken Außenwänden und innen 
teils leichten Trennwänden, teils tragenden Stützwänden. Konstruktion und Lage dieser Ruinen entsprechen also explizit der tribalen Steinarchitektur des Hijāz. Während die heutige Lehmarchitektur in den feuchteren Mulden angelegt ist, wo die Palmen gedeihen, thront die ältere Steinarchitektur auf den Kuppen und überblickt die Reste von verödeten Feldern darunter. ${ }^{169}$ Die lokale Überlieferung in al-'Aqīq schreibt diese Ruinen den B. Ḥalsān zu, einer Untergruppe der B. Șīd. Diese Ghāmid-Gruppe habe „bis vor 15 Jahren“ (also bis Mitte der 60er Jahre) jenen Teil von al-'Aqīq besiedelt, der al-Rawḍa (der Garten) geheißen habe.

Die heutige tribale Mehrheitsbevölkerung von al- ${ }^{`} A q \overline{1} q$ setzt sich aus den tribalen Gruppen der Hajāhija, 'Ubaydāt, und vor allem aus den Rifā'a der Ghāmid zusammen. Diese Rifāca hätten nach eigener Überlieferung die B. Halṣān vertrieben, mit denen sie davor zusammengelebt hätten. Die Rifāca seien die ältere Siedlungsgruppe gewesen; damals habe es in al-'Aqīq keine Lehmbauten gegeben. Die Rifā'a bezeichnen sich selbst als ehemalige Beduinen, die noch vor zwei Generationen „in schwarzen Zelten“ gelebt hätten. Vor der endgültigen Errichtung des saudischen Staates in dieser Region hätten die Rifāca zwar Felder und Gärten in al-'Aqīq besessen, aber sie selbst hätten nomadische Viehzucht betrieben. Ihre Gärten und Felder seien von den noch heute ansässigen „'abīd“ bestellt worden, also von „Sklaven“ afrikanischer Herkunft, die dafür Ernteanteile erhielten. Diese „Sklaven“ nennen sich selbst „Freigelassene“ ('atīg/'ataqa), was auch ihrem tatsächlichen heutigen Status entspricht. Sie sind die Bewohner der erwähnten 'ushash-Architektur in den östlichen Oasen. Teilweise stehen sie noch heute in abhängigem Pächterverhältnis zu ansässigen oder „absentée“ Rifā'a, teils bearbeiten sie bereits ihre eigenen Felder. Die heutigen Lehmbauten der Rifā'a gäbe es erst, seit sie selbst in al-`Aqīq seßhaft geworden seien, also seit zwei Generationen.

Auf engstem Raum nebeneinander treten daher in diesem ökologischen und sozialen Übergangsgebiet am Ostrand des Berglandes drei verschiedene Hausformen auf, die durch unterschiedliche Baumaterialien mitcharakterisiert sind: Die verfallenen Steinbauten einer abgedrängten tribalen Gruppe, die Lehmbauten der Najd-Architektur und die 'ushash der Freigelassenen aus vegetabilem Material.

Dieses Nebeneinander unterschiedlicher Baumaterialien und Konstruktionsweisen läßt zunächst bestimmte Schlußfolgerungen bezüglich des lokalen Wechselverhältnisses zwischen Architektur und natürlicher Umwelt zu.

Für die 'ushash können jene Ergebnisse bestätigt werden, welche ihre Analyse für die Tihāma bereits ergeben hat. Die Stämme und Zweige der Palmen und andere Bäume sind ein leicht verfügbares, lokales Material, das ohne großen Aufwand zum Bau der Hütten herangezogen werden kann. Der abhängige und niedrige Status der ‘abīd und 'ataqa auf der untersten Stufe der sozialen Hierarchie gibt ihnen kaum Möglichkeiten zum eigenständigen Einsatz von anderen, aufwendigeren Baumaterialien. Wie in der Tihāma, so

${ }^{169}$ Diese Ruinen stammen von bäuerlichen Wohnhäusern, sind also nicht ident mit dem zerfallenen Fort, das Tamisier 1834 hier sah und als quadratischen, massiven Turm auf der Kuppe einer Anhöhe nordwestlich der Siedlung beschrieb (Tamisier 1840, II: $67 \mathrm{f}$.). Davon unabhängig erwähnt Tamisier auch bewohnte Steinhäuser im al-'Aqīq seiner Zeit. 1982 konnte ich aber keine Spuren der Ruine jenes Forts ausmachen. Falls Tamisier hier nicht einen verfallenen bäuerlichen Wehrturm mit einem staatlichen Fort verwechselte, würde dies einen - durchaus möglichen - älteren Militärposten an jener Nord-Süd-Route anzeigen, die an al-'Aqīq vorbeiführt. 
werden hier diese - auch nach lokaler Eigen- und Fremdzuschreibung - „afrikanischen“ Formen von den durchwegs dunkelhäutigen ehemaligen Sklaven errichtet. Im heiß-trokkenen Klima am Najd-Rand kommen alle Vorteile, welche die Hütten auch in der Tihāma auszeichnen, zum Zug; allerdings bieten sie hier kaum Schutz vor den stärkeren Sandwinden.

In bezug auf die Stein- und Lehmarchitektur ist es ganz offensichtlich, daß die südwestlichen Übergangsgebiete des Najd keine eindeutig ökologisch bedingten Präferenzen für das eine oder andere Baumaterial nahelegen. Zu verschiedenen Perioden ist dem einen oder dem anderen Material der Vorzug gegeben worden, und zwar aus anderen als ökologischen Gründen. Dies gilt im übrigen nicht nur für die rezente Volksarchitektur von al-'Aqīq; auch die bedeutenden alt-südarabischen Fundorte von Qaryat al-Faw am Südrand des J. Thuwayq und von al-Ukhdūd im W. Najrān verweisen nachdrücklich auf die Existenz alter Steinarchitektur in denselben Orten, an denen sich dann in neuerer Zeit Lehmarchitektur durchsetzte. ${ }^{170}$

Die beiden letztgenannten Beispiele unterstreichen, daß die Steinarchitektur in Südwestarabien eine alte, in der Antike verwurzelte Geschichte und Tradition hat. Reste alter Lehmarchitektur sind materialbedingt seltener nachweisbar. Diese Beispiele belegen aber neben dem bescheidenen lokalen Fallbeispiel von al-'Aqīq, daß der Vorzug für das eine oder andere Baumaterial in dieser Übergangsregion durch eine Vielfalt von ökonomischen, politisch-militärischen und kulturellen Faktoren mitgeprägt ist.

Zunächst ist der historische Hintergrund der dritten Hausform von al-`Aqīq zu diskutieren, nämlich der 'ushsha. Die orale Überlieferung nennt sie ausdrücklich älter als die heutige Lehmbauweise, für das 19. Jh. ist sie in al-`Aqīq jedoch durch keine anderen Quellen belegt. Die soziale Existenz von 'abīd und 'ataqa ist für diese Zeit allerdings bestätigt, obgleich die unscheinbaren Hütten dabei in Beschreibungen für diese Region nicht ausdrücklich angesprochen werden. ${ }^{171}$ Tamisier erwähnt für 1834 bloß die freien und versklavten Schwarzen, die sich nach Mekka-Pilgerfahrten hier niedergelassen hätten und als einzige nicht vor der fremden Armee geflüchtet seien, sondern den Besitz ihrer Herren hüteten. Das Übergangsgebiet zum Najd war bis weit in das 20. Jh. hinein eine Region, in der Sklavenhandel und die resultierende Ansiedlung von Sklaven und Freigelassenen noch durchaus üblich waren. Philby beschreibt Bīsha für die dreißiger Jahre als Garnisonsstützpunkt, der darüber hinaus vom Handel mit Sklaven und mit jemenitischem Kaffee profitierte. ${ }^{172} \mathrm{Im}$ W. Bīsha verweist er auf zahlreiche Agrargebiete, whose tenants are „almost exclusively“ „freedmen of Negro origin“, während die Einwohner „mostly absentee Badawin landlords " seien. ${ }^{173}$

Dasselbe soziale Muster, auf das die orale Überlieferung für al-`Aqīq verweist, wird also für das frühe 19. und 20. Jh. in derselben Region bestätigt. W. Dostal analysiert in

170 Philby 1952: 257 (fig. 23, 24); für al-Faw: eigener Besuch 1982.

171 Im Bergland leben ehemalige Sklaven in denselben Steinhäusern wie ihre tribalen Herren. Diese Koexistenz verschiedener sozialer Schichten im selben Haustypus wäre also auch für die frühere Steinbauweise am Rande des Najd denkbar - als alleinige Form oder kombiniert mit separierten 'ushash der Schwarzen.

172 Philby 1952: 37, 40.

173 ibid.: 32; Tamisier (1840, II: 105) erwähnt nebenbei, daß die Beduinen des W. Tanya die Äste von jungen Bäumen zusammenbinden. Wenn sie wachsen, würden sie als Schattenspender genutzt. 
diesem Band die entsprechenden Zusammenhänge im Detail. ${ }^{174}$ Hier genügt es daher, auf zweierlei hinzuweisen: Erstens stellt der Ostrand des Berglandes eine Hauptroute der historischen Pilger- und Handelsroute dar, die als alter „Weihrauchstraße“ dann spätestens in osmanischer Zeit dem Sklavenhandel diente. ${ }^{175}$ Und zweitens kann die Nichterwähnung der 'ushash in den zitierten Berichten auch eine Verzerrung darstellen, die dann das zahlenmäßige (auch heute bestehende) Übergewicht von Lehm- und Steinarchitektur, und die materielle und soziale Geringschätzung der Hütten ausdrücken würde.

Angesichts der nachweislichen historischen Bedeutung, die dem Sklavenhandel und der sozialen Existenz von Freigelassenen und Sklaven in dieser Region zukam, halte ich es eher für wahrscheinlich, daß die Angehörigen dieser Gruppe schon lange vor dem 20. Jh. auch in 'ushash gelebt haben - wie es die lokale Überlieferung für al-'Aqīq dezidiert besagt.

Damit können wir uns von der 'ushash als bescheidener Begleiterscheinung der anderen Hausformen abwenden, und uns der historischen „Pendelbewegung“ der beiden architektonischen Hauptformen zuwenden.

Die oralen und materiellen Testimonia aus al- ${ }^{c}$ Aqīi ergeben wichtige Hinweise auf die ländliche Architekturgeschichte des östlichen Übergangsgebietes zum Najd hin. Diese werden auch durch die wenigen anderen historischen Quellen zur Region bestätigt. In der ersten Hälfte des 19. Jh. hielt sich Maurice Tamisier mit der türkisch-ägyptischen Armee etwas über eine Woche in al-'Aqīq auf (9.-17. 7. 1834). In seinem Bericht wird al-'Aqīq als Siedlung erwähnt, die halb aus Stein und halb aus Ziegeln gebaut sei. Die etwa 30 Häuser seien in Würfelform und oft mehrgeschoßig errichtet. ${ }^{176}$

Ausdrücklich bestätigen diese Angaben für die erste Hälfte des 19. Jh. die Existenz von Steinarchitektur in dieser Region; welche Art von „Ziegel“ (briques) gemeint ist, bleibt zwar offen, mit einiger Wahrscheinlichkeit dürfen aber auch für die damalige Zeit Lehmziegel angenommen werden. Unter dieser Voraussetzung bestand bereits 1834 ein gleichzeitiges Nebeneinander von tribaler Steinarchitektur und innerarabischer Lehmbauweise. Für die ersten Jahrzehnte des 20. Jh. („vor zwei Generationen“, also etwa 60 bis 70 Jahre vor 1982) belegt dann die orale Überlieferung, daß in al-'Aqīq zunächst nur Steinbauten bestanden; die früheren Lehmbauten (der ersten Hälfte des 19. Jh.) müßten demnach in der 2. Hälfte des 19. Jh. aufgegeben worden und verfallen sein. Mit der Niederlassung der $\operatorname{Rif}^{c}{ }^{c} a$ (in den ersten Jahrzehnten des 20. Jh.) setzt zunächst eine neuerliche Periode der Koexistenz von Steinbauten (B. Ḥalsān) und Lehmbauten (Rifāáa) ein, bis die B. Ḥalsān in den $60 \mathrm{er}$ Jahren des 20 . Jh. vertrieben werden und ihre Steinbauten verfallen. Die heutigen Lehmbauten setzen sich schließlich durch. Wenn sich diese Rekonstruktion weiter bestätigen ließe, so würde sie für das 19. und 20. Jh. ein periodisches Oszillieren anzeigen zwischen Phasen der Koexistenz beider Bauweisen (jeweils in den ersten Hälften des 19. und des 20. Jh.) einerseits, und andererseits der Dominanz von einmal Stein (2. Hälfte des 19. Jh.), und dann wieder von Lehm (2. Hälfte des 20. Jh.) (Tab. 11).

Betont sei der notwendigerweise vorläufige Charakter dieser Rekonstruktion, die sich nur auf drei Quellen (Tamisier's Bericht, materielle Ruinen und orale Überlieferung) stützen kann. Diese Quellen schließen allerdings zeitlich aneinander an und ergeben keine logischen Inkonsistenzen.

174 ef. den Beitrag von W. Dostal in diesem Band.

175 Groom 1981: 165-213; Toledano 1982: 10, 24; Galinier und Ferret 1843: 112.

176 Tamisier 1840, II: 61, 48-92. 
Tab. 11: Historische „Pendelbewegung“ (+ - ) und Kontinuitäten (+ umrahmt) von südwestarabischer Steinbauweise und innerarabischer Lehmbauweise in al- ${ }^{`}$ Aqīq.

\begin{tabular}{|l|c|c|l|}
\hline Sequenzen & $\begin{array}{c}\text { Südwestarabische } \\
\text { Steinbauweise }\end{array}$ & $\begin{array}{c}\text { Innerarabische } \\
\text { Lehmbauweise }\end{array}$ & Vorwiegende Form \\
\hline 1. Hälfte 19. Jh. & $|+|$ & + & Koexistenz \\
2. Hälfte 19. Jh. & $|+|$ & - & Dominanz Stein \\
1. Hälfte 20. Jh. & $|+|$ & $|+|$ & Koexistenz \\
2. Hälfte 20. Jh. & - & $|+|$ & Dominanz Lehm \\
\hline
\end{tabular}

Diese rekonstruierte „Pendelbewegung“ zwischen beiden Bauweisen scheint für das Übergangsgebiet zum Najd symptomatisch. Die Pendelbewegung impliziert zugleich eine ältere Kontinuität von Steinbauten und eine jüngere Kontinuität von Lehmbauten (Tab. 11). Zunächst soll die Pendelbewegung diskutiert werden. Die schrittweise Verdrängung der Steinbauten durch die innerarabische Lehmbauweise in al- ${ }^{c}$ Aqīq während des 20. Jh. wird anschließend erörtert.

Die „Pendelbewegung“ ist zunächst Bestandteil einer zyklischen Struktur, nämlich des oszillierenden Wechselverhältnisses zwischen nomadischen und seßhaften tribalen Gruppen in dieser Region. Auf diese permanente Wechselbeziehung wurde bereits im Zusammenhang mit den Halbnomaden der Tihāma hingewiesen. Am Rande Innerarabiens kommt diesem sozio-ökonomischen Pendelverhältnis noch größeres Gewicht zu. Im Fall der östlichen Oase von al-`Aqīq ordnet die orale Überlieferung die Steinbauten eindeutig den alteingesessenen Stammesgruppen zu, und die Reste der Siedlungsanlagen weisen diese klar als bäuerliche Verbände aus. Die Steinruinen überblicken die Reste von Getreidefeldern, Konstruktion und Anlage entsprechen den Bauerndörfern des südlichen Hijāz.

Die Rekonstruktion von vier Phasen des „Oszillierens“ hat also in al-'Aqīq zunächst eine kontinuierliche Existenz der Steinbauweise von der ersten Hälfte des 19. bis in die erste Hälfte des 20. Jh. ergeben. Es scheint mir aufgrund all dieser Indikatoren vertretbar, für diese Periode die kontinuierliche Ansäßigkeit eines ackerbäuerlichen Ghāmid-Elementes in der Bevölkerung von al- ${ }^{c}$ Aqīq abzuleiten, das in Steinbauten lebte. Diese kontinuierliche Existenz eines alteingesessenen bäuerlichen Elementes würde umgekehrt auch seine Präferenz für hochgelegene Steinbauten erklären.

Die Bearbeitung von Stein als Baumaterial stellt nicht nur eine Affinität zum tribalen Bauerntum des südlichen Hijāz dar, sie erfordert einfach ein Mindestmaß an spezialisiertem Wissen und besonderen Arbeitsgeräten. Diese praktischen, spezialisierten Fähigkeiten setzen eine entsprechende, über Generationen gewachsene Erfahrung voraus. Vor allem aber benötigen Getreidebauernhaushalte jede tiefergelegene, feuchtere Fläche für die Anlage von Feldern und weichen schon aus diesem Grund eher auf die Kuppen aus. Dort gibt es wiederum kaum Lehmböden, aber eher Steinmaterial, und weiters sind diese Standorte eher Sandwinden gegenüber exponiert, wovor die Steinhäuser besser schützen.

Die Rifā‘a bezeichnen sich selbst hingegen als ehemalige Beduinen, deren 'abīd und 'ataqa für sie nicht hauptsächlich Felder, sondern vor allem Palmgärten in al-'Aqīq bestellt hätten. Dies verlangt a priori eine weitaus geringere Notwendigkeit, tiefgelegene, feuchte Flächen einzusparen. Die Anlage von Palmen und Gärten erfordert sogar ein Netzwerk von kleineren Aussparungen an Zwischenräumen, um die Feuchtigkeitszufuhr nicht zu gefährden, was die Errichtung der Wohnhäuser in diesen „Zwischenräumen“ wiederum fördert und die Kultivierung erleichtert. Lehmböden und vegetabiles Material 
sind in diesen Mulden verfügbarer, weshalb Lehmbauweise in den tiefen Oasenmulden vorherrscht. Die Rifā'a ließen sich sinnvollerweise genau dort nieder, wo ihr Besitz war.

Damit soll keineswegs ausgesagt werden, daß die innerarabische Lehmbauweise eine typische Architektur seßhaft gewordener Beduinen darstellt. Aber das örtlich vorhandene Material für feste Bauten innerhalb der Oase war eher Lehm und Sand, und mit den 'abīd und 'ataqa verfügten die Rifā'a auch über die notwendigen Arbeitskräfte, um dieses Baumaterial nicht selbst herstellen zu müssen: Die Herstellung von Lehmziegeln ist äuBerst arbeitsintensiv, aber sie erfordert keine spezialisierten Fertigkeiten und Geräte, auBer der Benutzung von gitterartigen Ziegelformen. Diese aufwendige, aber einfache Tätigkeit konnten die Rifã'a also ihren 'abīd übertragen.

Die historische "Pendelbewegung" zwischen innerarabischer Lehm- und südwestarabischer Steinarchitektur in al- 'Aqiq erweist sich bei genauerer Analyse somit in einer bestimmten Hinsicht als materieller Ausdruck der variablen Wechselbeziehungen zwischen Nomaden und Bauern am Südwestrand des Najd. Ein Wechselspiel von ökonomischen und technischen Faktoren wirkt in diesem lokalen Fallbeispiel zusammen, und ergibt eine starke Tendenz der alteingesessenen, ackerbäuerlich-tribalen Bevölkerung für die dauerhaftere Steinarchitektur, und eine Bevorzugung der ehemals nomadischen „Oasengärtner" für die vergängliche Lehmarchitektur. Die Kontinuität der Steinarchitektur entspricht der permanenten Bewirtschaftung durch tribale Ackerbauern, - die Diskontinuitäten der Lehmarchitektur sind im hier gegebenen Lokalfall (der nicht verallgemeinert werden darf) ein Ergebnis der nomadischen Vergänglichkeit. Diese Gruppen bewegen sich historisch hin und her zwischen dem Status abwesender, nomadischer Grundeigentümer, die ihre Gärten von 'abüd bestellen lassen, der Niederlassung von Teilen dieser Nomaden, und der Vertreibung eingesessener tribalbäuerlicher Bevölkerung.

Die Pendelbewegung zwischen Koexistenz und alternierender Dominanz der einen oder anderen Bauform ist also in einer Hinsicht Ausdruck des permanenten Wechselverhältnisses von Nomaden und Seßhaften, das ein Strukturmerkmal der traditionellen Wirtschaft und Gesellschaft der Region ist. Dieses Strukturmerkmal äußert sich in immer wiederkehrenden, pendelartigen Mustern, und unterliegt insoferne einem zyklischen Rhythmus. Dieses traditionelle, lokale und zyklische Muster verläuft aber im 19. und 20. Jh. als schrittweise Ablösung einer älteren Kontinuität (Stein) durch eine jüngere (Lehm). Und diese Ablösung steht ihrerseits in einem größeren regionalen Zusammenhang, der vom schrittweisen Aufstieg Saudi Arabiens, seines ideologischen Systems und seiner politischen Dynastie gekennzeichnet ist. In diesem rezenten Zusammenhang kann von einem regionalen, dynastischen und linearen Prozeß gesprochen werden. Die vorliegende Fallstudie von al-'Aqiq führt somit zur Hypothese einer historischen Pendelbewegung zwischen Stein- und Lehmarchitektur im 19. und 20. Jh. In dieser Pendelbewegung kombinieren sich zwei unterschiedliche Prozesse: Dies ist erstens das zyklische Spannungs- und Wechselverhältnis zwischen seßhaften, freien Getreidebauern einerseits und andererseits abhängigen Oasenbauern mit ihren (halb-)nomadischen Herren. Der zweite Prozeß ist der allmähliche, phasenhafte und dynastisch-lineare Aufstieg des saudischen Staates und seine Ausdehnung nach Südwesten hin.

Man kann an der Architekturgeschichte von al-'Aqīq nicht übersehen, daß die letztendliche Abdrängung der Bewohner von tribaler Hijäz-Architektur aus Stein, und die Durchsetzung der innerarabischen Lehmarchitektur in einer Epoche stattfindet, die gleichzeitig vom siegreichen Aufstieg des saudischen Herrscherhauses und Staates ge- 
kennzeichnet ist. Immerhin fällt die erste nachgewiesene Periode der lokalen Lehmarchitektur in die Endphase des ersten saudischen Staates, und die rezente Periode der lokalen Najd-Bauten im 20. Jh. ist von der erfolgreichen Etablierung Saudi Arabiens auch im Südwesten gekennzeichnet. ${ }^{177}$

Zeitliche und räumliche Indikatoren erlauben also die Hypothese, wonach das schrittweise, rezente Vordringen der Najd-Architektur in al-'Aqī bis zu einem gewissen Grad auch zurückzuführen ist auf die historische Ausdehnung des saudischen Staates im Verlauf der letzten beiden Jahrhunderte. Erstens verweist die orale Tradition der Rifāca in al'Aqīq („vor zwei Generationen“) auf die ersten Jahrzehnte des 20. Jh. Damit ist aber auch jene Periode nach dem Ersten Weltkrieg berührt, in welcher der wachsende saudische Einfluß erneut aus Innerarabien nach Westen und Südwesten vorstieß und die Herrschaft der Sharīfen von Mekka bedrohte und schließlich stürzte. ${ }^{178}$ Eine der ersten Entscheidungsschlachten hatte 1919, im östlichen Randgebiet des südlichen Hijāz zum Najd, im W. Turaba stattgefunden. ${ }^{179}$

Wie auch immer die Zusammenhänge im Einzelnen verlaufen sein mögen, die endgültige Einführung der innerarabischen Lehmarchitektur in al-'Aqīq geht auf jene Periode zurück, in der sich der saudische Staat im Hijāz durchsetzt und zu etablieren beginnt. Die Rifāca, als Repräsentanten dieses Lehmstils verdrängen in späterer Folge die B. Halsān, deren Steinbauten zerfallen. Daraus ergibt sich nicht zwingend ein kausaler Zusammenhang zwischen der saudischen, regionalen Expansion und der lokalen Niederlassung der $\operatorname{Rif}^{-}{ }^{c} a$; aber die beiden Prozesse verlaufen in ungefähr zeitlicher Parallelität zueinander. Und der lokale Prozeß in al- ${ }^{`} A q \bar{i} q$ transportiert ebenso wie sein regionales politisches Pendant Elemente der Najd-Kultur nach Westen und Südwesten. Im übrigen wird das zeitliche und kulturelle Naheverhältnis zwischen beiden Prozessen durch einen weiteren historischen Umstand erhärtet. Die Bevölkerung des südwestlichen Najd war bereits in den ersten Jahrzehnten des 19. Jh. „a major source of support for the $1^{\text {st }}$ Saudi state“, ${ }^{180}$ und unter den saudischen Truppen, die 1815 von der Armee des Muhammad 'Alī geschlagen wurden, befanden sich bereits Ghāmid und Zahrān. ${ }^{181}$ Das Faktum der rezenten Etablierung der innerarabischen Lehmarchitektur in al-'Aqīq kann aufgrund dieser Indikatoren daher hypothetisch mit der Ausdehnung des saudischen Staates und seines ikhwān-Systems nach Südwesten korreliert werden.

Diese zweite, zeitlich-lineare Perspektive erfährt ihre räumliche Entsprechung, wenn wir uns nochmals den architektonischen Eigenschaften dieser Hausform zuwenden. Typologisch entspricht das Wohnhaus in al-'Aqīq nämlich in allen wesentlichen Details den traditionellen, einfacheren Hausformen von Bīsha, Sulāil oder Dar’̄̄ya (Abb. 59). Dazu zählen das typische, hofseitige Dreieckfenster, die Steinsäule und der Außenhof selbst.

Die größeren Oasen, Markt- und Garnisonsstädte des Najd sind freilich durch zusätzliche architektonische Merkmale charakterisiert. Als typisch für ihre Siedlungsanlage gelten das dichte, verschlungene Netzwerk von Gassen; ferner sind hohe, runde Lehmmina-

177 Knauerhase 1988: 333-337.

178 Troeller 1976: 127-158, 216-243; Almana 1980: 64-67.

179 Philby 1952: 89; die saudischen Truppen rekrutierten sich vor allem aus dem Najd-Stamm der

'Utayba, aber auch aus Ikhwān-Kontingenten der Südwest-Region des Najd (Almana 1980: 65).

180 King 1986: 161.

181 Burkhardt 1831, II: 310-321. 
rette und Garnisonstürme charakteristisch. ${ }^{182}$ In den größeren Ansiedlungen der traditionellen Najd-Architektur sind die Verwendung von Lehmziegeln oder mehrgeschoßige Wohnbauten häufiger, aber nicht ausschließlich gegeben. ${ }^{183}$

Als urbanes Element der innerarabischen Wohnarchitektur (aber nicht nur dieser) wird ferner der Innenhof angesehen, der für eine dichtgedrängte Siedlungsstruktur erlaubt, die klimatischen Besonderheiten und die moralischen Normen zu berücksichtigen. ${ }^{184} \mathrm{Den} \mathrm{Au}-$ Benhof in al-'Aqīq interpretiere ich als eine einfachere, ländliche Variante des städtischen Najd-Hofes: Die Ummauerung schützt ebenfalls vor Staub und fremden Blicken, sie spendet Schatten und erlaubt familiäre und häusliche Aktivitäten im Freien. Zugleich muß der ländliche Außenhof nicht auf die städtische Raumknappheit Rücksicht nehmen.

Und schließlich ist auch die Abwesenheit von Dekor ein gemeinsames Element, das die Lehmarchitektur von al-'Aqīq mit jener der Wohnhäuser von Bīsha, Sulāil und Dir ìya (Abb. 58) teilt. Ältere Motive von einfachem Holzdekor an manchen Bauwerken des Najd zeigen, ${ }^{185}$ daß auch die heutige, generelle Dekorarmut der innerarabischen Lehmarchitektur ein rezenteres Phänomen ist, das mit der asketischen und strengen Ästhetik des unitaristischen Islam zusammenhängt, wie ihn Muhammad 'Abd al-Wahhāb geprägt hat. Die zunehmende Ausbreitung der unitaristischen Ideale im 19. und 20. Jh. und die parallele Gründung von neuen ikhwān-Siedlungen bis in die 20er Jahre dieses Jh. hat zur Vereinheitlichung und zur Ausdehnung der innerarabischen Najd-Architektur beigetragen. Die Dekorlosigkeit ist der offenkundigste Ausdruck dieses expansiven Homogenisierungsprozesses. Damit ist gezeigt, daß das einfache Stadthaus und das ländliche Wohnhaus der innerarabischen Lehmarchitektur grundlegende Gemeinsamkeiten aufweisen. Im Gegensatz dazu zeigen die städtische und ländliche Wohnarchitektur der südwestarabischen Lehmbauweise markante Unterschiede in Stil und Konstruktion auf. ${ }^{186}$ Der einfachen städtischen, wie der ländlichen innerarabischen Architektur des Najd hingegen sind undekorierte Lehmwände und ebenerdige Bauweise mit Steinsäulen und țāqah gemeinsam. Diese Gemeinsamkeiten unterstreichen die ursprünglichen, egalitären und überlokalen Ideale jenes umfassenden religiös-politischen Weltbildes, das Ende des 18. Jh. von Innerarabien seinen Ausgang nahm.

\subsection{SÜDWESTLICHE DEFENSIVE HOCHBAUWEISE}

Der nun folgende Hauptteil dieser Arbeit dokumentiert und analysiert den vierten Architekturtypus des saudischen Südwestens. Die defensive Hochbauweise wird zunächst nach ihren typischen konstruktiven Gemeinsamkeiten untersucht. Danach werden ihre beiden Subtypen im einzelnen dokumentiert. Die Zusammenfassung vergleicht die Gemeinsamkeiten und Unterschiede des Dekors an diesem Typus, der unter allen Architekturformen des saudischen Südwestens der markanteste und zugleich der in sich vielfältigste ist.

182 Philby 1952: 96 (fig. 2); Talib 1984: 48, 52, 58; King 1986: 116, 118-125, 123, 129, 135-137, 141-144; für die Fenster: 166.

183 Beispiele dafür bei Talib 1984: 58, 61; Philby 1952: 96 (fig. I).

184 Talib 1984: 44, 50-57.

185 King 1986: 121 für eine ältere Moschee in Hầ̉il.

186 Niewöhner 1977: 24-27; Gingrich und Heiß 1983: 112-117 für die Lehmarchitektur des südwestarabischen Hochlandes. 


\subsubsection{Einleitung UND ÜBERBLICK}

Nach der Dokumentation und Diskussion der drei Architekturtypen von der Küste, in der Tihāma und aus dem Übergangsgebiet zum Najd behandelt der folgende Abschnitt die Wohnbauten der eigentlichen Kernregion der saudi arabischen Südwestprovinzen. Die südwestliche, defensive Hochbauweise ist ein typisches Charakteristikum der Kulturlandschaften in den Bergregionen des südlichen Hijāâ, des 'Asīr und des W. Najrān. Zugleich ist sie ein wesentliches Element von Gesellschaft und Lebensstil der hier lebenden bäuerlichen Bevölkerungsmehrheit, nämlich der südwestlichen Bergstämme. In geringem Maße ist die südwestliche Hochbauweise auch die traditionelle Wohnform der nicht-tribalen Minderheiten dieser Region - also einerseits der Gruppen von niedrigem sozialen Status und andererseits von Familien der traditionellen und modernen Oberschichten.

Die südwestliche Hochbauweise ist im wesentlichen eine alte, ländliche Wohn- und Verteidigungsarchitektur. Städtische Siedlungen gibt es im 'Asīr und südlichen Hijāz nur wenige. Diese haben sich mit wenigen Ausnahmen erst im Lauf der letzten Jahrhunderte auf der Grundlage der Dorfarchitektur und unter äußerem Staats- und Militäreinfluß herausgebildet. Von den wenigen, stadtähnlichen Siedlungszentren des südwestlichen Hochlandes werden im Mittelalter bei al-Hamdānī (10. Jh.) nur Abhā, ferner das heute verschwundene Jurash und die Streusiedlungen der Oase Najrān namentlich erwähnt, wobei Abhā wie die anderen heutigen Städte dann erst in der Neuzeit zur Garnisonsstadt staatlicher Herrschaft wurde, insbesondere für die Osmanen. Die älteren Militärbauten bei den heutigen Städten und entlang der alten Nachschubrouten zwischen ihnen und der Küste (Skizze 1) werden im folgenden nicht gesondert behandelt, wohl aber deren punktuelle Rückwirkung auf Lokalvarianten der Wohnarchitektur. Wo die traditionelle, zivile Bausubstanz der wenigen Städte noch erhalten ist, verweist sie aber eindeutig auf die Bauweise der jeweiligen, ländlichen und tribalen Umgebung. Dementsprechend beschränken sich die folgenden Darlegungen auf die ländliche Wohnarchitektur des Berglandes im saudiarabischen Südwesten. Einzelställe und Marktläden bleiben unberücksichigt; für ländliche Moscheen im südwestlichen Bergland sei auf die exzellenten Dokumentationen und Analysen von G. King (1986) verwiesen.

Der südwestlichen Hochbauweise sind, jenseits ihrer vielfältigen und oft spektakulären Varianten, wesentliche Merkmale gemeinsam. Diese Hauptmerkmale in ihrer Gesamtheit unterscheiden die Architektur des südwestlichen Berglandes zugleich eindeutig vom Küstenstil, offenkundig von den 'ushash und auch, wie zuletzt gezeigt, vom Najd-Architekturstil. Es scheint mir daher gerechtfertigt, grundsätzlich von einem einheitlichen, vierten traditionellen Typus von Wohnarchitektur im saudiarabischen Südwesten zu sprechen, der freilich in zwei Subtypen und mehrere Varianten mit Subvarianten gegliedert ist und zudem einige Ausnahmen aufweist.

Mit dem hier vorgeschlagenen Terminus „defensive Hochbauweise“ sind die konstruktiven Grundeigenschaften dieses Typs bereits prinzipiell erfaßt - nämlich die absolute Dominanz von mehrgeschoßiger Architektur und von (weiteren) Defensiveinrichtungen.

a) Ausnahmen

Variationen und Ausnahmen von diesen Grundeigenschaften treten in klar identifizierbaren Zusammenhängen auf. Als erstes folgt daher ein Überblick darüber, wo und wie diese mehrgeschoßige Defensivarchitektur im südwestlichen Bergland NICHT gegeben ist.

Erstens sind hier regionale Ausnahmen anzuführen. Generell nimmt bei den ländlichen Wohnhäusern die Anzahl der Stockwerke im Bergland von Südosten nach Nordwe- 
sten hin schrittweise ab. Im Hauptteil des 'Asīr und im W. Najrān sind die Wohnhäuser höher (3- bis 5 geschoßig), im nördlichen 'Asīr und im südlichen Ḥijāz werden sie dann niedriger: In seinem Zentralteil (B. Zaḥrān) sind sie 2- bis 3geschoßig, im Südteil (B. Ghāmid) und am Nordrand des südlichen Hijāa (Thaqīf) dominieren 1- bis 2geschoßige Wohnbauten. Dies bedeutet, daß im Süd- und Nordteil des südlichen Hijāz sowie im angrenzenden Nord-'Asīr ebenerdige Wohnhäuser (manchmal in dieser Region auch kombiniert mit einfachen Ausläufern des Küstenstils) eine häufige Ausnahme zur generellen Hochbauweise darstellen, welche aber selbst in diesen Regionen durch den Bestand an hohen Dorftürmen und mehrgeschoßigen Wohnhäusern dominiert. Dasselbe gilt auch im Übergangsgebiet des Südwest- 'Asīr zur Tihāma. Eingeschoßige Wohnhäuser haben durch den seitlichen Anbau der Wirtschaftsräume in der Regel eine größere horizontale Ausdehnung als einfache mehrgeschoßige Bauten. Diese erste Gruppe von Ausnahmen sind daher regionaler Art - am Nord- und am Südrand des südlichen Hijāaz, sowie am Südwestrand des 'Asīr.

Zweitens kommen ebenerdige Wohnhäuser außerdem im gesamten saudischen Südwesten als marginale Wohnform des ärmsten Teils der sozialen Unterschichten vor - also eines Teils der nicht-tribalen Minderheiten, die sich traditionell als Viehhirten ${ }^{187}$ oder Wanderhandwerker verdingt haben. Diese zweite Gruppe von ebenerdigen Wohnhäusern ist, im Unterschied zu den regionalen Ausnahmen, auch nicht auf Defensivaufgaben eingerichtet, und ebensowenig ist sie von hohen Türmen beschützt. Diese Abweichung teilt sie mit den Wohnhäusern aller traditionell „waffenlosen Minderheiten“ in dieser Region, nämlich den nicht-tribalen Statusgruppen von niedrigem und besonders hohem Rang.

Die Wohnhäuser von Familien nichttribaler Handwerker einerseits, und andererseits von Gelehrten und Nachfahren des Propheten sind also oft, aber nicht immer mehrgeschoßig, aber kaum mit anderen Defensiveinrichtungen (wie Wehrtürme, Schießscharten, oder Wehrbrüstungen) ausgestattet. Den quantitativen Anteil dieser qualitativ eindeutigen Ausnahmen schätze ich zum Erhebungszeitraum wie in Tab. 12 angegeben ein.

Tab. 12: Nicht-defensive und/oder eingeschoßige Ausnahmen: Verbreitung, Status, Anteil

\begin{tabular}{|l|l|l|l|}
\hline Ausnahmen & $\begin{array}{l}\text { eingeschoßig, } \\
\text { nicht-defensiv }\end{array}$ & $\begin{array}{l}\text { mehrgeschoßig, } \\
\text { nicht-defensiv }\end{array}$ & $\begin{array}{l}\text { eingeschoßig, defensiv } \\
\text { (mit mehrgeschoßigen Türmen) }\end{array}$ \\
\hline regionale Verbreitung & gesamtes Bergland & $\begin{array}{l}\text { gesamtes Berg- } \\
\text { land }\end{array}$ & $\begin{array}{l}\text { Teile des südlichen Hijāz und des } \\
\text { 'Asīr }\end{array}$ \\
\hline sozialer Status & $\begin{array}{l}\text { Unterschicht der } \\
\text { nicht-tribalen Grup- } \\
\text { pen von niedrigem } \\
\text { Status }\end{array}$ & $\begin{array}{l}\text { übrige nicht-tri- } \\
\text { bale Gruppen }\end{array}$ & tribale Gruppen \\
\hline $\begin{array}{l}\text { \%-Anteil an traditioneller } \\
\text { Wohnarchitektur }\end{array}$ & max. $3 \%$ & max. 10\% & $\begin{array}{l}\text { in beschränkten } \\
\text { Verbreitungsgebieten: } \\
\text { max. } 40 \%\end{array}$ \\
\hline
\end{tabular}

Auf die soziale Bedeutung dieser Ausnahmen wird in den folgenden Abschnitten noch einzugehen sein. In konstruktiver Hinsicht wird auf die Unterschiede bei der Erörterung der Hauptformen verwiesen.

187 Abdulfattah 1981: Foto 14. 
Zunächst aber kann festgehalten werden, daß die genannten Ausnahmen sicherlich weniger als $25 \%$ des Gesamtbestandes an traditioneller Wohnarchitektur ausmachen.

\section{b) Systematik der Hauptmerkmale}

Ohne diese Ausnahmen zu ignorieren, befassen sich die folgenden Ausführungen daher primär mit den gemeinsamen Konstruktionsmerkmalen des vierten Typs, der in seinem Verbreitungsgebiet mindestens drei Viertel der traditionellen Wohnarchitektur repräsentiert: Nach diesem Überblick über die Ausnahmen wenden wir uns nunmehr dem eigentlichen Thema dieses Abschnitts zu, also den mehrgeschoßigen Defensivbauten der tribalen Bauernfamilien. Beginnen wir mit der Systematik.

Die vier Hauptmerkmale dieses Typus sind in der Reihenfolge ihrer Bedeutung:

\section{Konstruktion:}

Das Wohnhaus hat mehrere Geschoße über vorwiegend rechteckigem Grundriß mit Flachdach. Wie auch alle anderen Formen dieses Typs ist die häusliche Architektur stets ohne echte Bögen und ohne Gewölbe konstruiert.

\section{Material:}

Feste Baustoffe dominieren durchwegs als Hauptmaterial: im Südosten herrscht gestampfter Lehm vor, der um Stein ergänzt sein kann; ansonsten dominiert Stein als Hauptmaterial, der im äußersten Norden durch wichtige Holzelemente ergänzt ist.

\section{Funktion:}

a) Die Defensivfunktion gibt der Wohnarchitektur in vierfacher Hinsicht ihr charakteristisches Gepräge.

- Die wirtschaftlichen und sozialen Raumfunktionen sind in einem Gebäude integriert (,fusion pattern "), ${ }^{188}$ was den einheitlichen Schutz von Familie, Vieh und Inventar gewährleistet;

- hohe, schlanke Wehrtürme schützen vorwiegend im südlichen Hijā̄z sowohl die Siedlungen als auch die Felder, im 'Asīr meist nur die Felder;

- die Eingangstüren sind niedrig gebaut, um Eindringlinge zum Bücken zu zwingen. Auch die Wohnräume der Obergeschoße haben (verschließbare) Fensteröffnungen, hingegen sind die Untergeschoße und Türme mit Schießscharten ausgestattet. Die Flachdächer von Wohnhäusern (vor allem im 'Asīr und W. Najrān) und aller Türme sind von Wehrbrüstungen umgeben, die als Erhöhung auf der Mauerkrone angelegt sind;

- die Fassaden sind mit stabilen Materialien (Stein, Farben) aus defensiven Gründen eher spärlich dekoriert, hingegen sind die großen Innenräume mit Farboder Holzdekor reichlich ausgestattet.

b) Die Wirtschaftsfunktionen und Umweltabstimmungen überschneiden sich teilweise mit den Defensivaufgaben der Wohnarchitektur.

- Möglichst hoch gelegene Standorte gewährleisten Überblick auf die Felder und potentielle Angreifer; aus Gründen der Statik und zur Einsparung von Anbauflächen werden unfruchtbare Baugründe bevorzugt.

188 Dostal (1981: 73) hat diesen Begriff geprägt, um derartige architektonische Typen von anderen arabischen Wohnformen zu unterscheiden. 
- Der hohe Bestand an Vieh, Gerätschaften und an Lagerbeständen (Saatgut, Nahrung) pro Haushalt ergibt einen großen Raumbedarf, der für die Wirtschaftsräume bei mehrgeschoßigen Gebäuden durchwegs im Erdgeschoß oder den unteren Geschoßen abgedeckt ist. Auch die Küche kann entweder dort, oder aber auf dem Dach eingerichtet sein. Nahezu überall gegeben ist die strikte funktionale Trennung zwischen diesen Wirtschafts- und den Wohnräumen. Letztere sind mit den meisten Fensteröffnungen ausgestattet und daher die hellsten Räume im Haus. Ein gemeinsames Merkmal der Wohnräume aller Varianten von südwestlicher Hochbauweise ist die Existenz eines „Wohnraumes“ in jedem Haus. Die Existenz dieses Aufenthalts-, Versammlungs-, Gast- - und oft auch Schlafraumes ist aber keine Besonderheit dieses Typs, sondern auch allen anderen Hausformen des Südwestens ebenso wie jenen in anderen Teilen Arabiens gemeinsam.

- Die festen Baumaterialien sind jeweils in der lokalen Umwelt vorhanden und werden zusammen mit konstruktiven Elementen auf die Erfordernisse von Eigentumsschutz und Klima abgestimmt.

\section{Verbreitung:}

Das Verbreitungsgebiet der südwestlichen Hochbauweise erstreckt sich wie ein allmählich breiter werdendes Band kontinuierlich von Nordwesten (südlich von al-Tẫ if) nach Südosten bis an die jemenitische Grenze (und weiter in den gesamten Jemen). Es umfaßt die gebirgigen Zonen (einschließlich der isolierten Tihāma-Berge) und die südöstlich davon gelegenen Talsysteme (W. Najrān). Damit entspricht dieser vierte Architekturtypus des Südwestens seinem größten Bevölkerungsanteil, und zugleich jener Verbreitungszone mit der - nach dem Küstenstil - geringsten flächenmäßigen Ausdehnung. Innerhalb dieses ökologisch reich gegliederten Verbeitungsgebietes treten die Subtypen und Hauptvarianten im wesentlichen nach der NW-SO-Ausrichtung der Hauptgebirgszüge auf.

Eine kubische, variantenreiche Hochbauweise - errichtet im "fusion pattern" an hoch gelegenen Standorten aus festen, isolierenden Materialien - welche deutlich von militärischdefensiver Funktionalität geprägt ist, und die ihr einheitliches, schmales und dicht bevölkertes Verbreitungsgebiet in den agrarischen Bergregionen und südöstlichen Talschaften hat: dies sind also die charakteristischen Merkmale des architektonischen Typus der südwestlichen Hochbauweise. Soziale Hauptrepräsentanten dieser Architekturformen sind die tribalen Bergbauerngruppen des 'Asīr und südlichen Hijā̄z.

Die vier genannten Hauptmerkmale der südwestlichen Hochbauweise sind natürlich keine voneinander unabhängigen Größen. Sie stehen zueinander, zu weiteren Merkmalen der Architektur, und zu Umwelt und Gesellschaft der Region in einem interaktiven Dependenzverhältnis, das im Sinn der Arbeiten von A. Rappaport ${ }^{189}$ analysiert werden kann. Eine derartige Analyse läßt a) Interdependenzen zwischen den verschiedenen Konstruktionsmerkmalen und b) zwischen architektonischen Konstruktionsmerkmalen und sozialen Bedingungsfaktoren unterscheiden. Ökologische Gegebenheiten und tribale Sozi-

189 Rappaport 1994: 460-502. 
alstruktur sind demgemäß (relativ unabhängige) Variable erster Ordnung, die eine Reihe von abhängigen Schlüsselvariablen zweiter Ordnung bedingen.

Daraus ergibt sich, daß die vier architektonischen Hauptmerkmale und einige weitere Elemente der südwestlichen Hochbauweise, abgesehen von ihrer Interdependenz zueinander, primär durch ihr Wechselverhältnis mit zweierlei geprägt sind: mit den ökologischen Besonderheiten des südwestarabischen Berglandes und mit den Charakteristika der tribalen Sozialstruktur. Ein gemäßigtes Klima im agrarischen Bergland und die Dominanz von (bis in die ersten Jahrzehnte des 20. Jh.) weitgehend autonomen, bewaffneten Stammesverbänden entsprechen nur diesem, und keinem anderen Typus von Wohnarchitektur im saudi arabischen Südwesten.

c) Systematik der Subtypen

Nach Abklärung der Grundfragen über regionale und soziale Ausnahmen sowie über die gemeinsamen Hauptmerkmale und deren spezifische Bedingungsfaktoren kann nun auf die beiden Subtypen und die Varianten der südwestlichen Hochbauweise eingegangen werden (Karte 11). Sie treten jeweils in relativ homogenen Verbreitungszonen auf, die in der erwähnten Abfolge (NW-SO) aneinander anschließen (Tab. 13, Karte 8). Im südlichen Hijāz und Nordwest- ${ }^{`}$ Asīr herrschen niedrigere 2-oder 3geschoßige Wohnbauten vor, deren leichteres Deckengewicht im Hausinneren durch hölzerne Stützsäulen abgesichert wird. Die Zugänge zu den Obergeschoßen verlaufen außen, oder seltener innen, durch schmale Leitern. Diese leichteren, niedrigeren Wohnhäuser werden zusätzlich durch hohe Verteidigungstürme innerhalb der Siedlungen (,in-towers “ oder „village towers") geschützt und überragt. Dieser Subtypus einer niedrigeren Hochbauweise mit Stützsäulen und Dorftürmen (Hijā̄ī-Architektur oder nordwestlicher Subtypus) tritt in drei Varianten auf. Die beiden größten stadtähnlichen Siedlungen im Verbreitunsggebiet dieser niedrigen Varianten von Wohnhäusern mit Stützpfeiler und Dorftürmen sind al-Bāḥa und Biljurshī.

Im 'Asīr und W. Najrān dominieren demgegenüber höhere, 3- bis 6geschoßige Wohnbauten. Die Größe dieser Bauten macht die Errichtung gesonderter Verteidigungstürme innerhalb der Dörfer meist überflüssig. Im Inneren des Wohnhauses wird das größere Gewicht einer höheren Zahl von Geschoßen und deren größere Spannweite abgestützt durch tragende Wände oder Mauern, um die zugleich die Stiegenhäuser errichtet sind. Dorftürme sind also wegen der ohnehin gegebenen Höhe der Wohnhäuser hier eher seltene Ausnahmen, etwa in umstrittenen Grenzgebieten, ${ }^{190}$ während Türme zum Schutz der Felder und Stammesgrenzen („field towers“ oder „out towers") ebenso üblich sind wie im südlichen Hijāz. Dieser zweite Subtyp einer „höheren Hochbauweise mit tragenden Wänden “ ('Asīri-Architektur) tritt in drei Hauptvarianten auf. Die größten stadtähnlichen Siedlungen in ihrem Verbreitungsgebiet sind al-Nimāṣ im Norden des 'Asīr, Abhā, Khamīs Mushayṭ und das alte Najrān in seinem Süden und Südosten.

190 Für eine solche cf. Dostal 1983c: Titelblatt. 
Tab. 13: Subtypen (2), Übergangsform (1) und Varianten (6) der südwestlichen defensiven Hochbauweise

\begin{tabular}{|c|c|}
\hline \multicolumn{2}{|c|}{ Typus: Südwestliche defensive Hochbauweise der Berg- und Hochlandstämme } \\
\hline $\begin{array}{l}\text { südöstlicher Subtypus 1: Hochbauweise mit tra- } \\
\text { genden Steinwänden } \\
\text { (Architektur von 'Asīr und W. Najrān) }\end{array}$ & $\begin{array}{l}\text { nordwestlicher Subtypus 2: ein- bis dreistöckige } \\
\text { Wohnbauten mit hölzernen Stützsäulen und } \\
\text { Dorftürmen } \\
\text { (Architektur des südlichen Ḥijāz) }\end{array}$ \\
\hline $\begin{array}{l}\text { Adobe-Bauten (Südwestarabische Lehmbauwei- } \\
\text { se): } 3 \text { - bis 5geschoßig; Ost-'Asīr (um Khamīs Mus- } \\
\text { hayț) und W. Najrān }\end{array}$ & Niedrige Felssteinhäuser (Bilād Ghāmid) \\
\hline $\begin{array}{l}\text { „Pagoden“-Bauten (auch: „Abhā-Stil“): 3- bis 5ge- } \\
\text { schoßig; Lehmwulste mit Schindelreihen }\end{array}$ & $\begin{array}{l}\text { Zwei- bis dreigeschoßige Schieferbauten (Bilād } \\
\text { Zahrān) }\end{array}$ \\
\hline $\begin{array}{l}\text { Steinarchitektur des West-'Asīr: } 3 \text { - bis 5gescho- } \\
\text { Big mit peripherer Subvariante im Südwesten }\end{array}$ & Niedrige Lattenwandhäuser (Bilād Thaqīf) \\
\hline \multicolumn{2}{|c|}{ Übergangsform zwischen beiden Subtypen im Nord-'Asīr um al-Nimāṣ } \\
\hline
\end{tabular}

Die Klassifikation dieser beiden Subtypen und ihrer Varianten ${ }^{191}$ folgt also primär konstruktiven und funktionalen Gesichtspunkten und baut auf einer Reihe von Vorarbeiten auf. ${ }^{192}$ Neu ist hier aber die methodische Unterscheidung zwischen dem „niederen“ und dem „höheren“ Subtypus mit ihren jeweiligen Korrelaten (Stützelemente und Türme), wodurch nicht primär Geographie (Wohnhäuser im Hijāāz oder im 'Asīr), oder Material (Stein und/oder Lehm, ergänzt um Holz), sondern eben die konstruktiven Eigenschaften selbst als primäres Differenzierungskriterium herangezogen werden können.

\section{d) Hausbau}

Die Techniken des Hausbaues ergeben sich aus Grundeigenschaften von Konstruktion, Material und Funktionen. Für den Mauerbau kommt im Süden und Südosten des 'Asīr und im W. Najrān primär die Adobe-Technik zur Anwendung, alle anderen Varianten werden mit trocken verlegten Steinblöcken errichtet. Steinerne Fundamente und leicht nach innen geneigte Außenseiten und Kanten der Mauern gewährleisten bei allen Varianten die nötige Stabilität. Dächer und Decken sind aus Balken und Hölzern konstruiert, die relativ geringe Spannweiten (von max. 2-3 m) überbrücken. Die Balken sind in der Regel entrindete und roh geglättete Stämme (nur in rezenteren Bauten finden sich vierkantige gehobelte Balken), die in die Mauer eingelassen sind; Dachbalken, die keine Brüstung tragen, sind der Mauerkrone bloß aufgelegt. Die Oberseiten von Decken und Dächern sind massiv verputzt, während an den Unterseiten das Holz meist frei liegt. Verputz der Außenwände tritt nur im Gebiet der Thaqif und im nordwestlichen B. al-Hajar auf und ist ansonsten selten.

191 Fünf der sechs Varianten wurden bereits in den siebziger Jahren verdienstvollerweise von Dostal (publ. 1983c) und King 1976: 24-27 identifiziert; darüber hinaus sind jene des B. Ghāmid wa Zahrān vom Autor ausführlich untersucht worden in Dostal 1983c: bzw. Gingrich 1983b: 91-113.

192 Dies bezieht sich auf die genannten Studien, ferner auf Dostal 1981: 56-84; Gingrich 1983: 74-121. Herangezogen wurden auch Abdulfattah 1981: map 6; King 1984: 93-110; Talib (1984) und Thesiger 1947: 193-198 zur Erarbeitung der hier vorgelegten Klassifikation, die jedoch über die Ansätze der genannten Autoren hinausgeht und sie gegebenenfalls auch korrigiert. 
Der technische Ablauf der Errichtung von Steinhäusern wurde von mir bereits früher am Beispiel des südlichen Hijāàz dokumentiert, und ebenso jener von südwestarabischen Adobe-Bauten (gemeinsam mit J. Heiß) am Beispiel des Nordost-Jemen, dem unmittelbaren Nachbargebiet zum Süd-'Asīr. ${ }^{193}$ Prinzipiell entspricht der technische Konstruktionsablauf aller hier dokumentierten Varianten den genannten Analysen, sodaß nur auf Details jeweils gesondert einzugehen sein wird. Was die Arbeitsorganisation des Hausbaues anbelangt, so ist diese ebenfalls keine Funktion der jeweiligen Subtypen oder Varianten; vielmehr stellen sich zur Errichtung jeglicher Form dieses Typus drei grundsätzliche Alternativen:

a) Der gesamte Hausbau kann als Auftragsarbeit gegen Entlohnung an Spezialisten vergeben werden. ${ }^{194}$

b) Nur die Herstellung einzelner Teile, insbesondere der dekorierten Holzelemente, erfolgt als Auftragsarbeit durch Spezialisten; der Rest jedoch wird von den zukünftigen Bewohnern, ihren Nachbarn und Verwandten errichtet.

c) Das gesamte Haus wird selbst von den zukünftigen Bewohnern, ihren Nachbarn und Verwandten errichtet.

Die Wahl zwischen diesen drei Alternativen ist also im Prinzip abhängig vom Ausmaß an Nachbarschafts- und Verwandtschaftshilfe (woran es selten mangelt) und vom Vorhandensein materieller Mittel zur Entschädigung der Spezialisten (die häufiger fehlen können). In letzter Konsequenz wird die Alternative a) nur von reicheren Familien gewählt, die völlig auf reziproke Hilfsleistungen Anderer verzichten können (bzw. dies wollen oder müssen, um sich sozial abzuheben). Auch Alternative c) ist dementsprechend selten und wird von ärmeren Familien ergriffen, die sogar die übliche, minimalste Dekorausstattung nicht an Spezialisten vergeben, sondern sie (qualitativ meist sichtbar schlechter) entweder selbst herstellen oder darauf verzichten. Alternative b) ist daher die häufigste Form der Arbeitsorganisation beim Hausbau und als solche schematisch in Diagr. 1 wiedergegeben.

Die Errichtung eines Wohnhauses ist ein seltenes Ereignis, dem hohe materielle, soziale und symbolische Bedeutung zukommt. Viele Familien des Berglandes leben in Häusern, die mindestens ein bis zwei Generationen (bei vergänglichen Lehmbauten) alt oder noch viel älter sind, und haben selten oder nie an einem Hausbau mitgewirkt. Wenn es aber zur Errichtung eines neuen Wohnhauses kommt, dann treten schlagartig alle Regeln der tribalen Sozialstruktur in Kraft. Gemeinschaftliche Eigentumsformen des Dorfes oder der tribalen Gruppe stellen den Zugang zu Rohmaterialien bereit, das partilineare Erbrecht sichert die Baufläche, die Formen der Allianz und Nachbarschaftshilfe gewährleisten Beistand beim Hausbau, der wiederum nach den lokalen Regeln geschlechtlicher und altersorientierten Arbeitsteilung zu erfolgen hat: Die Errichtung der wehrhaften, tribalen Wohnhäuser des bäuerlichen Berglandes aktualisiert somit unsichtbare Grundstrukturen jener Gesellschaft, deren sichtbarste und spektakulärste materielle Zeugen diese Bauten sind.

Nach diesem ersten Überblick wird nun jeder der beiden Subtypen im Detail dargestellt.

193 Gingrich 1983b: 107-113, 121, VIII (Illustr. 16); Gingrich und Heiß 1986a: 89-94.

194 Dieser Fall ist in Gingrich 1983b: 107-113 abgehandelt. 
Diagr. 1: schematische Abfolge eines Hausbaus im südwestlichen Bergland, mit teilweiser Auftragsarbeit durch Handwerker

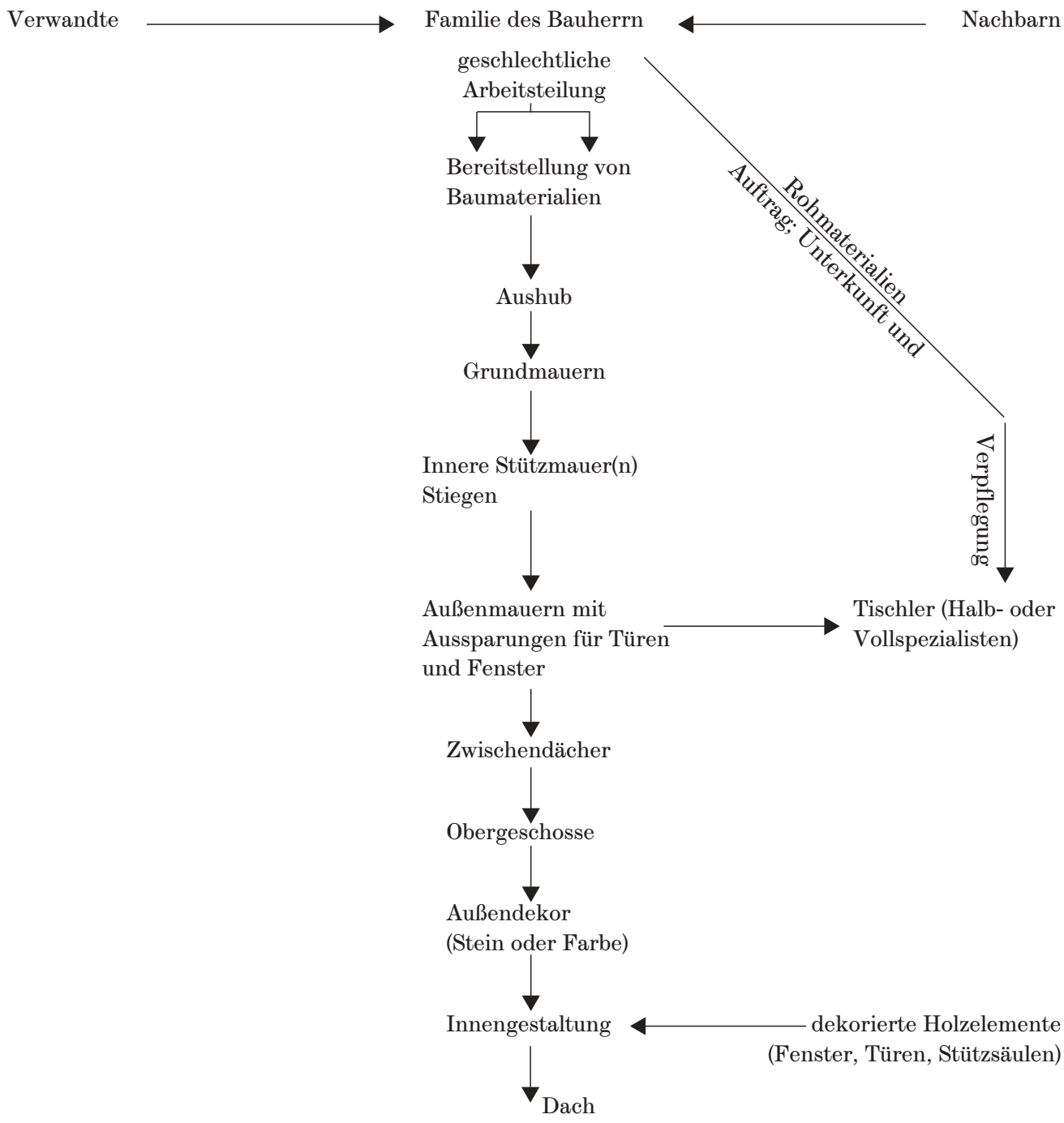


6.5.2. 'Asīr UND NAJRĀN: DREI- BIS SECHSGESCHOSSIGE HochBAUWEISE (SubTYPUS 1)

\subsubsection{Gemeinsame Merkmale des südöstlichen Subtypus}

Die drei- bis sechsgeschoßige, defensive Hochbauweise ist das zentrale, charakteristische Element der Wohnarchitektur im 'Asīr und dem W. Najrān. Mit ihren wuchtigen, hohen Formen kann diese Architektur als markantester Ausdruck der traditionellen materiellen Kultur des saudischen Südwestens schlechthin angesprochen werden: Während der Küstenstil, die 'ushash und die Lehmbauten am Najd-Rand auch außerhalb der südwestlichen Landesteile in anderen Provinzen des heutigen Saudi Arabien vertreten sind, haben diese defensiven Hochbauten keine Parallelen in anderen Regionen des Landes. Innerhalb der modernen Staatsgrenzen stellen diese Bauten also das charakteristische materielle Element der traditionellen Kultur des Südwestens dar.

Läßt man aber die heutigen politischen Grenzen außer Acht, so erweist sich die defensive Hochbauweise von 'Asīr und W. Najrān als nordwestlichster Teil eines weit umfassenderen Verbreitungsgebietes, das die Hochländer und Binnengebiete ganz Südwestarabiens umfaßt. Südlich von 'Asīr und W. Najrān schließen die Hochbauweisen der jemenitischen Hochländer an, von wo sich das Verbreitungsgebiet weiter über das Becken von San ${ }^{\complement} \bar{a}^{’}$ und südöstlich davon weiter bis ins W. Haḍramawt erstreckt. ${ }^{195}$ So verschiedenartig die lokalen Architekturstile des Jemen auch untereinander sind, innerhalb dieses Verbreitungsgebietes ist die Hochbauweise ein charakteristischer Faktor der ländlichen und städtischen Wohnarchitektur, der ihr mit jener von 'As̄̄r und W. Najrān gemeinsam ist. Die defensiven Wohnbauten dieser Region repräsentieren also den nordwestlichen Teil der südwestarabischen Hochbauweise.

Historisch ist die Hochbauweise dieser Region bereits eine Errungenschaft der vorislamischen Epochen, wie die Inschriften und Ausgrabungsstätten Altsüdarabiens im heutigen Jemen ebenso belegen ${ }^{196}$ wie jene im Süden Saudi Arabiens, etwa in al-Ukhdūd und al-Faw. ${ }^{197}$ Diese antike altsüdarabische Hochbauweise ist auf der arabischen Halbinsel einzigartig, und scheint mit der ähnlichen Architektur des nordostafrikanischen Aksum in Wechselbeziehung gestanden zu sein. ${ }^{198}$

Auf die Kontinuität der Existenz von Hochbauweisen in den ersten islamischen Jahrhunderten verweisen dann für die zentralen jemenitischen Hochländer entsprechende Passagen bei Ibn Rusta und al-Hamdān̄̄ (1. Hälfte des 10. Jh. $)^{199}$ und für dieselbe Zeit zu Najrān Passagen beim Biographen des ersten zayditischen Imām. ${ }^{200}$ Da die Hochbauweise auch in den ersten ausführlichen Berichten europäischer Reisender bezeugt ist, ${ }^{201} \mathrm{kann}$ prinzipiell von ihrer kontinuierlichen Existenz seit der altsüdarabischen Epoche über das islamische Mittelalter bis in die Neuzeit und Gegenwart Südwestarabiens ausgegangen werden.

195 Serjeant and Lewcock 1983: 463, 496.

196 Lewcock 1976: 15 und ebenso Serjeant und Lewcock 1983: 492 erwähnen jene himyaritische Inschrift im Museum von Ta a izz, die „speaks of a house, with six floors and six ceilings “" cf. weiters Müller 1972: 87-89.

197 Al-Ansārī 1982: 17-29.

198 Serjeant und Lewcock 1983: 492, 496. Archäologisch ist noch nicht eindeutig geklärt, ob die ersten, weitaus einfacheren Hochbauten im heutigen Nordarabien älter als jene Altsüdarabiens sind.

199 Lewcock 1976: 15.

200 Gingrich und Heiß 1986: 172.

201 Niebuhr 1772 (1969): 231. 
Es sind diese besonderen Dimensionen von räumlicher Kontinuität (in den Binnenund Hochländern Südwestarabiens) und ebenso von zeitlicher Kontinuität (ein kulturhistorisches Alter von über zwei Jahrtausenden), die dem ethnographischen Faktum der Wohnarchitektur von 'Asīr und W. Najrān seinen besonderen Stellenwert verleihen. Im Anschluß an Autoren wie King, Tālīb oder Dostal ${ }^{202}$ können drei Varianten der drei- bis sechsgeschoßigen Hochbauweise von 'Asīr und W. Najrān unterschieden werden - nämlich die Lehmbauten im „Adobe“-Stil, ${ }^{203}$ die Abhā- oder (nach Philby) „Pagoden“-Bauten ${ }^{204}$ und die Steinbauten. Im Licht der räumlich-zeitlichen Kontinuitäten südwestarabischer Wohnarchitektur überrascht es nicht weiter, daß zwei dieser drei Varianten direkte räumliche Fortsetzungen von genau jenen Formen repräsentieren, die ebenso im nördlichen jemenitischen Hochland vertreten sind: Dies sind die tribale Steinbauweise zu beiden Seiten des Grabenrandes und die Adobe-Bauten im Südosten Saudi Arabiens, weshalb letztere in Differenzierung zum Najd-Stil (cf. Abschnitt 6.4.) bereits als südwestarabische Lehmbauweise bezeichnet worden ist. Diese Variante ist im Ost-'Asīr und im W. Najrān vertreten, Hauptmaterial ist ein Lehmgemisch, das in Wulsten übereinander geschichtet wird. Nordwestlich daran schließt um Abhā das Verbreitungsgebiet der „Pagoden“-Bauten an, die ganz ähnlich gebaut sind, jedoch sind zwischen ihre schmäleren Lehmwülste parallele Reihen von Schieferplatten gesteckt. Die Verbreitungsgebiete dieser beiden Varianten beschränken sich also auf den südlichen Teil des Hochlandes und liegen oberhalb des Grabenrandes zum Roten Meer.

Die Steinbauweise hat hingegen im Südwesten des 'Asīr ihr Hauptverbreitungsgebiet unterhalb des Grabenrandes, und erst im Nord-'Asīr ist sie auch für die Siedlungsgebiete oberhalb des Grabenrandes typisch. Die Besonderheiten dieser drei Varianten werden im einzelnen später behandelt; hier geht es zunächst um ihre konstruktiven Gemeinsamkeiten.

Jenseits der materialbedingten Unterschiede zwischen diesen drei Hauptvarianten ist ihnen zugleich ein fundamentales Prinzip gemeinsam, das sie mit allen anderen vielstöckigen, defensiven Hochbauten Südwestarabiens, die permanent bewohnt werden, notwendigerweise teilen: Dies ist die architektonische Kombination von tragenden Innenmauern mit Stiegenaufgängen. Traditionelle Hochbauten jeder Art, die pro Geschoß mehr als einen Raum haben, müssen ab einer gewissen Höhe aus statischen Gründen in ihrem Inneren durch Stützwände stabilisiert werden, die zugleich die Zwischendecken tragen. Defensive Hochbauten werden die zwei bis fünf Zugänge - von einem Geschoß zum nächsten - sinnvollerweise nicht außen anlegen, wo die Bewohner exponiert wären. Im Inneren hingegen bieten sich für die Anlage dieser Zugänge eben jene tragenden Stützwände an: Kurzum, die mehrgeschoßigen und defensiven Wohnhochbauten des saudischen Südwestens haben ein Stiegenhaus, die zwei- bis dreigeschoßigen Wohnbauten hingegen haben meistens keines. Das Stiegenhaus untergliedert den Grundriß zugleich in mehrere Räume. Zu unterscheiden sind demnach einräumige und mehrräumige Hochbauten.

202 King 1976: 26 f.; Tālīb 1984: 94; Dostal 1983c: 13-32.

203 Ich verwende den Ausdruck „Stil“ hier fallweise als Synonym für „architektonische Variante eines der Subtypen“, aber nicht im kunsthistorischen Sinn.

204 Philby 1976: 139, 147. 
Konstruktiv und statisch stehen die Ausmaße von Grundriß und Höhe eines Gebäudes zueinander in direktem Wechselverhältnis: Über dem einräumigen rechteckigen Grundriß eines Turmes können mehrere Geschoße alleine durch die Außenwände getragen und überspannt werden. Dabei stützen diese kurzen Außenwände einander massiv genug ab, ohne daß statische Probleme entstehen: Zugleich ist der einräumige Grundriß klein genug, um mit traditionellem Material frei und flach überspannt zu werden, also ohne Rückgriff auf die hier nicht beherrschte Technik der Bogen- und Gewölbekonstruktion. Die Stiegen können dann entlang der tragenden Außenwände (meist innen) geführt werden. Innenwände würden hier nur Raumverlust schaffen und sind statisch überflüssig. Durch einen runden, einräumigen Grundriß wird zunächst die Innentemperatur besser gespeichert (was während der Einnahme von langdauernden Beobachtungsposten in freistehenden Türmen sehr wichtig sein kann). Vor allem aber wird die defensive Funktion durch weiteren Sichtwinkel verbessert; und schließlich erhöht die Kohärenz der Außenmauern die Statik - dies alles jedoch unter der einen Voraussetzung der dafür nötigen, besonderen technischen Fertigkeiten zur Anlage einer gleichmäßig belasteten Mauer.

Nur diese mehrgeschoßigen Bauten über einräumigem Grundriß, der rund oder rechtekkig sein kann, nenne ich im vorliegenden Text „Türme“: Dies entspricht der lokalen Terminologie, die im 'Asīr und W. Najrān „huṣn“ (Turm mit rechteckigem Grundriß) und „qașaba“ (Turm mit rundem Grundriß) unterscheidet. „Türme“ in diesem Sinn haben keine Innenmauer und stets nur einen Raum pro Geschoß. Diese Türme sind meistens nicht permanent bewohnt, sondern dienen als Beobachtungs-, Wach- und Verteidigungsbauten; sie stellen also spezialisierte architektonische Defensiveinrichtungen der tribalen Gesellschaft dar und sind sowohl im 'As̄̄r und W. Najrān als auch im südlichen Hijāz vertreten. Verteidigungstürme im Bereich der Wohnhäuser oder der Siedlung nenne ich, wie erinnerlich, „in-towers“, um sie von jenen anderen, isolierten Türmen zu unterscheiden, welche außerhalb der Siedlungen nicht die Wohnhäuser direkt schützen oder bewachen, sondern bei Feldern, Grenzgebieten oder Handelswegen stehen (,outtowers").

Über einem mehrräumigen Grundriß stellen sich hingegen andere Probleme für die defensive Hochbauweise als bei Türmen. Mehrräumige Grundriße sind im tribalen Bergland (anders etwa als im traditionellen Stil des urbanen Najd) stets rechteckig; ähnlich wie die Konstruktion von Bogen und Gewölben scheint die Anlage mehrräumiger Rundbauten nicht im architektonischen Inventar der tribalen Bevölkerung auf. Mehrräumige Geschoße verlangen per definitionem Trennwände und einen größeren Grundriß, was eine größere Länge der Außenwände bedingt. Daraus ergibt sich sowohl das Problem der Überspannung wie jenes der zunehmenden Belastung und mangelnden Abstützung der Außenwände bei wachsender Höhe. Diesem Problem kann bei gegebenen Material- und Klimabedingungen durch die Errichtung von tragenden Innenwänden begegnet werden, deren Funktion mit jener der ohnedies gegebenen Trennwände verbunden wird. Zunächst verlagern die tragenden Innenwände den Schwerpunkt von außen nach innen und unten. Weiters ermöglicht ihre Errichtung eine andere Behandlung von Außenwänden und Grundriß: Zum einen garantieren die tragenden Innenwände die Überspannung des Grundrisses, zum anderen trägt die Innenwand das Hauptgewicht der Obergeschoße, stützt die Außenwände mithilfe der Überspannung, und entlastet sie dadurch. Schwächere Außenwände müssen durch die Innenwände stärker entlastet werden und einander noch besser abstützen - dies erklärt die deutliche Neigung jener Außenwände, die grund- 
sätzlich aus ungebrannten Lehmwülsten errichtet sind - nämlich bei den Pagoden- und Adobe-Bauten.

Warum Hochbauten in diesen Regionen üblich sind, steht hier vorerst nicht zur Debatte. Sobald aber Hochbauten mit mehr als einräumigem Grundriß errichtet werden, sind tragende Innenwände unumgänglich. ${ }^{205} \mathrm{Da} ß$ bei defensiven Hochbauten tragende Innenwände sinnvollerweise für die Zugänge zwischen den Geschoßen genutzt und damit kombiniert werden, ist als fundamentales Konstruktionsprinzip identifiziert worden. Dieses Prinzip wird im 'Asīr und W. Najrān im wesentlichen in drei alternativen Kombinationsformen gelöst, die in jeder der drei Hauptvarianten auftreten können. Von den hier gewählten Beispielen stammen zwei aus Adobe-Bauten (Taf. XLI, XLII, XLIII), die Lösungen sind aber ethnographisch ebenso häufig in der häuslichen Architektur der „Pagoden"- und der Steinhäuser anzutreffen.

Die drei Kombinationslösungen sind:

- Solide, einfache Stützmauer von rechteckigem oder quadratischem Grundriß, um welche die Treppe hochgezogen wird (Taf. XLI).

- Mauerngeviert in Form eines Binnenschachtes, oder durch vier tragende Innenmauern, die innerhalb eines viereckigen Grundrisses miteinander einen quaderartigen Schacht bilden. Die Treppen können entweder im Inneren des Schachtes hochgezogen werden, oder entlang seiner Außenmauern, wodurch pro Geschoß Binnenräume ausgespart bleiben (Taf. XLII).

- Zwischenschacht: ein „teilendes Paar“ von zwei Binnenwänden durchschneidet den Grundriß in zwei gleich große Hälften, zwischen denen das Stiegenhaus hochläuft. Da der Hauseingang zum Stiegenhaus führen muß, stehen diese beiden Binnenwände stets im rechten Winkel zur Hauptfassade (Taf. XLIII). Das teilende Paar bildet somit einen schmalen, rechteckigen Zwischenschacht, dessen Länge durch die seitlichen Außenwände vorgegeben ist. Der für die Stiegen benötigte Raum ist meist kleiner als jener des Zwischenschachtes. Pro Geschoß kann dieser Raumüberschuß als langer Korridor genutzt werden, der an den Enden zu den Treppen und seitlich in die Zimmer führt, oder aber ein Teil des Schachtes wird pro Geschoß als Binnenraum abgetrennt, um die Stiegen nur an der Fassadenseite des Zwischenschachtes innen hochzuführen. Als einzige der drei Kombinationslösungen gibt der teilende Zwischenschacht auch der Fassade ein charakteristisches Gepräge: Seine Ansätze sind auf jeden Fall als senkrechter Streifen sichtbar, der sich in der Mitte der Fassade vom Haupteingang bis zum Dach hinaufzieht. In der Regel ist dieser mittlere Streifen aber gegenüber der Fassade etwas zurückversetzt: Diese Verringerung des Zwischenschachtraumes ist durch den Raumüberschuß üblicherweise leicht in Kauf zu nehmen. Die Rückversetzung des Haupteinganges verengt die Bewegungs- und Zugangsmöglichkeit für potentielle Angreifer, welche zugleich für die Verteidiger an den Fenster- und Maueröffnungen der Geschoße des Zwischenschachtes exponiert werden.

Theoretisch hört sich dies vorerst komplizierter an, als es in der Praxis manchmal ist: Eine einfache Anwendungsform der Zwischenschachtlösung besteht nämlich darin, zwei Häuser oder einräumige Türme von gleich großem, rechteckigem oder quadratischem

205 Serjeant and Lewcock 1983: 441, ohne den „central stone pier“ aber weiter zu differenzieren. 
Grundriß knapp nebeneinander als zwei „Flügel“ zu errichten. Der Zwischenraum kann dann zum zurückversetzten Schacht des Stiegenhauses ausgebaut werden.

Derartige wuchtige Bauten mit insgesamt rechteckigem Grundriß sind offenbar auch im Zuge sukzessiver Erweiterungen entstanden; das heißt, daß einer der beiden heutigen „Flügel“ wesentlich älter sein kann als der andere. Im Falle dieser einfachsten, manchmal sukzessiven Anlage der Zwischenschachtlösung durch zwei parallele Häuser oder Türme trägt sich jeder dieser beiden Flügel primär selbst - und zwar entweder durch allein tragende Außenmauern, durch einfache Stützmauern oder durch Innenschächte, also auch durch eine der beiden anderen Kombinationslösungen, dann von eigenen Stiegenaufgängen in jedem Flügel. In diesen Fällen ist der Zwischenschacht durch zwei der nicht allein tragenden Seitenwände der beiden Flügel gebildet; er gibt daher mit seinen Geschoßen nur eine sekundäre Abstützung für beide Flügel ab.

Daraus lassen sich zwei verschiedene konstruktive Formen der Zwischenschachtlösung im 'Asīr und W. Najrān erkennen:

- erstens die gerade erörterte „Flügelform“, bei der sich jeder der beiden Flügel primär selbst trägt und der Zwischenschacht eine sekundäre Abstützung bildet (diese Form hat immer rechteckiger Grundriß, und ist manchmal sukzessive errichtet; Abb. 62),

- und zweitens der „tragende“ Zwischenschacht, der das Gebäude zwar ebenfalls in zwei Hälften teilt, welche sich aber nicht primär selbst tragen (häufig quadratischer Grundriß, immer in einem Arbeitsprozeß errichtet; Abb. 82, 83).

Sowohl bei der tragenden wie der sekundär abstützenden Form des Zwischenschachtes wird sein Potential zur verbesserten Defensivfunktion durch Rückversetzung des Mittelstreifens der Fassade genutzt.

Einfache Stützmauer, Innenschacht und (tragender) Zwischenschacht sind also jene drei alternativen Lösungen, mit denen die defensive, häusliche Hochbauweise im 'Asīr und W. Najrān arbeitet. Jede dieser Lösungen kombiniert statische Stabilisierung des Hochbaues mit Verkürzungen für die Überspannung des Grundrisses und mit der Sicherung der Zugänge zwischen den Geschoßen.

Damit läßt sich rekapitulieren, welche Möglichkeiten und Notwendigkeiten jeder dieser drei Kombinationslösungen immanent sind:

- Die einfache Stützmauer ist die technisch anspruchsloseste Lösung. Sie eignet sich am besten für kleinere Grundrisse (oder aber als Teilelement in Flügelbauten), da sie im Zentrum des Grundrisses stehen muß und folglich die jeweilige Spannweite maximiert. Wenige oder kleine Zimmer pro Geschoß sind die Folge. Die Stiegen werden meist übereinander, zwischen Stützmauer und einer Außenwand geführt. Die zentrierte Position der einfachen Stützmauer bewirkt zugleich, daß sie sich am ehesten für Grundrisse eignet, die das Ausmaß eines einfachen oder doppelten Quadrats haben. Der kleinere Grundriß und die beschränkte Belastbarkeit der Stützmauer bedingen, daß die Höhe dieser Bauten etwas unter jener der anderen beiden Kombinationslösungen liegt.

- Der Innenschacht ist prinzipiell die flexibelste Kombinationslösung, insoferne sie auf nahezu jeden rechteckigen Grundriß abgestimmt werden kann: Jeweils parallel zur Vorgabe der Außenwände kann das innere Mauergeviert dazu angepaßt werden. Diese anspruchsvolle Lösung ermöglicht daher auch variable Spannweiten und sie erlaubt 
die Anlage von mehreren größeren Wohnräumen pro Geschoß. Wenn das Stiegenhaus nicht im Binnenschacht sondern um diesen herum geführt wird, bietet dieser zusätzlichen Schutz in versperrbaren, fensterlosen Räumen. Auch bezüglich der Höhe liegt die Kapazität des Mauergevierts über jener der einfachen Stützmauer, aber unter jener des tragenden $Z$ wischenschachtes.

- Der tragende Zwischenschacht schließlich ist eine Sonderlösung für besondere Anforderungen, während die Flügelform bloß eine verdoppelte Erweiterung der ersten oder der zweiten Form darstellt. Wie gezeigt, verlangt der Zwischenschacht eine Teilung des Hauses in zwei gleich große Hälften, und er bringt gegenüber den anderen beiden Lösungen einen definitiven, zusätzlichen Verteidigungsvorteil. Im W. Najrān, vor allem aber im 'Asīr werden diese Grundeigenschaften in zweierlei Hinsicht genutzt.

Zum einen handelt es sich um sehr hohe (bis zu sieben Geschoße), dauerhaft bewohnbare turmartige Bauten mit mindestens zwei Räumen pro Geschoß (Abb. 60) über relativ kleinem Grundriß. Diese „Schachttürme“ sind manchmal in abgelegenen Stammesgebieten errichtet, vor allem aber stehen sie isoliert entlang der großen, traditionellen Verbindungsrouten zwischen den alten Garnisonsstädten im Hochland und den Häfen an der Küste. Entsprechend ihrer Verbreitung werden sie im Zusammenhang mit der Steinarchitektur des 'Asīr näher diskutiert.

Zum anderen tritt der tragende Zwischenschacht bei extrem massiven und zugleich geräumigen, breiten Wohnbauten auf. Dies sind die Gebäude mit der deutlich größten Zahl von Bewohnern im gesamten saudischen Südwesten. Die große Tragkraft des Zwischenschachtes kann dabei der Nutzung schwerer Baumaterialien (aus Stein) zugute kommen, und ebenso der Anlage größerer Geschoße. ${ }^{206}$ Das enorme Raumangebot dieser breiten „Zwischenschachtgebäude“ ist von vornherein darauf angelegt, weitere $\mathrm{Zu}$ - und Anbauten soweit wie möglich überflüssig zu machen (Abb. 61). Die Vielzahl der Geschoße und das trennende Stiegenhaus in jedem Geschoß ermöglichen vielmehr die Absonderung von Kleinfamilien im Inneren ein- und desselben Gebäudes. Damit fördern diese Bauten die Koresidenz mehrerer verwandter Familien, denen sie gemeinsame, zusätzlich Verteidigungseinrichtungen anbieten.

Diese konstruktiven Alternativen sind, wie schon erwähnt, grundsätzlich bei allen drei architektonischen Materialanwendungen des saudischen südwestlichen Hochlandes angewandt worden. Man findet sie bei Steinbauten, Pagoden-Häusern und Adobe-Gebäuden: Die Kriterien der Konstruktion dominieren hier eindeutig jene des Materials.

Aus den Korrelaten und Gestaltungsformen der drei Kombinations-Lösungen ergibt sich bereits, daß die unauffällige, einfache Stützmauer die häufigste Form im 'Asīr und $W$. Najrān ist, während die spektakuläre und technisch anspruchsvollste Zwischenschachtlösung besondere, seltene Formen repräsentiert.

Quer durch die einzelnen Stammesgebiete und quer durch die demgegenüber größeren Verbreitungsgebiete der drei Varianten von Materialformen (Stein, Pagoden, Adobe) läßt sich damit zu den drei Kombinationslösungen in 'Asīr und W. Najrān feststellen: In der traditionellen, defensiven Hochbauweise der tribalen Bevölkerung stellt die tragende Stützmauer die am weitesten verbreitete Form dar, die mit etwas niedrigeren Gebäuden

${ }^{206}$ Lippens 1956: 124-126 (W. Najrān) und Gingrich und Heiß 1986a: 73 (J. Rāziḥ im Jemen) bieten Beispiele für beides; cf. auch Serjeant und Lewcock 1983: 453 für Șan' $\vec{a}$ '. 
und kleineren Residenzeinheiten verbunden ist und daher oft zahlreiche Zu- und Anbauten aufweist. Sie ist für das Wohnen der breiten Masse bäuerlich-tribaler Familien der Region charakteristisch. Das Innenmauergeviert ist seltener und am ehesten bei wohlhabenden, größeren Bauernhaushalten anzutreffen - also in manchen fruchtbaren Teilen der Region und bei einzelnen reichen Residenzeinheiten, die meist mehr als eine monogame oder polygyne Familie umfassen. Das „Zwischenschachtgebäude“ ist nahezu ein Repräsentationsbau der traditionellen tribalen und nicht-tribalen Oberschichten, wo die materiellen Mittel dafür eher gegeben sind, und wo die Bewahrung der Einheit von Verwandtschaftsgruppen und ihres Besitzes ein größeres politisches Gewicht hat als anderswo. Daneben ist es aber auch in einzelnen, fruchtbaren Schwerpunktzonen als Großgehöft von reichen, tribalen Bauernfamilien vertreten.

Damit sind die drei Kombinationslösungen und ihre jeweiligen architektonischen Korrelate für tribale, defensive Hochbauten im W. Najrān und 'As̄̄r einerseits den tribalen bäuerlichen Mehrheiten, und andererseits zwei Arten von privilegierten Minderheiten zugeordnet worden - nämlich dominanten Oberschichten und wohlhabenden Bauernhaushalten. ${ }^{207}$

Gemeinsam ist diesen Kombinations-Lösungen das Prinzip der Verbindung von tragenden Innenwänden mit geschütztem Zugang zwischen den Geschoßen. Mit weiteren Implikationen dieses gemeinsamen Prinzips für alle Materialformen befaßt sich der verbleibende Teil dieses Abschnittes.

Für die Schaffung von ausreichendem Wohn- und Lagerungsraum hat zwar jede der drei Kombinationslösungen unterschiedliche Kapazitäten, aber an sich ist der Raumbedarf den Einzelhaushalten kein grundlegender Anreiz für die Entwicklung der Hochbauweise per se. Erst in Verbindung mit den beiden anderen Faktoren von knappem Baugrund und hoher Bevölkerungsdichte entsteht daraus einer von mehreren selbstständigen Stimuli zur Dominanz von Hochbauweise. Dieser Stimulus ist zwar in manchen anderen Teilen Südwestarabiens extrem ausgeprägt; im südwestlichen Hochland von Saudi Arabien ist er in dieser Form aber eigentlich nur im oasenartigen Kulturland des W. Najrān und des Ost-'Asīr um Khamīs Mushayt gegeben. Im Südwest- und Nord-'Asīr scheint mir hingegen unter traditionellen Verhältnissen dieser Stimulus alleine nicht ausreichend zur Erklärung der Dominanz von Hochbauweise.

Dort kommen zwei weitere Faktoren hinzu, die im Prinzip aber auch im Südosten des saudischen Verbreitungsgebietes nicht unwichtig sind: Die Hochbauweise ermöglicht in den Obergeschoßen eine andere Gestaltung des Wohnklimas, ${ }^{208}$ und sie erhöht und verändert nachhaltig die defensiven Möglichkeiten der Architektur.

Geringe Widerstände im Vergleich zum Nahbereich der Erdoberfläche, das Nachlassen der Erdwärme und andere Faktoren bedingen bekanntlich eine größere Luftzirkulation in Höhen ab einigen Metern über dem Erdboden. In semiariden und randtropischen Gebieten resultiert dies in windigeren und damit potentiell etwas kühleren Verhältnissen für die

207 Diese vorsichtige Zuordnung der drei Kombinations-Lösungen zur tribalen Mehrheit einerseits, und zu an Reichtum oder Status privilegierten, dominanten tribalen Minderheiten andererseits ist vorläufig und hypothetisch. In Ermangelung systematischer statistischer Korrelationen scheint es mir dennoch geboten, diese hypothetische Zuordnung hier auf der Basis eigener, punktueller Erhebungen einmal aufzustellen. Ob jemals genügend Vergleichsdaten für die Zeit vor den technischen Umwälzungen am Ende des 20. Jh. eingebracht werden können, um diese Hypothese zu überprüfen, bleibt ungewiß.

208 Talib 1984: 99. 
Obergeschoße. Darin erblicke ich einen weiteren, wesentlichen Stimulus für die südwestliche Hochbauweise, der zudem die graduelle Abnahme der Geschoße nach Norden hin, vom 'Asīr zum Hịjāz, teilweise zu erklären hilft. Im 'Asīr und W. Najrān sind - sofern es überhaupt regnet - die Niederschläge auf eine Periode im Jahr konzentriert, nämlich Frühjahr und Sommer. Im südlichen Ḥijāz hingegen sind die Durchschnittstemperaturen niedriger, die Niederschläge sind etwas höher, und sie treten zudem häufiger sowohl im Winter als auch im Frühjahr und Sommer auf. Die jährlichen Trockenperioden im 'Asīr sind also in der Regel länger und wärmer als im südlichen Ḥijāz. Während dieser regelmäßigen, heißen und trockenen Jahreszeit bieten die Obergeschoße moderatere Lebensbedingungen, als sie in ebenerdigen Wohnräumen herrschen würden. Die erhöhte Zirkulation von kühlerer und weniger staubiger Luft ist daher hier ein selbstständiger Stimulus, gerade die Wohngebäude so hoch wie möglich zu errichten. Damit ist das dominante „fusion pattern “ hier durch eine Verschränkung von „push“- und „pull“-Faktoren für die Hochbauweise geformt: Arbeitsgeräte und Vieh sind praktischerweise nur in den Erdgeschoßen unterzubringen. Für die Wohnräume bieten sich unter der Bedingung des bereits genannten, ersten Stimulus die Obergeschoße auch aus klimatischen Gründen an: große Fensteröffnungen im obersten oder in den beiden oberen Geschoßen, die Nutzung der Dachterrasse, und oft auch die Anlage eines nur zur Hälfte überdachten Obergeschoßes sind daher die charakteristischen Merkmale für alle drei Materialformen der tribalen Wohnarchitektur. Während der heißen Trockenzeiten erlaubt dies eine verbesserte Abkühlung der Obergeschoße während der Nacht, die Nutzung der Dachterrassen als Schlafstätten, sowie tagsüber den Aufenthalt in und fallweise die zusätzliche Durchlüftung der kühlsten Räume im Haus. Manchmal, aber nicht immer ist auch die Küche in einem Obergeschoß oder auf der Dachterrasse eingerichtet, was die erhöhte Luftzirkulation zusätzlich für den Abzug nutzt.

Unter diesen spezifischen klimatischen Bedingungen stellt die deutlich erhöhte Lage der Wohnräume also eine Verbesserung ihres Innenklimas dar. Zugleich ergibt sich damit die Möglichkeit, dies auch in defensiver Hinsicht zu nutzen. Die defensiven Funktionen sind der südwestarabischen Hochbauweise generell gemeinsam, und zwar sowohl der städtischen wie der ländlich-tribalen Architektur. In den kleineren ländlich-tribalen Siedlungen, wo der Staatseinfluß traditionellerweise nur sporadisch gegeben war, lasteten diese militärischen Aufgaben von Schutz und Herausforderung kontinuierlich auf der Dorfbevölkerung selbst. Die architektonische Seite dieser Aufgabe wird im 'Asīr und dem W. Najrān vor allem auf das freistehende Wohnhaus übertragen - und dies stellt einen weiteren Anreiz zur Nutzung der Hochbauweise dar. Nur ausnahmsweise werden zwei weitere Möglichkeiten von Defensivarchitektur genutzt, nämlich Siedlungsanlage und „in-towers“.

Behandeln wir zunächst diese Ausnahmen: Bis zu einem gewissen Grad kann selbstverständlich bereits die gesamte Anlage eines Dorfes defensive Funktionen erfüllen, und zwar in Form dicht aneinander gedrängter Einzelhäuser, die nach außen hin eine gemeinsame „Front“ bilden. Dies ist dort gegeben, wo derartige tribale „Front“-Siedlungen entweder auch unterschiedliche mikroklimatische Vorteile mit sich bringen, und/oder wo besondere militärstrategische Notwendigkeiten bestehen.

Während tribale Frontsiedlungen im südlichen Hijāz die Regel sind, ${ }^{209}$ ist ihr Vorkommen im 'Asīr und W. Najrān selten und uneinheitlich. Sie herrschen in keiner Region ein-

209 King 1976: 25. 
deutig vor, aber in bestimmten Subregionen sind sie doch etwas häufiger als anderswo. Dies sind einige Orte des W. Najrān, wo das oasenartige Mikroklima und die bewegte politische Lokalgeschichte den Ausschlag zur Bildung einer solchen kompakten, defensiven Dorfanlage gegeben haben. ${ }^{210}$ Ähnliche Faktoren dürften auch für die Formierung mancher „Frontsiedlungen“ um Abhā und Khamīs Mushayt entscheidend gewesen sein. ${ }^{211}$ Ein Beispiel wäre dafür die Siedlung von al-Khalef, die besonders stark auf inter- und intratribale Fehden ausgerichtet ist. ${ }^{212}$ Gegenüber diesen Siedlungen im Adobe- und PagodenStil ist die Anlage kompakter Frontsiedlungen im Steinbau des 'Asīr noch etwas seltener. Das markanteste Einzelbeispiel ist die Siedlung al-Sūda nordwestlich von Abhā, wo Garnisonsnähe und die Lage an der strategischen Nachschublinie zur Küste entscheidend für ihre Ausgestaltung sind, wie noch zu zeigen sein wird. Im übrigen belegt das erwähnte Beispiel von al-Khalef, daß auch in „Frontsiedlungen“ das Konfliktpotential so strukturiert sein kann, daß jedes Einzelhaus auf Konfrontationen mit anderen Häusern derselben Siedlung eingerichtet ist. Dies bedingt, daß gerade in den wenigen dichtgedrängten Frontsiedlungen mit hohen Wohnbauten die „in-towers“ eher als anderswo im 'Asīr und W. Najrān auftreten: Sie erfüllen dann weniger eine defensive Funktion gegenüber Herausforderungen von außerhalb der Siedlung, als vielmehr eine sowohl offensive wie defensive Aufgabe gegenüber den Nachbarn.

Defensive Türme im Nahbereich des oder der Wohngebäude erlauben andererseits, die Wohngebäude im Schutzbereich der Türme niedriger zu erbauen, wo dies nötig ist. Im 'Asīr ist diese Lösung nur im Gipfelbereich mancher vorgelagerter, isolierter Tihāma-Berge gegeben: Dort legt zugleich das feuchtere und kühlere Klima geringere Höhen der Wohnhäuser nahe, weil zusätzliche Abkühlung nicht benötigt wird. Dies ergibt jene bereits als regionale Ausnahmen für niedrige Wohnhäuser erwähnte Formen: Es handelt sich dabei also um vereinzelte architektonische Defensiveinrichtungen im nördlichen und im Südwest-'Asīr, (J. Fayfā und J. B. Mālik) die im Grunde denen in Teilen des südlichen Hijāz ähneln: Einige ein-, zwei- oder dreigeschoßige Steinhäuser sind um einen oder zwei Wehrtürme gruppiert.

Insgesamt aber sind Einzelgehöfte und Streusiedlungen in der Steinarchitektur des 'Asīr noch häufiger als im Pagoden- und Lehmwulst-Stil der östlicheren Regionen. Die eindeutig besseren defensiven Schutzeigenschaften des Materials sind dafür sicher ein maßgeblicher Faktor. Die massive, defensiv optimal eingerichtete Form des steinernen Zwischenschachtgebäudes ist dementsprechend fast immer ein Einzelgehöft und fast nie Teil einer Frontsiedlung. Das steinerne Zwischenschachtgebäude bietet genügend Wohnraum, um die Anlage von Weilern zu vermeiden, und es bietet genügend Schutz, um auf „in-towers“ und Frontbildung mit anderen Häusern (die eher selbst eine potentielle Bedrohung wären) zu verzichten.

Einzelgehöfte und Streusiedlungen sind aber auch in der Steinarchitektur insgesamt die eindeutig dominante Form, und sie bilden im Pagoden- und Adobe-Stil ebenfalls einen substantiellen Anteil an den Siedlungsmustern. Dies bedeutet, daß die entscheidende architektonische Defensivverantwortung in all diesen Fällen dem Einzelhaus zufällt. Und umgekehrt sind Einzelhäuser und Streusiedlungen unter den Bedingungen latenter tribaler

210 cf. Abschnitt 4, Dostal 1983c: 53-55; Philby 1952: 228; Tuchscherer 1985: 54-56.

211 Hariri 1981: 25; Abdulfattah 1981: Photo 21.

212 Dostal 1983c: 25-28. 
Fehden und staatlicher Militärinterventionen historisch nur dort möglich, wo das Einzelhaus entsprechend defensiv gerüstet ist. Wo schon durch die klimatischen Bedingungen die Errichtung von hochgelegenen Obergeschoßen ohnedies erstrebenswert ist, dort wird es wesentlich sinnvoller, diese selbst defensiver auszurüsten und auch aus konfliktuellen Gründen so hoch wie nötig zu bauen. Die Wohnhäuser werden dann die entscheidenden Träger der Defensivarchitektur. Spezialisierte Verteidigungstürme im Wohnbereich werden dann selten, weil überflüssig. „In-towers “ sind also im 'Asīr und W. Najrān spezifizierbare seltene Ausnahmen - nämlich in „Frontsiedlungen“ wie al-Khalef oder im W. Najrān, im Gipfelbereich der J. Fayfā und J. B. Mālik, oder im Übergangsgebiet des Nord- 'Asīr zum südlichen Hijāz. Generell aber sind „, in-towers “ im 'Asīr und W. Najrān deshalb nicht oder kaum vorhanden, weil die hohen, defensiven Wohnhäuser erstens häufig als Einzelgehöfte oder in Streusiedlungen errichtet sind und dann keinen zusätzlichen Schutz gegen Nachbarn benötigen, und weil sie zweitens generell selbst die Hauptlast der architektonischen Defensivaufgaben nach außen übernommen haben.

Frontsiedlung, in-tower und bewehrter, hoher Wohnbau sind also die drei grundsätzlichen Defensiveinrichtungen in der tribalen Architektur des Hochlandes im Südwesten Saudi Arabiens. Aus diesem architektonischen Inventar einer defensiven „Triade“ wird im 'Asīr und W. Najrān primär das dritte Element genutzt, das manchmal (al-Khalef, W. Najrān) auch mit den beiden ersten kombiniert auftritt, die vereinzelt auch miteinander und ohne das dritte Element vertreten sind (J. Fayfa und J. B. Mālik, Nord-'Asīr). Generell aber dominiert im 'Asīr der freistehende, defensive und mehrstöckige Wohnbau ohne intowers.

Die Höhe und das Material sind bei diesem dritten Element der Triade die primären Defensiveinrichtungen. Die festen Grundmaterialien Stein oder Lehmwülste (Adobe- und Pagoden-Stil) sind vor der letzten Einfuhrwelle von moderner Waffentechnologie nach 1945 massiv genug gewesen, um auch den bis dahin regional üblichen Feuerwaffen zu widerstehen. Soferne es sich nicht um türkische Kanonen handelte, boten diese Materialien auch vor den älteren Feuerwaffen besten Schutz. Belagerungen von Häusern oder Siedlungen sind in den chronischen tribalen Fehden wohl eher die Ausnahme gewesen als bei den punktuellen Angriffen staatlicher Truppen. Die Defenisivfunktion der festen Mauern wurde also häufiger zur Deckung als im frontalen Stellungskampf benötigt. Dabei entzog die Höhe der Wohnräume ihre Bewohner der Zielgenauigkeit der Angreifer, ob diese nun mit älteren Feuer- oder mit Wurfwaffen operierten. Zugleich boten die hochgelegenen Stockwerke die Möglichkeit des kontinuierlichen Ausblickes in Gefahrenzeiten und den strategischen Vorteil, im aktuellen Konflikt aus der Deckung heraus von oben nach unten kämpfen zu können.

Daneben ergaben die Hochbauten aber auch die beschränkte Möglichkeit zum punktuellen, bewaffneten Angriff von oben im Bereich der Schußweite, also innerhalb der eigenen Siedlung oder um Umkreis des Einzelhauses - was gemäß der tribalen Logik von Ehre und Herausforderung nicht unbedingt eine Seltenheit darstellt. Die Eigenschaften dieser Wohnhochbauten im Bereich der Konfliktaustragung liegen primär im defensiven, aber sekundär auch im offensiven Bereich. In jeder Hinsicht sind diese Eigenschaften jenen ebenbürtig oder überlegen, welche niedrigere Wohnbauten rund um in-towers aufweisen.

Auch im 'Asīr und W. Najrān weist die defensive Hochbauweise von Wohnbauten ohne in-towers auf Grundlage der bereits diskutierten Material- und Konstruktionseigenschaf- 
ten eine Reihe von weiteren defensiven Einrichtungen auf, die bei allen Materialformen (Varianten oder „Stilen“) gegeben sind und für den gesamten Typus gelten. Dies sind niedrige Eingänge, die Eindringlinge dazu zwingen sich zu bücken, ferner die sparsame Verwendung von Schießscharten in allen unteren Geschoßen, und schließlich die Umwehrung der Dachterrasse(n) mit den Mauerkronen. Die zusätzlichen Defensivfunktionen, die man bei Häusern mit Zwischenschacht durch dessen Rückversetzung in der Fassade erzielt, ist bereits diskutiert worden. Alle anderen, kleineren Defensiveinrichtungen sind jeweils materialspezifisch und daher im Zusammenhang mit den jeweiligen „Stilen“ zu erörtern.

Das Vorwiegen von Einzelbauten, die häufige Abwesenheit von in-towers, die Kombinationslösung von tragenden Innenmauern mit innen geführten Stiegen zur Hochbauweise, die klimatische Nutzung der hochgelegenen Wohnräume, und die zusätzliche defensive Ausstattung dieser Hochbauten mit niedrigen Toren, Schießscharten und Dachbrüstungen sind also die charakteristischen Eigenschaften der Wohnarchitektur im 'Asīr und W. Najrān.

$\mathrm{Zu}$ diesen Eigenschaften treten als weitere generelle Merkmale die besonderen Akzente der Dekorierung dieses Subtyps und seiner Varianten hinzu. Für die Dekorformen der Wohnarchitektur im 'Asīr und W. Najrān sind, im Unterschied zu jenen des südlichen Hijāz, die geringere Bedeutung des Holzdekors und weiters die Betonung von Wandmalerei und von materialspezifischem Dekor typisch.

Die geringere Bedeutung des Holzdekors ergibt sich aus den konstruktiven Besonderheiten des Subtyps: Da ohnedies die tragenden Innenmauern das Gewicht der (drei bis sechs) Geschoße halten, kommen hier jene hölzernen Stützpfeiler kaum zur Anwendung, die bei den ein- bis zweigeschoßigen Wohnbauten des südlichen Hijāz zugleich die wichtigsten Dekorobjekte der dortigen Dorfarchitektur sind. Die Eingangstüre und hölzerne Fensterrahmen der Obergeschoße sind daher im 'Asīr und W. Najrān zwar die wichtigsten Trägerobjekte von geschnitzter Dekorierung. Ihre Qualität übertrifft aber jene des südlichen Hijāz nicht (wo Türen und Fensterrahmen in dieser Hinsicht der Bedeutung des Stützpfeilers erst mit großem Abstand folgen). Da die unaufwendigere Holzdekorierung im 'Asīr und W. Najrān im Prinzip von derselben Statusgruppe von Wanderhandwerkern hergestellt wird wie jene des südlichen Hijāz, verzichte ich auf ihre gesonderte Darstellung für die drei- bis sechsgeschoßigen Wohnbauten.

Der materialspezifische Dekor der Varianten im 'Asīr und W. Najrān hebt sich jeweils ab vom südlichen Ḥijāz, wo das Grundmaterial der Wohnbauten ja durchgängig (unverputzter) Stein ist, dessen beschränkter Raum für Dekorformen dort relativ uniform genutzt wird. Die Uniformität des wichtigsten Baumaterials und seiner darüber hinausgehenden Nutzung zur Dekorierung ist also ein markanter Unterschied zum Subtypus im 'Asīr und W. Najrān - der allerdings optisch und ästhetisch weitaus bedeutsamer ist als in konstruktiver Hinsicht. Die drei Varianten dieses Subtypus sind durch das jeweilige Grundmaterial charakterisiert - nämlich Lehm, Stein und schließlich Lehm zusammen mit Stein. Die spezifischen Dekorformen, die auf dem jeweiligen Grundmaterial aufbauen, werden im Zusammenhang mit den jeweiligen Varianten näher diskutiert. Insgesamt ergibt sich aber eine weitaus größere Heterogenität dieser variantengebundenen Dekorformen im 'Asīr und W. Najrān als Unterschied zur Uniformität des südlichen Hijā̄z, allerdings einschließlich einer teilweisen technisch bedingten, größeren Ähnlichkeit der Dekorierung an der Steinarchitektur des südwestlichen und nördlichen 'Asīr zu jener des südlichen Hijāz. 
Die Betonung der Wandmalerei schließlich hat ebenfalls materialspezifische Akzente, aber vor allem folgt sie einer regionalen Besonderheit. Materialspezifisch ist Lehm der Adobe- und der Pagoden-Variante als primärer Baustoff gemeinsam, der im einen Fall größere, im anderen Fall kleinere Flächen der Fassaden bildet. Die Lehmfassaden der beiden Varianten sind leichter zu verputzen als Stein. Dieser Verputz kann zu einer Außenbemalung ausgestaltet werden. Deren Funktion ist teilweise klimabedingt (was wiederum im Zusammenhang der Einzelvarianten zu diskutieren ist); teilweise aber entspricht diese weiße Ummalung der äußeren Fenster und Türen dem weißen Zierstein an den analogen Stellen in der Steinarchitektur des südlichen Hijāz, des nördlichen und des südwestlichen 'Asīr. In diesem materialunabhängigen Sinn handelt es sich um gemeinsame dekorative Akzentuierung aller Varianten und Subtypen, die erst am Ende des Kapitels für den gesamten Typus des südwestlichen Hochlandes erörtert wird.

Dieser regionale Zusammenhang ist für die defensive Hochbauweise des 'Asīr generell gegeben, und zwar in Form von bunter Bemalung der Wände des Wohn- und Versammlungsraumes. Hingegen tritt derartige Innenwandmalerei kaum im W. Najrān und im südlichen Hijāz auf. Diese dekorative Besonderheit der tribalen Wohnhäuser des 'Asīr wird anhand einiger dokumentierter Varianten beschrieben und ebenfalls am Ende des gesamten Kapitels interpretiert. Die Heterogenität der materialspezifischen Dekorierung und die Wandmalereien in den Wohnräumen des 'Asìr sind demnach Grundelemente einer dekorativen Ausdrucksweise, mit der die südwestliche, defensive Hochbauweise ausgestattet ist.

Aber auch jenseits des Dekors ist die lokale Architektur in ihrer Gesamtheit Bedeutungsträger zentraler Wertvorstellungen. In allen drei Varianten, deren Eigenschaften nun näher zu untersuchen sein werden, stellen die Hochbauten nämlich nicht nur mittels ihres Dekors, sondern in ihrer Gesamtheit ein traditionelles Zeichen von Wehrhaftigkeit, politischer Selbständigkeit und nicht zuletzt von tribaler Ehre dar. Einschränkungen für oder Zerstörungen an der Hochbauweise haben daher sowohl praktische wie symbolische Bedeutung: Dies gilt für das Gebot, daß Familien von niedrigem, nicht-tribalen Status keine drei- bis sechsgeschoßigen Bauten bewohnen dürfen, was ihre permanente Ausgrenzung von tribaler Wehrhaftigkeit und Ehre hier viel markanter als im südlichen Hịjāz ausdrückt (wo, sieht man von den hohen in-towers ab, viele tribale Wohnhäuser ebenso niedrig sind). Und ebenso gilt dies für staatliche Beziehungen. Seit dem islamischen Mittelalter ist es üblich gewesen, daß erfolgreiche staatliche Militärexpeditionen gegen lokale staatliche oder tribale Führungen damit abgeschlossen wurden, daß man die Türme und Wohnbauten der Unterlegenen „kürzte“: Die Gebäude wurden nicht immer zerstört (um die Erniedrigung des Gegners in Grenzen zu halten), aber eine Einschränkung ihrer Geschoßhöhe wurde häufig dekretiert oder erzwungen. ${ }^{213}$ Derartige Formen von „architektonischer Entwaffnung “ als Zeichen politischer Unterwerfung und nachhaltiger Herausforderung der Ehre sind bis in das 20. Jh. das symbolische Gegenstück zur defensiven Hochbauweise Südwestarabiens geblieben.

Wir haben damit die konstruktiven Merkmale jenes Subtypus von defensiver, südwestlicher Hochbauweise identifiziert, der im 'Asīr und W. Najrān vorherrscht. Dies erlaubt einerseits die Abgrenzung zum nordwestlichen Subtypus, wie er im südlichen Ḥijāz gegeben ist. Zum anderen leiten sich daraus konstruktive und materialbedingte Bestimmungen für

213 Gingrich und Heiß 1983: 172. 
die einzelnen empirischen Formen dieses südöstlichen Subtyps ab: Das gemeinsame Prinzip des Subtyps (tragende Innenmauern mit Stiegen) ist auf drei verschiedene Arten gelöst (einfache Stützmauern, Mauerngeviert und Zwischenschacht), die sozialen Kriterien zugeordnet werden können. Diese drei Kombinationslösungen finden in jeder der drei regionalen Arten von Materialnutzung (Varianten“,Stile“) ihre Anwendung - also im Steinbau, bei den Adobe-Bauten und den Pagoden-Gebäuden. Daraus ergeben sich bereits neun empirische Grundformen für Wohnbauten dieses Subtyps - je drei Kombinationslösungen für drei „Stile“, von denen die drei einfachsten zugleich die häufigsten sind. Das defensive, „triadische“ architektonische Inventar kombiniert oder modifiziert diese neun dominanten Grundformen manchmal mit ergänzenden Anlagen des Siedlungsmusters und von Türmen. Die dominanten Grundformen sind aber primär als Einzelgehöfte oder in Streusiedlungen errichtet. „Frontsiedlungen“ sind in Adobe- und Pagoden-Stil etwas häufiger, bei Steinbauten des 'Asīr hingegen eine seltene Ausnahme. Daher sind die raren steinernen Zwischenschachtgebäude kaum in Frontsiedlungen anzutreffen. In-towers sind im 'Asīr und W. Najrān äußerst selten; sie treten nur in manchen Frontsiedlungen auf, sowie im Südwest- und Nord-'Asīr, dort aber jeweils in Verbindung mit klimabedingten Ausnahmen von niedrigeren Wohnbauten. Als Türme wurden prinzipiell nur einräumige, vielgeschoßige Gebäude ohne Innenmauer definiert, die in diesem Subtypus von rundem oder rechteckigem Grundriß sein können. Auch sie treten in jedem der drei Stile auf, aber meistens in der dominanten Position als „out-towers“. Als eine Sonderform, die aus dem Konstruktionsprinzip der Zwischenschacht-Gebäude abgeleitet ist und nur im Steinbau angetroffen wurde, ist der freistehende Schachtturm des West-'Asīr identifiziert worden.

Damit ist nicht bloß ein erstes methodisches Instrumentarium erstellt, um die technische und soziale Bestimmung der Formenvielfalt von Wohnarchitektur im 'Asīr und W. Najrān zu gewährleisten. Drei mal drei Grundformen als Einzelbauten und in Streusiedlungen mit diversen $\mathrm{Zu}$ - und Anbauten bei den drei häufigsten Formen, und daneben die um in-towers gruppierten lokalen Sonderformen von Frontsiedlungen und von Weilern aus niedrigeren Wohnhäusern - all dies vermittelt auch einen ersten Überblick über die praktische und symbolische Kreativität, mit der die Bevölkerung von 'Asīr und W. Najrān das kulturhistorische Erbe südwestarabischer Hochbauweise bewahrt, entwickelt und ausgestaltet hat.

\subsubsection{Südwestarabische Lehmbauweise: Adobe-Bauten im Ost-' ${ }^{`}$ Asīr und W. Najrān}

Nach dieser notwendigerweise umfangreichen, konzeptiven und methodischen Klärung von Gemeinsamkeiten (Typus) und Unterschieden (Subtypus und Varianten) innerhalb der südwestlichen Hochbauweise können nun die einzelnen Varianten selbst diskutiert werden. Dazu knüpfen wir bei jener typologischen Differenzierung wieder an, die zuletzt empirisch (Abschnitt 6.4.) behandelt wurde - nämlich jener zwischen ländlichen, innerarabischen Najd-Bauten und der südwestarabischen Lehmbauweise.

Wie erinnerlich, sind die ländlichen Najd-Bauten meist ebenerdig und nutzen zur Raumüberspannung eine Steinsäule mit fragiler Dachkonstruktion. Charakteristisch sind ferner die dreieckigen Fenster, die Anlage eines Außenhofes, und die Abwesenheit von Defensiveinrichtungen und Dekor.

Nachdem nunmehr die großen architektonischen Gemeinsamkeiten im 'Asīr und W. Najrān (Subtypus) herausgearbeitet worden sind, dürften die Unterschiede dieser speziel- 
len Variante gegenüber der ländlichen Najd-Architektur noch deutlicher hervortreten als im unmittelbaren Vergleich. Die für die defensive Hochbauweise charakteristischen Kombinationslösungen (tragende Innenmauern mit Innenstiegen und massive Geschoßumspannungen) sowie die markanten Defensiveinrichtungen des gesamten Typus sind auch in der Adobe-Variante gegeben, die darüber hinaus spezifische Materialeigenschaften und Dekorelemente aufweist, aber keine dreieckigen Fenster und kaum Außenhöfe hat. Ummauerungen schließen hier Gärten, aber selten Höfe ein. An diesen Adobe-Bauten des saudischen Südwestens sind die charakteristischen materiellen, konstruktiven und raumfunktionalen Eigenschaften der Wohnbauten und Türme zu behandeln, und im Anschluß daran die Unterschiede zwischen den Formen im Ost- ${ }^{-}$Asīr und im W. Najrān, die vor allem am Dekor deutlich werden.

Das dominante Material dieser Variante ist ein ungebranntes Lehmgemisch, das in einer spezifischen Aufbereitung und Mischung als Baumaterial für Wohnbauten und Türme verwendet wird. Ohne hier näher auf den Arbeitsprozeß selbst einzugehen soll zunächst dieses Baumaterial diskutiert werden.

Bauen in Lehm ist zum einen an örtliche Vorkommen des Materials gebunden, zum anderen ist es nur innerhalb relativ trockener, heißer klimatischer Schwellenwerte möglich. Von diesen beiden Faktoren stellt der erste im saudischen Südwesten die geringeren Probleme; geeignete Vorkommen scheinen im Hochland überall in Siedlungsnähe gegeben zu sein. Neben der Nähe zu agrarischen Anbauflächen und Wasserquellen ist das Vorkommen derartiger Lehmgruben damit als positiv standortprägend für die Siedlungslagen anzusehen.

Die klimatischen Schwellenwerte geben andererseits negative Verbreitungsgrenzen vor, jenseits derer die Niederschläge zu häufig und zu hoch ausfallen, die Fluten zu reißend sind, oder die Luftfeuchtigkeit zu hoch wird (an der Küste), als daß ungebrannter und ungeschützter Lehm derartigen Witterungsverhältnissen widerstehen könnte.

Aus diesem Grunde treten Adobe-Bauten erstens nur im südlichen Teil des saudiarabischen, südwestlichen Berglandes auf, wo die durchschnittlichen Jahrestemperaturen höher und die Niederschlagsmengen niedriger sind als im Nord-'Asīr oder im südlichen Hijāz. Das Verbreitungsgebiet von Adobe-Bauten im Ost-'Asīr und dem W. Najrān ist das nördlichste in Südwestarabien; wie erwähnt, setzt es sich aber nach Süden hin kontinuierlich in den Jemen fort.

Zweitens bedingen die klimatischen Schwellenwerte, daß Adobe-Bauten nie unterhalb des Grabenrandes (Shifā ${ }^{-}$), und oberhalb des Grabenrandes nur in wenigen Ausnahmefällen (bei Zahrān al-Janūb) direkt beim Grabenrand, also im Nahbereich an der Shifāe vorkommen. Die Shifā̄ und, von der Ausnahme bei Zahrān abgesehen, der angrenzenden Hochlandrücken markieren also eine primär ökologisch bedingte Verbreitungsgrenze der Adobe-Architektur nach (Nord-) Westen hin. Hinzu kommt, daß rund um die Shifā' Stein in handlichen Formen das reichlich vorhandene und natürliche verfügbare Baumaterial ist.

Das Gebiet der Adobe-Bauten ist durch diese klimatischen Schwellenwerte also nach Norden und Westen hin negativ begrenzt und damit auf die Ostabhänge und östlichen Ausläufer des Hochlandes konzentriert. Innerhalb dieser negativen Verbreitungsgrenzen gibt Lehm jenes Material ab, das ohne zwingenden Aufwand von spezialisierter oder abhängiger Arbeit genutzt werden kann (wie das vegetabile Material für die 'ushash, die ja hier ebenfalls auftreten). Zugleich erfüllt das Material durchaus die Anforderungen der Defen- 
sivfunktionen und der Hochbauweise (wie Stein, der hier aber primär als Fels auftritt und daher als systematisch eingesetztes, zentrales Baumaterial einen enormen Arbeitsaufwand voraussetzt - der in der Antike offenbar eher als heute zur Verfügung stand).

Innerhalb jener negativen, ökologisch bedingten Verbreitungsgrenzen sind es also die Anforderungen einer freien Arbeitsorganisation kleiner Lokalgruppen für die Zwecke der defensiven Hochbauweise, die den positiven Ausschlag für Lehm als zentrales Baumaterial geben.

Lehmziegelbauten setzen wiederum nicht zwingend spezialisierte, aber meist abhängige Arbeit voraus und erfüllen defensive Aufgaben bloß mit Ergänzungen. Das Bauen mit Lehmwulsten erlaubt hingegen die Anlage dicker Außenmauern, die sowohl tragen wie schützen. Druck- und Klimaschwankungen können durch die Wulstlagen bis zu einem gewissen Grad aufgefangen werden.

Die Grundsubstanz ist aus lokalen Gruben gewonnener natürlicher Lehm, den man mit Wasser, Häcksel, Sand und Mist verrührt und mischt, einschließlich einer letzten Phase, in der diese Masse geschlagen und durchgetreten wird. Das Lehmgemisch rastet dann einige Tage, wozu es manchmal auch mit Erde überdeckt wird. In dieser Zeit verbinden sich die Mischstoffe zum Baumaterial, das dann nochmals angerührt und mit den Händen zu Klumpen geformt wird, aus denen man die Adobe-Wulste errichtet. ${ }^{214}$ Der eigentliche Bauprozeß beginnt aber auch bei der Errichtung dieser Gebäude nicht mit Lehm (den man währenddessen anrichtet), sondern mit Stein. In die ausgehobenen Gräben für AuBenmauern (harra) und tragende Innenmauern ('așla, 'uṣla) wird das entsprechende Steinfundament (rabad) versenkt. Diese gut behauenen Steinquader sind auch das Baumaterial der tragenden Innenwände in deren voller Höhe. Auch der Stiegensockel und die Türstöcke des Eingangs (jāmic; al-bāb al-jāmic ${ }^{c}$ ) sind manchmal aus Stein errichtet, ebenso wie die Stöcke der großen Fensteröffnungen mancher Obergeschoße.

Ein quantitativ kleiner, aber qualitativ wichtiger Anteil der Konstruktion von Lehmbauten ist also immer aus Stein. „Reine“ Lehmbauten gibt es zumindest im Südwesten Saudi Arabiens nicht; Stein und selbstverständlich Holz (zur Überspannung) sind essentiell: ohne Stein und Holz wären mehrgeschoßige Adobe-Bauten nicht konstruierbar. ${ }^{215}$

Die Wulste aus Lehmgemisch (zabūr) heißen midmāk (pl. midāmik), sie sind jeweils etwa $50 \mathrm{~cm}$ hoch und mindestens $75 \mathrm{~cm}$ dick. Diese Wulste werden von Innen her aufgelegt. In der Länge durchläuft ein Wulst idealerweise alle Seiten der Außenwände, was die charakteristischen, horizontalen und parallelen Streifen der unverputzten Fassaden ergibt. Nur an den Stellen für Außentüren, Schießscharten und Fenster werden die Wulste unterbrochen und mit Holz oder Stein verschalt, um die Stöcke einzusetzen. ${ }^{216}$ Im niederschlagsreicheren Ost- ${ }^{C}$ Asīr werden über den Fensteröffnungen hervorragende Schieferplatten eingemauert, die Regenschutz bieten und zugleich auf die benachbarte PagodenVariante verweisen. Nach der Fertigstellung jedes Wulstes wird ein Intervall von ein bis zwei Tagen eingeschoben, bis er trocken und fest genug ist, um Grundlage für den nächsten abzugeben.

214 Lewcock 1976: 16; King 1976: 26. King meint dazu, das Vergraben der Lehmmasse mache das lokale Material gegen Regen resistenter.

215 Vielleicht war dies auch in den Mitteilungen eines Gewährsmannes an Passama im frühen 19. Jh. gemeint, wonach Badra als Hauptort des W. Najrān „aus Stein und Stroh “gebaut sei (Passama 1843b: 226).

216 Maréchaux 1998: 90. 
Im Querschnitt ragt der Unterrand jedes Wulstes an der Fassadenseite über dem Oberrand des darunterliegenden Wulstes hervor; sein eigener Oberrand wird jedoch gegenüber dem Oberrand des darunterliegenden Wulstes leicht zurückversetzt. Dies ergibt jene nach innen gerichtete Neigung der Außenwände, ${ }^{217}$ die bei Adobe-Bauten prononcierter ist als bei den beiden anderen Varianten von Hochbauten (Abb. 84). Wie erwähnt, ist dies aufgrund der geringeren Festigkeit des Materials der Außenwände eine ergänzende statische Vorkehrung, die zugleich das Wandgewicht gleichmäßig im Material verteilt. Die Innenseite der Außenwände ist hingegen nahezu senkrecht gezogen. Die Wulste werden also von unten nach oben immer schmäler, und zwar um jenes Volumen, das der Neigungswinkel der Fassade festlegt. An den Enden jeder Fassadenseite schließlich sind die parallelen Wulste jeweils zu Ecken hochgezogen, die auf Erhöhungen im Steinfundament ruhen. Wie Lewcock bemerkt hat, führt dies dazu, daß das Gebäude mit zunehmendem Alter und damit einhergehenden Rissen und Sprüngen in der Mauer dazu tendiert sich zu konsolidieren, weil diese verstärkten Ecken sich nach innen schieben. ${ }^{218}$

Diese Fassadenecken, durch welche die erhöhten Wulste ja ohne Unterbrechung durchlaufen, sind also außen rund. Nur bei jener Minderheit von Adobe-Bauten, deren Fassade nachträglich mit Lehm glatt verputzt ist, können auch die Fassadenecken scharf und nicht rund gezogen werden.

Die Decken der Geschoße werden mit Trägerbalken ('aslah, 'islih) aus Akazien- oder Palmstämmen eingezogen, auf welche quer ein dichtes Netz von Ästen (rāḥil, pl. ruḥ̣al) und Zweigbündeln $\left(\operatorname{jară}^{-}\right.$) aufgelegt wird, über welchem die oberste Lehmschicht aufgetragen wird. ${ }^{219}$

Die Treppen der jeweiligen Kombinationslösungen sind normalerweise Steinplatten. Im W. Najrān und den Oasen des Ost-'Asīr werden sie Lehmstufen aufgelegt, die ihrerseits auf der flachen Seite gespaltener Baumstämme ruhen. Dieses Prinzip, das auch in den örtlichen Moscheen Verwendung findet, führt die Palmstammtreppe ('ișfa) von einer Plattform zur nächsten. ${ }^{220} \mathrm{Im}$ übrigen Verbreitungsgebiet der Adobe-Bauten, also nordwestlich von Najrān zwischen Ẓahrān und Khamīs Mushayț, werden die Lehmstufen auf runden Hölzern von der Art der Deckenbalken geführt, oder auf Stein- und Lehmsockeln (mic ${ }^{c}$ sar) aufgebaut. ${ }^{221}$

Ein Vorteil der Adobe-Konstruktion (aber auch jener von Pagodenbauten, Abb. 90) ist die Möglichkeit, die Innenräume mit diversen Zubauten und Aussparungen plastisch ausgestalten zu können. Für Zubauten im Rauminneren kann ja dasselbe Lehmgemisch verwendet werden, das ohnedies während des Hausbaues ständig bereitstehen muß. Und für Aussparungen (Wandvertiefungen) bietet dieses formbare Material weitaus mehr Möglichkeiten als die Steinbauten im 'Asīr und südlichen Hijāz. Vor allem die Wohnräume, aber auch Küche und Magazine sind daher durch diese beiden Gestaltungsmöglichkeiten geprägt. Aussparungen sind Nischen und Wandverbauten; die wichtigsten Zubauten sind Regale (raff, pl. rufūl), Herde und Feuerstellen, sowie vor allem Lehmbänke entlang von drei Wänden der diwāne (mafraj). Von den Männerräumen getrennte diwāne der Frauen

217 ef. inter alia Lippens 1956: 124-126 für das W. Najrān.

218 Lewcock 1976: 16.

219 Mauger 1993: 22.

220 Tamisier 1840 II: 299-303; cf. auch King 1986: 100, 102 f., 110, 113.

221 Lippens 1956: 59. 
scheinen im Verbreitungsgebiet der Adobe-Bauten etwas häufiger zu sein als im Westund Nord-'Asīr.

Dies führe ich allerdings nicht auf konstruktive oder materielle Eigenschaften der Adobe-Architektur selbst zurück, sondern ich interpretiere es analog den Analysen zur Architektur der Tihāma als Ergebnis von kontinuierlichen Einflüssen staatlicher und gelehrter Tradition auf diese Architektur. In dieselbe Interpretationsrichtung deutet eine zweite, besondere Raumfunktion, die im Verbreitungsgebiet dieser Variante etwas häufiger ist als in jenen der beiden anderen. Gemeint sind eigene Toiletten und Waschräume (hammām), manche mit anschließendem Gebetsraum im Wohnhaus.

Diese Bade- und Gebetsräume können in einem der Geschoße liegen, in denen auch ein diwān untergebracht ist. Ihre Funktion wirkt sich auf die Anlage dahingehend aus, daß der Toilettenabfluß durch eine der Steinwände oder die Rückseite ins Freie führt, aber nie an der Eingangsseite der Fassade. Vorrichtungen am Fuß der Außenwand zum Auffangen des Kots (für seine weitere Nutzung als Dünger, wie sie aus dem Jemen bekannt sind ${ }^{222}$ ) treten hier nur vereinzelt auf. Manchmal ist im Wohnhaus ein Schacht eingerichtet, durch den Bad und Küche über eine Seilwinde mit Wasser versorgt werden können, das aus einem ebenerdigen Becken geschöpft wird. Wenn es in diesen Wohnhäusern ein ḥammām und einen eigenen Gebetsraum gibt, so liegen die Räume meistens nebeneinander, um die Wassernutzung für die rituellen wie für die profanen Waschungen gleichermaßen zu erleichtern. Sondereinrichtungen (wie Kotrecycling und Wasserschacht) sind aber selbst unter den wenigen Häusern, die Bade- und Gebetsräume aufweisen, eine Rarität. Üblicherweise wird das Wasser in diese Räume nicht gezogen, sondern getragen, und der Abfall am Fuß der Außenwand wird nicht weiter genutzt, sondern er verrottet.

Diese Zusatzräume verweisen auf ihre eigene architektonischen und sozio-kulturellen Voraussetzungen: Architektonisch ist zunächst das Lehmmaterial durch seine plastische Gestaltbarkeit und durch den Verputz über dichterem ritzenlosen Material (im Gegensatz zu trockem verlegten Stein) weit besser zur Anlage von Abflüssen geeignet. Dies ist ein erster (technischer) Grund, warum die Bade- und Gebetsräume bei Adobe- und PagodenBauten häufiger als in Steinbauten zu finden sind. ${ }^{223}$ Zweitens stellen Zusatzräume wie Frauen-diwān, Bad und Gebetsraum eine erhöhte Raumanforderung dar, welcher die häufigsten Binnenwandbauten mit ihrer geringen Anzahl an kleineren Räumen selten gewachsen sind.

Logischerweise sind diese Zusatzräume, wenn sie überhaupt angelegt werden, daher in Innen- und Zwischenschachtbauten untergebracht. Und dies bedeutet, daß sie Teil der Wohnkultur von reicheren und sozial privilegierten Haushalten sind.

Während der separierte Frauen-diwān in größeren Steinbauten des 'Asīr nahezu ebenso häufig (oder selten) ist wie in Adobe- oder Pagoden-Bauten, ${ }^{224}$ treten hammām und Gebetsraum in den Innen- und Zwischenschachtbauten dieser beiden letztgenannten Varianten häufiger auf als in Steinbauten. Als erster Grund dafür ist die bessere Eignung von Lehmgemisch als dem Grundmaterial beider Varianten für die Gestaltung der Abflüsse genannt worden.

222 Gingrich und Heiß 1986a: 92f., 95, 116.

223 Philby 1952: 130-132; Hariri 1981: 11, 26.

224 Lippens 1956: 59. 
$\mathrm{Zu}$ diesem technischen Grund tritt noch der zweite, sozio-kulturelle Faktor hinzu. Das Verbreitungsgebiet dieser beiden Varianten liegt ausschließlich im Hochland. Im Westen reicht es bis an den Grabenrand (die Shifa $\bar{a}$ ) heran, und zieht sich von dort über die Ostabhänge des 'Asīr in das W. Najrān hinein. Vier der fünf größeren städtischen oder stadtähnlichen Siedlungen von 'Asīr und W. Najrān liegen innerhalb des Verbreitungsgebietes von Adobe- und Pagoden-Bauten, nämlich Abhā (Pagoden-Variante), Khamīs Mushayṭ, Zahrān und die alte Hauptsiedlung des W. Najrān, Badr (Adobe-Variante). Hinzu kommt noch Bīsha im Nordosten, wo der Adobe-Stil in den innerarabischen Najd-Stil übergeht. Hingegen umfaßt das Verbreitungsgebiet der Steinvariante nur eine einzige stadtartige Siedlung, nämlich al-Nimāṣ weit im Norden des 'Asīr. Innerhalb der mehrgeschoßigen, defensiven Hochbauweise ('Asīr und Najrān) ist die Kombination des städtischen Elementes mit den Pagoden- und Adobe-Varianten daher substantieller und intensiver als gegenüber der Steinbauvariante.

Die städtische Tradition des Hochlandes im saudischen Südwesten konzentriert sich also hauptsächlich auf den Süden und Südosten dieses Hochlandes, und dies wiederum ist das Verbreitungsgebiet jener zwei von drei Varianten des mehrgeschoßigen Subtyps, die Lehm zum Grundmaterial haben. Die räumliche Konzentration auf den Süden, und dort auf dessen zentrale und östliche Teile, stellt eine offensichtliche Parallele zu den alten Traditionen im angrenzenden nord- und zentraljemenitischen Hochland dar.

In den Lehm bestimmter Adobe- und Pagoden-Bauten trägt sich also ein Faktor ein, welcher der tribalen Architektur selbst nicht immanent ist, sondern kulturhistorisch von außen kommt. Diesen Faktor erblicke ich aufgrund der angeführten Korrelation im intensiveren staatlichen Einfluß auf das Zentrum und den Südosten des südlichen Hochlandes von Saudi Arabien.

Der städtische Einfluß in dieser Region hat unterschiedliche historische Tiefen, und verschiedenartige staatspolitische und theologische Komponenten. Über die historische Zuordnung der genannten Zusatzräume zu bestimmten Perioden der lokalen Geschichte lassen sich in Ermangelung präziserer Quellenangaben nur mehr oder minder plausible Annahmen aufstellen: Die Entwicklung von Toilettenanlagen sehe ich als das rezentere Phänomen an, welches angesichts seiner Parallelen zur jemenitischen Architekturgeschichte mit der osmanischen Präsenz in Südwestarabien zwischen dem 16. und dem frühen 20. Jh. in Verbindung stehen dürfte. ${ }^{225}$ Gebetsraum und separierter Frauenraum könnten hingegen in ersten, punktuellen Ansätzen schon im islamischen Mittelalter Eingang in die lokale Architektur gefunden haben. Diese „Sonderräume“ sind direkte, räumlich-materielle Vergegenständlichungen theologischer und moralischer Prinzipien jener gelehrten Glaubenswege und der besonderen Betonung patrilinearer Orientierung, die der Islam in dieser Region im Prinzip seit dem 7. Jh. entfaltet hat.

Diese Annahme einer ungleichzeitigen, sukzessiven Einführung der Sonderräume ändert nichts an der Tatsache, daß sie seitdem einen architektonischen und sozialen Zusammenhang bilden, der bezeichnend ist. Erstens sind diese Sonderräume Bestandteil ,gehobener Wohnkultur" im ländlichen Raum, wodurch sich wenige privilegierte Haushalte vom Rest der tribalen Bevölkerung distinguieren. Zweitens hat sich auch hier diese geho-

${ }^{225}$ Lewcock und Serjeant 1983: 44. Die Autoren zitieren auch (S. 493) eine Stelle bei al-Hamdānī, bei der aber erst von „cess-pits“ die Rede ist. 
bene Wohnkultur, von städtischen Zentren aus, vorerst bei Teilen der ländlichen Oberschichten durchgesetzt, und ein Weg dieser Durchsetzung war die Vergegenständlichung zentraler, höchster moralischer und theologischer Wertvorstellungen in der Architektur.

Drittens eben bildet die Struktur dieser Sonderräume, zusammen mit den anderen Wohnzimmern der Bauten, eine explizit symbolische Aussage. Das Gebet als eine der fünf Säulen des Islam hat seinen spezifischen, getrennten Ort im Wohnhaus erhalten, der architektonische Alltag ordnet sich dem unter. Der geschlechtsneutrale Zustand der Unreinheit erhält demgegenüber seinen eigenen, besonderen Ort im hammām, und die geschlechtsspezifische Segregation wird als stabile räumliche Grenze materialisiert: Die Einrichtung der Frauenräume markiert die Festschreibung der rituellen Meidung zwischen den Geschlechtern, unter welchen den Frauen die Unreinheit regelmäßiger und unüberwindlicher zugeschrieben ist. ${ }^{226}$ Nicht bloß raumfunktionale Differenzierung, sondern zugleich rituelle Trennung ist die symbolische Aussage dieser Anlagen.

Der gehobenen Wohnkultur der ländlichen Oberschichten eingetragen ist also eine Ritualisierung des Alltags, in dem unreine Substanz (Kot) und zyklisch unreines Geschlecht (Frauen) separiert, und ein Ort besonderer Reinheit etabliert wird. Die rituelle Trennung impliziert zugleich eine hierarchische Wertung. Der Gebetsraum als „Ort der rituellen Reinheit“ und der Zuwendung zur göttlichen Gnade steht an der Spitze einer symbolischen Hierarchie, in welcher als nächstes mit dem Männerraum der „Ort der Ehre“ nachfolgt. Separierter diwān und die Küche der Frauen sind davon wiederum nicht nur getrennt, sondern dem auch untergeordnet. Das hammām schließlich markiert das untere, unreine Ende dieser Hierarchie, die insgesamt von den zentralen Werten der Gnade, der Reinheit und der Ehre strukturiert wird. Das räumliche Nebeneinander von hammām und Gebetsraum markiert die extremen Pole dieser Hierarchie der Werte, die der Ordnung der Räume und der Körper durch Architektur so auferlegt ist, daß sie zur Selbstverständlichkeit wird.

Es ist diese intensive „Einverleibung“ der zentralen Wertvorstellungen in die Architektur des Hauses und die choreographische Ordnung der Körper, welche den Alltag in einem dieser wenigen großen Wohnhäuser des gehobenen Lebensstils unterscheidet von der Masse einfacher, tribaler Defensivbauten. Selbstverständlich verrichten aber auch die Angehörigen der normalen tribalen Haushalte ihre Notdurft an separierten Orten, aber im Freien. Wenn von ihnen gebetet wird, so geschieht dies meist im Freien, manchmal im diwān oder am Dach; vielleicht befolgen manche unter ihnen auch die rituelle Meidung der Geschlechter. Aber dennoch hält die materielle Struktur der Architektur die Gewohnheiten der Angehörigen dieser einfachen Haushalte nicht permanent zu einem spezifischen rituellen Verhalten an. Zumindest theoretisch hätte die Nichtbefolgung jener ritualisierten Normen dort mehr Spielraum, wo sie noch nicht zu Lehm materialisiert sind. De facto allerdings sind sie meist auch dort in den Köpfen als ein noch unerreichtes Ideal vorgestellt, in welchem große Räume und mehr Hygiene mit der moralischen Notwendigkeit von ritueller Trennung zu einem homogenen Ganzen verschmelzen.

Das hier über die Zusatzräume Gesagte bezieht sich sowohl auf die Adobe- wie auf Pagoden-Bauten. Bei der nun folgenden Behandlung der Türme und der Innen- und Außendekorierung der Wohnbauten beschränken wir uns hingegen wieder auf die Adobe-Variante.

226 Bousquet 1950: 53-71. 
In-towers sind aus den bereits dargelegten Gründen unter den Adobe-Bauten des W. Najrān und des Ost-'Asīr etwas häufiger als in den beiden anderen Varianten, aber auch hier sind sie gegenüber out-towers in der krassen Minderzahl. Der Unterschied zwischen beiden ist zwar funktional wichtig, aber konstruktiv entsprechen beide Formen einander völlig.

Das entscheidende gemeinsame Merkmal der Adobe-Türme ist der außerordentlich häufig gegebene runde Grundriß. ${ }^{227}$ Viereckige Türme werden in der Adobe-Technik dieser Region aus materialbedingten Gründen viel seltener errichtet.228 Der runde Grundriß gewährleistet eine weit gleichmäßigere Belastung dieses Baumaterials, das weniger resistent gegen Druck, Erschütterungen, Temperaturschwankungen und Niederschläge ist als jenes der beiden anderen Varianten. Dort sind also sowohl runde wie vierkantige Türme üblich, hier sind häufiger runde Grundrisse gegeben.

Das Fundament der Adobe-Türme wird wie bei den Wohnbauten durch eine Steinreihe gebildet. Die Technik der Aufschichtung von Lehmwulsten ist ebenfalls dieselbe. Da aber keine Kanten gegeben sind, müssen die Wulste auch nicht an deren Ecken hochgezogen werden; ${ }^{229}$ sie verlaufen hier durchgängig in parallelen Ebenen zueinander. Die runden Außenwände sind zur inneren Abstützung meist stärker geneigt als bei den Adobe-Wohnhäusern, was den Türmen das Aussehen eines Kegelstumpfes verleiht, auf dem oben ein leicht vorragender Aufsatz liegt. Dieser Aufsatz wird durch überspannende Dachbalken gebildet, auf denen eine Brüstung ruht. Unterhalb der Brüstung kann ein Kranz jener „Nasen“ (mawshaq) angebracht sein, die im Zusammenhang mit dem Dekor erörtert werden, obwohl sie auch defensive Funktionen haben. Zusammen mit jenen der Schießscharten in den Außenwänden und der Brüstung selbst bilden sie die bescheidene militärische Ausstattung der Adobe-Türme, die überdies wegen der geringen Belastbarkeit des Materials oft nur drei Geschoße haben, also deutlich weniger als Pagoden-oder Steintürme.

Vereinzelt treten im Verbreitungsgebiet der Adobe-Variante auch Bauten aus Lehmziegeln auf. Dies sind manchmal Prestigebauten hochstehender Familien, ${ }^{230}$ häufiger handelt es sich um Moscheen, vor allem im W. Najrān. ${ }^{231}$ Diese traditionellen Ziegelbauten weisen keine der charakteristischen Elemente des Najd-Stiles auf; insgesamt handelt es sich um seltene Sonderformen im städtischen Nahbereich, ähnlich wie im jemenitischen Hochland. ${ }^{232}$

Da manche Dekorformen den Wohnbauten und den Türmen dieser Variante gemeinsam sind, bildet ihre ausführliche Diskussion den Schluß unseres Überblickes zur AdobeBauweise. Zugleich sind bestimmte Dekorformen auch das charakteristische Element von lokalen Unterschieden innerhalb der Variante, zwischen dem (nord-) westlichen und dem (süd-) östlichen Verbreitungsgebiet der Adobe-Bauten - also zwischen jenem, das sich von der Gegend um Khamīs Mushayṭ nach Zahrān al-Janūb erstreckt und jenem des W.

227 qașaba, wörtlich „Röhre“ bezeichnet, wie erwähnt (anders als bei Prochazka 1977: 118 angeführt) Rundtürme aller Baumaterialien im 'Asīr. Für das W. Najrān führt Prochazka die Dialektvariante "gṣibah" an.

228 Eine Ausnahme fand ich bisher nur auf einer Photographie Philby's aus dem Jahr 1936 (1952: 352, fig. 29).

229 Maréchaux 1998: 91.

230 Philby 1952: 299-303.

231 King 1986: 101, 106, 110.

232 Gingrich und Heiß 1986a: $153 \mathrm{f}$. 
Najrān. Letzteres wiederum teilt einige dekorative (und technische) Aspekte mit der Pagoden-Variante. Diese dekorativen Unterschiede an der Wohnarchitektur verweisen zunächst auf unterschiedliche sozio-kulturelle Akzentuierungen in der Vorgeschichte der Region um Khamīs Mushayṭ und im W. Najrān.

Das W. Najrān ist ein relativ geschlossenes, langgezogenes System von Talschaften mit inselartig auseinander liegenden größeren und kleineren Oasen (als „a broad oval of palms " beschreibt Philby die größte dieser Oasen). Rund um diese fruchtbaren Kernbereiche erstrecken sich die ausgedehnten, angrenzenden Steppengebiete. Dieses teils sehr fruchtbare, teils semiaride Talsystem wird traditionell mit Brunnen, Quellen und durch die periodischen Fluten aus dem entfernten Hochland bewässert. Seine Vorgeschichte ist einerseits geprägt von der kontinuierlichen Präsenz des teils seßhaften, teils nomadischen Stammes der Yām, ${ }^{233}$ deren traditionelle Steppengebiete sich weit nach Innerarabien ausdehnten, wo im Osten manche Brunnen mit Stämmen des Najd (Dawāsir) und des Haḍramawt (Say'ar) geteilt wurden. Zum anderen war dieses Gebiet der Yām ab der ersten Hälfte des 17. Jh. dreihundert Jahre hindurch kontinuierlicher Lokalsitz eines isma ${ }^{c} \bar{l}$ litischen Glaubensweges mit quasi-staatlichem Anspruch, der vom Verband der Makramī getragen wurde. ${ }^{234}$ Die Elemente staatlicher Vorgeschichte in Najrān sind aber bekanntlich weitaus älter, sie reichen über das islamische Mittelalter ${ }^{235}$ bis in die Antike zurück, aus welcher Zeit die steinernen Ruinen von al-Ukhdūd stammen, ${ }^{236}$ einer einst blühenden Station an der alten „Weihrauchstraße“. In der ausgehenden Antike gelangte die römische Expedition 25/24 v. Chr. unter Aelius Gallus bis in dieses Gebiet, und im 5. Jh. war Najrān der Schauplatz des berühmten Martyriums seiner christlichen Gemeinde. ${ }^{237}$ Nach Najrān schickte der Prophet Muhammad Emissäre und später Statthalter, und auch in den ersten Jahrhunderten des Islam blieb es von überregionaler Be-

233 Die Yām des 20. Jh. sind der nördlichste Teilstamm der großen Hamdān-Föderation des zentralen und nordöstlichen jemenitischen Hochlandes (Philby 1952: 225, 243; cf. auch Grohmann in EI' 1248f.); darauf spielt auch der Name einer Bergkuppe im W. Najrān an, die „Abū Hamdān" heißt (Philby 1952: 253). Im 10. Jh. nennt al-Hamdānī bereits die Yām als eine der Hauptgruppen der Region (im W. Haba), allerdings führt er auch noch die Banū l-Ḥārith) und die Hamdān (Wãdaca und wenige Wā’ila) als Bewohner von Najrān an. Die Banū l-Ḥārith) mit ihrer früher engen Beziehung zum lokalen Christentum (die Ka 'ba von Najrān ist bei al-Hamdānī noch erwähnt) dürften sich damals bereits in einer Phase des Niederganges und der Auflösung befunden haben; die Verbindung der Yām mit den Hamdān scheint im 10. Jh. nach den angeführten Quellen aber noch loser als im 20. Jh. gewesen zu sein; al-Hamdānī (Müller 1884-86: 67, 115, 118, 124, 127, 169, 188).

234 Der Hauptsitz der Makramī im W. Najrān war (zumindest bis 1933/ 34) der Palast in Khushaywa (Philby 1952: 234, 283). Zu den Makramī cf. Tuchscherer 1985: 54-56 und Fußnoten; Griffini 1915: 82 ff.; Dostal 1983c: 53-55 und Fußnoten; sn in EI ${ }^{2}$.

235 Arendonk 1960: 139-145, 181-186; al-Hamdānī (ed. Müller 1884-86): 50, 124, 127, 169, Ibn al-Mujāwir (ed. Löfgren): 208-217.

236 Philby 1952: 254 f., $267 \mathrm{f}$.

237 Wissmann 1975: 6, 60; Shahid 1994: 66-69; de Blois 1990: 110-128; Philby 1952: 254f., 265, 267. Daß Sure 85 (4-9) des Qur'ān auf das Martyrium der Christen von Najrān Bezug nehmen könnte, wird von einer Mehrheit der Spezialisten bezweifelt (Paret 1980: 505f.). Eine christliche Gemeinde mit eigenen Bischöfen bestand in Najrān bis mindestens in das 9. oder 10. Jh. (ibid.). Außerdem hatte Najrān zu dieser Zeit eine jüdische Bevölkerungsgruppe (Arendonk 1960; Madelung 1984: 184-207), deren Herkunft wohl weit älter war und die im Prinzip bis in die 30er und 40er Jahre des 20. Jahrhunderts fortbestand (Philby 1952: 277-281; 315-318; fig. 21). 
deutung: ${ }^{238}$ Wenn es auch bis zum 17. Jh. kaum Zentralsitz einer Staatsmacht wurde, so blieb es doch stets ein Vorposten von strategischer Bedeutung entlang einer der großen Handelsrouten Innerarabiens, an dem sich jede der relevanten Staatsmächte zu etablieren trachtete.

Nordwestlich des W. Najrān ist die Region zwischen Khamīs Mushayṭ und Zahrān al-Janūb hingegen ein uneinheitliches Übergangsgebiet zum eigentlichen, schmalen Hochland entlang des Grabenrandes. Bei Khamīs Mushayt grenzt das Verbreitungsgebiet der Adobe-Variante an jenes der Pagoden-Bauten und beschränkt sich damit auf die Ostabhänge; südlich bei Ẓahrān al-Janūb hingegen reicht es selbst bis zum Grabenrand und umfaßt damit diesen Abschnitt des Hochlandrückens. Dieser westliche Teil des Adobe-Verbreitungsgebietes um Sarāt 'Abīda ('Ubayda) ${ }^{239}$ überschneidet sich teilweise mit den Siedlungsgebieten mehrerer tribaler Großverbände. Dasselbe gilt in deutlich geringerem Ausmaß auch für die Pagoden-Variante im 'Asīr. Es gibt also keine definitive Kongruenz zwischen tribalen Siedlungsgebieten und den architektonischen Verbreitungsgebieten dieser Varianten. Für den westlichen Teil des Adobe-Verbreitungsgebietes (Südost-'Asīr) ist die Aussage noch am zutreffendsten, daß es Agrargebiete jener großen Verbände umfaßt, die an die eigentliche 'Asīr-Föderation in deren östlicher Nachbarschaft angrenzen. Die langgestreckten, traditionellen Siedlunsggebiete der Shahrān, Qaḥțān oder (mit geringen Ausnahmen) von Sinḥān durchschneiden von Nordosten aus Innerarabien kommend den 'Asīr in südwestlicher Richtung; zwischen ihnen liegen beim Grabenrand kleinere Stammesgebiete, wie jene der Rufayda oder der Shurayf um das W. al-Fayḍ.

Im wesentlichen umfaßt daher das (nord-)westliche Verbreitungsgebiet der AdobeBauten (Ost-'Asīr) die Siedlungsgebiete der Shurayf und von Untergruppen der Rufayda, Shahrān, Qaḥțān und Sinḥān. ${ }^{240}$ Schon diese Namen, die der Terminologie der mythischen altsüdarabischen Genealogie entstammen und Entsprechungen bei al-Hamdānī im 10. Jh. haben, ${ }^{241}$ zeigen alte tribale Territorien an. Die Einflüsse der mittelalterlichen Regionalstaaten in der Nachbarschaft des 'Asīr (mit Sitz in Șa da, Najrān oder in der Tihāma) auf diese bäuerlich tribalen Gebiete scheinen bestenfalls nur sporadischer Natur gewesen zu sein. ${ }^{242}$

Nachhaltige Staatseinflüsse entwickeln sich hier wohl erst ab dem Beginn des 19. Jh. Auf den Aufstieg des zweiten saudischen Staates, der auch das südliche Bergland erfaßte, folgten ägyptisch-türkische Feldzüge bis 1840 . Nach der Öffnung des Suezkanals verstärkte die Hohe Pforte ihren Zugriff durch eine instabile militärische Besetzung des 'Asīr (bis 1918). Im Zusammenhang mit diesen Entwicklungen des 19. Jh. gewinnt Khamīs Mushayt an Bedeutung, das bis dahin bloß Wochenmarkt (Khamīs) und Sitz einer Gruppe der MushaytSektion der Shahrān (Mushayț) ist. Unter den Ahl ' $\bar{A}^{\prime}$ iḍ, dem tribalen Häuptlingsverband der B. Mughayd, die sich ab 1823/24 als lokale Führungskraft etablierten und Abhā zum Hauptsitz des 'Asīr gemacht hatten, wurde Khamīs Mushayt erst in den 30er Jahren des

238 Forrer 1942: $5 \mathrm{f}$.

239 Mauger 1993: 17; Prochazka 1978: 113-118.

240 cf. Abdulfattah 1981: maps 5, 6; Philby spricht an einer Stelle über ,the ancient antipathy of the Shahran tribes" (um Khamīs Mushayț); "for the highlanders of 'Asīr" (Philby 1952: 144).

241 al-Hamdānī (Müller): 49, 84, 118, 124.

242 Headly, Mulligan and Rentz 1960: 709. 
19. Jh. mit einer Festung und Forts ausgestattet und zu einem Garnisonsmarkt gemacht. ${ }^{243}$ Seine Kontrolle wurde in der Folge daher ein unweigerliches strategisches Ziel zunächst ägyptischer, dann türkischer und idrisidischer und schließlich saudischer Politik. ${ }^{244}$

Diese kursorischen historischen Andeutungen mögen genügen, um das unterschiedliche sozialhistorische Umfeld herauszustellen, in dem die nordwestliche gegenüber der südwestlichen Verbreitungszone von Adobe-Bauten plaziert ist. Im einen Fall ist ein älteres, quasi-staatliches Zentrum in einer Oasenkultur etabliert und mit einer einheitlichen großen Föderation (Yām) verbunden. Im anderen Fall ist eine Vielfalt tribaler Gruppen mit schwankenden Führungskräften erst spät mit mächtigen Staatsentwicklungen konfrontiert. Angesichts dieser divergierenden sozialhistorischen Akzente gilt es aber festzuhalten, daß abgesehen von Teilen des Dekors sich sonstige Unterschiede innerhalb der Adobe-Variante auf bestimmte Nuancen und Einzelelemente beschränken, jenseits derer die großen konstruktiven und materiellen Gemeinsamkeiten eindeutig dominieren. Dies legt den Schluß nahe, daß die ökologisch-technischen und die kulturellen Faktoren hier wesentlicher sind für die Herausbildung der architektonischen Varianten als die Wechselfälle der Staatsgeschichte oder die tribalen Affiliationen.

Die Konjunkturen der rezenteren Staatsgeschichte haben daher keine allzu gravierenden Auswirkungen auf diese (und die anderen) Varianten südwestlicher Hochbauweise hinterlassen. Vor dem ersten Drittel des 20. Jh. hatten in der Neuzeit also verschiedene Dynastien oder tribale Führungsgruppen in dieser Region mehr oder minder stabile staatliche Macht inne. Aber ob es die Makramī oder die Ahl ' $\bar{A}$ 'i ̣̣ waren, die Armee des Muhammad 'Alī, die zayditischen Imāme oder die Türken - die Grundformen der traditionellen Architektur, die heute vorliegen, erhielten durch diese verschiedenen Mächte keinerlei spezifisches Gepräge. Staatskulturlicher Einfluß schlechthin hat zur peripheren Einrichtung der häuslichen Sonderräume mit ihrer besonderen symbolischen Sprache in der tribalen Oberschichte geführt, vielleicht mit einem speziellen Beitrag von osmanischer Seite. Und der nachhaltige Staatseinfluß inmitten der kohärenten tribalen Struktur des W. Najrān hat dort zu einer spezifischeren Entwicklung der Dekorformen in der Architektur beigetragen als im Nordwestgebiet der Adobe-Variante, deren Dekorformen ihr teils aber ähneln, teils zu jenen der anderen Varianten im 'Asīr überleiten.

Jenseits dieser Sonderformen der Oberschicht und der dekorativen Unterschiede zwischen Nordwesten und Südosten ist die architektonische, materielle und konstruktive Grundsubstanz der Adobe-Bauten dieser Region jedoch dieselbe. Der Blick auf die rezente Geschichte von Ost- ${ }^{`}$ Asīr und W. Najrān unterrichtet uns also vor allem darüber, was diese nicht in der Architektur bewirkt hat. Die eine signifikante Veränderung der lokalen Architektur im 19. Jh., auf die noch zu sprechen zu kommen sein wird, ist eine regionale Homogenisierung und soziale Stratifizierung der Bauformen jener Zeit. Diese Veränderung bewahrte dennoch alle wesentlichen Konstruktionsmerkmale weiter fort.

Am Beispiel des Küstenstils von al-Qunfudha konnte gezeigt werden, wie dynamisch dort jede größere staatspolitische Veränderung ab dem ausgehenden 18. Jh. zugleich drastische architektonische Neuerungen mit sich brachte. Im Ost- ${ }^{c}$ Asīr und W. Najrān, wo die historische Quellenlage in Ansätzen einen ähnlichen Überblick erlaubt (was wir für den

243 Tamisier 1840 II: 281-298, 361

244 Philby 1952: 132, 136, 143-144; Headly, Mulligan and Rentz 1960: 709. 
vorliegenden Zweck nutzen konnten) wird die traditionelle Architektur hingegen viel weniger von dieser rezenteren Staatsgeschichte umgewälzt. Erst die saudische Regierung schafft dann die Grundlagen einer umfassenderen Transformation der Wohnarchitektur, und nicht nur in diesem Bereich.

Daraus kann der Schluß gezogen werden, daß die typologischen und konstruktiven Grundeigenschaften und die materiellen Implikationen der Varianten von südwestlicher Hochbauweise älter sind als der rezente Staatseinfluß.

Zugleich ist am Beispiel der Adobe-Bauten bereits gezeigt worden, daß die Varianten der südwestlichen Hochbauweise keineswegs mit dem sozio-politischen Territorium einzelner Stämme des 'Asīr und W. Najrān übereinstimmen. Ob Yām oder Shurayf - beide Gruppen leben mit ihren seßhaften Bevölkerungsanteilen nicht in jeweils verschiedener „Stammesarchitektur", sondern in nahezu identischen Adobe-Bauten; in diesen Fällen bewohnen sie aber auch keine anderen architektonischen Varianten. Ob Shahrän oder Qahțān - mit ihren seßhaften Anteilen leben die Familien dieser tribalen Verbände hingegen im nordöstlichen Innerarabien in Najd-Bauten, und dann im 'Asīr im Osten in Adobe- und im Zentrum des 'Asīr in Pagoden-Bauten. Die soziopolitische Entwicklung und Ausbreitung der Hochlandstämme hat sich also nicht an jene Besonderheiten der Ökologie kümmern müssen, welche das Gebiet der Adobe-Bauten negativ eingrenzen. Diese Varianten der traditionellen Architektur sind also weder das Ergebnis spezifischer Staatseinflüsse (bloß gewisse Details sind das Ergebnis genereller Staatseinflüsse), noch sind diese Varianten das Erbe spezifischer Stammestraditionen: Der architektonische Typus der defensiven Hochbauten entspricht in seiner Verbreitung zwar ungefähr jenem aller Siedlungsgebiete der Bergstämme in ihrer Gesamtheit; aber die Verbreitung der Subtypen entspricht nur jener von großen Gruppen und Teilgruppen der Stämme, und die Gebiete der Varianten schließlich korrelieren überhaupt nicht durchgängig mit einzelnen Stämmen. Die generell tribalen Sozialbedingungen des Berglandes prägen also den architektonischen Typ der defensiven Hochbauweise, und teilweise den Subtyp der mehrgeschoßigen Wohnbauten. Aber spezifisch tribale Bedingungen prägen nicht dessen Varianten.

Die Varianten und teilweise, wie gezeigt wurde, auch die Subtypen sind ganz offensichtlich entscheidend geformt von den ökologischen, technischen und Subsistenzbedingungen, für die unter vorindustriellen Verhältnissen eine relativ große Konstanz markant war. Diese Bedingungen sind für die Adobe-Variante aufgezeigt worden, und werden für die anderen Varianten ebenfalls zu untersuchen sein. Darüber hinaus sind die Subytpen und Varianten aber auch Teil einer generell-tribalen, jedoch nicht spezifisch-tribalen materiellen Kultur, die in zusammenhängenden Verbreitungsgebieten auftritt und den Angehörigen mehrerer Stämme und Stammesteile gemeinsam ist. Daß die Ausgestaltung der Varianten zwar primär aber nicht ausschließlich durch Umwelt, technisches Wissen, Arbeitsorganisation und Subsistenz bedingt ist, zeigt sich besonders in den Dekorformen. In ihnen sind relativ konstante überlokale Muster erkennbar, die mit der individuellen Gestaltung durch ihre Hersteller nicht entscheidend variieren. Die Rede ist hier von jenen Dekorformen, die nicht in Holz gearbeitet sind (bei dem wenige Kunsthandwerker überlokal tätig sind), also von Farb- und Lehmdekoration. Diese Formen werden von denselben Personen hergestellt, die zusammen auch das ganze Haus errichten. Das können in einer Minderheit von Fällen überlokal tätige Bautrupps sein, die für Auftragsarbeiten zur Errichtung von Moscheen oder Prestigebauten der Oberschicht tätig sind. Eine gewiße normative Ausstrahlungskraft von standardisierten Dekormustern in Lehm kann dadurch gefördert werden 
(der Farbdekor wird stets von den Bewohnern selbst angebracht). Aber dies allein erklärt weder die große, einheitliche Verbeitung von Dekorformen, noch ihre relativ konstante Tradierung über mehrere Generationen hinweg.

Die Dekorformen der Architektur in Farbe und Lehm fungieren als nicht-individuelle, überlokale Codes, die mit den Varianten der Architektur korrelieren, aber auch kleinere und größere Verbreitungsgebiete (wie im W. Najrān) prägen. Auch die Dekorformen sind, wie noch zu zeigen ist, zu einem gewißen Grad an materiell-praktische Faktoren gebunden. Diese praktisch-materiellen Faktoren würden aber auch andere Formen als die üblichen erlauben. Die regional üblichen Formen des Dekors haben somit eine eigenständige symbolische Komponente. Aber auch die Dimensionen der Fenster oder die Anlage der Stiegen beinhalten ästhetische Aspekte und Nuancen, die zusammen mit dem Dekor als der Symbolsprache par excellence eine überlokale, nicht spezifisch-tribale Ausdrucksweise ergeben, die die Varianten und Subtypen jeweils verbindet oder voneinander abhebt. Und schließlich sind mir keinerlei ausreichende ökologische Gründe dafür bekannt geworden, weshalb das Adobe-Verbreitungsgebiet im Süden bis an den Grabenrand heranreicht und im Norden nicht. Ob dafür vergessene intertribale Bündnisse den historischen Ausschlag gaben, oder schon damals bloß die gemeinsame Abgrenzung zur Pagoden-Variante, die weiter nördlich an den Grabenrand grenzt und eher für Teile der 'Asīr-Föderation charakteristisch ist - ökologisch-technische Gründe sind es jedenfalls in diesem Fall kaum; und wenn es einmal Faktoren tribaler Politik waren, so sind sie als historisches Phänomen nicht mehr rekonstruierbar und den Betroffenen nicht mehr bewußt. Heute und zumindest in der überschaubaren Retrospektive ist die Tatsache, daß die Adobe-Variante im Gebiet der Shurayf und um Zahrān ${ }^{245}$ bis an den Grabenrand reicht (aber im Norden um Abhā nicht) in ihrer Gesamtheit auch ein übertribales Symbol. Es erlaubt die Abgrenzung gegenüber Gruppen von Teilstämmen (den nördlichen, westlichen und südlichen Nachbarn) und die Betonung von Gemeinsamkeiten mit den östlich benachbarten, tribalen Gruppen: Daran wird exemplarisch deutlich, daß auch die Varianten in ihrer architektonischen Gesamtheit, und nicht nur die Dekordetails, integrative symbolische Aspekte aufweisen.

Die architektonischen Varianten sind damit als markantester Bestandteil eines Phänomens zu begreifen, für das ich den Begriff der tribalen „Regionalkultur“ verwenden möchte. Er verweist auf die praktischen Bedingungen und das zusammenhängende Verbreitungsgebiet (regional) und auf jenen symbolischen Aspekt (Kultur), der Angehörigen von mehr als einer Stammesgruppe im südwestarabischen Hochland gemeinsam ist. Unter einer Regionalkultur verstehe ich also ein überlokales Ensemble ökologisch-technischer Zweckmäßigkeit und gemeinsamer symbolischer Ausdrucksformen. Diese werden auch innerhalb der regionalen Sozialhierarchie größtenteils geteilt und relativ kontinuierlich tradiert; sie akzentuieren eher horizontale Unterschiede zu anderen, gleichwertigen regionalen Gruppen.

Der Rückgriff auf die rezente Geschichte und die tribalen Verhältnisse im Ost-'Asīr und W. Najrān erlaubt uns damit ein Konzept zu entwickeln, das auch für die Analyse der folgenden Varianten und Subtypen zur flexiblen Anwendung und Überprüfung nützlich ist. Ausgegangen wird davon, daß bestimmte Varianten der südwestlichen, defensiven Hochbauweise tribale, regionalkulturliche Elemente darstellen, die in ihren Verbreitungsgebieten nur marginal durch neuzeitliche staatspolitische Einflüsse geprägt sind, und die-

245 Thesiger 1947: 195. 
sen in ihrer Grundsubstanz historisch ziemlich sicher vorangehen. Diese regionalkulturlichen Elemente sind weiters nicht Erbe und Inventar spezifischer Einzelstämme der Gegenwart, sondern sie bilden ein gemeinsames, praktisches und symbolisches Medium mehrerer derartiger Stämme, und sind wohl auch älter als manche unter den Stämmen in ihren neuzeitlichen Konstellationen, Namen und Ausdehnungen.

Die Strukturen des architektonischen Dekors werden folglich als symbolisches Medium aufgefaßt, das mittels „feiner Unterschiede“ diese tribalen, regionalkulturlichen Elemente zueinander in Beziehung setzt. Die Farbausstattung der Innenräume und Außenwände, Lehmnasen und Maueraufsätze sind solche dekorativen Grundelemente, welche den Adobe-Bauten des saudischen Südwestens zum Teil gemeinsam sind, durch die sich die nordwestlichen von den südöstlichen Adobe-Bauten aber auch deutlich voneinander differenzieren. Andere architektonische Nuancen haben ökologische oder historische Ursachen, wie die erwähnten Regendächer über den Fenstern im Ost-'Asīr, oder die Palmstammtreppen und die etwas größere Häufigkeit von Ziegelbauten im W. Najrān. Eine Besonderheit dieses Talsystems war auch das „Oasenfieber“ in Zeiten der Flut. Da sich in den feuchten Lehmbauten dann die Ansteckungsgefahr extrem erhöhte, übersiedelten die Bewohner bei derartiger Seuchengefahr periodisch in 'ushash, wo die Lebensbedingungen unter derartigen Umständen gesünder waren. ${ }^{246}$

Die hervorragenden „Lehmnasen“ (mawshan, mawāshin) unterhalb der Mauerkronen sind grundsätzlich ein gemeinsames, typisches Element der Adobe-Variante in dieser Region (Abb. 86). Wie erwähnt, haben sie sowohl dekorativen wie defensiven Charakter. In einigen Lehmnasen befinden sich Röhren, die vom Inneren der Terrassen und Turmplattformen durch die Nasenlänge hinaus ins Freie auf die Außenmauer führen. Durch diese Öffnungen kann daher von oben auf unwillkommene Zudringlinge heißes Wasser oder Öl gegossen werden. Nur wenn man direkt unter diesen Nasen steht ist manchmal erkennbar, welche von ihnen für defensive (oder offensive) Zwecke nutzbar sind und welche nicht. Die gesamte Reihe von Lehmnasen dient ansonsten bloß dekorativen Zwecken und zugleich der Tarnung. Es handelt sich also um eine, den plastischen Möglichkeiten des Lehmgemisches abgerungene, zusätzliche Defensiveinrichtung, die durch Dekor getarnt ist und die geringeren sonstigen militärischen Kapazitäten der Adobe-Bauten etwas ausgleicht. Ganze Reihen von Lehmnasen an den Obergeschoßen der Wohngebäude und volle Umkränzungen der Kegelstumpftürme sind häufiger im W. Najrān vertreten als im Nordwesten, wo die Erbauer mancher Wohnhäuser überhaupt darauf verzichtet haben und andere Bauten nur kurze Reihen über Fenstern und Türen aufweisen. ${ }^{247}$

Nur prinzipiell ist der Farbdekor durch Bemalung von Teilen der Innen- und Außenwände den nordwestlichen wie den südöstlichen Adobe-Bauten gemeinsam; die jeweilige Gestaltung markiert aber auch Unterschiede und verbindet andererseits die nordwestlichen Adobe-Varianten in einer bestimmten Hinsicht mit den anderen Varianten des 'Asīr. ${ }^{248}$

246 Philby 1952: 228, 296, 303; Lippens 1956: 106. Einige ältere Wohnbauten der Oberschichten des 20. Jh. weisen im W. Najrān überdies die großen „qamarīya“-Fensterbögen auf, die ansonsten aus den Städten des nord- und zentraljemenitischen Hochlandes bekannt sind: Minosa 1983 passim; cf. auch Gingrich und Heiß 1986: 92-95; Bonnenfant 1981: passim.

247 Al-Ḥarīī 1987: 60, $90 \mathrm{f}$.

248 Al-Harīin̄ 1987: $80 \mathrm{f}$. 
Teile der Außenwände der Wohnbauten sind im Südosten immer, im Nordwesten nur manchmal weiß getüncht. Dies betrifft zumindest Mauerkronen, Maueraufsätze und Fensterrahmen. Im Nordwesten geht die weiße Außenbemalung, sofern sie überhaupt gegeben ist, kaum über dieses Minimum hinaus, im W. Najrān hingegen schon: Üppige, aber einfache weiße Vermalungen von großen Partien um die Fenster und Türen sind hier an traditionellen Wohnbauten und Moscheen üblich (Abb. 83, 85). Diesen weißen Markierungen werden hygienische Wirkungen (gegen Ungeziefer in den Lehmritzen) zugeschrieben; ferner sollen sie die jinn (Dämonen) abwehren, und schließlich sind sie ein optisches Signal, das den Blick schon aus der Ferne auf die Adobe-Bauten aufmerksam macht, deren Außenfarbe sich ansonsten nicht immer von der natürlichen Umwelt abhebt.

Die Innenbemalung der Wohnräume unterscheidet sich noch deutlicher: Sie ist im W. Najrān durchgängig weiß, so wie im Großteil des südlichen Hijāz und im jemenitischen Hochland. Im nordwestlichen Gebiet zwischen Khamīs Mushayṭ und Zahrān hingegen sind die Innenräume der diwāne manchmal auch weiß, meist aber in bunten Streifen, einfärbig bunt oder in bunten Schachbrettmustern vom Erdboden bis zur Schulterhöhe, manchmal auch bis zur Decke bemalt. Im Prinzip weisen diese Muster zahlreiche individuelle Variationen auf, entsprechen aber im wesentlichen jenen, die auch für die Wohnräume der anderen beiden Varianten des Asīr typisch sind. ${ }^{249}$ Wie noch zu diskutieren sein wird, sind alle derartigen Innenbemalungen im Zentral-'Asīr Frauenarbeit.

Die Maueraufsätze (hajwa, pl. hajwāt) schließlich sind wiederum ein dekoratives Element, welches auch defensiv-offensive Funktionen haben kann, und das im Prinzip für die Adobe-Bauten spezifisch ist: Ausläufer dieser Lehmzinnenformen treten auch bei den Pagoden-Bauten auf; zugleich weist die Ausgestaltung der Lehmzinnen von Adobe-Bauten deutliche Unterschiede zwischen dem Nordwesten und dem Südosten auf.

An der Mauerkrone der Wohnbauten ergeben bereits die hochgezogenen Ecken feste, zinnenartige Aufsätze, welche Deckung bieten. Diese Eckzinnen können dekorativ mit kleinen Stufen versehen sein, was im W. Najrān (aber auch dort häufiger bei Moscheen) manchmal der Fall ist. ${ }^{250}$ Zwischen diesen Eckzinnen auf den vier Längen, oder auf der runden Mauerkrone der Türme sind häufig, und dann in regelmäßigen Abständen perforierte Zinnen (mạ̣rab, pl. mạ̣̄āib) mit schmalen Aufsätzen angebracht (Abb. 85, 86). Während die Eckzinnen auch eine echte Schußdeckung darstellen, bieten die Zinnen dazwischen kaum mehr als Sichtdeckung. Das dekorative Moment ergänzt hier wiederum die tarnend-defensive Funktion, ähnlich wie bei Lehmnasen. ${ }^{251}$

Und wie schon bei der Außenbemalung und den Lehmnasen sind auch diese einfachen Zinnen im nordwestlichen Gebiet nur manchmal gegeben, und auch dann umfaßt der Dekor der Mauerkronen kaum mehr als diese. Im W. Najrān hingegen ist diese Dekorform ein sehr häufiges Minimum, das aber auch mehr umfassen kann. Aus den Arbeiten von P.

249 Einige wenige Besitzer von traditionell errichteten Bauten im nordwestlichen Gebiet der Adobe-Architektur, also im Zentral-'Asīr, haben diese bunten Innenbemalungen auch auf die Stiegenhäuser und vereinzelt sogar auf Außenwände ausgedehnt, was ich für ein rezentes Phänomen halte (Mauger 1993 passim).

250 King 1986: 104, 113f.; Maréchaux 1998: 94 f.

251 Der folgende Abschnitt stützt sich auch auf die Veröffentlichungen bei King (1986: 99-114), Minosa 1983, Maréchaux (1985: 104-115) und Mauger (1993: 119-141), sowie auf die umfangreichen Photoarchive der beiden Letztgenannten, für deren Nutzung ich ihnen herzlich danke. 
und M. Maréchaux, King und anderen läßt sich für die Wohnbauten und Moscheen eine veritable Hierarchie der Maueraufsätze ableiten (Tab. 14).

Tab. 14: Dekorativer Code der Mauerzinnen im W. Najrān

\begin{tabular}{|c|c|c|c|}
\hline $\begin{array}{l}\text { Dekorative Codes von } \\
\text { Mauerzinnen im W. Najrān }\end{array}$ & & & \\
\hline I. Formen & 1: Perforierte Zinnen & 2: Gestufte Mauerzacke & $\begin{array}{l}\text { 3: Zusammengesetz- } \\
\text { te Mauerzacke: ver- } \\
\text { größerte Version von } \\
1 \text { mit Stufenelemen- } \\
\text { ten }\end{array}$ \\
\hline $\begin{array}{l}\text { II. Kombinationen von 1, } 2 \text {, } \\
3 \text { in Reihe }\end{array}$ & $\begin{array}{l}\text { 1: Einzeln; oder } \\
\text { zusammengesetzt mit } \\
2(=\text { Komb. A) }\end{array}$ & $\begin{array}{l}\text { 2: Einzeln; oder zusam- } \\
\text { men mit } 1 \text { (= Komb. A); } \\
\text { oder zusammen mit } 3 \text { (= } \\
\text { Komb. B) }\end{array}$ & $\begin{array}{l}\text { 3: Zusammen mit } 2 \\
\text { (= Komb. B) }\end{array}$ \\
\hline $\begin{array}{l}\text { III. Struktur der } \\
\text { Kombinationen }\end{array}$ & $\begin{array}{l}\text { Komb. A: Eine oder } \\
\text { drei zentrale Positio- } \\
\text { nen für 2; zwei oder } \\
\text { mehr seitliche Positio- } \\
\text { nen für } 1\end{array}$ & $\begin{array}{l}\text { Komb. B: Eine oder drei } \\
\text { zentrale Positionen für } \\
\text { 3; zwei oder mehr seitli- } \\
\text { che Positionen für } 2\end{array}$ & \\
\hline IV. Ordnung der Hierarchie & $\begin{array}{l}\text { 1: „Einfache Form“: } \\
\text { Simpel, häufig einzeln } \\
\text { verwendet; auch als } \\
\text { Seitenelement in } \\
\text { Komb. A, aber nicht } \\
\text { in B }\end{array}$ & $\begin{array}{l}\text { 2: „Mittelform“: } \\
\text { Ausgearbeitet weniger } \\
\text { häufig, selten als Einzel- } \\
\text { form verwendet; häufi- } \\
\text { ger als Mittelposition in } \\
\text { Komb. A oder als Seiten- } \\
\text { position in Komb. B }\end{array}$ & $\begin{array}{l}\text { 3: „Spitzenform“: } \\
\text { Komplex, selten; nie- } \\
\text { mals als einzige } \\
\text { Form verwendet, } \\
\text { ebenso wenig in } \\
\text { Komb. A. Mittelposi- } \\
\text { tion in Komb. B }\end{array}$ \\
\hline
\end{tabular}

In dieser Hierarchie stehen die perforierten Zinnen an der untersten Stelle, die gestuften Mauerzacken belegen die mittlere Position und die dreiteilig zusammengesetzten Mauerzacken stehen an der Spitze dieses hierarchischen Codes.

Die einfachste Form ist also jene, die dem nordwestlichen und dem südöstlichen Dekor an Maueraufsätzen gemeinsam ist. Im W. Najrān kann sie entweder alleine auftreten oder aber in Kombination mit der mittleren Form, die dann eine zentrale Position auf der Mauerkrone erhält. Diese erste Kombination von einfacher und mittlerer Form tritt im Nordwesten des Adobe-Gebietes und bei Pagoden-Bauten nur in Ausnahmefällen auf. Aber auch die mittlere Form kann im W. Najrān manchmal alleine auftreten, oder häufiger in einer zweiten Kombination, nämlich mit der zusammengesetzten Spitzenform. In dieser Kombination belegt dann die Spitzenform die wenigen zentralen Positionen, während die mittlere Form sie flankiert.

Der Dekor dieser Maueraufsätze im W. Najrān folgt somit einer einfachen, hierarchischen Logik von zunehmender Komplexität und Zentrierung. Die einfachste ist nicht mit der „höchsten“ oder komplexesten kombinierbar, und letztere tritt nicht alleine auf.

Als Grundmotiv, das sowohl die häufigste unterste Form ausmacht, wie auch in der seltensten obersten Form als Zentralelement enthalten ist, sind die beiden an der Spitze zusammenlaufenden und sich verjüngenden Schenkel zu identifizieren. Die mittlere Form tritt selten alleine und viel häufiger in Kombination mit einer der beiden anderen Formen auf, sodaß 
das „Schenkelpaar“ (Abb. 88) auf den Mauerkronen der älteren Wohnhäuser, Türme und Moscheen im W. Najrān nahezu allgegenwärtig ist. Die Befolgung eines einheitlichen, dekorativen Codes quer durch diese Vielfalt der Adobe-Bauten ist in sich bereits beachtlich. ${ }^{252}$

Betrachten wir nun diese drei Dekorformen (Nasen, Bemalung, Zinnen) im funktionalen und im regionalen Vergleich. Zwei der drei Dekorformen sind mit defensiven Funktionen verbunden - nämlich die beiden Lehmformen der „Nasen“ und der Zinnen. In diesen Fällen wird die Plastizität des Materials genutzt, um zusätzliche defensiv-offensive Vorteile zu erzielen; der Dekor hat neben seiner ästhetischen und symbolischen Seite auch die praktische Funktion der Tarnung. Bei den Zinnen ist diese Funktion weniger ausgeprägt, was durch ihre Verwendung auf Moscheedächern nachhaltig unterstrichen wird.

Bemalungen schließlich erfüllen eine gewisse hygienische Wirkung. Jede der Dekorformen hat also auch praktische Aufgaben, die von gewisser Bedeutung sind. Aber diese Aufgabe wird formal in einen Code eingebunden, der die praktische Notwendigkeit der dekorativen Form unterordnet. Diese ist nicht individuell, weil kaum von persönlichem Gestaltungswillen geprägt; sie ist überlokal, weil in ihrer Verbreitung nicht an einzelne Siedlungsorte gebunden; und schließlich ist sie generell-tribal, aber nicht spezifisch-tribal. Der Dekor ist die explizit symbolische Verkodung der Adobe-Bauten, die ein tribales regionalkulturliches Element in Südost-'Asīr und dem W. Najrān repräsentieren.

Mithilfe dieses Codes werden zentrale Gemeinsamkeiten (der Adobe-Variante alleine bzw. des ganzen Subtypus) aber auch innere Differenzierungen (zwischen Nordwesten und Südosten), und Verbindungen (des Nordwestens mit dem Pagoden-Stil bzw. dem restlichen 'Asīr) unterstrichen und betont (Tab. 15).

Tab. 15: Dekorative Codes der 'Asīr-Architektur

\begin{tabular}{|c|c|c|c|c|}
\hline \multirow[t]{2}{*}{ Dekorformen } & \multicolumn{2}{|c|}{ A. Adobe-Stil } & \multirow[t]{2}{*}{ B. Pagoden-Stil } & \multirow[t]{2}{*}{ C. Steinbauten } \\
\hline & W. Najrān & Südost-'Asīr & & \\
\hline 1. Lehmnasen & ++ & + & o & $\mathrm{O}$ \\
\hline 2. Außenbemalung & ++ & + & $\mathrm{x} b$ & $\mathrm{x} \mathrm{c}$ \\
\hline 3. Innenbemalung & - & - & - & - \\
\hline 3a: weiß & ++ & + & + & + \\
\hline 3b: bunt & o & + & + & + \\
\hline 4. Zinnen & ++ & + & + & $\mathrm{x} \mathrm{c}$ \\
\hline Eckzinnen & ++ & ++ & + & $\mathrm{x} \mathrm{c}$ \\
\hline Mittelzinnen & ++ & + & + & $\mathrm{x} \mathrm{c}$ \\
\hline Untere Form & ++ & + & + & o \\
\hline Mittlere Form & ++ & + & + & o \\
\hline Obere Form & + & o & o & o \\
\hline
\end{tabular}

Legende: + + sehr häufig

+ fallweise vorhanden

o nicht vorhanden

x b, x c: in abgewandelten, für die Varianten B. und C. spezifischen Ausführungen vorhanden

${ }^{252}$ Mündliche Hinweise örtlicher Informanten und der Dekor auf manchen Moscheen (Al-Ḥarīī 1987: 61; Maréchaux 1987: Abb. 117) bezeichnen dieses Schenkelpaar manchmal als Palmblätter. Maréchaux (1987: Abb. 70) erwähnt in diesem Zusammenhang: "Interior decoration with lime. Palm-tree representation calls for prosperity.” Altsüdarabische Felszeichnungen (Anati 1968: 111-114, 136, 141, 183) könnten andererseits auch motivische Bezüge zum Thema des Stier- und Steinbockrituals belegen, wie es auch an rezenten Wohnhäusern von Șacda im Nordjemen auftritt. 
Unter diesen vier Dekorformen hebt der Code der Innenbemalung den 'Asīr (bunt) deutlich vom W. Najrān (weiß) ab. Lehmnasen und Außenbemalung hingegen betonen primär die übergreifenden Gemeinsamkeiten der Adobe-Bauten, sekundär aber auch ihre Unterschiede durch die jeweils üppigere Ausgestaltung im W. Najrān. Bei den Lehmzinnen schließlich wird ein Ost-West-Gefälle noch deutlicher, dessen Ausläufer bis in das Gebiet der Pagoden-Variante reichen, dessen Zentrum aber mit jener hierarchischen Ausgestaltung rund um das Palmdach-Motiv im W. Najrān und seiner alten Kulturgeschichte liegt.

\subsubsection{Pagoden-Gebäude der regionalen Variante um Abhā}

Mit Pagoden verglichen hat Philby jene auffällige Bauweise, die den Wohnbauten der Region um Abhā ihr charakteristisches Aussehen gibt. ${ }^{253}$ Ich übernehme diesen griffigen Kurzbegriff aus Gründen der Anschaulichkeit. Aber selbstverständlich haben diese vierbis fünfgeschoßigen Adobe-Bauten mit parallelen Reihen von hervorragenden Schieferplatten absolut nichts mit Einflüssen aus Ostasien zu tun: ganz im Gegenteil handelt es sich um eine originäre Leistung der tribalen Lokalkulturen des Berglandes im 'Asīr (Abb. 59).

Die Grundmaterialien dieser Bauten sind wiederum Stein und Lehm; in dieser Hinsicht verlangt die Konstruktion der Pagoden-Variante daher ähnliche materielle und ökologische Voraussetzungen wie jene der Adobe-Bauten. Dementsprechend schließt das Verbreitungsgebiet der Pagoden-Variante direkt an jenes der Adobe-Bauten an, und zwar in westlicher und nordwestlicher Richtung.

Die Standorte der Pagoden-Siedlungen sind also an das Vorkommen geeigneter Lehmgruben gebunden; darüber hinaus wird ein zusätzliches Steinmaterial benötigt, das man bei den Adobe-Bauten nur spärlich verwendet: dies ist der schwarze Schiefer, aus dem die herausstehenden Platten gearbeitet werden.

Derartigen Schieferplatten (raqafa; raqaf) sind wir bei der Adobe-Variante nur anhand zweier unscheinbarer Details begegnet. In ihrem nordwestlichen Verbreitungsgebiet um Khamīs Mushayṭ (also nahe dem benachbarten Gebiet der Pagoden-Bauten um Abhā) treten vereinzelt jene Regendächer an den Fassaden über den Fenstern auf; weitaus häufiger ist in Adobe-Bauten desselben Gebietes aber die Verwendung von Schiefer im Inneren, als Trittplatten auf den Stiegen. Trotz der äußerlichen, markanten Unterschiede gibt es also fließende Übergänge zwischen beiden Varianten. Dies gilt nicht bloß für die zuletzt erörterte Dekorierung und die grundlegenden konstruktiven Gemeinsamkeiten des Subtypus, sondern auch für die Baumaterialien von Lehmgemisch für Wulste, von Holz für Balken und Rahmen, von Fels für Fundament und Innenmauern und in geringerem Maß eben auch für Schiefer. Der Unterschied liegt zunächst bloß im höheren Bedarf an Schiefer, der für die Pagoden-Bauten gegeben ist. Da es sich dabei aber um leicht bearbeitbares und transportierbares Material handelt, ist eine unmittelbare Nähe der Schiefervorkommen nicht so entscheidend für den Siedlungsstandort wie die Existenz von nahen Lehmgruben.

Das Verbreitungsgebiet der Pagoden-Bauten liegt also westlich und nordwestlich angrenzend an jenes der Adobe-Bauten. Es reicht von der Nachbarschaft des W. Fayḍ im Süden bis zum Abstieg des W. Tayya von der Shifā im Norden. Wie die Adobe-Bauten tritt

253 Philby 1952: 139. 
auch die Pagoden-Variante nahezu ausschließlich oberhalb des Grabenrandes auf, bloß vereinzelte Ausnahmen finden sich auch in der hügeligen Tihāma. ${ }^{254} \mathrm{Im}$ Unterschied zu den Adobe-Bauten erstreckt sich das Gebiet der Pagoden-Variante jedoch nicht auf die eigentlichen Ostabhänge des 'Asīr. Innerhalb dieser Grenzen - also oberhalb der Shifā zwischen W. Fayḍ und W. Tayya - bilden die Siedlungsgebiete mit Pagoden-Wohnbauten eine lose, aber relativ kontinuierliche Verbreitungszone, von einigen Steinbauten in Abhā abgesehen. Es handelt sich somit um jene der drei architektonischen Varianten des südöstlichen Subtypus, welche im zentralen Bergland des 'Asīr liegt und sich gleichsam an die Shifā herandrängt.

Nur nordwestlich von Abhā weicht die „Pagoden-Zone“ von der Shifā zurück. In diesem nördlichen Teil sind es die Steinbauten um al-Șūda, die direkt am Grabenrand stehen.

Damit ergibt sich entlang der Shifā im Zentral- ${ }^{`}$ Asīr eine signifikante Abfolge der architektonischen Varianten. Im Süden reichen die Adobe-Bauten bis an den Grabenrand (wie erwähnt hier nur bei Zahrān) und treten von diesem dann in nördlicher Richtung zurück. Daran schließen die Pagoden-Bauten im Zentralteil entlang der Shifā an, bis sie ihrerseits von ihr zurücktreten und den Steinbauten Platz machen.

Das Verbreitungsgebiet der Pagoden-Bauten ist folglich ein eng begrenztes, ökologisches und klimatisches Übergangsgebiet im Zentral-'Asīr entlang der Shifā. Es liegt zwischen den Gebieten der Lehmbauten im Südosten und jenen der Steinbauten im Westen und Nordwesten. Die negativen, ökologischen und spezifisch-klimatischen Schwellenwerte der beiden anderen Varianten ergeben also den kleinen „Zwischenraum“, in dem sich diese originelle Bauweise entwickeln konnte. Sie ist eine einzigartige Kombination zwischen den beiden anderen Varianten. Das Verbreitungsgebiet der Adobe-Bauten nach Nordwesten hin endet dort, wo - grob gesprochen - die durchschnittlichen Temperaturen zu niedrig und die Niederschläge zu hoch werden. Hinzu kommt das allmählich geringere Vorkommen von Lehmböden im schrofferen Teil des Berglandes. Das Verbreitungsgebiet der Steinbauten nach Südosten und Osten hin endet im 'Asīr entlang der Shifā dort, wo das Klima im Durchschnitt wärmer und trockener und wo der Schiefer seltener wird: Bei der „Pagoden-Zone“ handelt es sich also um ein klimatisches Übergangsgebiet, in dem zusätzlich ausreichende, natürliche Lehm- und Schiefervorkommen auftreten.

In diese doch sehr spezifischen geomorphologischen und klimatischen Rahmenbedingungen intervenieren dieselben sozio-politischen Anforderungen, die den gesamten Subtypus charakterisieren: Das Konstruktionsprinzip der defensiven Hochbauweise, das in der Organisation freier, kleinerer Arbeitsgruppen angewendet wird, hat hier aus engen Rahmenbedingungen eine spezifische und kreative Lösung erfahren. Hinter dieser empirischen Lösung ahnt man förmlich die alten kulturgeschichtlichen und lokalen Erfahrungen von Generationen, das langwierige Probieren und Verwerfen von alternativen Lösungen, bis sich schließlich diese eine durchgesetzt hat.

Und dennoch steht das elegante und pittoreske, in Südarabien einzigartige äußere Aussehen der Pagoden-Bauten in einem verblüffenden Gegensatz zur technischen Einfachheit, mit der diese Varianten errichtet werden. Auf einem höheren Steinfundament werden schmälere Lehmwulste (madāmik) aufgeschichtet, die man nicht nur innen, son-

254 Einen out-tower im Pagoden-Stil sah ich 1981 im Nordgebiet der Rijāl Almac 
dern auch außen verputzt, wo man dann zwischen die Wulste die Schindeln steckt. In diesem ökologischen „Zwischenraum“ um Abhā sind auch die grundlegenden technischen Eigenschaften der beiden anderen Varianten kombiniert; Lehmwulste auf Steinmauern sind um das spezifische Detail der Schindelreihen ergänzt worden: Die Pagoden-Bauten sind im Prinzip eine technische Mischform zwischen den beiden anderen Varianten; diese technische Mischform ist erweitert und zugleich ermöglicht durch das variantenspezifische Detail der Schindelreihen.

Errichtet sind Pagoden-Wohnhäuser und Türme auf einem breiten Steinfundament (rabad), das den Grundriß markiert und die Innenmauern vorgibt - also in jedem Fall von derselben Art ist (und dieselben Bezeichnungen trägt) wie das Steinfundament der Adobe-Bauten. ${ }^{255}$

Dieses Steinfundament ist dort zu einem steineren Erdgeschoß ausgebaut, wo in der „Pagoden-Zone“ mindestens eine von zwei Bedingungen zutrifft. Das sind stärkere Niederschläge, die den Lehm direkt angreifen, und/oder solche Standorte, wo die Flutabgänge ein Lehm-Erdgeschoß gefährden würden.

Aus diesen Gründen haben Wohnbauten und Türme in der Nähe der Shifā und in Hanglage eher ein steinernes Erdgeschoß als anderswo in der Pagoden-Zone. Vereinzelt treten auch explitite Mischformen auf, bei denen zwei oder drei untere Geschoße in der Steinbauweise des Zentral-'Asīr errichtet sind (cf. Abschnitt 5.2.4.B), auf denen dann Obergeschoße im Pagodenstil ruhen. ${ }^{256}$ Diese steinernen Erdgeschoße werden dann auf dieselbe Weise errichtet und überdacht wie jene der dritten Variante, was daher im entsprechenden Abschnitt über die Steinbauten zur Sprache kommt. Da die Eingangstüren (sīb) aus defensiven Gründen generell niedrig sein sollen und im Erdgeschoß ansonsten nur Geräte und Vieh in Lagerraum (mukhwāl) und Stall (rīsha) untergebracht sind, liegt die Höhe dieser steinernen Erdgeschoße knapp bei der einheimischen Körpergröße, nur bei wenigen Bauten ist noch ein weiteres Geschoß aus Stein errichtet. ${ }^{257}$ Die Küche (milhab) kann dann entweder hier, oder aber am Dach eingerichtet sein; die Wohnräume (majlīs) sind immer im höchsten Stock untergebracht. Die Lehmwulste der Pagoden-Bauten liegen also entweder - in trockeneren Lagen - auf der Krone des Steinfundaments auf, oder im anderen Fall auf jener des steinernen Erdgeschoßes. In beiden Fällen muß es sich - wie bei den Adobe-Bauten - um gut und regelmäßig zubehauene Felsblöcke handeln, die sich glatt aneinanderfügen und die Basisfläche für die Lehmwulste abgeben können.

Das Grundmaterial für diese Wulste der Pagoden-Bauten ist das gleiche Lehmgemisch wie für jene der Adobe-Variante, aber die Anlage und Funktion der Wulste ist hier etwas anders. Dies ergibt sich aus der technischen Notwendigkeit, die Schindeln und Schindelreihen zwischen den Lehmwulsten zu fixieren. Diese Notwendigkeit belastet das Lehmmaterial durch Spannung. Jede einzelne Schindel (nata $\vec{a}^{\prime}$, pl. nutü $\left.{ }^{\prime}\right)$ ist etwa 50-60 cm lang, $10 \mathrm{~cm}$ breit und $1 \mathrm{~cm}$ dick und ragt zur Hälfte ihrer Länge aus der Mauer heraus. ${ }^{258}$ Diese länglichen, flachen Platten dürfen untereinander nicht allzusehr variieren, damit die

255 Al-Harīīì 1987: 46, 53, 59, 84 f.

256 Mauger 1993: 27.

257 King 1976: 27; Al-Harīīī 1981: 18; Thesiger 1947: 194; Talib 1984: 104f. erklären die Pagoden-Häuser mit steinernem Erdgeschoß zu eigenen „types“ oder „categories“.

258 Dostal 1983c: 25-28. 
Spannung im Lehm gleichmäßig gehalten und die gemeinsame regenabweisende Wirkung nicht unterbrochen wird (Abb. 89). Gleichzeitig können Druck und Spannung für das Lehmgemisch auch dadurch minimiert werden, daß die einzelnen Lehmwulste der Pagoden-Bauten von vorneherein etwas niedriger und flacher angelegt werden als bei den Adobe-Bauten. Auch das erhöht die Kompaktheit und Belastbarkeit des Lehmmaterials, fördert seine Konsolidierung nach der Errichtung des Hauses unter dem Druck des (im Vergleich zu den Adobe-Bauten) erhöhten Gewichts, und mindert die Rißanfälligkeit.

Die Lehmwulste der Pagoden-Bauten sind also etwas niedriger (etwa 0,5 m) als jene der Adobe-Variante, und sie bilden an den vier Kanten der Wohnhäuser nicht jene charakteristischen, abrupt hochgezogenen Ecken der Adobe-Häuser: Dieses konsolidierende und stabilisierende Prinzip der Adobe-Bauten entfällt bei der Pagoden-Variante aus zwei Gründen. Erstens würden abrupt hochgezogene Ecken dazu zwingen, auch die Schindelreihe hochzuziehen. Dies ergäbe ein starkes Gefälle in der ansonsten horizontalen Reihe, wodurch das Regenwasser von den Ecken weg zur Lehmfassade hin- und nicht weggeführt würde. Zweitens wird die konsolidierende Wirkung hier auf andere Weise erzielt. Die Ekken sind einerseits an den Innenwänden etwas verstärkt, und dann verleihen die Schindelreihen selbst in der Horizontalen zusätzliche Stabilität bei seitlicher Druckrichtung (Taf. XLIVa). Bei Häusern mit besonders breiten Fassaden schließlich werden die Wulste von der Mitte weg sachte ansteigend zu den Ecken hin erhöht, sodaß die Schindelreihen einen in der Mitte durchhängenden Eindruck erwecken (Taf. XLIVc). Dies sind Gebäude mit einem Innenmauerngeviert, das ja die Außenwände am stärksten entlastet. Derartige Außenwände sind durch ihre Breite besonders anfällig für Risse, die nur in diesen Fällen durch den erhöhten Druck von den Ecken her wieder ausgeglichen werden können.

Die Schindelreihen verlaufen - vom „durchhängenden“ Sonderfall abgesehen - parallel zueinander und zu den Wulsten. Die Schindeln sind dabei so in die Wulste gesteckt, daß sie stets eine fortlaufende Oberfläche bilden, die sich von der Wand weg leicht nach unten neigt. Daß eine mindere, lokale Lehmqualität als jene der Ostabhänge den Ausschlag gibt für die Nutzung der Schindeln, wie King vermutet hat, ${ }^{259}$ konnte ich an keiner Stelle bestätigt finden. Die Lehmqualität ist prinzipiell die gleiche wie jene im Ost- ${ }^{`}$ Asīr; vielmehr ist Dostals Beobachtung zu unterstreichen, der im Niederschlag den entscheidenden Faktor erkannt hat. ${ }^{260}$ Dies bewirkt, daß der seitlich niedergehende Regen kaum direkt auf den Lehm, sondern stets auf die Schindelflächen fällt (Taf. XLIVb), von wo er nach außen abrinnt. Die Schindelreihen verhindern also sehr weitgehend, daß der Lehm direkt vom Niederschlag getroffen wird, und daß das Regenwasser an ihm selbst abrinnt. Daran wird weiters deutlich, daß die steinernen Erdgeschoße auch dagegen schützen, daß das auf den Erdboden abgetropfte Regenwasser von Außen das Fundament gefährdet.

Die regenabweisende Wirkung der Schindelreihen wird verstärkt durch intensiven weißen Verputz der schmalen Lehmwulste. Daraus ergibt sich von selbst die sekundäre Funktion dieser architektonischen Komposition, und diese liegt in der ästhetischen Gesamtwirkung: Zwischen dem steinernen Fundament und den Dachzinnen wechseln einander die schwarzen Schindelreihen und der weiße Lehmverputz als parallele, horizontale

\footnotetext{
259 King 1976: 27.
}

260 Dostal 1983c: 28. 
Streifen ab. Da und dort unterbricht ein Fenster (qutra oder kutra) diese Abfolge. Die Silhouette ist geprägt von den leicht geneigten Außenwänden, aus denen die Schindeln wie parallele Sporne herausragen, und dem Dekor der Mauerkronen. ${ }^{261}$ Lokale Technik und indigene Ästhetik haben sich hier zu faszinierenden Gesamtkunstwerken verbunden.

Die Pagoden-Wohnbauten vereinigen also in sich die Vorteile der beiden anderen Varianten, und stimmen sie auf die Bedingungen ihres eigenen, beschränkten Verbreitungsgebietes ab. Steinernes Fundament und steinerne Innenmauern tragen ein größeres Gewicht als jene der Adobe-Bauten, und schützen vor Rinnsalen und der hier höheren Luftfeuchtigkeit. Die Schindelreihen erzielen eine ähnliche regenabweisende Wirkung wie die Mauern der Steinbauten, zugleich stellen sie ein eigenständiges Dekorelement dar, das jenen der Adobe-Bauten um nichts nachsteht und die kärgliche Außendekorierung der Steinbauten nachdrücklich übertrifft. Die Lehmwulste schließlich erlauben einen intensiveren Austausch der häuslichen Binnen- und Außentemperaturen, als dies bei den Steinbauten möglich ist. Und natürlich bieten sie im Inneren der Pagoden-Häuser alle jene plastischen Gestaltungsmöglichkeiten an, die schon am Beispiel der Adobe-Bauten diskutiert wurden: Dies sind Zubauten und Aussparungen, Toilettenabflüsse, Herdstellen oder Bänke. Um den technischen Preis eines besonderen Aufwandes zur Herstellung und Einrichtung der Schindeln wird damit ein Ergebnis erzielt, in dem fast jeder Einzelaspekt den Paralleleigenschaften der beiden anderen Varianten gleichkommt oder sie übertrifft.

Die Schindelreihen sind auf die klimatischen Erfordernisse abgestimmt und genügen zugleich höchsten ästethischen Ansprüchen. Die technischen Probleme, die ihre Einfügung durch Druck und Spannung erzeugt, werden durch ihre eigene Regelmäßigkeit und die schmäleren Wulste ohne abrupt hochgezogene Ecken minimiert. Eine besondere Defensivfunktion erfüllen die Schindeln aber nicht. Weder bieten sie zusätzliche Deckung oder Tarnung, noch verstärken sie auf nennenswerte Weise den mechanischen Schutz vor Feuerwaffen oder anderen Geschoßen. Die defensiven Kapazitäten der Pagoden-Bauten sind grundsätzlich die gleichen wie jene der Adobe-Variante, also jenen der Steinbauten eine Spur unterlegen. Die vorspringenden Schindelreihen verunmöglichen weiters, daß die „Lehmnasen“ der Adobe-Bauten hier angebracht werden können; die Schindeln würden Sicht und Fall aus den „Nasen“ nur behindern. Und auch die Verbreitung der Lehmzinnen auf den Mauerkronen nimmt, wie bereits gezeigt worden ist, im Bereich der Pagoden-Zone deutlich ab. An dieser exponierten Stelle hält der Lehm den Niederschlägen nur schwer stand. Hinzu kommt schließlich, daß Reparaturen am Schindelwerk (die durch Kämpfe oder Unwetter regelmäßig notwendig sind) mühselige Außenarbeiten an der Fassade erfordern: Die Verteidigung und Instandhaltung der Pagoden-Wohnbauten ist also um eine Nuance aufwendiger als in den beiden anderen Varianten.

Weil Lehmbauten den Steinbauten in defensiver Hinsicht insgesamt etwas nachstehen, und weil bei den Pagoden-Bauten jene beiden zusätzlichen Defensiveinrichtungen (Nasen und Zinnen der Adobe-Bauten) kaum Verwendung finden können, wird dieses „defensive Defizit" in der Pagoden-Zone durch andere Akzentuierungen wettgemacht. Erstens ist die durchschnittliche Größe der Wohnbauten hier höher als bei den anderen beiden Varianten; fünf- und sechsgeschoßige Bauten dominieren, die das an sich gegebene, strukturelle Defensivpotential der Hochbauweise voll ausschöpfen. Und zweitens sind out-towers im Nahbe-

261 Al-Harīrī 1987: 84 ff. 
reich der Siedlungen hier etwas häufiger als in den beiden anderen Varianten. Hinzu kommen einzelne „Frontdörfer" wie al-Khalef, das verschließbare Dorfeingänge und in-towers hat. ${ }^{262}$

Dieses dichte Auftreten von Pagoden-Türmen folgt grundsätzlich denselben Prinzipien der Konstruktion und Materialanwendung, die bereits für die Wohnbauten aufgezeigt worden sind. Steinernes Erdgeschoß, flachere Wulste und die Anlage der Schindelreihe sind also bei den Türmen nach denselben Gesichtspunkten angelegt. Die „durchhängende" Schindelreihe ist weder bei runden noch bei vierkantigen Pagoden-Türmen gegeben, da die Fassadenbreite hier kurz genug ist, um von vornherein jene erhöhte Rißanfälligkeit zu vermeiden. ${ }^{263} \mathrm{Im}$ nördlichen und westlichen Teil der Pagoden-Zone sind viereckige out-towers (und in Frontdörfern wie al-Khalef auch viereckige in-towers) häufiger, nach Osten und Südosten hin nimmt die runde Turmform allmählich zu, wie etwa im Dorf Hijla an der Straße von Abhā nach Khamīs Mushayț. ${ }^{264}$

Dieser graduellen Verschiebung des Verhältnisses von viereckigen zu runden Türmen entlang der Nordwest-Südost-Richtung liegen ähnliche Faktoren zugrunde, die auch für die Dominanz runder Turmformen in der Adobe-Variante maßgeblich sind. Die runde Turmform garantiert höhere Stabilität, die für das Lehmmaterial noch wichtiger ist als schon für Stein, und sie gewährleistet einen weiteren Sichtwinkel vom Turm aus. Allerdings setzt sie die technische Fertigkeit voraus, eine regelmäßige Kegelwand hochzuziehen, was durch die Modellierbarkeit des Lehmgemisches etwas erleichtert wird. Nun bieten die Schindelreihen andererseits erhöhten seitlichen Druckwiderstand, sodaß vierekkige Pagoden-Türme stabiler sind als viereckige Adobe-Türme, und weniger Sorgfalt für technische Präzision verlangen als runde Pagoden-Türme. ${ }^{265}$

Grundsätzlich sind viereckige Türme in der Pagoden-Variante also stabiler, und werden daher häufiger errichtet als im Adobe-Stil. Zugleich m üssen Türme im dichter bevölkerten und niederschlagsreicheren Westteil der Pagoden-Zone auch häufiger errichtet, oder nach Zerstörung und Beschädigung repariert werden - wofür man offenbar nicht jedesmal bereit gewesen ist, den höheren Präzisionsaufwand für runde Türme in Kauf zu nehmen.

Im übrigen weisen die Pagoden-Türme entlang derselben Richtung eine weitere Variation auf, die direkt mit der Abnahme der Niederschläge zusammenhängt. Innerhalb der Pagoden-Zone werden die Lehmwulste der Türme nach Osten hin etwas dicker, und die Abstände zwischen den parallelen Schindelreihen folglich größer. Hier ist man angesichts der sporadischeren Regenfälle also bereit, auch die regenabweisende Wirkung der Schindelreihen zu mindern. Dies verringert den Arbeitsaufwand zur Herstellung und Anbringung der Schindeln. Auch die Instandhaltungsarbeiten für die Schindelreihen selbst werden zwar geringer; gleichzeitig nimmt man in Kauf, daß bei sporadischen Unwettern der Lehm ähnlich wie bei den Adobe-Bauten angegriffen werden kann.

Im Übergangsgebiet zwischen Adobe- und verschiedenen Pagoden-Varianten wird dadurch am Beispiel der Türme deutlich, wie sich das jeweilige Gewicht der einzelnen Fak-

262 Dostal 1983c: 26 verweist dabei auf den Umstand, daß die Bewohner von al-Khalef im Winter größtenteils in die (hügelige) Tihāma übersiedeln, was die Notwendigkeit der Dorftore als Eigentumsschutz in dieser Periode unterstreicht.

263 Mauger 1988: $98 \mathrm{f}$.

264 Dostal 1983c: 25-28 (bezieht sich auf Al-Khalef); Philby 1952: 130, 160 (Fig. 10).

265 Al-Harīrī 1987: 52 f., $58 \mathrm{f}$. 
toren (Statik, Niederschlag, Konstruktionsgenauigkeit und Reparaturaufwand) verändert, die für die Ausgestaltung der Bauten entscheidend sind. Von Osten oder Südosten her ergibt dies eine ganz allmähliche Variierung der Turmformen: Zunächst dominieren noch die runden out-towers der Adobe-Variante, dann treten die runden out-towers der Pagoden-Variante mit wenigen Schindelreihen auf, deren Wülste fast ebenso dick sind wie die der Adobe-Türme. In die Verbreitung dieser Form mischen sich allmählich dorfnahe Pagoden-Türme mit flacheren Wulsten und engeren Schindelreihen, die zunächst ebenfalls noch rund sind, aber dann nach Westen zur Shifā hin immer häufiger von solchen mit quadratischem Grundriß abgelöst werden.

Dieser graduelle Übergang der Turmformen vom Nordwestteil des Adobe-Verbreitungsgebietes zum Ostteil der Pagoden-Zone wird ergänzt durch zwei andere graduelle Übergangsformen. Das eine ist die Tatsache, daß der weiße Verputz der Pagoden-Bauten nach Osten hin seltener wird, und auch wo er gegeben ist, umfaßt er nicht immer das ganze Haus, sondern nur die oberen Stockwerke, die zum Regen hin exponiert sind, mit den bemalten Außenpartien um die Fenster. Im farblichen Gesamteindruck dominiert daher im Ostteil noch das Braun des Lehms (wie bei den Adobe-Bauten), das nach Westen hin vom Weiß des Verputzes dann weitgehend abgelöst wird. Und zweitens ist der erwähnte Rückgang des Zinnendekors auf den Mauerkronen der Pagoden-Bauten von Ost nach West in Erinnernung zu rufen (Abb. 88). ${ }^{266}$ Diese beiden Variationen sind primär auf den Übergang vom trockeneren, heißen Klima der Ostabhänge zum feuchteren, kühleren der Sarāt zurückzuführen.

Der graduelle Übergang vom nordwestlichen Adobe-Verbreitungsgebiet zum Ostteil der Pagoden-Zone (und die damit gegebenen „feinen“ architektonischen Unterschiede innerhalb der Pagoden-Zone) wird also an den Turmformen, an den Farbwerten der Fassaden, und am Zinnendekor sichtbar (Abb. 89). Erste Grundlage dieser unschein baren technischen und ästhetischen Variationen entlang eines Kontinuums ist die Identität der Baumaterialien in beiden Varianten, die den Prinzipien desselben architektonischen Subtypus folgen. Diese erste Grundlage ist eingebunden in ähnliche ökologische und spezifisch-klimatische Rahmenbedingungen, die in den beiden benachbarten Verbreitungsgebieten ihrerseits graduell variieren.

Eine zweite, davon relativ unabhängige Grundlage für die unscheinbaren architektonischen Variationen entlang eines Kontinuums erblicke ich in den Affinitäten und Überschneidungen, die beiden Verbreitungsgebieten in sozialer und historischer Hinsicht gemeinsam sind, die aber auch sozialhistorische Unterschiede markieren.

Was die staatspolitische Vorgeschichte anbelangt, so ist bereits für die Ostabhänge des 'Asīr auf deren relativ rezenten Hintergrund verwiesen worden. Angesichts der mangelhaften Quellenlage ist eine große Nähe zu den alten Überlandsrouten des Fernhandels eine der wenigen gesicherten Angaben, die man für ältere staatsgeschichtliche Enflüsse im Sinne eines Strukturmerkmales treffen kann. Diese größeren (im Vergleich zu jenen des Zentral-'Asīr) Affinitäten der tribalen Gebiete des Ost-'Asīr mit überregionalen Einflüssen haben auf eine lose und periphere Weise schon lange vor dem ausgehenden 18. Jh. gewirkt. In dieser punktuellen und sporadischen Hinsicht repäsentiert der Ost-'Asīr also eine der zahlreichen Peripherien zum antiken und mittelalterlichen Fernhandelssystem,

266 Al-Harīīi 1981: 25. 
dessen lokales Zentrum durch die alte Oase Najrān verlief. Als eine Facette dieses alten peripheren Verhältnisses kann das graduelle „Abflachen“ der Dekorformen der AdobeVariante mit ihren nordwestlichen Ausläufern in die Pagoden-Zone hinein interpretiert werden, allerdings nur soweit dies nicht zwingend ökologisch bedingt ist.

Gegenüber dieser etwas größeren Affinität des Ost- ${ }^{c}$ Asīr zu den alten, städtisch-staatlich beeinflußten Fernhandelsrouten repräsentiert der Rest des 'Asīr in noch höherem Maß tribales, bäuerliches Rückzugsgebiet. Die Pagoden-Zone liegt im Zentrum dieses tribalen Kerngebietes, das erst in jüngerer Vergangenheit mit nachweislichen äußeren Staatseinflüssen konfrontiert worden ist, mit Abhā im Zentrum.

Der Ortsname Abhā wird zwar bei al-Hamdān̄̄ im 10. Jh. bereits erwähnt, und dies recht eindeutig in derselben Lokalität wie heute. ${ }^{267}$ Aber nichts an dieser Textpassage weist auf mittelalterliche Staatseinflüsse in Zusammenhang mit Abhā und seiner Umgebung hin; vielmehr wird für diese Region im Mittelalter das Vorherrschen tribaler Siedlungsverbände betont. Erst Ende des 18. und zu Beginn des 19. Jh. wird die Region um Abhā in dieselben politischen Probleme einbezogen, auf die schon im Zusammenhang mit Khamīs Mushayṭ verwiesen worden ist, und die nun näher ausgeführt werden können. In dieser Hinsicht durchlaufen der nordwestliche Teil des Adobe-Gebietes (um Khamīs Mushayț) und die Pagoden-Zone (um Abhā) ähnliche rezente Entwicklungen.

Im Gefolge des ersten historischen Aufstieges der $\bar{A} l \mathrm{Sa}^{c} \overline{\mathrm{u} d}$ als den politischen Trägern jenes islamischen Weges, der von Muhammad 'Abd al-Wahhāb inspiriert ist, haben die (sogenannten) „Wahhabiten“, also eigentlich die Vertreter des Unitaristischen Islam, um 1800 den 'Asīr erstmals in ihren spirituellen und politischen Einflußbereich zu ziehen vermocht. Die „Wahhabiten“ sind es auch, die in jener Zeit Gouverneure des 'Asīr aus den Reihen einer örtlichen, tribalen Häuptlingsfamilie (zunächst der Rufayda) ernennen. ${ }^{268}$ Der letzte Vertreter der Sharīfen-Dynastie der Khayrāt in Abū 'Arīsh, die schon im 18. Jh. ergebnislos versucht hatten, Teile des Südwest- ${ }^{c}$ Asīr unter ihre Kontrolle zu bekommen, ${ }^{269}$ entwickelte erneute Animositäten zu diesen neuen, tribalen Gouverneuren des 'Asīr, die bis 1818 bestanden zu haben scheinen. In diesem Jahr fällt schließlich Dar'īya, die saudische Hauptstadt im Najd. ${ }^{270}$

Gegen den zweiten Aufstieg der $\bar{A} l \mathrm{Sa}^{\mathrm{c}} \mathrm{u} d$ unternehmen dann in den 30er Jahren des 19. Jh. die ägyptischen Truppen unter Muhammad 'Alī nach der Besetzung des Hijāz mehrere Kampagnen nach Inner- und Südwestarabien. 1834 erfolgt auch die Invasion des 'Asīr unter Muhammad 'Alī. ${ }^{271}$ Diese Periode des intensiven Ringens um Arabien kulminiert 1839 im britischen Machtantritt in Aden und 1840 im Rückzug der ägyptisch-türkischen Truppen unter westlichem Druck, der gegen die ägyptisch-türkischen Aspirationen auf den Kaffeehandel am Roten Meer erfolgt. ${ }^{272}$ Im 'As̄̄r verbündeten sich die „Wahhabiten“ in dieser Periode zunächst wieder mit einer der lokalen Häuptlingsfamilien, und zwar diesmal mit jener von den B. Mughayḍ. 1823/24 wird 'Alī al-Mughayḍ̂̄ so zum neuen Gouverneur der Saudis im 'Asīr. Sein Nachfolger ' $\bar{A}$ 'iḍ, der demselben Verband entstammt,

267 al-Hamdānī (Müller 1884-86): 118.

268 Headley, Mulligan and Rentz 1960: 709.

269 Gingrich 1989: 92-95.

${ }^{270}$ Headley, Mulligan and Rentz 1960: 709.

271 Facey 1993: 16.

272 ibid.: Philby 1952: $140 \mathrm{f}$. 
wird zum Begründer der Ahl ' $\bar{A}$ 'iḍ, einer tribalen Lokaldynastie, welche die folgenden hundert Jahre hindurch eine Schlüsselrolle in den wechselnden politischen Konstellationen des 'Asīr spielt.

Nach dem ägyptischen Rückzug von 1840 bleiben die Ahl ' $\bar{A}$ 'iḍ zunächst als eine weitgehend autonome Führungskraft im 'Asīr zurück, die schrittweise ihre Machtposition auch gegen die Sharīfen in Abū 'Arīsh auszudehnen suchen. Dagegen beziehen die im Jemen und im Hijāz sich neu etablierenden Osmanen Position, was durch die Eröffnung des Suezkanals erleichtert wird und 1872 zur Errichtung einer instabilen osmanischen Militärverwaltung im 'Asīr führt, die bis 1918 währt. Die Ahl ' ${ }^{\prime}$ 'iḍ müssen sich daher auf Kooperationen mit den Osmanen einrichten. Nach dem Zusammenbruch des Osmanenreiches versuchen die nunmehrigen Führer der Ahl ' $\bar{A}$ 'id erneut, sich selbständig zu behaupten. Unter Druck geraten seitens der von den Briten kurzfristig unterstützten Idrisīden aus Abū 'Arīsh, die schon 1911 Abhā einmal belagert haben, rufen die Ahl ' $\bar{A}$ 'iḍ allerdings die $\bar{A} l \mathrm{Sa}^{\mathrm{c}} \mathrm{u} \mathrm{d}$ zu Hilfe, was schließlich deren bleibende Etablierung im 'Asīr einleitet. ${ }^{273}$ 1922 stirbt Muḥammad al-Idrīsī; die Fraktionskämpfe unter seinen Nachfolgern beendet 'Abdul 'Azīz b. Sa'ūd durch Aufhebung auch der letzten nominellen Kontrolle der Idrisiden in der Region.

Dieser geraffte Überblick zur jüngeren Staatsgeschichte des 'Asīr mag als Orientierungshilfe dienen, um einige Probleme der lokalen Architektur des zentralen (und in der Folge des westlichen) 'Asīr nun näher zu erörtern.

Zunächst ist festzustellen, daß einige der bereits diskutierten Nachschubwege und Transportlinien, die an Küstenorten des Roten Meeres wie al-Qunfudha, Qahma oder Jizān beginnen, hier im Hochland bei Abhā und Khamīs Mushayṭ enden. Als tribale Verbindungsrouten zu den „ports of trade“ an der Küste hatten diese Wege wohl schon weit länger bestanden, aber in ihrer befestigten und ausgebauten Form sind sie ein Ergebnis des 19. Jh. Die Ahl ' $\bar{A}$ 'id machten Abhā, das im Gebiet ihres eigenen Stammes, der B. Mudhayḍ lag und liegt, ab den 20er Jahren des 19. Jh. zur Hauptstadt des 'Asīr. Die Türken befestigten Abhā weiter mit zahlreichen Forts, ${ }^{274}$ bauten Wege nach Khamīs Mushayṭ zu einer Straße aus, und sie legten die Straße von Abhā über al-Sūda und das W. Tayya zur Küste an, entlang derer sie Brücken und Wehranlagen einrichteten. ${ }^{275}$

In dieser Form also hat die rezente Staatsgeschichte ihre architektonischen Spuren im Zentral-'Asīr hinterlassen: Erstens als spezialisierte, militärstaatliche Bauten und als infrastrukturelle Einrichtung von Routen. Zweitens ist festzustellen, daß das 19. Jh. im 'Asīr vor allem eine tribale Führungsschicht hervorbringt, die mit den jeweiligen, von außen eindringenden Staatsmächten fallweise kooperiert und sich ihnen fallweise auch widersetzt, bis die dynastische tribale Führung nach 100 Jahren relativer politischer Kontinuität schließlich vom dritten saudischen Staat abgelöst wird. Innerhalb der wechselnden Konjunkturen und Rivalitäten zwischen Ägyptern und Osmanen, den jeweiligen Lokalherrschern in Abu 'Arīsh, sowie dem ersten und zweiten saudischen Staat entwickelt und festigt sich also eine lokale

273 Mueller 1960: 98.

274 Tamisier 1840, II: 361, 365; Weisl 1927: 281; Lippens 1956: 43-48.

275 Philby 1956: 139, 142-147, 152f. Philby (ibid: 146) vermutet zwar, daß die Hauptfestung von Abhā "probably of great antiquity" sei, doch liegen dafür keine weiteren Belege vor. Tamisier (1840, II: $361 \mathrm{f}$., 365 f.) verweist zwar auf die Festung des ' $\overline{\mathrm{A}}$ ’iḍ in Manādir, einem Ortsteil von Abhā, doch kann damit auch bloß eine größere, defensive Wohnanlage gemeint gewesen sein. 
Führungsschicht der Stammesgesellschaften. Gestützt auf ihre gewohnheitsrechtliche Legitimierung in der tribalen Bevölkerungsmehrheit trachtet sie relativ erfolgreich danach, ihre Sonderinteressen im Namen dieser tribalen Mehrheit quer durch die wechselnden Machtkonstellationen hindurch zu behaupten. In dieser Hinsicht sind die Ahl 'A' ${ }^{\prime} i d$ nahezu die einzige politische Konstante des zentralen 'Asìr im 19. Jh.

Daraus ergibt sich aber, daß parallel zum zunehmenden Staatseinfluß von außen, und teilweise im Widerstand dagegen, für das 19. Jh. eine Transformierung und Verstärkung älterer tribaler Werte und Strukturen im 'Asīr vor sich geht. Die Etablierung einer tribalen Häuptlingsfamilie (der Ahl 'A' 'iḍ) als regionale Führungskraft hebt diese über ihren eigenen Stamm, und mit diesem zusammen auch über die anderen Stämme. Diese rezente Einführung eines verstärkten hierarchisierenden Elementes transformiert die ältere tribale Sozialordnung; zugleich kann hypothetisch von einer gewissen Revitalisierung und Homogenisierung ausgegangen werden: Die politische Behauptung gegenüber mächtigeren äußeren Staatsapparaten war nicht nur durch Kooperation mit diesen und durch wechselseitige Beeinflussungen möglich. Mindestens ebenso wichtig für eine derartige dynastische Behauptung muß der verstärkte Rückgriff auf die gegebenen tribalen Werte und Strukturen angesehen werden, um die eigene soziale Basis zu erhalten und auszubauen. Ein unumgänglicher Aspekt davon ist die Wahrung eines politischen Bündnissystems mit den Führungskräften anderer Stämme des Hochlandes, die gegenüber neuen äußeren Gegnern insgesamt enger zusammenrücken.

Diese theoretischen Schlußfolgerungen aus den vorliegenden Angaben zum 19. Jh. die durch zukünftige Quellenstudien weiter zu überprüfen sind - ergeben für den zentralen 'Asīr des 19. Jh. also vorerst das Bild eines bestimmten sozialen Ambientes für die örtliche Architektur. In diesem sozialen Ambiente bilden sich tribale Oberschichten der Stämme heraus, die sich um die Ahl ' $\bar{A}$ 'iḍ der B. Mughayḍ oder deren Gegner gruppieren, und angesichts des zunehmenden staatlichen Drucks von außen gezwungen sind, die eigenen, tribalen Wertvorstellungen und Strukturen zu stärken. Zugleich werden die Oberschichten zunehmend den neuen Staatseinflüssen ausgesetzt und sukzessive in diese auch institutionell integriert.

Diese Überlegungen beanspruchen für die nachfolgende Diskussion der Steinbauten ebensosehr Geltung wie für die vorangegangenen der Adobe-Bauten. Dort wurden die "Sonderräume“ der Oberschicht in ihren konstruktiven, funktionalen und symbolischen Zusammenhängen diskutiert, während der historische Hintergrund nur kurz berührt wurde. Jene konstruktiven, funktionalen und symbolischen Zusammenhänge der „Sonderräume" (Gebetsraum, Frauenraum, hammām) sind auch für die Wohnhäuser der Oberschicht in der Pagoden-Zone identisch, ${ }^{276}$ und müssen daher an dieser Stelle nicht wiederholt werden. Da der dynastische Teil dieser tribalen Oberschicht des 19. Jh. aber hier, im Zentrum der Pagoden-Zone seinen Sitz hatte, ist auf seine ambivalente Genese anhand der Ahl ' $\overline{\mathrm{A}}$ 'ị̣ näher einzugehen gewesen.

Auch für die Pagoden-Variante gilt damit, daß die rezenten Staatseinflüsse die tribale Architektur nur im Teilbereich der "gehobenen Wohnkultur" dieser Oberschicht verändert haben. Die Überlegungen zum sozialen Ambiente einer relativen Homogenisierung und Revi-

276 cf. auch Philby 1952: 142; al-Harīīi 1981: 20, 26. In diesem Kontext ist auch Philby's Beobachtung hervorzuheben, wonach speziell die Frauen der Oberschicht von Abhā zur Zeit seines Besuches die Norm eingeschränkter Mobilität einhielten, die ansonsten kaum beachtet wurde (Philby 1952: 142f.). 
talisierung der tribalen Kultur legen aber zugleich den Schluß nahe, daß das 19. Jh. auch im Bereich der Architektur eher einen verstärkten Rückgriff auf indigene, lokale Prinzipien hervorbringt. Ob im Zuge dieser Homogenisierung eventuell ältere lokale bauliche Unterschiede verschwunden sind, wird sich im Detail nicht mehr rekonstruieren lassen, aber einige der folgenden Untersuchungsergebnisse zur Steinarchitektur weisen darauf hin. Daraus leite ich die Vermutung ab, daß die verstärkte Herausbildung tribaler Oberschichten im 'Asīr des 19. Jh. von einer gewissen, regionalen Homogenisierung und Stratifizierung der Adobe- und Pagoden-Varianten begleitet worden ist.

Die Hauptaspekte der Pagoden-Variante sind aber, ungeachtet der eventuellen Homogenisierung architektonischer Details, schon vor dem 19. Jh. vorhanden und werden in dessen Verlauf beharrlich fortgeführt. Noch 1936 erfährt Philby, daß Abhā nach den großen Zerstörungen, die es im Zuge der saudischen Machtübernahme von 1921 erlitten hatte "fortunately for the most part in the traditional style of the district" wiederaufgebaut worden war. ${ }^{277}$

Die Beharrlichkeit, mit der diese architektonische Tradition bis in die 80er Jahre des 20. Jh. bewahrt und fortgeführt worden ist, unterstreicht zum einen ihre hochspezialisierte Abstimmung auf die klimatisch-ökologischen, wirtschaftlichen, sozialen und politischen Bedingungen. Diese spezialisierte architektonische Abstimmung ist nicht ohne weiteres ersetzbar gewesen. Zum anderen verweist diese Beharrlichkeit auch auf den darüber hinausreichenden Zustand, daß gerade derart markante Wohnhäuser wie die Pagoden-Bauten eine Form von regionaler, tribaler Identität repräsentieren. Dies gilt zunächst für jene Teilgruppen von Stämmen, die im Zentral- ${ }^{`}$ Asīr oberhalb der Shifā siedeln - also von Südost nach Nordwest für die Banī Bishr, Rufayda (Qahtān), Shahrān im Südosten der 'AsīrFöderation, und dann in nordwestlicher Nachbarschaft dazu die Banī Mālik des 'Asīr und die B. Mughayḍ selbst. Die beiden letztgenannten Verbände leben mit nahezu ihrer gesamten seßhaften Bevölkerung in der Pagoden-Zone, und zugleich repräsentieren sie die wichtigen Ostgruppen der 'Asīr-Föderation. ${ }^{278}$ Der Nordwestteil der Pagoden-Zone deckt sich also mit dem Ostteil des Territoriums der 'Asīr-Stämme: Hier liegt Abhā und hier siedelt jener Stamm, dessen Häuptlingslinie im 19. Jh. die Geschichte der gesamten Region entscheidend mitgestaltet hat. Es ist selbstverständlich, daß das lokale Wissen um diese $\mathrm{Zu}$ sammenhänge die Pagoden-Bauten zu einem Element und Symbol regionaler, und darüber hinaus von 'Asīr-Identität im weiteren Sinn werden hat lassen. Hinzu kommt die Einzigartigkeit dieser Variante. Dem einheimischen Wissen ist längst bekannt, was die ethnologische Untersuchung in dieser Hinsicht aufzeigt: Adobe-Bauten gibt es auch im Jemen, Steinbauten gibt es in ähnlichen Formen wie im West- und Nord-' Asīr auch im südlichen Hijäz und im Jemen - aber Pagoden-Bauten gibt es nur im 'Asīr, und nirgendwo sonst in Arabien.

In diesem Sinn sind es weniger Konstruktion und Funktionalität, als vielmehr die Ästethik der Form und des Dekors der Pagoden-Bauten, die sie in ihrer Gesamtheit für die Bewohner zu einem materiellen Symbol regionaler Identität machen. Das typische Erscheinungsbild der Pagoden-Bauten ist für ihre Bewohner quasi ein Wahrzeichen des 'Asīr und seiner heroischen tribalen Geschichte.

277 ibid: 147.

278 Abdulfattah 1981: map 5. 
Damit lassen sich die drei dekorativen Codes an der Wohnarchitektur der Pagoden-Bauten als regionalkulturliche Elemente und Querverweise entschlüsseln. Zwei von ihnen verweisen auf spezifische weitere Zusammenhänge.

1. Die von Osten nach Westen abnehmende Bedeutung der Zinnen unterstreicht, zusammen mit den graduellen technischen Übergängen, die Affinitäten zum Nordwestteil der Adobe-Architektur, und damit die Gemeinsamkeiten mit dem Ost- ${ }^{\mathrm{A}}$ Asīr und die periphere Position zu Najrān.

2. Die auch in den Wohnzimmern der Pagoden-Häuser oft gegebene, typische Wandmalerei ist eine Gemeinsamkeit, sowohl mit den Adobe-Bauten des Ost-'Asīr wie mit den Steinbauten des West- und Nord-'Asīr; sie unterstreicht die Gemeinsamkeiten der tribalen Wohn- und Alltagskultur des gesamten 'Asīr. Auch heute noch sind die Innenwände der diwāne von älteren Pagoden-Bauten bis in Schulterhöhe bemalt, wobei bunter Streifendekor vorherrscht. ${ }^{279}$

3. Die auffälligsten dekorativen Eigenschaften der Pagoden-Bauten aber sind durch ihre Außenansicht gegeben, als untrennbarer Bestandteil materialspezifischer Konstruktion dieser Variante. Die parallele Abfolge von ebenmäßig hervorragenden Schindelreihen, deren dunkle Farbe sich mit dem Weiß des Verputzes oder dem Braun der Lehmwulste rhythmisch abwechselt, ist selbst der dritte und wichtigste dekorative Code an den PagodenBauten. Andeutungsweise verweist der weiße Verputz um die Fenster (wo er früher mit bunter Farbe manchmal besonders hervorgehoben gewesen sein soll) auf den weißen Zierstein und die weiße Bemalung der Stein- und der Adobe-Variante. Aber von eindeutig gröBerem Gewicht als diese Andeutung ist der kompositorische Gesamteindruck, der diese, und nur diese Variante auszeichnet. Sie hat keinen anderen, für sie spezifischen Dekor als ästhetische Gesamtgestaltung der Fassaden (Abb. 59). In dieser architektonischen Komposition sind technische Zweckmäßigkeit und optisch-ästethische Wirkung durchgehend miteinander integriert. Die dekorative Einzigartigkeit ist damit zu einem regionalen Symbol geworden, das zum einen die tribalen Bewohner der Pagoden-Bauten oberhalb der Shifā von allen anderen distinguiert. Zum anderen wird auch von den Einwohnern anderer Teile des 'Asīr kaum bestritten, daß die Pagoden-Bauten ein architektonisches non plus ultra der Gesamtregion darstellen. Insoferne verweist diese Spitzenposition unter den „Wahrzeichen“ über die Pagoden-Zone im engeren Sinn hinaus auch auf den Gesamt- ${ }^{`} A s \bar{v} r$, und ist ähnlich wie die Innenwandmalerei ein Schlüsselelement der Dekorsprache des südlichen, tribalen Berglandes.

\subsubsection{Steinbauten des West- und Nord- ${ }^{\mathrm{C}}$ Asīr}

Die defensiven, drei- bis fünfgeschoßigen Wohnbauten aus Stein machen bei weitem den größten Anteil an der traditionellen Architektur des 'As̄̄r aus. Dies gilt sowohl für die Anzahl der Bauten und ihrer Bewohner, wie auch für die flächenmäßige Ausdehnung dieser Variante.

Zieht man auf einer Karte durch die Gebiete des 'Asīr imaginäre Grenzlinien, um alle Verbreitungsgebiete von Steinarchitektur miteinander zu verbinden, so ergibt sich das Bild eines langgestreckten, schmalen Bandes. Dieses Band folgt ungefähr dem Verlauf der

279 Thesiger 1947: 195. 
Shifā, indem es sich im Nord-'Asīr oberhalb des Grabenrandes erstreckt und sich dann im West- ${ }^{` A s i ̄ r ~ p r i m a ̈ r ~ u n t e r h a l b ~ d e s ~ G r a b e n r a n d e s ~ f o r t s e t z t . ~}$

Wenn also im folgenden von Steinarchitektur im Norden des 'Asīr die Rede ist, so wird damit jene Architektur angesprochen, die im Bergland oberhalb der Shifā auftritt: Ab dem Oberlauf des W. Qanūna von der Shifā über al-Namās bis hin in die nordwestliche Nachbarschaft der Pagoden-Zone bei Abhā. Diese nördliche Steinarchitektur geht in ihrem eigenen nördlichen Randgebiet in die Architektur des südlichen Hijāz über, und vermischt sich im Nordwesten mit Ausläufern des Küstenstils.

Mit der westlichen (und südwestlichen) Steinarchitektur des 'Asīr ist hingegen die südliche Fortsetzung dieses Bandes gemeint, die etwa ab der Höhe von Abhā unterhalb des Grabenrandes beginnt und sich bis zur jemenitischen Grenze im Süden erstreckt. Diese (süd-) westliche Steinarchitektur ist charakteristisch für die hohen, dem Grabenrand vorgelagerten, isolierten Tihāma-Berge. Sie ist im Osten von der Pagoden-Zone und den Ausläufern der Adobe-Variante (bei Ẓahrān) durch den Grabenrand und die darunterliegenden Fluttäler getrennt, und sie geht an den tiefen, westlichen Ausläufern dieser Berge über in 'ushash-Mischformen und volkstümliche Varianten des Küstenstils.

Klimatische Faktoren haben in diesem langgezogenen Verbreitungsgebiet den Ausschlag für Stein als dem primären Baumaterial gegeben. Generell handelt es sich um die kühlsten und feuchtesten Teile des 'Asīr. Der Norden ist entlang der Shifā stärker als der Süd-'Asīr den Winterregen ausgesetzt, die hier an den Grabenrand getrieben werden, ohne daß vorgelagerte hohe Bergstöcke die Regenwinde substantiell abfangen könnten. Im Südwest- 'Asīr hingegen sind es eben derartige, hohe Bergstöcke vor dem Grabenrand, welche die hier schwächeren Winterregen, aber auch Ausläufer der Monsune auffangen. Wo im 'Asīr die hauptsächlichen Steigerungsregen niedergehen, dort herrscht also Steinarchitektur vor. Lehmmaterial ist im hohen Bergland nicht widerstandsfähig genug gegen die Niederschläge und außerdem etwas knapper. Für defensive Wohnzwecke bietet sich Stein als das einzige örtlich verfügbare Material an. In dieser elementaren Hinsicht endet die Verwendung von Stein als zentralem Baumaterial daher auch nicht an den Grenzen des 'Asīr: Das langgezogene Band hat vielmehr seine Fortsetzung nach Norden hin in den südlichen Ḥijāz, wo zu beiden Seiten der Shifā ebenfalls Steinarchitektur vorherrscht - allerdings unter Anwendung anderer konstruktiver Prinzipien. Und auch in südlicher Richtung findet die Steinarchitektur des 'Asīr ihre Fortsetzung in jener des Jemen, wo sie ebenfalls im Bereich des dort zerklüfteteren Grabenrandes vorherrscht. Entlang des westund südwestarabischen Grabenrandes ist Steinarchitektur also die Regel, Pagoden- und Adobe-Bauten stellen in diesen Lagen hingegen (vor allem spezifisch-'asïrische) Ausnahmen dar.

Innerhalb des gesamten saudischen Südwestens sind jedoch die konstruktiven Gemeinsamkeiten der Steinarchitektur des 'Asīr mit den Pagoden- und Adobe-Varianten vorherrschend, während die materiellen Affinitäten zur Steinarchitektur des südlichen Hijāz nur ein sekundäres Merkmal darstellen, sieht man vom nördlichsten Teil des 'Asīr einmal ab. Trotz großer Variationsformen innerhalb der Steinarchitektur des West- und Nord-'Asīr weist sie neben jenen konstruktiven Eigenschaften, die ihre Zuordnung zum übergeordneten Typus und Subtypus veranlaßt haben, auch einige variantenspezifische, technische Gemeinsamkeiten auf.

Zunächst sollen zweckmäßigerweise die konstruktiven Eigenschaften rekapituliert werden, die der Typus und Subtypus impliziert. Wir haben es also auch hier mit primär 
kubischen, drei- bis sechsgeschoßigen, defensiven Wohnbauten mit Flachdächern zu tun; den fusion-patterns entsprechend sind die Wirtschaftsräume in den unteren und die Wohnräume in den oberen Geschoßen untergebracht. Nur letztere haben größere Fensteröffnungen, ansonsten herrschen schmale Schießscharten und niedrige Türen als Maueröffnungen vor. Einfache Stützmauer, Innen- oder Zwischenschacht sind die alternativen Lösungen, um Innenzugänge zwischen den Geschoßen mit tragenden Binnenmauern zu kombinieren. Out-towers herrschen generell vor, in-towers und Frontdörfer sind lokale Ausnahmen, die auch hier genau spezifizierbar sind. Holzdekor ist von etwas nachrangiger Bedeutung gegenüber dem (hier spärlicheren) Dekor außen, an den Fassaden und auf den Mauerkronen, und gegenüber den Wandmalereien innen, in den Wohn- und Versammlungsräumen.

$\mathrm{Zu}$ diesen Eigenschaften von Typus und Subtypus treten nunmehr jene hinzu, die variantenspezifisch durch das primäre Baumaterial Stein gegeben sind. Unabhängig von seiner jeweiligen lokalen Beschaffenheit ist Stein generell aufwendiger zu bearbeiten als die vorherrschenden Lehmwulste (und Schindeln) bei Pagoden- und Adobe-Bauten. Stein kann aber Innentemperaturen etwas besser speichern als Lehm, wenn man ihn sorgfältig schließt und abdeckt. Dementsprechender Nachdruck muß bei dieser Variante darauf gelegt werden, die Ritzen zwischen den Steinblöcken zu minimieren. Die Steine sind (im 'Asīr wie im Hijāaz) durchwegs trocken verlegt. Je nach Material und Bearbeitung ergibt sich daher entweder die Möglichkeit, eben behauene Flächen aneinander zu fügen, oder aber weniger regelmäßig bearbeitete Steine bilden kleine Zwischenräume, die mit Geröll aufgefüllt werden. Ob es sich jedoch um gleichmäßig gearbeitete oder um unregelmäßige Blöcke mit Geröllfüllung handelt - in beiden Fällen müssen verbleibende Ritzen zusätzlich abgedeckt werden, einmal mehr, das andere Mal weniger: Intensiver Innenputz ist daher für alle Steinbauten entlang des Grabenrandes unumgänglich; Außenverputz würde hingegen der Witterung oft nicht standhalten. Die höhere Speicherkapazität für Innentemperaturen entspricht also dem kühleren und feuchteren Klima als dem primären, variantenbestimmenden Faktor. Zugleich bietet Steinmaterial den Wohnbauten auch mehr defensiven Schutz als das Lehmgemisch der Pagoden- oder Adobe-Bauten. Dies erlaubt erstens, die Außenwände manchmal etwas weniger dick zu gestalten als bei den anderen beiden Varianten, was die mühselige Anfertigung der Steinblöcke in Grenzen hält. Zweitens entfällt durch dieses prinzipiell erhöhte Potential die Notwendigkeit für defensive Zusatzeinrichtungen. Die Lehmnasen, die Vielfalt der Zinnen oder die maximale Ausschöpfung der Hochbauweise im Zentral- und Ost-'Asīr haben also keine analoge Entsprechungen im Steinbau des nord- und südwestlichen 'Asīr. Die Wohnbauten können generell etwas niedriger sein und sind außen wie innen meist einfacher gestaltet als im Ost- und Zentral-'Asīr. Die plastischen Gestaltungsmöglichkeiten von Lehminnenwänden entfallen hier.

Der geringeren Höhe und Dicke der Steinmauern liegen aber auch statische und klimatische Faktoren zugrunde. Festigkeit und Härte des Materials erlauben zwar auch seine erhöhte Belastung, aber dieser sind Grenzen gesetzt. Die trocken verlegten Steinschichten müssen einander nämlich in höherem Maße als die Lehmwulste selbst tragen, um nicht zu kippen. Dies bedingt, daß breite Außenwände im Steinbau weniger stark geneigt werden können als bei der Pagoden- und Adobe-Variante, was wiederum den Druck der oberen auf die unteren Reihen erhöht. Durch besonders massive Steinblöcke für Grundmauern und Erdgeschoß und durch die Vermeidung von maximalen Höhen 
wirkt man dem entgegen. Hinzu kommt, daß die durchschnittlich niedrigeren Temperaturen und die intensiveren Regenperioden häufiger das Bewahren wärmerer Innentemperaturen erfordern, und die Kühlung der Obergeschoße keine permanente Notwendigkeit ist. Auch aus diesen Gründen ist weniger Anlaß gegeben, in maximale Höhen zu bauen.

Trocken verlegte Reihen von regelmäßig oder uneben gefertigten Steinblöcken, geringe Neigung der Außenmauern, etwas dünnere Wände und etwas geringere Haushöhe als im Zentral- und Ost- ${ }^{`}$ Asīr, massiver Innenverputz bei ansonsten karger Innenausstattung und meist unverputzte Fassaden mit spärlichem Dekor - dies ist das generelle Erscheinungsbild dieser Variante.

Alle weiteren Details sind durch die Besonderheiten der jeweiligen Region geprägt. Die langgestreckte Ausdehnung dieses Verbreitungsgebietes bedingt zum Teil beträchtliche klimatische, aber auch geologische Unterschiede, mit den entsprechenden Auswirkungen für Standorte der Häuser und Siedlungen, auf die physische Beschaffenheit und Farbe des Steinmaterials, wie auf Niederschläge und Temperaturen. Diese unterschiedlichen ökologischen und technisch-konstruktiven Akzentsetzungen werden im Südwesten nochmaligen Variationen ausgesetzt, die dort durch die unterschiedlichen Höhenstufen auf den isolierten Tihāma-Bergen gegeben sind.

Diese ökologisch-technischen Differenzierungen kombinieren sich mit den sozialen und historischen Besonderheiten des jeweiligen Gebietes. Die isolierten Tihāma-Berge des Südwestens zählen zu den unzugänglichsten Teilen des 'Asīr (administrativ zählen diese Gebiete bereits zum Ostteil der Provinz Jīzān), deren tribale Bevölkerung sich besonders lange den äußeren politischen (aber deshalb nicht unbedingt auch den wirtschaftlichen und kulturellen) Einflüssen staatlicher Herrschaft entziehen konnte. Die tribalen Gebiete zwischen Abhā und al-Nimaṣ hingegen waren in weitaus stärkerem Maß in jene politischen Entwicklungen des 19. Jh. einbezogen, die bereits im Abschnitt über die Pagoden-Zone zusammengefaßt wurden.

Die südwestliche Steinarchitektur umfaßt ihrerseits zwei inselartige, größere Verbreitungszonen, die mit den hochgelegenen Partien von zwei Gruppierungen isolierter Tihāma-Berge identisch sind. Die südliche dieser zwei Gruppierungen ist das Bergland, das sich von den J. al-Qahr und Harūb bis zu den Gebieten der Khawlān erstreckt, wo es die Stammesgebiete der Ahl Fayfā und Bani Mālik (Khawlān) auf den gleichnamigen Bergstöcken umfaßt und an die jemenitische Grenze heranreicht. Jenseits der Grenze setzen sich die Hauptsiedlungsgebiete der nördlichen Khawlān bis Șa da fort; Ahl Fayfā und B. Mālik gehören zur Nordwestgruppe dieser Föderation. Nordwestlich davon liegt als zweite Berggruppe in der Tihāma das Gebiet der Rijāl Almac, mit den J. Faqwa und Șalab als höchsten Gipfeln. Es erstreckt sich von den Oberläufen des W. lalī zu jenen des W. Rīm und liegt vor dem Grabenrand etwa westlich von Abhā.

Oberhalb des Grabenrandes im Nord-'Asīr ist die Steinarchitektur ebenfalls auf zwei Verbreitungsgebiete konzentriert. Nordwestlich von Abhā schließt an die Pagoden-Zone direkt die Steinarchitektur um al-Sūda und Tahlaf an. Als kleine Einsprengung reichen einzelne Steinbauten sogar bis Abhā in die Pagoden-Zone; die Siedlungsgebiete mit diesen Steinbauten liegen größtenteils in Stammesgebieten der Rufayda und Alkam, und schlieBen in der Luftlinie, also vom Grabenrand getrennt, nordöstlich an jene der Rijāl Alma ${ }^{c}$ an. Rijāl Alma ${ }^{c}$, Alkam und (Rabī'a wa) Rufayda machen den Großteil der westlichen Teilstämme der 'Asīr-Föderation aus. 
Das zweite Gebiet der Steinarchitektur im Nord-'Asīr schließt an den Nordrand der Pagoden-Zone an. Es erstreckt sich vom Grabenrand oberhalb der rechten Seite des W. Tayya über al-Nimaṣ bis auf die Höhe des W. Qanūna und umfaßt damit die bäuerlichen Siedlungsgebiete der B. al-Ḥijr entlang der Shifā und die ihrer beiden nördlichen Nachbarstämme, Balqarn und Shumrān.

Die Verbreitung der südwestlichen Steinarchitektur des 'Asīr ist also auf die zwei gebirgigen Rückzugsgebiete der (nordwestlichen) Khawlān und deren kleinere Nachbarstämme sowie auf jene der Rijāl Alma konzentriert. Die nördliche Steinarchitektur schließt daran in den Gebieten der Rufayda und Alkam an, wodurch für die westlichen Hauptgruppen der 'Asīr-Föderation oberhalb und unterhalb des Grabenrandes diese Architekturvariante charakteristisich ist. Im nördlichen 'Asīr folgen darauf die Siedlungsgebiete der B. al-Hijr und ihrer Nachbarn entlang der Shifā.

Khawlān (und Nachbarn) im Südwesten, im Zentrum ein Teil der 'Asīr-Stämme, sowie im Norden die Banū l-Ḥijr (und Nachbarn) - dies ist die ungefähre Zuordnung von tribalen Teilgebieten entlang der Shifā zum Verbreitungsgebiet der Steinarchitektur im 'Asīr. Angesichts der ökologischen und sozialen Unterschiede der Steinarchitektur sollen diese lokalen Besonderheiten im folgenden als tribale Subvarianten etwas näher ausgeführt werden.

\section{A. Steinarchitektur der isolierten Tihāma-Berge im (Süd) West- ${ }^{\complement} A s \bar{r} r$}

Die Steinarchitektur der Khawlān und ihrer Nachbarn wird im folgenden am Beispiel der Ahl Fayfā erörtert, jene der Rijāl Alma c wird primär anhand der Ahl Ṣalab behandelt. ${ }^{280}$ Die Ahl Fayfā siedeln im äußersten Südostteil der saudischen Tihāma und sind Teil der großen Föderation der Khawlān b. 'Amīr, deren Hauptgruppen in den nach Südosten hin anschließenden, heute jemenitischen Gebieten siedeln. Daher gehören die Ahl Fayfā zur peripheren Nordwestgruppe der Khawlān b. 'Amīr;'281 die Ahl Șalab sind hingegen ein Teilstamm der Rijāl Alma ${ }^{c}$ im West-'Asīr, die selbst wiederum der Westgruppe der 'Asīr-Föderation angehören.

Zunächst soll auf einige soziale und historische Parallelen zwischen diesen beiden Verbänden hingewiesen werden, welche die Rahmenbedingungen der örtlichen Architektur beeinflussen, die sie überdies auch mit den anderen Stämmen isolierter Tihāma-Berge teilen. In beiden Fällen stimmt der Name des Stammes mit jenem des Bergstockes über-

${ }^{280}$ Das Gebiet der Rijāl Alma ' besuchte ich Anfang 1982 im Rahmen des saudisch-österreichischen Kooperationsprojektes zusammen mit 'Abdul 'Azīz al-'Ashbān, 'Abdallāh al-Zahrānī und Johann Heiß. Das Gebiet der Ahl Fayfā habe ich selbst hingegen bisher nicht besucht. 1983 (gemeinsam mit Johann Heiß) und 1986 habe ich Feldforschungen beim Nachbarstamm der Ahl Fayfā durchgeführt, nämlich auf der jemenitischen Seite der Grenze, bei den Munebbih (b. Furūdh b. Khawlān b. 'Amīr), die ebenfalls der Khawlān-Föderation angehören. Die Architektur der Ahl Fayfā war von meinen Erhebungsgebieten an der West- und Nordwestseite des J. Munebbih aus nicht nur mit Fernglas, sondern auch mit freiem Auge gut sichtbar. Besuche von Mitgliedern der Ahl Fayfā bei den Munebbih waren alltäglich, was mir die Gelegenheit zu mehreren Interviews gab. Trotz dieser Einschränkungen werden die solchermaßen erhobenen Angaben hier präsentiert, da meines Wissens ansonsten nur Philby zwei Tage (Ende 1936) und die Mitglieder des saudisch-französischen Teams einige Tage (in den frühen 1980er Jahren) ethnologisch relevante Daten am J. Fayfā erhoben und veröffentlicht haben. In diesem Zusammenhang danke ich erneut M. und P. Maréchaux, die Mitglieder jenes Teams waren, für die Möglichkeit der Nutzung ihres photographischen Archivs.

281 Gingrich 1989: 75-81 und 1993: 253-263, $272 \mathrm{f}$. 
ein, den er besiedelt (Ahl und J. Salab, ebenso wie Ahl und J. Fayfā). Es handelt sich innerhalb zweier größerer tribaler Föderationen jeweils um Teilstämme, deren Name explizit einen territorialen und keinen genealogischen Bezug aufweist. Die Föderationen existieren zwar bereits mit heutigem Namen im 10. Jh. (Alma ${ }^{c}$ und Khawlān), ${ }^{282}$ aber die Teilstämme mit heutigen Namen werden in dieser Zeit noch nicht genannt. In beiden Fällen handelt es sich also um Siedlungsgebiete, die im 10. und 13. Jh. noch nicht nachweislich von Verbänden des heutigen Namens bewohnt waren. Die Formierung dieser Teilstämme in ihren heutigen Siedlungsgebieten ist frühestens mit dem ausgehenden Mittelalter anzusetzen. Mit großer Wahrscheinlichkeit steht dies im Wechselverhältnis zur „Detribalisierung" der mittelalterlichen Tihāma-Bevölkerung, die bereits im dritten Abschnitt dieser Arbeit angesprochen worden ist. ${ }^{283}$ Während die Zusammenhänge zwischen Stammesnamen und Territorien im westarabischen Plateaugebiet und teilweise auch im Bergland eine weit ältere historische Kontinuität aufweisen, handelt es sich bei der Formierung dieser Teilstämme der isolierten Tihāma-Berge daher um relativ junge Prozesse. Diese rezenten Neuformierungen sind vielleicht in den nicht-genealogischen Territorialnamen der Teilstämme bewahrt worden.

Die ökologischen Ähnlichkeiten dieser und anderer isolierter Tihāma-Berge liegen erstens in ihrer Exposition gegenüber den Regenwinden vom Westen, noch bevor diese den Grabenrand erreichen. Daraus resultieren äußerst günstige agroklimatische Bedingungen an den oberen und an den Westhängen dieser Berge. Gegenüber dem semi-ariden Tiefland nehmen sie sich als „Regenfänger" wie grüne, dichtbevölkerte Inseln aus. Zweitens haben die isolierten Tihāma-Berge häufig sehr steile mittlere Hänge, während ihre höchsten (und fruchtbarsten Teile) flacher sind. Mit vorindustrieller Waffentechnik waren diese Berge von den umliegenden Ebenen aus kaum einnehmbar; sie fungierten in ihrer Gesamtheit wie riesige, unzugängliche Burgen, die von oben aus effizient verteidigt werden konnten.

Diese parallelen Vorteile von großer landwirtschaftlicher Fruchtbarkeit, hoher Bevölkerungsdichte und günstiger militärstrategischer Lage sind von den Ahl Fayfā und Ahl Șalab in der Neuzeit mit voneinander unterschiedlichen Orientierungen genutzt worden.

\section{a) Architektur der nordwestlichen Khawlān}

Für die Ahl Fayfā ist belegt, daß sie sich im 17. und 18. Jh. über längere Perioden hinweg erfolgreich gegen Unterwerfungsversuche der benachbarten Regionalstaaten wehren konnten. Die Zugehörigkeit zur Khawlān-Föderation hat ihre Islamisierung vom zayditisch dominierten jemenitischen Hochland gefördert, ${ }^{284}$ von wo die Imāme auch mehrere Militärexpeditionen auf den J. Fayfā unternahmen - die wichtigste darunter im Zuge des qasimitischen Aufstandes gegen die Türken ab dem ausgehenden 16. Jh. ${ }^{285}$ Diese staatlichen Vorstöße bleiben aber bloß von punktueller Bedeutung und führten weder zur Eta-

282 al-Hamdānī (Müller): 113-115, 121.

${ }^{283}$ Einen lokalen Beleg für diese These erblicke ich in der Tatsache, daß eine führende Gruppe der Ahl Fayfā B. Hakam heißt - also nach jener mittelalterlichen tribalen Tihāma-Föderation benannt ist, die heute nicht mehr existiert. (cf. Philby 1952: 493; Gingrich 1989: 182, 579).

284 Philby 1952: 493; die bei King 1986: 79 f. dokumentierte Moschee dürfte jedoch eher auf Einflüsse aus Abū 'Arīsh zurückgehen.

285 Tritton 1925: 81-83. 
blierung einer Garnison (wie etwa am J. Rāzih im Jemen) oder zur Herrschaft einer lokalen Linie von Ashrāf (wie bei den Rijāl Almac). Die Ahl Fayfā nutzten zwar - ähnlich wie ihre beiden unmittelbaren Nachbarstämme, B. Mālik und Munebbih - die seit dem ausgehenden Mittelalter und der frühen Neuzeit intensivierte Handelstätigkeit an der Küste des Roten Meeres schrittweise und zeitverschoben auch für ihre eigenen wirtschaftlichen Interessen: Der Anbau von marktorientierten Agrarprodukten wie Banane, Baumwolle oder Qāt am J. Fayfā setzt eine teilweise Umorientierung ihrer Landwirtschaft für Marktbedürfnisse voraus, deren Anfänge bei den Ahl Fayfā auf das 17. und 18. Jh. zurückgehen dürften. Diese partielle wirtschaftliche Integration in das Handelsnetz der Küstenebene wurde aber zugleich zur verstärkten Aufrechterhaltung der politischen Selbständigkeit genutzt. Die Unterwerfungsversuche der Sharīfen von Abū 'Arīsh im 18. Jh. blieben erfolglos, ${ }^{286}$ und noch in den $30 \mathrm{er}$ Jahren des 20 . Jh. beklagten sich zayditische Erklärungen darüber, daß auf den Bergen der westlichen Khawlān keine staatliche Ordnung herrsche. ${ }^{287}$ Daran hatte auch die kurzfristige Unterstützung für die Idrisīden nach dem 1. Weltkrieg nichts geändert; de facto ist die saudische Verwaltung seit den 30er Jahren die erste stabile Staatsordnung, der die Ahl Fayfā in ihrer Geschichte ausgesetzt sind. ${ }^{288}$

Die potentielle Marktorientierung ihrer Landwirtschaft bei Wahrung ihrer politischen Selbstständigkeit bis in die 30er Jahre des 20. Jh. (ohne Einflüsse einer überlokalen Herrschaft) sind meines Erachtens die ausschlaggebenden Faktoren für eine Reihe von Besonderheiten an der Steinarchitektur der Ahl Fayfā. Relativer Wohlstand und ausgeprägte Defensiverfordernisse in einer abgelegenen Region, in der sich überlokale Herrschaftseinflüsse lange nicht durchgesetzt haben - all dies hat den allgemeinen Charakteristiken der Steinarchitektur hier im äußersten Südwesten spezifische Akzente verliehen.

Die Gesamtanlage von Siedlungen der Ahl Fayfā schildert Philby so, wie er sie im Dezember 1936 von Nordwesten aus wahrhnahm:

"It was 4 p. m. when we remounted the asses and resumed our march up the valley, with the great slopes of the Faifa massif coming right down to the channel along our right. On them, wherever we looked, there seemed to be human habitation, little castles rather than houses, generally standing on some pinnacle or eminence, but sometimes in small groups where the lie of the land was favourable. I had never seen anything like it before. Faifa was a mountain city with its dwellings scattered over a vast area in every convenient position, while the intervening spaces were filled with terraced fields, terrace upon terrace from near the foot to the very top. It is locally reckoned that the Faifa community has 6.000 such dwellings, and I can readily believe that it was so - a population of about 25.000 souls. At the Jaura ghail we were about 1.200 feet above sea-level and $S \bar{u} q$ ' Aiban upstream was about 250 feet higher, while the summit of Faifa is 5.700 feet above the sea. Its main axis from north-east to south-west, between the Jaura and Dhamad rivers, must have been about five miles in length with a greatest cross-section of perhaps three miles. At least half of the total area must have been occupied by houses or terraced cultivation. "289

Dieses generelle Muster variiert mit der Höhenlage. An den steileren Hängen in unterer und mittlerer Lage ist die Baufläche knapp. Zugleich waren diese Lagen historisch von außen zugänglicher als die oberen Hänge, das Klima ist hier in unterer und mittlerer Lage trockener, und es dominieren Einzelbauten mit drei oder vier Geschoßen, in deren

\footnotetext{
286 Tuchscherer 1985: 193-201; Gingrich 2000: 75-92.

287 Oriente Moderno 1934: 246-247.

288 Philby 1952: 492, 494.

289 ibid.: 486.
} 
Nähe sich zusätzliche out-towers befinden oder befunden haben. ${ }^{290}$ Auf den höher gelegenen, flachen Hängen liegen andererseits die fruchtbarsten Anbaugebiete, und hier lebten daher auch die größten Bevölkerungsteile. Zugleich ist das Klima hier ähnlich feucht und kühl wie am Grabenrand des 'Asīr oder im südlichen Hijāan. Deshalb dominieren kleine Weiler mit weniger (ein, zwei oder drei) Geschoßen, die fallweise auch um in-towers gruppiert sind. Auf dieses, für den Subtypus seltene Auftreten von in-towers im Gipfelbereich isolierter Tihāma-Berge wurde bereits im einleitenden Abschnitt 6.5.2. als regionale Ausnahme verwiesen. Die Obergeschoße der Wohnbauten müssen hier nicht immer wieder durchlüftet werden: Da es relativ kühl ist, „kauern“ die Häuser vielmehr in Bodennähe; das dadurch verminderte Defensivpotential wird durch in-towers ausgeglichen. Die Gruppierung von wenigen derartigen Häusern um jeweils einen in-tower unterstreicht, daß in diesen Lagen die Defensivarchitektur primär auf intratribale Konflikte ausgerichtet war.

Auch 1986 ließen sich diese niedrigen Wohnbauten im Gipfelbereich unterscheiden in ebenerdige, runde (qușayb) oder viereckige (marbū a) Steinhütten mit flachem Lehmdach, in zweigeschoßige runde oder viereckige Häuser, und in dreigeschoßige Bauten (Abb. 91). Die dominanten, niedrigen und engen Formen dieser Wohnbauten bedingen, daß die tragende Binnenmauer hier entfallen kann oder jedenfalls nur in ihrer einfachsten Form auftritt: Häuser mit Zwischenschächten der Innenmauergevierte treten auf den südwestlichen, isolierten Tihāma-Bergen kaum auf. Stall (sifl, pl. asfāl) und Lagerraum (makhzan) liegen also ebenerdig beim Eingangstor (khalwa); Küche (markab) und Wohnraum (majlīs) liegen gegenüber oder im Obergeschoß. Die zwei- und dreigeschoßigen Wohnbauten weisen die charakteristische leichte Neigung der Außenwände auf, die auch den Türmen zu eigen ist, welche sowohl rund wie vierkantig sind. ${ }^{291}$ Charakteristischerweise sind am J. Fayfā manchmal ein oder zwei der niedrigen Wohnbauten direkt an einen dieser runden in-towers angebaut. Die noch bestehenden in-towers der Ahl Fayfā (wie auch jene der B. Mālik) in höheren Lagen sind besonders hoch gebaut, um das „defensive Defizit“ der niedrigen Wohnbauten auszugleichen, insbesondere im Steilhang. Für runde Türme ergibt sich aus ihrer großen Höhe das konstruktive Problem, daß die kegelförmig geneigte Wand im Oberteil derartiger Türme zu wenig Innenraum bietet, um die Treppen noch entlang der Innenwand weiter hochführen zu können. Das Problem hat man dadurch gelöst, daß im oberen Drittel dieser Türme von der Innentreppe eine Türöffnung ins Freie führt, wo die Treppe das letzte Stück entlang der Außenwand bis zur Dachplattform weitergeführt wird (Taf. XLV).

Stabile und solide Steinarbeit ist für derartig waghalsige Konstruktionen eine wesentliche Voraussetzung. Die glatte und regelmäßige Bearbeitung der Steinblöcke ist zumindest teilweise, wie mir Gesprächspartner der Ahl Fayfā versicherten, das Ergebnis lokaler Auftragsarbeit, die an tribale Bauernhandwerker vergeben wird. Die Dekorierung dieser Steinbauten beschränkt sich hingegen auf das absolute Mindestmaß: Die weißen Ziersteine oberhalb der Fensteröffnungen sind meist gegeben; Wandbemalung der diwāne soll nach Auskunft meiner Informanten manchmal vorkommen, während Holzdekor am Türstock selten ist. Die Mauerkronen tragen keine Zinnen, aber die Brüstung der Dachterrassen von Türmen und Wohnbauten ist leicht nach außen versetzt.

290 cf. auch Philby 1952: 416, fig. 38 mit out-towers zwischen einzelnen Wohnbauten, wobei ein Gutteil der out-towers offenbar als Folge des Krieges von 1934 zerstört ist. 1986 gab es am J. Fayfā, soweit ich sah, weitaus weniger Türme als 1934 .

291 King 1986: 80 und 81 mit Wohnhäusern im Hintergrund der beiden Moscheen. 
An eine andere bemerkenswerte Sonderform von Türmen, die Philby beschrieben hat, konnten sich hingegen nur mehr ältere Informanten der Ahl Fayfā erinnern; jüngeren Besuchern war sie gänzlich unbekannt. ${ }^{292}$ Dies sind permanent bewohnte, dreigeschoßige runde Türme, bei denen nur das Erdgeschoß zur Gänze überdacht ist (bis auf den Zugang zum nächsten Stock über eine Leiter oder Wandtreppen). Die beiden Obergeschoße sind hingegen nur teilweise überdacht, und außerdem

"the two rooms open in different directions, presumably to allow the occupants to use either at choice according to the weather conditions of any time or day". (...) "The effect of this peculiar feature of local architecture is to give these mansions a wrenched or spiral appearance, which is quite attractive against a setting of terraced fields."

Ein Teil der hier vorgestellten Formen lokaler Wohnarchitektur des J. Fayfā ist durch die Besonderheiten des generellen Subtypus mit seiner materialspezifischen Variante in Stein also durchaus verständlich. Ein weiterer Teil (niedrigere Wohnhäuser und hohe $i n$ towers) ist durch die Abstimmung auf die lokalen ökologischen Bedingungen im hochgelegenen Berggebiet erklärbar. Ein dritter, kleinerer Anteil allerdings bleibt damit noch unberührt: dies sind die genannten Sonderformen der Türme, und das nahezu gleichwertige Auftreten von runden mit rechteckigen Formen der Grundrisse.

Die beiden Sonderformen der Türme sind der Kegelturm mit Außentreppe im oberen Drittel, und der von Philby beschriebene, bewohnte „Spiralenturm“ (Taf. XLVI). Im südlichen Hijāz, 'Asīr und nördlichen Jemen sind diese Turmformen nur von den isolierten Tihāma-Bergen im saudischen Khawlān-Gebiet bekannt, und auch hier sind sie nahezu verschwunden, was mit der Etablierung der saudischen Verwaltung seit 1934 zusammenhängt.

Es gibt am J. Fayfā also keine zwingenden, spezifischen ökologischen oder sozialen Faktoren, derentwegen diese Formen hier, und nur hier auftreten. Es gibt andererseits aber auch keine zwingenden Hindernisse (bis etwa zur Hälfte des 20. Jh.), derentwegen diese Sonderformen hier nicht möglich wären. Unter den gegebenen Bedingungen und Möglichkeiten sind also am J. Fayfā pragmatische, lokale Sonderformen entwickelt worden, die Eingang in das tribale Inventar der Architektur gefunden haben. Man kann vermuten, daß sie wohl als kreative Erfindung begabter, örtlicher Bauherrn entstanden sind und sich dann als architektonische Mode in diesem Stammesgebiet verbreitet und erhalten haben. Offenkundig ist jedenfalls, daß diese Sonderformen sich genau in jenem Gebiet der saudischen Tihāma feststellen und rekonstruieren lassen, in dem Formen von relativer lokaler und politisch-militärischer Autonomie am längsten bewahrt werden konnte.

Die verbleibenden Sonderformen am J. Fayfā stützen damit aber indirekt eine These, die wir im vorangehenden Abschnitt für den zentralen 'Asīr entwickelt haben: Für diese Region war von Tendenzen einer Revitalisierung, Hierarchisierung und Homogenisierung der tribalen Kultur im 19. Jh. gesprochen worden, die im Zusammenhang mit der damaligen Herausbildung der Ahl ' $\bar{A}$ '̄ọ zu einer tribalen Oberschicht und ihrer intensi-

292 Philby 1952: 496 f. für die folgende Beschreibung. Als ich einem älteren Mann der Ahl Fayfā aus meiner Erinnernung an diese Stelle in Philby's Buch die Hausform beschrieb, brach er in Gelächter aus und bestätigte schließlich, daß es diese Bauten früher bei seinem Stamm gegeben habe (Taf. XLVI). Sein erwachsener Sohn und sein Neffe, die ihn begleiteten, kannten diese Form hingegen nicht und begannen mit dem Mann fast zu streiten - so wenig konnten sie es fassen, daß ihre vertraute örtliche Architektur sich in bloß einer Generation derart gewandelt hatte, ohne daß sie davon wußten. 
vierten Auseinandersetzung mit Staatsmächten zu sehen ist. Hingegen waren die Stammesgebiete der südwestlichen Tihāma-Berge, ungeachtet aller äußeren wirtschaftlichen und spirituellen Einflüsse, nicht von derartigen politischen und militärischen Umwälzungen im 19. Jh. betroffen: Die Reste an architektonischen Sonderformen am J. Fayfā informieren uns also in Andeutungen darüber, welche Arten von lokalen und regionalen Sonderformen, auf ihre jeweils verschiedene Weise, auch im zentralen Hochland vor den dortigen Entwicklungen des 19. Jh. bestanden haben könnten. Die Ahl Fayfā sind im 19. Jh. eben nicht durch eine ähnliche Periode der Homogenisierung ihrer sozialen und materiellen Kultur hindurchgegangen. Daraus ziehe ich den hypothetischen Schluß, daß architektonische Sonderformen dieser oder ganz anderer Art vor dem 19. Jh. auch im Zentralund Ost- ${ }^{-}$Asīr den dortigen Wohnbauten noch stärkere lokale Akzente gaben als heute.

Die Ausprägung dieser Sonderformen steht weiters in einer bemerkenswerten, umgekehrten Relation zu jener des Dekors. Nur die minimalsten Gemeinsamkeiten des architektonischen Dekors im südlichen Bergland des 'Asīr finden sich noch am J. Fayfā. Steindekor ist hier selten, weil das örtliche Vorkommen von Quarz sehr beschränkt ist; statt dessen werden auf den Mauerkronen die Steinzinnen errichtet. Fast hat es den Anschein, als würde bloß das allernotwendigste auf diese spezifisch ästhetische Weise zum Ausdruck gebracht werden, um die Gleichwertigkeit und Ebenbürtigkeit der Ahl Fayfā mit den Stämmen des Berg- und Hochlandes in einer minimalistischen Sprache des Dekors zu betonen.

Diesem dekorativen Minimalismus steht die Bewahrung der genannten architektonischen Sonderformen gegenüber: Die spezialisierte Sprache des Dekors ist hier minimiert, aber statt dessen ist die generelle Sprache architektonischer Sonderformen kultiviert worden. Die tribale Peripherie am Südwestrand des 'Asīr steht auch in dieser Hinsicht im Gegensatz zum alten quasi-staatlichen Zentrum von Najrān am Südostrand. In Najrān ist die spezialisierte Sprache des Dekors komplexer und elaborierter als in irgendeiner anderen lokalen Form von traditioneller Architektur des 'Asīr, während dieselben lokalen Wohnbauten von Najrān ansonsten keine nennenswerten Sonderformen der Adobe-Variante bewahrt haben. In der Architektur der Ahl Fayfā ist es genau umgekehrt - die Dekorformen sind unbedeutend, die architektonischen Sonderformen sind elaboriert. Während also in der Adobe-Variante der Dekor einer relativ uniformen Architektur lokale, regionale und überregionale Akzente aufsetzt und in der Pagoden-Variante Dekor und Architektur homogen miteinander verschmolzen sind, setzt im südwestlichen Steinbau die Architektur selbst die lokalen Akzente. Wenn irgendwo im Südwesten Saudi Arabiens, dann kann hier von (spezifisch-) „tribalen“ Sonderformen der Architektur gesprochen werden. Die Sonderformen sind hier eines von vielen materiellen und ideellen Zeichen der Identität wenn schon nicht für die Identität eines einzigen Stammes, dann doch für die Identität von nur wenigen benachbarten Stämmen der Peripherie.

Innerhalb dieser Sonderformen und lokalen Akzente der Wohnarchitektur nimmt der runde Grundriß einen eigentümlichen Platz ein. Nur aus der Sicht des systematischen Vergleichs mit allen anderen Wohnbauten der südwestlichen Bergländer stellen die runden Wohnbauten eine Sonderform dar. Den Ahl Fayfā ist dieser Unterschied (zum Hochland) nur vage bewußt. Daß bei ihnen nahezu die Hälfte der Wohnbauten rund sind (während sie im übrigen Hochland durchwegs vierkantig sind), ist für sie weniger ein Ausdruck der Distinktion zum Hochland, als vielmehr ein Zeichen der Gemeinsamkeiten mit der Architektur der Küstenebene. 
Tatsächlich besteht eine derartige räumliche Kontinuität der Verbreitung nach Westen hin, nämlich zu den runden Wänden der 'ushash. Diese sind, wie erinnerlich, noch aus vegetabilem Material im flacheren Teil der Tihāma, was dann übergeht in die hügelige Tihāma am Fuß des J. Fayfā, wo Mischformen der 'ushash mit ebenfalls runden, aber bereits steinernen Wänden existieren.

Die runden, ein- und zweigeschoßigen steinernen Wohnbauten mit Flachdächern der Ahl Fayfā sind also in räumlicher Hinsicht der kontinuierliche, in Stein variierte Übergang der Tihāma-Architektur zu den Bauten des Hochlandes. Paradox erscheint blo $\beta$, daß die runde Form in der Küstenebene eine klare ökologische Funktion erfüllt, im Berggebiet jedoch nicht. Weder Material, noch Klima, noch die Besonderheiten der Fehde können das häufige Vorkommen des runden Grundrisses in der Wohnarchitektur der Ahl Fayfā ausreichend erklären. Auch hier gibt es weder zwingende praktische Ursachen, noch Hindernisse für die Existenz dieser Form. Mir scheint daher, daß das Selbstverständnis der räumlichen auch einen Hinweis auf zeitliche Kontinuität bewahrt hat. Die in pragmatischer Hinsicht ,funktionslose" Häufigkeit runder Wohnformen ist eine symbolische Affinität zur Tihāma. Diese Affinität drückt im Verständnis der übrigen Hochlandstämme minderen Status aus, im Eigenverständnis der Ahl Fayfa ist sie hingegen Bestandteil ihrer besonderen Traditionen.

Nun ist bereits darauf verwiesen worden, daß der Formierungsprozeß der Ahl Fayfā, wie auch der anderer Stämme der isolierten Tihāma-Berge, ein relativ rezentes Phänomen ist, das auf das ausgehende Mittelalter zurückreicht. Dem ging die Auflösung älterer Tihāma-Stämme in der Küstenebene voran. Aus deren Restbeständen und einigen Teilen der Hochlandstämme formierten sich jene neuen Stämme, deren Nachfahren heute die isolierten Bergstöcke der Küstenebene besiedeln. Insoferne stammen Gruppen wie die Ahl Fayfā zumindest teilweise von alten, verschwundenen Tihāma-Stämmen ab - auch wenn der nicht-genealogische Name diese heute als minderwertig qualifizierte Herkunft leugnet. Ich interpretiere daher die runden Wohnformen der Ahl Fayfā als das tradierte, materielle Erbe ihrer relativ rezenten Herkunft von ehemaligen Tihāma-Stämmen. Nicht nur die runde Wohnform stammt also aus der Tihāma (was man weiß), sondern auch ihre Bewohner (was verschwiegen wird). Die materielle Sonderform bewahrt die verschwiegene soziale Erinnerung. Derartige materielle Testimonia haben in der deutschsprachigen und speziell Wiener Anthropologie der ersten Hälfte des 20. Jh. das klassische Exerzierfeld des sogenannten „Formkriteriums“ geliefert - mit allen daran geknüpften, weitreichenden und irreführenden Spekulationen. Am Ende des 20. Jh. wird in Auseinandersetzung mit einer gleichartigen Art von Testimonia, im Anschluß an die Arbeiten von W. Dostal $^{293}$ ein völlig anderer methodischer Weg beschritten. Derartige Testimonia werden hier als gesellschaftliche und historische Phänomene begriffen, deren praktische und symbolische Bedeutung aus den jeweils konkreten Zusammenhängen zu erschließen ist. Unter dieser Prämisse einer Verbindung von Sozialanthropologie mit Struktur- und Kulturgeschichte liefert unsere Analyse daher Ergebnisse, die andere Forscher bestätigen oder widerlegen mögen, die aber jedenfalls der kritischen wissenschaftlichen Überprüfung zur Verfügung stehen und sich ihr nicht durch Spekulationen entziehen. Die hier angedeuteten methodologischen Überlegungen führen mich also zur Schlußfolgerung, daß die runde Form steinerner Wohnbauten am J. Fayfā kein isoliertes Zitat aus der Archi-

293 Dostal 1984: 179. 
tektur der Küsteneben ist, das sich auf einen benachbarten Berggipfel hinauf „verirrt“ und dort seine Funktion verloren hätte. Dieses materielle Zitat hat einen räumlichen Bezug, der den Akteuren selbstverständlich ist. Dieser aber hat seinerseits eine zeitliche Entsprechung in der Geschichte der Akteure selbst - einer Geschichte der tribalen Formierung, die von den heutigen Akteuren aus Statusgründen „vergessen“ worden ist, während die Forschung die realen Prozesse hinter dieser structural amnesia ausleuchten kann. In diesem Spannungsfeld zwischen realer Geschichte und genealogischem Konstrukt erhält die runde Form also ihre Funktion, als „bewußt in Vergessenheit geratene“, nonverbale und materialisierte Erinnerung an die eigenen Vorläufer - die mittelalterlichen Stämme der Küstenebene.

b) Architektur der Rijāl Almac

Die Ahl Fayfā haben also einzelne architektonische Sonderformen im Kontext einer tribalen Peripherie bewahrt, welche wirtschaftliche Integration mit politischer Abkapselung verbunden hat.

Die Ahl Șalab haben hingegen als Teilstamm der Rijāl Alma` die wirtschaftlichen, demographischen und militärischen Kapazitäten ihres Siedlungsgebietes auf andere Weise nutzen können. Ihre Berggebiete haben historisch nicht nur fallweise den Rückzug in die tribale Peripherie erlaubt, sondern vor allem auch von da aus den eigenen Zugriff nach auBen hin auf die wichtigsten regionalen Transport- und Verbindungsrouten ermöglicht.

Dies sind jene Routen, denen wir nun schon mehrmals im Verlauf dieser Untersuchungen begegnet sind. Sie verbinden die beiden wichtigsten „Ports of Trade“ des 'Asīr und südlichen Hịjāz an der Küste, al-Qunfudha und Qạ̣ma und eine Seitenroute von Jīzān aus mit dem zentralen Hochland des 'Asīr.

Die von al-Qunfudha nach Südosten verlaufende Route (eine weitere führt vom Hafen ostwärts Richtung an-Namāṣ) kann zunächst zwar mehreren Alternativen folgen, aber sie muß im Mittelteil der Tihāma unweigerlich auf das W. Halī treffen. Um dann von dort das zentrale Hochland des 'Asīr zu erreichen, gibt es vor dem 20. Jh. zwei Alternativen (Karte 10). Entweder man folgt beim Markt- und Garnisonsort Mahā’ il dem W. Tayya, das hier in das W. Halī mündet (Route a). Dieser kürzere Weg führt über den Oberlauf des W. Tayya mit steilen Anstiegen den Grabenrand zum Paß al-Shac ${ }^{c} \bar{r}$ hinauf, wo der Weg im Nordteil des Gebietes der Rufayda dann parallel zur Shifā weiter nach Südosten Richtung Abhā führt. Die zweite Alternativroute (b) folgt hingegen von Mahā̄il aus weiter dem W. Halī bis zu dessen Oberlauf, der zwischen den Bergen der Rijāl Alma ${ }^{c}$ und dem Grabenrand zunächst hindurchführt, um dann bei al-Sha 'bayn nach Norden abzuknicken und steil den Grabenrand hinaufzuführen. Dort führt die Route über Al-Sūda (im Grenzgebiet der Alkām) durch das Gebiet der B. Mughayḍ nach Abhā. Die Routen von Qaḥma aus können entweder in nordöstlicher Richtung auf eine der beiden bisher genannten treffen (c), oder in östlicher Richtung das W. Rīm und von dort aus Sha 'bayn anstreben (d), oder aber vom W. Rīm aus das W. Dala ${ }^{c}$ erreichen, und damit den Verlauf der heutigen Asphaltstraße zwischen Abhā und al-Darb (e). Und schließlich führte eine der Routen zwischen Jayzān und Abhā (f) über die eine oder andere der beiden letztgenannten Wege. Der Verlauf dieser Routen ist durch jenen der Fluttäler in der Tihāma und die Gliederung des Grabenrandes fast zwingend vorgegeben, unter nicht industriellen Bedingungen noch mehr als heute. Betrachtet man das in Skizze 3 schematisch wiedergegebene Netz der Verbindungsrouten zwischen den wichtigsten Küstenorten der Region in der Neuzeit und dem 
zentralen Hochland um Abhā (und Khamīs Mushayṭ), so wird klar: An den Rijāl Alma ${ }^{c}$ führte kaum ein Weg vorbei.

Über die sowohl von Jīzān als auch von Qaḥma und al-Qunfudha aus längeren und schwierigeren Routen a) und c) konnte man das Gebiet der Rijāl Alma ${ }^{c}$ zwar nur am Rande streifen, aber auch diese umständlicheren Routen lagen noch in ihrer Reichweite. Die beiden anderen Wege $(b, d)$ waren kürzer und bequemer, aber sie führten am Kern der Siedlungsgebiete der Rijāl Alma ${ }^{c}$ vorbei und durch Sha'bayn hindurch: Dies war zugleich der wichigste Marktort der Rijāl Alma` Förderation.

Damit befinden sich die Rijāl Almac vor den 30er Jahren des 20. Jh. in einer ähnlichen strukturellen Ausgangsposition, wie ich sie zusammen mit Johann Heiß für die nordostjemenitischen Wā̉ila und ihre Gebiete zwischen Najrān und Sa ${ }^{c}$ da beschrieben habe:294 Wer immer diese Routen sporadisch oder dauerhaft benutzen wollte, war mehr auf die Wà̉ila, und in diesem Fall auf die Rijāl Alma' angewiesen, als sie auf ihn. Bei den Rijāl Almac kam (im Unterschied zu den Wā̉ila) hinzu, daß sie diese strategische Positionierung auch nutzen konnten, um ihre eigenen Produkte und Beutestücke entlang dieser Routen zu veräuBern.

Dies bedeutet aber auch für die Rijāl Almac, daß das jeweilige, überlokale Gewicht dieser strukturellen Ausgangsposition nicht primär von den Rijāl Alma selbst abhing, sondern von denjenigen politischen Kräften, welche die Endpunkte dieser Routen kontrollierten und Interesse an der Versorgung über die Routen hatten. ${ }^{295}$ Solange die Rijāl Alma $^{c}$ also politisch-militärische Lokalautonomie bewahren konnten, erhöhte ein intensiviertes Interesse an Handel und Transport über diese Routen auch ihr eigenes lokales Gewicht gegenüber diesen Mächten und anderen Stämmen der Region. In Perioden von geringer Handels- und Transporttätigkeit konnten sie dieses strategische Gewicht hingegen kaum in die Waagschale werfen.

Schon aus rein logischen Gründen läßt sich daraus ableiten, daß im 19. Jh. die Möglichkeiten zur Nutzung dieses strategischen Gewichtes für die Rijāl Alma ceine historisch für sie beispiellose Hochkonjunktur - zumindest an potentiellen Möglichkeiten - durchlaufen haben müssen, insbesondere nach der Eröffnung des Suezkanals. Weiters läßt sich daraus ableiten, daß diese spezifische Hochkonjunktur mit dem dauerhaften Verlust der politischen Autonomie - also mit dem Machtantritt des dritten saudischen Staates Mitte der 20er Jahre des 20. Jh. auch in der Region der Rijāl Alma ${ }^{c}$ - eine systematische Abflachung erfahren haben muß.

Der monopolartige Zugriff auf diese Routen hat den Rijāl Alma ${ }^{c}$ folglich in bestimmten historischen Perioden ein zusätzliches strategisches Gewicht verliehen, das parasitär von der Existenz ökonomischer und politischer Kräfte an den Enden dieser Routen einerseits abhing, und zugleich politische Unabhängigkeit von ihnen voraussetzte.

Diese Überlegungen verbinden das regionale Strukturmodell bäuerlicher Bergstämme und ihres monopolartigen, lokalen Zugriffs auf Überlandrouten mit der tendenziellen Herausbildung überregionaler ökonomischer und politischer Systeme - ein Ansatz, der selbstverständlich von Eric Wolf inspiriert ist. ${ }^{296}$

294 Gingrich und Heiß 1986a: 130; Gingrich 2000: 75-92.

295 Gingrich 1993: 263-267, 271 f., 274-276.

296 Wolf 1982: 47-184, 372-435. 
Das zusätzliche strategische Gewicht der Rijāl Almac hatte also ihre eigene politischmilitärische Autonomie zur unbedingten Voraussetzung, unter der es einen relativ permanenten, lokalen und strukturellen Aspekt hatte, sowie einen veränderlichen, internationalen und konjunkturellen Aspekt. Diese Abklärung erleichtert es, nun einige Fakten zur Geschichte der Rijāl Alma im 19. und frühen 20. Jh. zusammenzustellen, wobei wir eine in der Zeit zurückschreitende regressive Darstellung wählen.

Philby, der das Gebiet der Rijāl Almac selbst nie besucht hatte, nahm noch in den 30er Jahren, also bereits nach der Etablierung saudischer Herrschaft in der Gesamtregion, die markanten Restbestände der skizzierten Monolpolstellung der Rijāl Almac wahr, und zwar an beiden Enden der Route, im Bergland und an der Küste. In Jīzān erfuhr er von lokalen, zusätzlichen „Zöllen“ zwischen $8 \%$ und $25 \%$ auf jene Güter des Fernhandels, die von Jīzān ins Landesinnere weitervertrieben wurden. Diese „age long tradition “ wurde noch in jenen ersten Jahren saudischer Herrschaft nach dem 1. Weltkrieg im Südwesten „maintained“; die lokalen Zölle wurden unter anderem im Gebiet der Rijāl Alma` eingehoben - also wohl in Sha'bayn, und sicher auch zu dieser Zeit mit entsprechenden Anteilen für die Vertreter der Rijāl Almac, um ihnen den Verlust der Autonomie erträglicher zu gestalten. ${ }^{297}$

Und in Abhā, am anderen Ende der Route, ließ sich Philby über die ortsüblichen Preise junger Sklavinnen informieren.

"Hiswa (ebenfalls im Gebiet der Rijāl Almac, A. G.) and Sha'bayn seemed to be the main intermediaries in this traffic in African girls from the Tihama plain, often kidnapped while herding their flocks in the bush." 298

Diese Restbestände örtlichen Sklavenhandels und -raubes verweisen zurück auf die zweite Hälfte des 19. Jh., als al-Qunfudha einer der letzten verbliebenen türkischen Umschlagplätze des ostafrikanischen Sklavenhandels gewesen war. ${ }^{299}$ Neben diesem mittlerweile verschwundenen Erwerbszweig des Skalvenhandels und dem anderen wichtigen des Waffenhandels, ${ }^{300}$ nutzten die Rijāl Alma ${ }^{c}$ auch ihre eigenen agrarischen Ressourcen zur Vermarktung. Dazu zählte Tabak (in den 30er Jahren ein teures Luxusprodukt), Honig, Kaffee, Leder, ${ }^{301}$ Sesamöle am Gebirgsfuß und Trauben in höheren Lagen, was auch 1982 noch den Hauptteil der örtlichen Spezialprodukte ausmachte.

Auf dieser wirtschaftlichen und strategischen Grundlage verfolgten die Rijāl Almac durch die wechselnden politischen und militärischen Konstellationen des 19. und frühen 20. Jh. hindurch ihre eigenständigen Interessen - die im wesentlichen darin bestanden, keine der um die Region ringenden Staatsmächte so stark werden zu lassen, daß die Unabhängigkeit der Rijāl Alma ' bedroht worden wäre - um auf diese Weise ihr eigenes Profitieren am Zwischenhandel sicherzustellen, das zugleich von eben jenen Staatsmächten abhing. In den Jahren vor und nach der Osmanenherrschaft im 'As̄̄r unterstützten die Rijāl Alma ${ }^{c}$ die Idrisīden in der Küstenebene, „but rather as equals than subjects, and (they) have never consented to pay him taxes" ${ }^{302}$ Diese Allianz hatte also wohl kaum religiöse

297 Philby 1952: $475 \mathrm{f}$.

298 ibid.: 168.

299 Peters 1994: 267.

300 Cornwallis 1976: 19, 61 .

301 Cornwallis 1976: 20, 61 .

302 Cornwallis 1976: 59; cf. auch Weisl 1927: 281 und Philby 1952: 142-145. 
Aspekte, sondern war noch 1872 gegen die Türken und die Ahl ' $\bar{A}$ ’iọ im Hochland gerichtet. Vor der osmanischen Besetzung, in der ersten Hälfte des 19. Jh., scheinen die Rijāl Alma ' hingegen eher mit dem Begründer der Ahl ' $\bar{A}$ 'i ̣̣ kooperiert zu haben, zumindest gegen den ägyptischen Feldzug. ' $\overline{\mathrm{A}}$ 'iḍ Vorgänger hatte sich mit mehreren benachbarten Stämmen verbündet oder sie unterworfen. Die Ägypter waren hingegen mit einem Teil der Rabī'a wa Rufayda und ihrem in Kairo erzogenen Führer verbunden. ${ }^{303}$ Erst nach dem ägyptischen Sieg über 'Alī al-Mughayḍ̂̄ von 1834 unterwarfen sich auch die Rijāl Alma ${ }^{c}$ den Ägyptern. ${ }^{304}$ Bereits für diese Periode wird der Kaffeeanbau bei den Rijāl Alma $^{c}$ erwähnt, ${ }^{305}$ und auch für den florierenden Sklavenhandel jener Zeit gibt es klare Hinweise, wonach er in der ersten Hälfte des 19. Jh. für die Rijāl Almac nicht unwichtiger war als in der von Philby bezeugten späteren Zeit seines Niederganges. Auf das militärisch-strategische Potential der Rijāl Alma ${ }^{c}$ und ihr Bündnis mit den B. Mughayḍ verweist nämlich ein Bericht über ihre Vorräte, Sklaven und Schätze in einer „Zitadelle“ der tribalen Führung, welche die Ägypter im Verlauf ihres erfolgreichen Feldzuges 1834 ebenfalls zerstört hätten. ${ }^{306}$

Kaffee, Sklaven und Waffen bestimmten jene wirtschaftlichen Interessen, die den zunehmenden Rivalitäten der Großmächte am Roten Meer im 19. Jh. zugrundelagen, und die Rijāl Almac jener Zeit partizipierten in einem international bescheidenen, aber lokal durchaus beachtlichem Ausmaß an diesen Entwicklungen. Die Herausbildung einer äuBerst wohlhabenden, tribalen Oberschicht war sowohl ermöglicht durch diese Partizipation, und sie bot ihrerseits die Gewähr für verstärkte Zentralisation und Koordination der tribalen Einheit, für welche gerade diese Föderation berühmt war, ${ }^{307}$ angesichts des zunehmenden politischen Drucks von außen.

Dies bedeutet nicht, daß die strategische Lokalposition der Rijāl Almac vor dem 19. Jh. strukturell völlig anders gewesen wäre - aber konjunkturell und international war sie es notwendigerweise. Die Bedeutung des Fernhandels am Roten Meer wuchs seit dem ausgehenden Mittelalter zwar von einem niedrigen Niveau aus tendenziell an, aber dies vollzog sich in weitaus langsameren Rythmen, und mit längeren Flauten und Unterbrechungen. Es ist bereits gezeigt worden, daß Jīzān und al-Qunfudha relativ spät, nämlich im Spätmittelalter oder der frühen Neuzeit, entstandene Hafenorte sind. Erst mit ihrer Gründung stellte sich aber die Notwendigkeit für zentrale Handelsrouten entlang der OstWest-Achse ins Hochland. Der monopolartige Zugriff der Rijāl Almac auf diese zunächst noch schwach ausgeprägten zentralen Handelsrouten der Ost-West-Richtung kann also erst mit der frühen Neuzeit entstanden sein. Es überrascht daher nicht, daß eine Föderation, die im 19. Jh. derartig bekannt und berüchtigt geworden ist, im 10. Jh. bei al-Hamdānī nur an einer Stelle nebenher erwähnt wird. ${ }^{308}$

Die vermutlich spätere Formierung der Ahl Șalab als Teilstamm der älteren Rijāl Alma ${ }^{c}$ könnte also in die Epoche des sich entwickelnden Fernhandels und allmählich zu-

\footnotetext{
303 Tamisier 1840, II: $307-316,324$.

304 ibid.: 185, 187, 307-316, 322.

305 Passama 1843b: 236.

306 Galinier und Ferret 1843: 106-117.

307 Cornwallis 1976: $59 \mathrm{ff} ., 103$.

308 al-Hamdan̄̄ in: Forrer 1942: 209. Einer lokalen Oraltradition zufolge führen sich die Rijāl Alma ${ }^{c}$ auf Nachfahren von Einwanderern aus Mārib zurück; Mauger 1993: 72.
} 
nehmender Staatseinflüsse an der Ostküste des Roten Meeres fallen. Der J. Salab ist der südlichere der beiden Hauptmassive der Rijāl Alma ${ }^{c}$, während der J. Faqwa im Nordosten liegt. Wie die anderen fünf Teilstämme, so haben auch die Ahl Șalab einen Shaykh al-Qabīla, dessen Gruppe im Gipfelbereich des Berges residiert. Am südlichen Ausläufer des Massives liegt noch im Gebiet der Ahl Șalab der Marktort Makhlūṭa. An den nördlichen Ausläufern des J. Șalab, im Übergangsgebiet zum J. Faqwa und damit im Ursprungsgebiet des W. Rīm, liegt der Wochenmarkt Sūq al-Thulūth al-Rīm, der den Ahl Șalab gemeinsam mit anderen Teilstämmen der Rijāl Alma` vom J. Faqwa untersteht. Dieser Wochenmarkt wird mehrheitlich von Käufern und Verkäufern der Rijāl Alma ${ }^{c}$ frequentiert und ist damit ein zentraler Umschlagplatz für Warenverkehr im Inneren der Föderation (Abb. 63). Demgegenüber ist Makhlūṭa mehr auf den Warenumschlag der Ahl Șalab nach außen, Richtung Küste orientiert, während Sha'bayn an den tiefgelegenen östlichen Ausläufern des J. Faqwa für den kommerziellen Verkehr der Rijāl Alma ' mit dem Hochland zuständig war. Daneben spielt Sha ${ }^{\complement} b a y n$ die Rolle jenes erwähnten „Nadelöhrs“, durch welches die Hauptrouten von der Küste zum Hochland führten - und damit war es ein historischer Ort eben jenes tribalen Zugriffs auf die Route, die von hier entlang der 'Aqabat Samä' den Grabenrand hinauf über Sūda nach Abhā führt. Dementsprechend wohlüberlegt hat die saudische Regierung in Sha'bayn das administrative, moderne Zentrum des Distrikts angelegt. ${ }^{309}$

Inmitten des semi-ariden Umlandes der mittleren Tihāma, die etwas weiter westlich durch das breite Basaltfeld völlig öde ist, unterstreicht dieses dichte System von Marktorten der Rijāl Alma 'ihre Positionierung in einer begrenzten, agroklimatisch und strategisch extrem begünstigten „Nische“. Die Marktorte zeugen dabei nicht nur von der historischen Integration in den Fernhandel, sondern auch vom besonderen Entwicklungspotential dieses Distriktes.

Die politische und wirtschaftliche Partizipation am Fernhandel haben, wie erwähnt, die Herausbildung einer wohlhabenden tribalen Oberschicht gefördert. Auf einen der beiden Flügel dieser Oberschichte ist bereits verwiesen worden - dies sind die Gruppen des Shaykh al-Qabīla des jeweiligen Teilstammes und seiner Lokalvertreter mit eindrucksvollen Residenzen in den hohen, gut verteidigbaren Bergpartien. Neben der politischen Führung ihrer Teilstämme haben die Rijāl Alma ${ }^{c}$ aber noch einen zweiten, übergeordenten Flügel ihrer Oberschicht hervorgebracht, nämlich die Führung der gesamten Stammesföderation der Rijāl Almac.

Diese Führung rekrutierte sich aus den männlichen Mitgliedern eines großen Deszendenzverbandes von Ahsrāf/Sāda (Nachfahren des Propheten Muhammad über 'Alī’s Söhne Hasan und Husayn), welcher im Gebiet der Rijāl Alma ' bis heute ansässig ist, nämlich den $\overline{A l} \mathrm{Na}^{c} \mathrm{~m} \overline{\mathrm{l}}$.

Daß die politische Führung eines Stammes oder einer Gruppe von Stämmen durch Stammesfremde von hohem Status gestellt wird, ist in West- und Südwestarabien an sich keine Seltenheit. Das Besondere an der Position der Âl Na'mī liegt zum einen an der historischen Fähigkeit ihrer Repräsentanten im 19. Jh., die politische Einheit von derart großen Stämmen nach außen hin gewährleistet zu haben. Und zum anderen hat der spezielle Siedlungsort der Āl Na'mī am Fuß der 'Aqabat Rūz solche Ausmaße, daß er heute

309 Alma'ī 1986: 54. 
von der Bevölkerung „Stadt“, Madīnat Rijāl Almac oder Madīnat Rijāl genannt (Abb. 62), gelegentlich aber auch nur mit „Rijāl“" oder „Rijāl Alma“" bezeichnet wird, also mit dem Föderationsnamen. ${ }^{310}$ Diese „Stammeshauptstadt“ war bereits vor 1918 örtlicher Sitz der

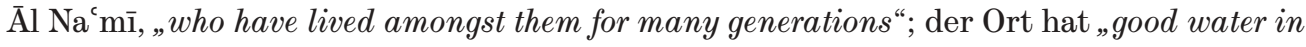
deep wells" “311 und repräsentierte das „Zentrum des Handels und der Wissenschaft" im Stammesgebiet. ${ }^{312}$

Vor dem solchermaßen skizzierten historischen Hintergrund sind es diese politischen, rechtlichen und wirtschaftlichen Verhältnisse, die zu einer Differenzierung der tribalen Architektur führen, welche deutlicher als anderswo an der Hierarchie des sozialen Status orientiert ist. Unterschieden werden können die Wohnhäuser der einfachen Stammesfamilien, ferner die Residenzen des Verbandes des Shaykh al-Qabīla und seiner Vertreter, und schließlich die Wohnarchitektur der Āl Na ${ }^{c} m i ̄$ in Madīnat Rijāl Almac.

Die Wohnhäuser der einfachen Stammesfamilien sind meistens nur zwei- bis dreistökkig, das kühlere und feuchtere Klima im Berggebiet wirkt hier also ebenfalls als begrenzender Faktor auf die Höhe der Wohnbauten. Dafür sind diese Häuser häufiger in die Breite gebaut, wobei eine dieser Breitseiten stets quer zum Hang als talseitige Tor- und Fensterfassade liegt. ${ }^{313}$

Die Ursachen für diese häufige Form von niedrigen, breiten „Kästen“ liegen neben der klimatischen Höhenbegrenzung in einer Reihe weiterer Faktoren. Als Siedlungsform dominiert das Einzelgehöft, in dem mehrere patrilateral verwandte Familien zusammenleben. Die Einzelgehöfte sind also a priori so gebaut, daß räumliche Segmentierungen möglichst minimiert werden. Dies erleichtert die Bewahrung des gemeinsamen Besitzstandes und erhöht die menschliche Verteidigungskraft der Residenzeinheit. Der dadurch gegebene erhöhte Raumbedarf wird noch zusätzlich gesteigert durch Speicher- und Lagerungsbedürfnisse, denen der im Vergleich zum Hochland überdurchschnittliche Wohlstand dieser Haushalte zugrundeliegt.

Aus diesen niedrigen und breiten architektonischen Akzentsetzungen ergibt sich, daß Gebäude mit Innenschächten sowie solche mit tragenden und nicht-tragenden Zwischenschächten am J. Șalab und im Gebiet der Rijāl Alma' häufiger als anderswo im 'Asīr auftreten. Unter den Wohnhäusern einfacher Stammesfamilien des J. Șalab sind aber die Bauten mit einfacher Stützmauer noch ebenso häufig wie die breiten Gebäude; in diesen Fällen hat ein Geschoß nur zwei oder drei Räume (Abb. 61, 64).

Obwohl es am J. Șalab also kaum Dörfer gibt, ist die Bevölkerungsdichte außerordentlich hoch: Schon die breiten Einzelgehöfte bieten jeweils einer größeren Zahl von Menschen Wohnraum als die meisten anderen Hausformen des 'Asīr. Hinzu kommt, daß die überwiegende Mehrheit der Einzelhöfe in den agrarisch fruchtbaren Teilen des J. Șalab in kurzen Distanzen voneinander errichtet sind (Abb. 64). So gesehen, sind ganze Subzonen des Bergmassivs riesige Streusiedlungen, wobei die Häuser meist nahe bei, oder inmitten ihrer Felder stehen, und dort kaum weitere Baufläche zur Errichtung neuer Häuser besteht. Die Bevölkerungsentwicklung hat in diesem fruchtbaren, aber begrenzten Gebiet also einen hohen Schwellenwert erreicht. Die Entwicklung von besonders geräumigen

310 Cornwallis 1976: 61; Philby 1952: 163, 166; $\operatorname{Alma}^{`} 1 ̄ 1978: 67$.

311 Cornwallis 1976: 61; nach ihm heißt der führende Verband Sāda al-Na'amiyan.

312 Alma'ī 1978: 67.

313 Mauger 1993: 16. 
Wohnbauten kann daher auch als Teil eines darauf reagierenden sozialen Bemühens verstanden werden, weitere Segmentierungen und Neugründungen von Haushalten möglichst zu vermeiden. In diesem Siedlungsmuster am J. Șalab fehlen in-towers völlig (wie normalerweise auch im übrigen 'Asīr), aber auch out-towers sind selten. Sie sind meist auf unfruchtbaren Kämmen als viereckige Stümpfe errichtet, in recht entfernter Sichtweite vom Siedlungsgebiet, dem sie zugeordent sind.

Die lokalen Verteidigungsaufgaben ruhen primär auf dem Einzelgehöft und sind überdies durch ein dichtes Rechtssystem minimiert. Zwischen dem Shaykh al-Qabīla und den tribalen Lokalgruppen gibt es in der Sozialhierarchie der Ahl Șalab noch eine Schicht, die sich aus dem jeweiligen örtlichen, tribalen Rechtsvertreter $(\mathrm{N} \overline{\mathrm{a}} \mathrm{ib})$, dem tribalen chief und aus dessen Familie zusammensetzt. Der Shaykh al-Qabīla ist also die oberste Instanz für intratribale Rechtsfälle, die nach dem Gewohnheitsrecht ausgetragen werden; der Nà̉ib (pl. Nuwwāb) als sein örtlicher Vertreter repräsentiert eine niederere Instanz, bei der die Mehrheit der kleineren Konfliktbeilegungen endet.

Die Nuwwāb sind meist über Heiratsbeziehungen mit der Familie des Shaykh al-Qabīla verbunden und genießen schon dadurch vermehrtes Prestige; hinzu kommt ein erhöhter Wohlstand, der sowohl Voraussetzung wie Resultat ihres Status ist. Die Wohnarchitektur dieser Nuwwāb hat diesem vermehrten Wohlstand und dem sozialen Status der Bewohner Rechnung zu tragen. Diese Wohnhäuser tragen die Zeichen von höherem Status und größerem Reichtum, indem sie geräumiger, luxuriöser und sorgfältiger dekoriert sind. In der Wohnarchitektur jeder verstreut siedelnden Lokalgruppe gibt es daher ein derartiges Gebäude des jeweiligen $\mathrm{Na}$ ỉ $\mathrm{ib}$ und seiner Familie; diese Gebäude unterscheiden sich nicht wesentlich vom Prunkbau des Shaykh al-Qabīla (der bloß noch etwas größer ist) und können daher zusammen mit diesem erörtert werden.

Der erhöhte Raumbedarf der Wohnhäuser dieser tribalen Oberschicht (Familien der Nuwwāb und des Shaykh al-Qabīla) ergibt sich zum einen aus dem genannten Grund von erhöhtem Wohlstand und Prestige, was sowohl größere Lagerungsmöglichkeiten für materielle Güter und Vorräte, wie auch demonstrative Bedürfnisse nach größeren Wohnräumen mit sich bringt. Was bereits am Beispiel der tribalen Oberschichten im Ost- und Zentral-'Asīr ausgeführt wurde, gilt auch hier: Besondere, geräumige Frauenräume, Gebetsräume und Baderäume sind in den Häusern des Shaykh und der Nuwwāb die Regel. Der Toilettenabfluß an der Außenmauer ist manchmal mit einem kleinen Vorbau ummauert, was ein Ergebnis der intensiven Interaktionen dieser tribalen Oberschichten mit der staatlichen Außenwelt seit dem 19. Jh. sein könnte. Vor allem aber ergibt sich aus dem sozialen Status des spezialisierten, permanenten Schlichters und Schiedsrichters nach tribalem Recht eine besondere, räumliche Notwendigkeit: Shaykh al-Qabīla und Nā̉ib müssen regelmäßig Streitparteien und Bittsteller empfangen, und benötigen dafür große und gut ausgestattete diwāne. In diesen Hallen ist die alltägliche Funktion des Aufenthalts-, Wohn-, Speise- und Gastzimmers eines Hausherren von hohem Status also verbunden mit der spezialisierten Funktion von „tribalen Amtsräumen“.

Da die geräumigen Häuser der Ahl Șalab ohnedies mehr in die Breite gebaut werden, können diese „Amtsräume“ das halbe oder gesamte Obergeschoß einnehmen, welches meist als vierter und letzter Stock eingerichtet ist. Einfache, kaum dekorierte hölzerne Stützsäulen ( $\operatorname{sitā}^{c}$ ) tragen in diesen Hallen die Decke und gewährleisten, daß die großen Hallen nicht direkt durch die Innenmauern der unteren Stockwerke unterteilt werden müssen. An den Seiten stützen als Steinsäulen gemauerte Wandvorsprünge (batra) die 
Decke (ghashāb) zusätzlich ab. Diese ist, wie überall im 'Asīr, aus quer zueinander eingezogenen Lagen von Hauptbalken (macdal, pl. ma`ādil), Ästen (sarya, pl. sawāri) und Zweigen (mirkāb, pl. marākīb) konstruiert.

Wenn schon die Wohnhäuser einfacher Stammesmitglieder zu einem guten Teil als breite Bauten mit Zwischen- oder Innenschächten errichtet werden, so gilt dies für die traditionellen Wohnbauten der tribalen Oberschicht der Ahl Ṣalab immer. Zusätzliche, besondere Akzente sind also das vierte Geschoß mit den Amtsräumen (masqūqa), die übrigen Sonderräume (Frauenraum, Gebetsraum und Waschraum [mughsil] mit ummauertem Abfluß) und eine etwas elaboriertere Gestaltung des Dekors, auf die wir noch zu sprechen kommen. Der besondere Wohlstand mancher Haushalte dieser bäuerlich-tribalen Oberschicht bedingt überdies, daß etliche von ihnen auch über eigene, gemauerte Speichergebäude für Getreide (sirdāb, pl. sarādīb) verfügen. Da und dort wird die Hirse auch hier mehrjährig in jenen unterirdischen Speichern (mukhtaba) gelagert, die man hauptsächlich aus dem Jemen kennt (wo sie „madfan“ heißen).

Über diese besonderen Akzente dürfen auch die grundlegenden Gemeinsamkeiten nicht übersehen werden, welche die Wohnbauten der tribalen Oberschicht zumindest mit den Zwischen- und Innenschacht-Bauten der tribalen Mehrheit teilen.

Diese Gemeinsamkeiten bauen auf der talseitigen Orientierung der breiten Eingangsfassade auf. Wie im gesamten Typus der südwestlichen defensiven Hochbauweise, so dominieren auch hier Schießscharten als Maueröffnungen in den unteren beiden Geschoßen, in denen sich Stallungen (sifli) und Lagerräume (raff) befinden. Auch die Küche (milhab) ist meist hier untergebracht. Die Scharten (quțra, coll. nom. of qațr) dienen zugleich der Luftzirkulation, die durch den Schacht im Hausinneren noch verstärkt werden kann. Der Zwischenschacht ist für die Luftzirkulation ohnedies durchlässig, da das Stiegenhaus direkt an den Mittelteil der Fassade (und deren qutra) angrenzt. Beim Innenschacht sind hingegen zusätzliche Öffnungen in seinen Mauern angebracht, um die vollständige Durchlüftung des Hauses sicherzustellen. Meist sind die Treppen (daraj) nicht im, sondern um den Innenschacht herum geführt. Die so freibleibenden, gut durchlüfteten Binnenräume (die als Schlafzimmer [naffarīya] oder Magazine dienen) heißen generell șarha (ṣ-r-ḥ: to be or become pure, uncontaminated, clear). Die breite und relativ niedrige Anlage dieser Bauten, derentwegen sich die Luft einfach von unten nach oben austauscht, macht die zusätzliche Verbindung von defensiven mit innenklimatischen Einrichtungen notwendig.

Über den zwei unteren, parallelen Reihen von Schießscharten erstreckt sich im Obergeschoß die breite Reihe von Fenstern, in Häusern der Oberschicht mit „Amtsräumen“ sind es zwei; die Fenster haben verschließbare Holzläden. Trotz der niedrigen Höhe sind die Fensteröffnungen relativ groß und für längere Kampfsituationen nicht sonderlich praktisch. $^{314}$ Aber bewaffnete Vorstöße von außen gelangten früher nur selten in das Zentralgebiet des Stammes auf die Berghöhen hinauf, und im Inneren des Stammes scheint das dichte System lokaler, tribaler Rechtsvertreter die Anfälligkeit für Fehden stark minimiert haben.

Über nahezu jedem Fenster dieser einzelnen oder doppelten Fensterreihen ist der weiße Steindekor angebracht, der sowohl an Häusern einfacher Stammesmitglieder, wie auch

314 Prochazka (1978: 117) gibt folgende Termini für die Fensterteile in Madīnat Rijāl an: radm für Sturz und bāb für die Läden; der Unterteil „consists of an inside sill baṭn il-gutrah, a ledge, maradd, a low vertical partition, sarf, and an outside sill, xarīj il-gutrah". 
auf jenen der tribalen Oberschicht und schließlich auch an den Häusern der $\bar{A} l \mathrm{Na}^{c} \mathrm{~m} \overline{\mathrm{I}}$ in Madīnat Rijāl Alma c in leicht abgewandelter Form auftritt. Der einzige „feine Unterschied" im Dekor, der der tribalen Oberschicht zur sozialen Distinktion nach unten hin dient, ist die Vollständigkeit. Hier tragen in der Regel alle Fenster den Steindekor, also über beiden Reihen, während er ansonsten über der bloß einfachen Fensterreihe der Eingangsfassade und um die quțra angebracht ist, und auch dies nicht immer. Zusätzlich zum weißen Steindekor und zur weißen Ummalung der steinernen Fensterreihen sind auch die vier Hauskanten und die Mauerkronen mancher Wohnbauten wohlhabender Familien weiß bemalt. All dies gibt ein kontrastreiches Bild von weißen Linien und Mustern auf dem dunklen oder schwarzen Untergrund des Schiefers, das sich in seiner Lebhaftigkeit deutlich vom kargen, monotonen Äußeren der Steinbauten in den meisten anderen Teilen des südwestlichen Berglandes abhebt.

Die Wohnhäuser von Madīnat Rijāl Alma ${ }^{c}$ schließlich unterscheiden sich erkennbar, aber doch nur graduell von den anderen architektonischen Formen der Rijāl Alma ${ }^{c}$. Der wichtigste Unterschied liegt zweifellos im Siedlungsmuster selbst; daneben fehlen in Madīnat Rijāl charakteristischerweise die Defensiveinrichtungen der tribalen Bauten; und schließlich differieren Aspekte des Dekors, während der Steindekor insgesamt aber der Architektur aller Schichten gemeinsam ist und hier detaillierter abgehandelt wird.

Madīnat Rijāl liegt am Fuß der 'Aqabat Rūz im Talschluß (Abb. 65). Diese Lage am Bergfuß ist verantwortlich für die erwähnte günstige Wasserversorgung durch Sickerquellen. Von der leicht erhöhten Lage zur eigentlichen Talsohle hin abgesehen, ist der Ort an den drei anderen Seiten von Steilhängen umgeben. Schon aus Gründen des mangelnden Siedlungsraumes ist die dichtgedrängte Agglomeration von Wohnhäusern daher zweckmäßig. Dies gewährleistet überdies einen gewißen Nachbarschaftsschutz gegenüber allfälligen Bedrohungen von außen. Die kompakte, für die Territorien der Rijāl Alma a ansonsten völlig untypische Siedlungsform schafft damit auch einen Innenraum von engen Gassen und kleinen Plätzen, der für Fremde (außer von oben) nicht unmittelbar einsehbar oder zugänglich ist.

In dieser Bildung eines nach außen sozial (jedoch nicht militärisch) abgeschirmten und für die Bewohner nach innen hin öffentlichen sozialen Raumes sehe ich das entscheidende Merkmal der Siedlungsanlage. Sie entbehrt jeder wirksamen Defensiveinrichtung, welche die tribale Architektur der Rijāl Alma' oder generell des 'Asīr auszeichnet. Die tiefe Lage der Talsohle verzichtet a priori auf den defensiven Standortvorteil im Hang oder auf Kämmen und Kuppen; der Ort betont geradezu seinen unmilitärischen Charakter gegenüber den Rijāl Almac', indem er sich auf drei Seiten offen und schutzlos gegen die Hänge hin darbietet. Zugleich ist die Abwesenheit von Schießscharten (und Zinnen) an den Einzelwohnhäusern ihr charakteristischer Unterschied zur tribalen Architektur. Bis auf den Dekor entsprechen die Einzelwohnhäuser von Madīnat Rijāl in Austattung und Dimension ansonsten den Wohnbauten von Shuyūkh und Nuwwāb, sieht man einmal davon ab, daß sie um durchschnittlich ein Geschoß mehr in die Höhe gebaut sind, weil der Raummangel hier die Nutzung der Horizontale beschränkt. Absonderung und eigene militärische Schutzlosigkeit sind also die wesentlichen Eigenschaften dieser Anlage und ihrer Einzelhäuser. Schon die weitere architektonische Umgebung von Madīnat Rijāl belegt, daß der Ort eigene militärisch-defensive Einrichtungen nicht nötig hat, weil er von anderen geschützt wird. Spezielle architektonische Mittel dafür sind massive, vierkantige und hohe out-towers, die im Gebiet der Rijāl Almac sowohl die wichtigsten Zugänge nach Ma- 
dīnat Rijāl wie auch jene zum Sūq al-Thulūth im W. Rīm bewachen (Abb. 66). ${ }^{315}$ Im Prinzip sind diese Wehrtürme auch für längere Zeit bewohnbar. Offensichtlich beruht die eigene militärische Schutzlosigkeit von Madīnat Rijāl also auf der rechtlichen Verpflichtung zum Schutz seiner Bewohner durch die sechs Stämme der Rijāl Almac. Derartige tribale Beistandsverpflichtungen für die ortsansässigen Nachfahren des Propheten sind aus weiten Teilen Südwestarabiens bekannt ${ }^{316}$ und haben hier ihre besondere architektonische Ausformung erhalten.

Die militärische Schutzfunktion der Stammesgesellschaft ist demnach die essentielle Voraussetzung für die Existenz dieses besonderen „Ortes des Friedens“, in dem die Āl $\mathrm{Na}^{c} \mathrm{mī}$ einerseits einem abgeschirmten und abgehobenen eigenen Alltag nachgehen können. In diesem Alltag der Familien von Nachfahren des Propheten erhält jener gehobene, quasi-städtische Lebensstil in der ganzen Siedlung seinen größeren sozialen Raum, der sonst auf die Einzelwohnhäuser der tribalen Oberschicht beschränkt bleibt. Die Abschirmung der Gesamtsiedlung nach außen und die Öffnung eines inneren Siedlungsraumes (Straßen, kleine Plätze) ist also keine militärische, sondern ausschließlich eine moralischrechtliche Einrichtung mit Hilfe der Architektur. Sie erlaubt auch den Frauen der Āl $\mathrm{Na}^{c}{ }^{\mathrm{m}} \mathrm{i}$ ein limitiertes Maß an Mobilität im geschützten Siedlungsraum unter Wahrung der muslimischen Etikette.

Zum anderen ist Madīnat Rijāl Alma a aber auch ein Ort der Wahrnehmung von Gesamtinteressen aller sechs Stämme - und zwar sowohl ihrer gemeinsamen Beziehungen nach außen wie jener untereinander. Die hochgelegenen Empfangsräume der Wohnbauten dienen also auch dem repräsentativen Empfang von auswärtigen, hochgestellten Gästen - ob dies nun Fernhändler, Gelehrte, Führer anderer Stämme oder Vertreter der Staatsorgane sind. Und ebenso wichtig ist auch hier die Rolle der Wohnräume als Orte der Rechtssprechung: Diejenigen seltenen Fälle intra- oder intertribaler Konflikte, die nicht nach dem tribalen Gewohnheitsrecht durch Nuwwāb und Shuyūkh geschlichtet werden konnten, sind den $\bar{A} l \mathrm{Na}^{c} \mathrm{~m} \overline{\mathrm{l}}$ zur Beilegung unterbreitet worden. Und selbstverständlich haben sich die $\bar{A} l \mathrm{Na}^{c} \mathrm{~m} \overline{\mathrm{l}}$ dabei vor allem auf die Sharī'a gestützt, besonders wo diese über das örtliche Gewohnheitsrecht hinausgeht oder davon differiert. Die Einheit der sechs Stämme nach außen beruht letztlich auf der fortgesetzten Fähigkeit der $\bar{A} l \mathrm{Na}^{c} \mathrm{mi}$, das Konfliktpotential im Inneren radikal einzudämmen. Der „Ort des Friedens" hat daher eine entscheidende Bedeutung gegenüber der tribalen Mehrheitsbevölkerung: Er setzt voraus, daß zutiefst verfehdete Konfliktparteien mehr oder minder freiwillig auf gegenseitige Gewaltausübung verzichten und vor den $\bar{A} l \mathrm{Na}^{c} \mathrm{~m} \overline{\mathrm{l}}$ erscheinen, um sich der Rechtssprechung nach der Sharī ${ }^{\complement} a$ als höchster Instanz zu beugen. Madīnat Rijāl Almac ist also nicht bloß ein Ort des Handels, der frommen Lebensführung, der Gelehrten und der politischen Macht: Es ist auch und vor allem jener Ort, an dem die übergeordnete Rolle des islamischen vor dem Gewohnheitsrecht praktiziert wird.

Damit läßt sich eine semi-staatliche Struktur an der politisch-rechtlichen Spitze der tribalen Organisation identifizieren. Der Dekor der Wohnhäuser von Madīnat Rijāl Alma ${ }^{c}$ akzentuiert diese Gegebenheiten in der ihm eigenen Sprache der Ästhetik.

315 cf. auch Mauger 1993: 72.

316 Serjeant 1962: 41-57; Puin 1984: 483-494. 
Zunächst sind die Wohn- und Empfangsräume (hier: majlis oder diwān) hier weiß ausgemalt, während die tribalen diwāne der Rijāl Alma ${ }^{c}$ zumindest teilweise ebenso bunt ausgemalt sind wie im zentralen und Ost-'Asīr (mit der signifikanten und analogen Ausnahme des W. Najrān). ${ }^{317}$ Das Weiß dieser Innenräume der Nachfahren des Propheten gilt ihnen als normgerechter, und hebt sich dezidiert von der spezifischen „'Asīrī" Sitte der bunten Innenbemalung ab. Weiters fehlt an den Außenwänden dieser Wohnhäuser jene Dekorierung mit weißer Farbe an den vier Fassadenecken, die viele Wohnhäuser der wohlhabenden tribalen Familien kennzeichnet. In Madīnat Rijāl sind hingegen die Mauerkronen mit einem weißen Streifen dekoriert.

Diese Defizite an bemaltem Dekor (keine bunte Farbe innen, weniger weiße Farbe auBen) heben die Wohnhäuser der Āl Na'mī und ihre Bewohner sowohl von den Shuyūkh und Nuwwāb ab, wie von der tribalen Mehrheit. Sie unterstreichen ihren besonderen sozialen Status, ihre genealogische Herkunft, und ihre moralische, rechtliche und politische Autorität bezeichnenderweise durch größere Einfachheit des gemalten Dekors. Das auffälligste und anspruchvollste Dekorelement aber ist den Wohnhäusern der Āl Nacmī prinzipiell gemeinsam mit jenem aller übrigen Rijāl Almac, und darüber hinaus auch mit einem Teil der Steinarchitektur im Hochland zwischen Abhā und al-Nimās. Dies ist die spezifische Musterung mit weißem Zierstein über den Fensteröffnungen, und im Fall der tribalen Wohnhäuser auch über den Schießscharten, die zugleich Luftlöcher sind.

Der weiße Zierstein aus Quarz wird überall im 'Asīr und südlichen Hijāz marw, „Marmor", genannt und tritt in natürlichen Vorkommen an der Oberfläche als langer, aderartiger Einschluß im Fels auf (Abb. 92). Er ist sehr hart und kann nur grob in etwas größere oder kleinere, aber bloß annähernd regelmäßige Elemente behauen werden. Daher können die Ziersteine nicht in den Schiefer eingepaßt werden, sondern kleinere und größere Elemente des leichter bearbeitbaren Schiefers werden um den Zierstein eingepaßt, um ihn zu fixieren (Abb. 95). ${ }^{318}$ Die gleiche Art von Schiefersplittern, die zum Auffüllen der Ritzen zwischen den grob behauenen Blöcken verwendet werden, stabilisiert also auch den Zierstein. Die dunklen Schieferfelder rund um die und innerhalb der Muster von weißem Zierstein sind immer aus filigranem, kleinem Splittermaterial gefertigt. Die weißen Ziersteine im Schiefersplitter bilden dabei die Grundform eines stehenden Rechteckes, das aus kleineren Quadraten gebildet ist.

Je ein derartiges rechteckiges Dekorfeld steht zentriert zu je einer Maueröffnung, wobei die Dekorfelder zu den Fensteröffnungen aber eine andere Stellung einnehmen als zu den quțra. Um die quțra sind Dekorfelder angelegt, die größer sind als die Schießscharten und sie mit gleicher Grundlinie wie ein „Rahmen“ umgeben (Abb. 93). ${ }^{319}$ Die Fensteröffnungen sind hingegen von kleineren Dekorfeldern "gekrönt", die oberhalb der Fensterrahmen beginnen (Abb. 94). Trotz etlicher Variationen lassen sich daher einige Grundelemente in den Dekorfeldern bestimmen. Die senkrechte Linie dominiert, welche die hochgestellten Formen der quṭra und der Fenster betont. Die senkrechten Linien werden durch voneinander abgesetzte, weiße Ziersteine gebildet, was manchmal auch die Möglichkeit bietet, parallele Linien versetzt als schachbrettartige Muster anzulegen (Abb. 94).

\footnotetext{
317 Die hier vorgelegten Informationen über die Innenräume von Madīnat Rijāl Alma c erhielt ich von einem französischen Techniker, der den Ort 1985 besuchte und mich um Anonymität ersucht hat.

318 Thesiger 1947: 194; Mauger 1993: 79.

319 Mauger 1993: 79.
} 
Die selteneren waagrechten Linien können das Dekorfeld (über Fensteröffnungen) manchmal unterteilen, bilden aber auch oft nur seinen oberen Abschluß. Diese waagrechten Linien sind meist durchgängig aus weißem Zierstein gebildet. Schräge, dachartige Linien sind sehr selten (Abb. 95) ${ }^{320}$ über Eingangstüren und Schießscharten, wo sie wiederum ein untergeordnetes Detail bilden - während im südlichen Ḥijāz das gleichschenkelige Dreieck aus weißem Zierstein ein Hauptmotiv ist.

Das hochgestellte Rechteck als „Krone“ über dem Fenster oder als „Rahmen“ um die qutra stellt also das Hauptmotiv aus weißem Zierstein an den Wohnhäusern der Rijāl Alma“ dar, und in geringerem Maße auch an der tribalen Steinarchitektur des nördlichen 'Asīr. Innerhalb dieser Rechtecke dominieren Linien und Vierecke; Dreiecke fehlen fast völlig.

Bei den Āl Na ${ }^{c}$ mì ergibt sich daraus erstens, daß ihre Wohnhäuser anstelle der Schießscharten auch in den unteren Geschoßen Fensteröffnungen haben und zweitens, daß an ihren Fassaden die „Kronen“ dominieren und „Rahmen“ kaum vorkommen (Abb. 96). Die schlankeren und höheren Gebäude von Madīnat Rijāl, mit ihren weißen Streifen am Oberrand der Fassade, und den Kronen-Feldern über jedem Fenster vermitteln dadurch eher einen nach oben strebenden, fast schwebenden Eindruck. Hingegen ist bei den massigen, kastenartigen tribalen Bauten durch die Bemalung der Kanten und den Rahmendekor der qutra insgesamt eher die Breite und die Verbundenheit mit dem Boden akzentuiert.

Die rechteckigen Ziersteine sind somit bei den Rijāl Alma ${ }^{c}$ in einen dekorativen Kontext eingebunden, der mit seinen Nuancen und Akzenten insgesamt dreierlei leistet: Er hebt sowohl die Führungsschichten von der tribalen Mehrheit hervor, er verbindet sie zugleich mit der tribalen Mehrheit, und schließlich setzt er die Gesamtheit der Rijāl Alma ${ }^{c}$ mit den nahegelegenen Stämmen des Nord-'Asīr in ebenbürtige, aber kontrastreiche Verbindung. Das krönende Rechteck über den Fenstern hat dabei vor allem verbindenden und integrierenden Charakter, während (weiße und bunte) Farbmalerei und quṭra-Rahmen eher die Unterschiede betonen.

In den vorangegangen Überlegungen ist das Wechselverhältnis zwischen der Lokalarchitektur eines relativ autonomen Bundes von Bergstämmen mit monopolartigem Zugriff auf die Transportrouten und den schwankenden internationalen Konjunkturen für diese Routen herausgearbeitet worden. In einem zweiten Schritt sind innerhalb der Führungsschichten dieser Lokalstruktur zwei Flügel identifiziert worden, nämlich die Nuwwāb und Shuyūkh der Einzelstämme, sowie die Sāda und Ashrāf als Repräsentanten des Gesamtbundes der Rijāl Almac. Und schließlich ist gezeigt worden, daß die schrittweise Zunahme der Bedeutung von internationalen Fernhandelsnetzen mit Beginn der Neuzeit die Voraussetzungen für die materielle und politische Festigung der tribalen Oberschicht der Rijāl Alma ${ }^{c}$ schuf und umgekehrt ihre Aufgaben der Koordination und Repräsentanz umfassender wurden. Diese Entwicklungen gipfelten zunächst in einer Hochkonjunktur am Ende des 19. und zu Beginn des 20. Jh., die den Rijāl Alma ${ }^{c}$ das Ausschöpfen ihrer strategischen Position ermöglichte, danach aber in den Verlust der Lokalautonomie mündete.

Diese halbstädtische und halbstaatliche Struktur an der politisch-rechtlichen Spitze der Stammesorganisation kann nun als funktionierender Mechanismus relativer Autonomie mit einiger Sicherheit den Phasen zunehmender internationaler Rivalitäten am Ro-

320 Mauger 1993: 78. 
ten Meer im 19. Jh. zugeordnet werden. Der von Galinier und Ferret ${ }^{321}$ redigierte Bericht Chédufau's über die kurzfristige ägyptische Unterwerfung der Rijāl Alma c von 1834 führt jene bereits erwähnte „Zitadelle“ („redda“) an, die sich in einer engen Schlucht am Bergfuß befunden habe und Versteck wie Zufluchtsort gewesen sein. Diese Lagebeschreibung und der Hinweis auf seine politische Bedeutung (für die damaligen Verbündeten der Rijāl Alma $\left.{ }^{c}\right)$ weisen mit großer Wahrscheinlichkeit auf Madīnat Rijāl hin. ${ }^{322}$ Es ist also zumindest sehr wahrscheinlich, daß bereits lange vor 1834 ähnliche, wenn auch schwächer ausgeprägte Strukturen bei den Rijāl Alma ${ }^{c}$ bestanden haben. Deren zeitlicher Horizont ließe sich hypothetisch auf die Periode nach der Etablierung neuer, zentralerer Küstenorte im Spätmittelalter beziehen. Angesichts der alten Tradition, die abgesonderte Orte des Friedens ansonsten in Südwestarabien darstellen, tendiere ich dazu, auch für Madīnat Rijāl eine längere Vorgeschichte anzunehmen, die aber im 19. Jh. auf jeden Fall eine bedeutende Transformation durchlaufen haben muß. Erst in diesem Zeitraum wurden die politisch-militärischen Konfrontationen mit der staatlichen Außenwelt zu einem regelmäßigeren Faktor, nahmen die wirtschaftlichen Einflüsse und Möglichkeiten dramatisch zu, was insgesamt die moralische, politische und rechtliche Position der Āl Na ${ }^{c}$ mì zugleich indirekt festigte.

Die traditionelle Architektur der Rijāl Almac drückt zum einen, als Resultat dieser historischen Prozesse, die soziale Hierarchie innerhalb der tribalen Gemeinsamkeiten aus. Zum anderen ist sie Teil einer Subvariante, die auch im südlichen Abschnitt des Nord- ${ }^{`}$ Asīr, wie noch zu zeigen ist, fortexistiert. Der gesonderte und ausgeprägte Dekor in Farben und Stein, den die Architektur der Rijāl Alma` aufweist, artikuliert parallel dazu genau dieselben Akzente, nämlich die der tribalen Gemeinsamkeiten, die der intratribalen Hierarchie und schließlich die der intertribalen Bindungen.

Die Häuser der $\bar{A} l \mathrm{Na}^{c} \mathrm{~m}$ ī heben sich durch kleineren Grundriß und größere Höhe (was beides das Vorherrschen der einfachen Stützmauer bedingt), durch die Abwesenheit defensiver Einrichtungen und in ihrem Dekor durch die Schlichtheit der Bemalung und das Vorherrschen des „krönenden“ Steindekors am deutlichsten vom Rest der tribalen Architektur ab (Abb. 62). Die Häuser von Madīnat Rijāl sind jedoch im Prinzip die wichtigsten unter jenen nicht-defensiven Ausnahmebauten des 'Asīr, deren Gesamtanteil wir mit weniger als $25 \%$ geschätzt haben. Für die defensive Wohnarchitektur repräsentativ sind also die übrigen, hier diskutierten Häuser der Rijāl Alma ${ }^{c}$ und ihrer Shuyūkh und Nuwwāb.

Die Architektur dieses „tribalen Flügels“ der Oberschicht und jene der tribalen Mehrheit haben weniger ausgeprägte Unterschiede als Gemeinsamkeiten. Breite, drei- oder viergeschoßige Bauten mit Binnen- und Zwischenschächten, und in der tribalen Mehrheit auch solche mit einfachen Stützmauern sind die charakterstischen Hausformen, wobei in Innenschachthäusern die schwierige Luftzirkulation der breiten Häuser durch die șarḥa

321 Galinier und Ferret 1843: 106-117.

322 ,edda' könnte entweder rada'a wiedergeben, den örtlichen Terminus für einen mächtigen Türsturz (als pars pro toto), oder auch radha - den klassisch arabischen Terminus für large hall, reception hall. Die „rechteckige“ Zitadelle mit hohen Mauern, von der im Bericht die Rede ist, könnte entweder eine damals existierende, und von den Ägyptern zerstörte Stadtmauer sein, oder aber es liegt ein Übertragungsfehler von Galinier und Ferret vor (die ja selbst nicht in diesem Gebiet waren). In diesem Fall sind geschlossene Fassaden der Wohnhäuser mit „Mauern“ verwechselt worden. 
zusätzlich erleichtert wird. Große Einzelgehöfte bei dichter Besiedlung lassen die Notwendigkeit für in-towers völlig entfallen, und ergeben auch einen außerordentlich niedrigen Stand von out-towers, die sich auf exponierte Lagen beschränken.

Die auch im Zentral- und Ost- 'Asīr gegebenen Sonderräume, hier ergänzt um ummauerte Außenabflüsse, und die „Amtsräume“ heben die Wohnhäuser beider Flügel der tribalen Oberschicht von jenen der tribalen Mehrheit zusätzlich ab. Im Dekor überwiegen die häufige, bunte 'Asīrī-Bemalung der Innenwände der diwāne, und die weiße Bemalung der Außenkanten als tribale Gemeinsamkeiten im Unterschied zu Madīnat Rijāl; wohingegen der Steindekor mit der Grundform des stehenden Rechteckes die Häuser aller Schichten kennzeichnet - dies allerdings weniger ausgeprägt bei der tribalen Mehrheit, und ohne quțra und „Rahmen“-Dekor bei den Häusern der Āl Na ${ }^{c}$ mī.

Die Zusammenschau dieser konstruktiven und dekorativen Haupteigenschaften der Architektur der Rijāl Alma'a verdeutlicht zugleich die Unterschiede zur Steinarchitektur der Ahl Fayfā, und zwar in zweierlei Hinsicht. Erstens sind die Unterschiede zwischen der Steinarchitektur der Ahl Fayfā und jener der Rijāl Alma ${ }^{c}$ hinsichtlich der Siedlungsform, der Hauskonstruktion und des Dekors so ausgeprägt, daß sie als jene zwischen Subvarianten anzusprechen sind. Die südwestliche Subvariante teilen die peripheren Stämme der nordwestlichen Khawlān in Saudi Arabien, die zuletzt behandelte ist hingegen den Rijāl Alma ${ }^{c}$ des West-'Asīr graduell mit den nächstgelegenen des Nord-'Asīr gemeinsam und kann als Subvariante des Zentral-'Asīr bezeichnet werden. Dies bedeutet aber in der Konsequenz, daß die materialspezifische Variante hier nicht als Indikator einer „Regionalkultur" gelten kann. Im Unterschied zur Adobe-Variante des Ost-'Asīr und W. Najrān, und zur Pagoden-Variante des Zentral-'Asīr ist die Steinarchitektur aus West-'Asīr also in zwei Subvarianten gegliedert, für die der Begriff einer gemeinsamen Regionalkultur nicht adäquat ist.

Zweitens ist die Subvariante des Zentral-'Asīr jenseits der Differenzierungen nach der sozialen Hierarchie von relativer Homogenität gekennzeichnet, wie die Zusammenschau bereits am Beispiel der Rijāl Alma cerdeutlicht hat. In ihrer Architektur haben sich als Resultat dieser Prozesse keinerlei volkstümliche Sonderformen erhalten, die etwa zu den charakteristischen Turmformen der Ahl Fayfā analog wären. Die einzigen Sonderformen der tribalen Architektur, die im traditionellen Baustil errichtet worden sind, stellen jene bewohnbaren out-towers dar, welche die Zugänge nach Madīnat Rijāl und zu den Wochenmärkten bewachen: Sie sind als architektonisches, defensives Resultat eines gemeinsamen tribalen Interesses aller Rijāl Alma ‘ anzusprechen. Auch wenn die jeweilige Verantwortung bei der einzelnen tribalen Lokalgruppe liegt, in deren Gebiet diese bewohnbaren out-towers errichtet sind, geschieht dies im übergeordneten Interesse. Die historischen Bedingungen für die Herausbildung dieser einzigen architektonischen Sonderform der Rijāl Alma ${ }^{c}$ waren schon in der ersten Hälfte des 19. Jh. gegeben, also in der rezenten Periode intensivierter äußerer Bedrohung durch ebenbürtige oder mächtigere Gegner. ${ }^{323}$

Auf der Grundlage dieser historischen und konstruktiven Analysen zur Architektur der Rijāl Alma ' läßt sich eine Annäherung an jene „Schachttürme“ vornehmen, die bereits als architektonische Sonderformen mit Zwischenschacht unter 6.5.2.1. erwähnt worden

323 Galinier und Ferret 1843: 106-117 berichten, daß ihre „Zitadelle“, also höchstwahrscheinlich Madīnat Rijāl, von fünf Türmen mit Schießscharten und Zinnen bewacht gewesen sei. 
sind (Abb. 60). Ihre Hauptverbreitung haben diese hohen, dauerhaft bewohnbaren Bauten über kleinem Grundriß und (daher mit zwei Räumen pro Geschoß) entlang der beiden Haupthandelsrouten durch das W. Tayya und das W. Dala ${ }^{c}$ (Routen a und c in Karte 10). Die hohen Schachttürme stehen am Fuß und am Rand der Shifā entlang der Oberläufe dieser beiden Wādis; ihre leicht erhöhten Standorte sind von den heutigen Siedlungsorten relativ weit entfernt. ${ }^{324} \mathrm{Im}$ Prinzip sind sie damit zwar in den tribalen, hier aber kaum besiedelten heutigen Territorien der Rabī'a wa Rufayda, der B. Mughayḍ, oder kleinerer tribaler Verbände der hügeligen Tihāma errichtet; die nächstgelegenen größeren Siedlungsgebiete sind jedoch jene der Rijāl Alma ${ }^{c}{ }^{325}$ Die beiden Routen durch das W. Tayya und das W. Dalac sind jene beschwerlichen Alternativen, die das Gebiet der Rijāl Almac am ehesten umgehen oder es nur am Rande streifen. Rechtlich und militärisch ist die Anlage dieser Schachttürme also eher gegen die Rijāl Alma ${ }^{c}$ gerichtet gewesen, als daß es sich um deren eigene vorgeschobenen Posten hätte handeln können. Die lokalen Oraltraditionen, die mir mitgeteilt wurden, betrachteten die Schachttürme als von Türken errichtete Bauten und sie stehen auch an jener Route, die im Hochland als gut gebaute türkische Straße weiterlief. ${ }^{326}$

Diese und einige weitere Hinweise erlauben die Formulierung einer Hypothese: Die Schachttürme stellen nämlich eine Kombination zweier architektonischer Formen dar, die zuletzt am Beispiel der Rijāl Alma ${ }^{c}$ abgehandelt wurden, aber die etwas seltener auch in der übrigen Steinarchitektur des Zentral-'Asīr auftreten. Dies sind die Wohnbauten mit „echtem“ Zwischenschacht, und jene bewohnbaren out-towers, welche die Zugänge zu Märkten und zu Siedlungen wie Madīnat Rijāl bewachen.

In der Konstruktion der Schachttürme ist also das Prinzip des echten Zwischenschachtes von den defensiven Wohnbauten, und das Prinzip der bewohnten, hohen Türme von jenen Wachtürmen übernommen und kombiniert worden. Dies deutet daher eher auf eine Errichtung durch Stammesgruppen als durch türkische oder andere Soldaten hin: Gerade die statisch komplizierte Errichtung eines Zwischenschachtes über kleinem Grundriß ist kein Charakteristikum der erhalten gebliebenen türkischen Militärbauten im 'Asīr, sie setzt andererseits beträchtliche örtliche Erfahrung voraus. Die Räume dieser Schachttürme sind für die permanente Stationierung von kleineren Wachmannschaften angelegt, die Fassadenöffnungen sind auch in den Obergeschoßen selten Fenster, sondern Schießscharten. Da die Türme zwar nicht in Ruf- aber in regelmäßiger Sichtweite voneinander errichtet sind, war ihre Kommunikation untereinander mittels Licht- oder Rauchsignalen möglich. Die Erbauer der Türme dürften daher mit einiger Sicherheit tribale Gruppen gewesen sein; ihre Nutzung war wohl alles andere als unumstritten, aber primär für reguläre Truppeneinheiten und ihre Verbündeten gedacht - woran sich die Gegner sicher nicht immer gehalten haben.

324 cf. auch King 1976: 24; Philby 1952: 171 für das W. Tayya.

325 So liegt z. B. der Markt- und Garnisonsort Maḥā'il im Gebiet des kleinen semi-tribalen Tihāma-Verbandes der Āl-Mūsa, deren Shaykh al-Qabīla hier auch seinen Sitz in einem größeren Defensivbau (Qașr) hat. Außerhalb von Maḥāंil sind auf einem Hügel die Reste eines - nach örtlicher Überlieferung - türkischen Forts zu sehen. Der breite Zusammenfluß (daghbaj) des W. Tayya mit dem W. Ḥalī knapp außerhalb von Maḥāi il ist jedoch bereits Gebiet der Rijāl Almac. In unmittelbarer Nähe des daghbaj waren 1982 noch einige Schachttürme zu sehen.

326 Thesiger 1947: 194. 
Auf dieser Grundlage erlaube ich mir die Hypothese, daß die Schachttürme in der Konsolidierungsphase der osmanischen Herrschaft zwischen 1872 und 1914 durch mit ihnen verbündete tribale Gruppen der Rabī'a wa Rufayda und B. Mughayḍ errichtet wurden, um die Nachschubrouten von Abhā zur Küste zu sichern und die strategische Position der Rijāl Alma ${ }^{c}$ zu schwächen ${ }^{327}$ - ein Vorhaben, das erst einige Jahrzehnte später die saudische Regierung mit dauerhaftem Erfolg verwirklichen sollte.

\section{B. Steinarchitektur des Nord-'Asīr}

$\mathrm{Zu}$ Beginn dieses Abschnittes über die Steinarchitektur des 'Asīr ist auf ihr Verbreitungsgebiet hingewiesen worden, das sich wie ein zweiteiliges Band die Shifā entlang windet. Daher wurde zunächst nach diesem evidenten geographischen Kriterium der (süd-)westliche Teil des Bandes unterhalb der Shifā vom fast daran anschließenden, nördlichen Teil oberhalb des Grabenrandes unterschieden. Die nähere Untersuchung des südwestlichen Architekturgebietes hat nun aber ein Ergebnis geliefert, das von jenem der anderen Varianten der defensiven Hochbauweise im 'Asīr und W. Najrān signifikant abweicht. In den Gebieten der Adobe- und Pagoden-Bauten sind nämlich die jeweiligen Baumaterialien und Konstruktionstechniken die bestimmenden Merkmale für architektonische Varianten mit ziemlich homogenen Verbreitungszonen. Für die dritte Variante hingegen hat schon die bisherige Untersuchung die Existenz zweier ausgeprägter Subvarianten erbracht, die inselartig auf Gruppen vorgelagerter Tihāma-Berge konzentriert waren. Die zweite dieser Subvarianten wurde aber auch deshalb am Beispiel der Ahl Șalab für die Rijāl Alma causführlicher abgehandelt, weil sie mit gewißer Nuancierung ebenso oberhalb des Grabenrandes auftritt.

Jener nördliche Teil des Bandes, den das Verbreitungsgebiet der Steinarchitektur im 'Asīr beschreibt, erstreckt sich vom Übergangsgebiet zum Hijāz im Nordwesten bis zur Region vor Abhā im Südosten. Diese agrarischen Siedlungsgebiete entlang der Shifā schließen also vor Abhā an die Pagoden-Zone an, und ziehen sich dann relativ kontinuierlich bis zum Rand des Hijāz hin, wo das Verbreitungsgebiet des zweiten Subtypus mit seinen viel niedrigeren Wohnbauten einsetzt. Diese Positionierung im ökologischen und sozio-kulturellen Raum macht eine graduelle Zweiteilung verständlich, welche die Steinarchitektur in diesem nördlichen Teil des Bandes auszeichnet. Er kann wiederum in einen nördlichen (nordwestlichen) und einen südlichen (südöstlichen) Abschnitt unterschieden werden. Der nördliche Abschnitt um die Hauptorte al-Namāṣ und Khamīs al-'Irq umfaßt jene tribalen Teilgebiete der nördlichen Banū l-Hajar und ihrer Nachbarstämme, welche an die Shifā angrenzen, sowie Siedlungsgebiete auf einigen kleineren isolierten TihāmaBergen vor diesem Teil des Grabenrandes. Die bäuerliche Architektur im nördlichen Abschnitt ist von Übergangsformen zu den Bauten des südlichen Ḥijāz und von Mischformen zum Küstenstil im Nordwesten geprägt. Insgesamt sind ihre markantesten Merkmale Häuser von geringerer Höhe und eine größere Zahl von in-towers als im südlichen Abschnitt. Dort wiederum, im Gebiet des Grabenrandes gegenüber den Bergen der Rijāl Alma $^{c}$ und zugleich nordwestlich von Abhā, herrscht jene nuancierte Subvariante vor, die wir bereits im Gebiet der Rijāl Alma ${ }^{c}$ kennengelernt haben. Der südliche Abschnitt ober-

327 Diese Hypothese steht überdies in Einklang mit Hinweisen bei Philby (1952: 171), wonach die Osmanen die Route zwischen Abhā und der Küste über Maḥāil mit „Kasernen“ befestigt hätten. 
halb der Shifā, und das Gebiet der Rijāl Alma ${ }^{c}$ unterhalb des Grabenrandes sind also im wesentlichen mit denselben architektonischen Subvarianten ausgestattet.

Bevor nun die architektonischen Nuancen des Südabschnittes und die Hauptmerkmale des nördlichen Abschnittes etwas genauer diskutiert werden, muß ich auf den provisorischen Charakter der folgenden Darlegungen hinweisen. Unter allen Verbeitungsgebieten traditioneller Architektur im Südwesten Saudi Arabiens habe ich vom Nord-'Asīr die geringsten Kenntnisse aus persönlich durchgeführten Untersuchungen. Lediglich in zwei Gebieten des Nordabschnittes (Shumrān 1981 und B. Shihr 1982) führte ich kürzere Erhebungen durch; die ländliche Architektur der übrigen Teile dieses Nordabschnittes konnte ich leider nur als Durchreisender bewundern. Die folgende, provisorische Zusammenstellung stützt sich also primär auf die zitierten Publikationen und Photodokumentationen, und ist in noch höherem Ausmaß als andere Teile dieses Textes offen für zukünftige Korrekturen und Ergänzungen.

a) Steinarchitektur im südlichen Abschnitt

Geographisch umfaßt das Verbreitungsgebiet der Steinarchitektur im südlichen Abschnitt des Nord-'Asīr, wie erwähnt, die Regionen oberhalb der Shifā nordwestlich von Abhā. Dieses Gebiet bildet den Hauptkamm des Grabenrandes, der hier den Oberlauf des W. Tayya in einem weiten Bogen umläuft und sich dann in seiner Hauptrichtung weiter nach Nordwesten ausrichtet. ${ }^{328}$

Südlich des Tayya-Bogens befinden sich oberhalb der Shifā jene Regionen, die den Gebieten der Rijāl Alma ${ }^{c}$ direkt gegenüberliegen. Dies sind die Westgebiete der 'Asīr-Stämme des Hochlandes ('Asīr al-Sarāt), also der Hauptteile von Rabī'a wa Rufayda und Alkam, sowie des Westteils der B. Mughayḍ. ${ }^{329}$ Hier, im südlichsten Teil ihres saudischen Verbreitungsgebietes oberhalb der Shifā, ist die Steinarchitektur nur direkt entlang des Hauptkammes dominant. Nach Osten hin geht sie in einem losen und inhomogenen Übergangsgebiet in die Pagoden-Zone über. In den ländlichen Westgebieten der B. Mughayḍ ist die traditionelle Architektur daher als eine Durchmischung von Pagoden-Bauten (mit steinernem Erdgeschoß) und reinen Steinbauten charakterisierbar; das örtlich beschränkte Nebeneinander dieser beiden Varianten reichte traditionell bis in die Vororte von Abhā. ${ }^{330}$

Die Pagoden-Zone erstreckt sich im Gebiet der B. Mālik ('Asīr), wie erinnerlich, nochmals bis knapp an die Shifā, wo sie an die Kehre des Tayya-Bogens reicht. Am Nordrand des Tayya-Bogens setzt sich dann das Verbreitungsgebiet der Steinarchitektur weiter fort, nun aber im Südgebiet der Banū 'l-Hajar. In diesen Hochlandgebieten der Balaḥmar und der südlichen Balasmar, welche auch die beiden vorgelagerten, kleinen Tihāma-Berge J. Hādā und Dhirim umfassen, ist die Steinarchitektur nicht nur für die Dörfer entlang des Hauptkammes charakteristisch, sondern auch für die Oberläufe der nach Osten hin abgehenden Zuflüsse zum W. Bīsha. ${ }^{331}$ Dies verdeutlicht die veränderten, feuchteren und kühleren klimatischen Bedingungen im Nord-'Asīr, die hier auch an den Ostabhängen des Hauptkammes Steinarchitektur erfordern, wohingegen weiter südlich für die Ostabhänge Pagoden- und Adobe-Bauten charakteristisch sind.

328 Abdulfattah 1981: map 1.

329 Philby 1953: 165.

330 King 1986: 86, 88 und 1976: 26.

331 Abdulfattah 1981: map 6. 
Die beiden durch den Nordrand der Pagoden-Zone an der Tayya-Kehre getrennten Gebiete der Steinarchitektur in diesem südlichen Abschnitt sind also zugleich Teilgebiete zweier verschiedener Stammesgruppen. Südlich des Tayya-Bogens sind dies die Westgebiete der 'Asīr al-Sarāt, nördlich des Tayya-Bogens die Kerngebiete der Balaḥmar und der südlichen Balasmar, also der Südgruppe der Banū 'l-Hajar. Trotz dieser unterschiedlichen politischen Zugehörigkeit der tribalen Verbände weisen alle mir zur Verfügung stehenden Angaben und Daten darauf hin, daß die Steinarchitektur ihrer Siedlungsgebiete einander im wesentlichen gleicht, und nur geringfügig von jener der Rijāl Almac abweicht.

Diese Abweichungen zur Architektur der Rijāl Alma ${ }^{c}$ liegen zunächst in anderen Siedlungsmustern. Nicht nahe beeinander stehende Einzelgehöfte herrschen vor, sondern engere Streusiedlungen, einzelne kompakte Dorfanlagen oder isolierte Einzelgehöfte prägen das Bild, ${ }^{332}$ das damit eher dem übrigen Hochland des 'Asīr gleicht. Die Wohnhäuser sind mit großen, nur roh zugeschlagenen Blöcken errichtet ${ }^{333}$ und in der Regel drei- bis vierstöckig, im Gebiet der Balaḥmar und Balasmar fallweise aber auch fünfstöckig. Die Häuser sind also höher als im Gebiet der Rijāl Alma ${ }^{c}$ und ihre Obergeschoße haben recht kleine Fensteröffnungen. Die Fassaden sind um Fenster und Schießscharten mit weißem Zierstein geschmückt, ${ }^{334}$ der hier insgesamt aber spärlicher ist. Unter den konstruktiven Kombinationslösungen scheint die einfache Stützmauer wie im übrigen 'Asīr-Hochland wieder die weitaus häufigste Form zu sein; Wohnhäuser mit Zwischen- oder Innenschacht sind also weitaus seltener als bei den Rijāl Alma ${ }^{c}$ und treten nur bei isolierten Einzelgehöften oder als Einzelfälle in Dorfsiedlungen auf. Daraus ergibt sich wiederum, daß auch die Nutzung der Innen- und Zwischenschächte zur Durchlüftung der Häuser seltener anfällt, die etwas größere Höhe der üblichen Wohnbauten erleichtert andererseits das Abziehen der Luft nach oben.

Andere Siedlungsmuster, Wohnbauten mit größerer Höhe als bei den Rijāl Alma ${ }^{c}$, aber seltener mit Innen- oder Zwischenschächten ausgestattet- dies sind die wichtigsten Abweichungen der Wohnbauten zur Architektur der isolierten Berge des West- ${ }^{\mathrm{C}}$ Asīr, die ich feststellen konnte. Diese Nuancen verweisen auf ähnliche sozio-politische und ökologische Rahmenbedingungen wie im südlich benachbarten Hochland, und unterstreichen den Sonderstatus der Verhältnisse bei den Rijall Almac. Im Hochland hat sich offensichtlich nicht jene übergreifende politisch-rechtliche Sozialordnung herausgebildet, die auf der Grundlage von lokalem Reichtum und einer extrem hohen Bevölkerungsdichte das gefahrlose „Zusammenrücken“ der Wohnhäuser zu einer einzigen, riesigen Streusiedlung ermöglicht hat. Vielmehr zeigt die Seltenheit der Innen- und Zwischenschachthäuser und die Dominanz isolierter, defensiver Dörfer und Einzelbauten an der Steinarchitektur oberhalb der Shifā Verhältnisse an, die jenen der übrigen 'Asīr al-Sarāt vergleichbar sind. Dennoch sind diese Abweichungen, wenn man sie auf die Konstruktion der einzelnen Wohnhäuser bezieht, nur gradueller und nicht qualitativer Art. Die Gestaltung von Material und Fassaden entspricht jener der Wohnhäuser bei den Rijāl Alma'; runde Grundrisse der Wohnbauten wie im Gebiet der nordwestlichen Khawlān kommen hier ebensowenig

\footnotetext{
332 ibid.: Photos 17, 20 und eigene Beobachtung; lokale Termini zur Architektur konnte ich in dieser Region nicht erheben.

333 Philby 1953: 165 für die Gegend zwischen al-Sūda und Dhahya.

334 Thesiger 1947: 198.
} 
vor wie bei den Rijāl Alma ${ }^{c}$; und auch die absolute Dominanz von vielstöckigen Wohnbauten ist eine Gemeinsamkeit, die sie von den Wohnbauten des Nordabschnittes wie von jenen der isolierten Khawlān-Berge im Südwesten klar abhebt.

$\mathrm{Zu}$ diesen Faktoren tritt ein entscheidendes, gemeinsames Merkmal hinzu: Im Prinzip sind die Dekorformen aus weißem Zierstein nämlich an den Wohnbauten des südlichen Abschnittes von derselben Art wie bei den Rijāl Alma ${ }^{c}$. Kronenfelder sind also über den Fensteröffnungen zentriert, und Rahmenfelder um die Schießscharten. Als Musterung dominieren wiederum senkrechte und waagrechte Linien und Schachbrettformen, hingegen sind schräge Linien und Dachformen auch hier von völlig untergeordneter Bedeutung (Abb. 97). ${ }^{335}$ Die Farbbemalung der Fassadenkanten tritt zwar hier nicht auf, und jene der Mauerkronen ist seltener. Aber die generelle 'Asīî-Form der bunten Innenbemalung ist auch hier gegeben. Der Steindekor ist, wie erwähnt, zwar etwas spärlicher - er ist nicht an allen Wohnhäusern angebracht, und wo er auftritt, ist dies auch nicht über allen Fassadenöffnungen der Fall. Aber dies ist auch bei der Dekorierung jener Wohnhäuser gegeben, welche die Mehrheitsbevölkerung der Rijāl Alma` bewohnen: Anlage und Musterung des weißen Steindekors, Material und Konstruktion der Wohnbauten sind also der Architektur der Rijāl Alma` und jener des südlichen Abschnittes gemeinsam. Diese Gemeinsamkeiten der Wohnbauarchitektur halte ich für wesentlicher und charakteristischer als die noch zu erörternden Besonderheiten der Turm- und einzelner dörflicher Sonderformen. Das für die Hochländer des 'Asīr typische (und von jenem der Rijāl Alma' differierende) Siedlungsmuster im südlichen Abschnitt bedingt, daß zwischen den isolierten Höfen und Dörfern wiederum out-towers die Regel sind, während - für den 'Asīr typischerweise - in-towers kaum vorkommen.

Drei Turmformen sind in diesem Abschnitt des 'Asīr-Berglandes charakteristisch: Erstens tritt hier selten der bewohnbare Turm auf rechteckigem Grundriß auf, der bei den Rijāl Alma ${ }^{c}$ zur strategischen Bewachung der Zugänge nach Madīnat Rijāl und zu den Märkten dient (Abb. 66). Die zweite Form sind schlanke Steintürme mit rundem Grundriß, die aus demselben dunklen Material wie die Wohnhäuser errichtet sind (Abb. 67). Die Fassaden können einmal oder mehrfach pro Geschoß ihrer Zylinder- oder Kegelform durch jeweils eine fortlaufende Zierleiste aus weißem Quarz unterteilt sein. Je nach Höhe dieser out-towers weisen sie bei vier Geschoßen drei, und bei fünf Geschoßen vier solcher paralleler Zierleisten auf. ${ }^{336}$ Die solchermaßen dekorierten Turmformen treten fast nur im Südabschnitt auf; im Gebiet der Rijāl Alma (mit einzelnen, ähnlichen Ausnahmen an den flachen Ausläufern ihrer Berge) sind out-towers ja nicht die Regel. Funktion, Form und Dekor weisen diese „Streifentürme“ unzweideutig als regionale Elemente der tribalen architektonischen Tradition aus. Die dritte Form sind jene Schachttürme, die bereits für die beiden Routen durch die W. Tayya und W. Dala’ untersucht worden sind. Sie sind häufiger vor Abhā und oberhalb des W. Tayya anzutreffen, kommen aber auch oberhalb der Shifā im Gebiet der Banū 'l-Hajar entlang der Route nach al-Namāṣ vor, ${ }^{337}$ das ja vor 1918 türkische Garnison war. Konstruktion, isolierter Standort und strategische Verbreitung dieser Schachttürme scheinen also die Hypothese zu bestätigen, die auf der Grundlage ihres Vorkommens unterhalb des Grabenrandes entwickelt worden ist: Auch in diesen Fäl-

335 cf. auch King 1986: 83 f.; Mauger 1993: $76 \mathrm{f}$.

336 Thesiger 1947: 194; Mauger 1993: 75.

337 King 1976: 26. 
len handelt es sich mit einiger Wahrscheinlichkeit um permanent belegbare Garnisonstürme, die auf türkische Initiative hin von indigenen Stammesleuten errichtet worden sind.

Ebenfalls auf den militärstrategischen und historischen Hintergrund des 19. Jh. verweist die spezielle Siedlungsanlage von al-Sūda. Sie konnte 1978 von Dostal noch verdienstvollerweise dokumentiert werden, bevor sie im Zug der baulichen Veränderungen der späten 80er Jahre verschwunden ist. ${ }^{338}$ Die kompakte Wehrsiedlung al-Sūda lag oberhalb der 'Aqabāt Samā entlang der Route von Abhā nach Sha'bayn, auf deren Bedeutung bereits hinlänglich verwiesen worden ist. Der Ort war in den 30er Jahren des 20. Jh. eine „Frontsiedlung" besonderer Art:

"Suda was a very curious village, not large but consisting of a solid block of dingy, single-storey houses with no streets or alleys and no doors except in the houses forming the periphery, whose entrances faced outward. There was no means of internal circulation from house to house, but every house - and they all appeared to consist of a single living-room with kitchen attached and occasional recesses more like cupboards than rooms - had a fixed ladder leading from the ground floor to the roof by way of a wooden skylight. This served to let out the accumulated smoke in the rooms, and also afforded the inhabitants the means of visiting from house to home without going outside the village black. If one went a-visiting one knocked on the door but on the skylight. The reason for this strange arrangements was obviously to be found in the state of insecurity which had marked these highlands till quite recent times, neccessitating the barring and bolting of all outer doors at night to convert the village block into a self-contained fortress. " 339

Diese Dorffestung beherbergte noch Ende der 70er Jahre die Angehörigen von neun Linienverbänden, die jeweils in geschlossenen Dorfvierteln lebten. Der Ort liegt im Ostgebiet der Alkām. Die besondere Defensivanlage dieses Dorfes ohne in-towers ${ }^{340}$ erklärt sich durch die Lage an der strategisch entscheidendsten Route der gesamten Region, deren Kontrolle ausschlaggebend für die aktuellen Machtverhältnisse sein konnte. Die etablierten Sicherheitseinrichtungen von al-Sūda haben andere Siedlungsgruppen entlang dieser umkämpften Strecke veranlaßt, ihre eigenen Weiler aufzugeben und in das besser geschützte al-Sūda zu übersiedeln. Philby berichtet von einem Fall, in dem sogar eine Untergruppe der B. Mughayḍ ihr eigenes Dorf (Sahwa) verlassen habe und nach al-Sūda im Alkām-Gebiet übersiedelt sei. ${ }^{341}$

Die Materialien von Philby und Dostal zu al-Sūda veranschaulichen damit zweierlei: In architektonischer Hinsicht verweisen sie auf möglicherweise rezente Sonderformen der tribalen Architektur, die sich wohl erst mit der gestiegenen strategischen Bedeutung derartiger Routen ins Hochland, vor allem im Lauf des 19. Jh. herausgebildet haben dürfte. Die Siedlungsanlage von al-Sūda kann als tribale architektonische Antwort besonderer Art auf dieses strategische Ringen zwischen Staatsmächten und lokalen Verbänden entlang einer zentralen Route interpretiert werden. Insoferne ist diese Sonderform ähnlich zu beurteilen wie die Schachttürme, nämlich als architektonische Lösung für militärstrategische Herausforderungen des 19. Jh., die unter dem zunehmenden Einfluß von Staatsinteressen entstanden sind. Aber während die Schachttürme vermutlich direkt auf osmanische Initiative hin von örtlichen Verbündeten errichtet worden sind, stellt die Sied-

338 Dostal 1983c: Ground Plan IV A, sowie Ground Plan IV B: 23.

339 Philby 1953: 159.

340 Dostal 1983c: 21-23, und Illustr. p. III no. 6.

341 Philby 1953: 164. 
lungsanlage von al-Sūda wohl eher eine Initiative von unten, durch die örtliche Bevölkerung selbst dar: Hier wurde das Prinzip der Frontsiedlung angesichts einer besonderen strategischen Lage in einem Maß perfektioniert, das sie zum Schutzort auch für andere tribale Gruppen werden ließ.

Zum zweiten nämlich verweisen die hier diskutierten Materialien auf intensivierte soziale Wanderungs- und Homogenisierungsprozesse: Unter zunehmendem äußeren Druck haben sich, wie Philby's Bericht belegt, Untergruppen der B. Mughayḍ zur Niederlassung in einem Dorf der Alkām entschlossen, und von jenen das Recht dazu erwirkt. Dies ist nicht bloß ein Beispiel für Prozesse der „nucleation" 342 von Gruppen diverser tribaler Herkunft in wenigen, aber besser befestigten Siedlungen. Da sich diese unterschiedliche tribale Herkunft aus der Zeit vor 1936 (Philby) dann 1978 (Dostal) nicht mehr rekonstruieren ließ, kann hier vom Eintritt einer tribalen Gruppe in einen anderen Verband mit anschließender „structural amnesia“ ausgegangen werden. Prozesse dieser Art hat es in der mittelalterlichen und neuzeitlichen Geschichte des tribalen Südwestarabien immer wieder gegeben, ${ }^{343}$ aber unter geänderten wirtschaftlichen und waffentechnischen Bedingungen und bei zunehmendem äußeren Druck haben sie sich auch im Hochland des 'Asīr während der letzten beiden Jahrhunderte zweifellos intensiviert. Die damit einhergehende soziale, linguistische und kulturelle Homogenisierung von davor ausgeprägteren, älteren lokalen und tribalen Unterschieden hat auch die Architektur des Hochlandes nicht unberührt gelassen.

b) Steinarchitektur im nördlichen Abschnitt

Ungefähr nordwestlich der Luftlinie zwischen dem J. Dhirim (vor dem Grabenrand) und Sūq al-Ithnayn Ballasmar (am Hauptkamm) beginnt sich das Erscheinungsbild der dörflichen Architektur des Hochlandes sukzessive zu ändern; die Höhe der Wohnhäuser nimmt ab, je mehr man sich dem Nordwestrand des 'Asīr nähert. Dominieren im Gebiet der südlichen Balasmar noch drei- bis vier-, teilweise auch fünfgeschoßige Wohnbauten, so herrschen nordwestlich davon, um Tanūma bis nach al-Namāṣ zwei- bis dreigeschoßige Wohnhäuser vor, zu denen sich dann nördlich von al-Namāṣ und Khamīs al-'Irq zunehmend ein- bis zweigeschoßige Steinhäuser hinzugesellen. Die Steinarchitektur der losen Kette kleinerer Tihāma-Berge, die dem Grabenrand auch hier vorgelagert sind (vom J. Barkū vor Tanūma bis zum J. Thuraybān nordöstlich von al-Qunfudha) bietet ein ähnliches Bild.

Gemäß diesem ersten Kriterium der Höhe von Wohnbauten ist der nördliche Abschnitt der Verbreitung von Steinarchitektur im 'Asīr also mit jenen Gebieten entlang des Grabenrandes und auf den vorgelagerten Tihāmah-Bergen ungefähr zu umschreiben, die durch die Bögen zweier großer Wādis eingegrenzt sind: Im Süden ist dies das W. Tayya (dessen unmittelbarste nördliche Nachbargebiete in architektonischer Hinsicht allerdings dem Südabschnitt zuzurechnen sind), und im Norden ist dies der Oberlauf des W. Qanūna. Ähnlich wie das W. Tayya in südöstlicher Richtung bildet der Oberlauf des W. Qanūna nach Nordosten hin einen großräumigen Bogen im Grabenrand, der von der heutigen Ortsbevölkerung als natürliche Grenze zwischen dem 'Asīr und dem südlichen Hịjāz angesehen wird.

342 McC. Adams 1966: 140.

343 Gingrich 1993: 264. 
Die Aufstiege vom Oberlauf des W. Qanūna zur Shifā bilden dabei die strategische Durchgangsstelle für die Hauptroute von al-Qunfudha aus nach Nordosten, in das Hochland des südlichen Hịjāz und des nördlichsten 'Asīr. In diesem Bereich habe ich 1982 die Shumrān-Siedlung von Hawāla oberhalb der Shifā bei Qiżạane dokumentiert. ${ }^{344}$ Ihre wesentlichen Merkmale waren ebenerdige, direkt aneinander anschließende Wohnbauten mit Ställen, die ein zusammenhängendes Dach bildeten. Diese Reihensiedlung war von einer dreifachen Linie von speziell ausgestatteten out-towers zum südlichen Hijāz hin geschützt. Wie ich gestehen muß, entging mir damals der entscheidende Umstand, daß diese ganze Grenzanlage der Shumrān vor allem einen der strategisch wichtigsten Abstiege zum Oberlauf des W. Qanūna hinunter gegen die benachbarten Ghāmid des Hijāz beschützte (und weniger das Land der Shumrān selbst, wie ich damals glaubte). Aus diesem Blickwinkel wird verständlich, daß Hawāla am Nordrand des 'Asīr eine ähnliche Art von Frontsiedlung oder Wehrdorf darstellt wie im Süden al-Sūda entlang der Route zwischen Abhā und Sha'bayn. Das einheitliche Dach mehrerer direkt aneinander gebauter Häuser dient auch hier der kollektiven Verteidigung, die geringere Anzahl von Häusern wird durch die Kapazitäten der Verteidigungslinien von Wehrtürmen, die im nördlichen Abschnitt insgesamt besonders häufig auftreten, mehr als wettgemacht. Hawāla ist also keineswegs typisch für die lokale Architektur des Nord-'Asīr, sondern wiederum eine spezifische, tribale Sonderform von Frontsiedlung an einem strategisch bedeutsamen Ort.

Insgesamt bildet der Nordabschnitt mit der Begrenzung durch die beiden Bögen der W. Tayya und Qanūna ein langgezogenes, aber sehr schmales Band, dessen Ausmaße die agroklimatische Grundlage erkennen lassen. Die vorgelagerten Tihāma-Berge sind weniger ausladend als im Südwesten und liegen näher am Grabenrand, in dessen unmittelbarem Bereich die Hauptniederschläge abgehen. Dadurch sind auch die sanfteren Partien der eigentlichen Steilabfälle (asdar) und die dort abgehenden Zuläufe zu den Tihāma-Wādīs wirtschaftlich nutzbar. Der Hauptkamm bildet mehrere Bergkanten entlang des, oder hinter dem Grabenrand (J. Man`a, J. Marīr) und breite intermontane Becken (shu'ul). Nach Osten hin treten die Zuläufe zum W. Bīsha aber relativ abrupt in die semiariden Gebiete ein.

Ein schmales, langgezogenes Verbreitungsgebiet mit niedrigen Wohnbauten ist also das erste Kennzeichen der Architektur im nördlichen Abschnitt. Auch die geringere Haushöhe hat primär klimatische Gründe. Intensivere, längere Niederschlagsperioden und kühle, im Winter auch nebelige Jahreszeiten verlangen hier kaum mehr nach Kühlung durch Obergeschoße. Ganz im Gegenteil bieten die größere Nähe zum Erdboden und insgesamt kleinere Räume hier bessere Möglichkeiten zur Bewahrung eines wärmeren Innenklimas. Bereits diese architektonischen Abstimmungen auf die agroklimatischen Verhältnisse verweisen auf eine ausgesprochene Übergangszone zum südlichen Hijāz.

Ein zweites Merkmal der Architektur im nördlichen Abschnitt ist durch das Siedlungsmuster gegeben. Die Wohnhäuser sind hier selten dicht aneinander gedrängt, und die damit vorherrschenden Streusiedlungen sind häufiger in den flachen, offenen Talsohlen errichtet. ${ }^{345}$ Die lose Anlage von niedrigen und daher als Einzelbau für bewaffnete Konflikte schlechter gerüsteten Wohnhäuser ergibt ein markantes defensives Defizit. Dieses wird

344 Gingrich 1983b: 95f., 100-102.

345 Aloshban 1987: $234 \mathrm{f}$. 
durch eine Viezahl strategisch günstig errichteter, hoher Wehrtürme an den Rändern, aber auch innerhalb der Siedlungen ausgeglichen. Zusätzlich zu den out-towers ist diese größere Bedeutung der in-towers als drittes, aus dem zweiten Merkmal resultierendes Kennzeichen der Architektur im Nordabschnitt anzusehen. Es signalisiert gleichfalls den Übergang zum südlichen Hijāza, wo aber lose Streusiedlungen (im Gegensatz zu den intowers) die Ausnahme darstellen.

Diese drei Merkmalsausprägungen der traditionellen Architektur im nördlichen Abschnitt sehe ich auf der Grundlage der veränderten agroklimatischen Rahmenbedingungen durch wirtschaftliche und historische Umstände beeinflußt. Die intramontanen Bekken, breiten Wādī-Sohlen und die flachen Hänge des Nord-'Asīr bieten zum einen die für den 'Asīr ansonsten außerordentlich seltene Möglichkeit, Regenfeldbau in größerem Umfang entweder auf breiten, niedrigen Terassen oder überhaupt auf flachen Feldern zu betreiben (Abb. 98). Zugleich ist dieses fruchtbare Terrain aber schwierig zu verteidigen. Dies und die größere Nähe zum Hijā̄z, zu al-Qunfudha im Westen und zu Bīsha im Nordosten, scheinen äußere Staatseinflüsse hier früher und kontinuierlicher ermöglicht zu haben. Hinzu kommt, daß die Gebiete der (nördlichen) Banū l-Hajar und ihrer nördlichen Nachbarstämme wie den Shumrān an zwei Abschnitten des Grabenrandes von der Küste aus ziemlich leicht zugänglich sind: Im erwähnten Gebiet der Qanūna-Bogens bei Hawāla im Norden und weiter südlich im Bereich des W. Khaṭ vor al-Namāṣ ist der Abstieg des Grabenrandes jeweils soweit aufgelöst, daß relativ bequeme, traditionelle Routen von der Tihāma aus eingerichtet werden konnten. All dies scheint bereits regelmäßigere Einflüsse der Sharīfen von Mekka und der ersten beiden saudischen Staaten ermöglicht zu haben, und hat jedenfalls vor 1919 stabilere türkische Kontrolle als im übrigen 'Asīr gewährleistet: In dieser Periode errichteten die Osmanen die Nachschubroute zwischen al-Qunfudha und al-Namāṣ durch das W. Khat über die 'aqabat Sinān (nach dem gleichnamigen Pascha), und bauten al-Namāṣ zu ihrer zentralen Garnison im Nord-'Asīr aus. ${ }^{346}$ Aus dieser Sicht sind die loseren Streusiedlungen im offenen Terrain mit dorfnahen out- und in-towers möglicherweise die materiellen Zeichen von längeren historischen Perioden des Friedens zwischen örtlichen Verbänden der Stämme und Nachfahren des Propheten mit den genannten Staatsmächten. Im Detail konnte ich an den traditionellen Wohnbauten im nördlichen Abschnitt bisher keine weiteren, für sie spezifischen Merkmale feststellen. Vielmehr verweist die Konstruktion der Einzelhäuser deutlich auf die Architektur zweier Nachbarregionen - nämlich jene des einfachen Küstenstils in der Tihāma und die des südlichen Hịjāz.

Am Nordwestrand des nördlichen Abschnittes reicht der einfache Küstenstil (Formen 2A und 2B aus Tab. 1) bis in das Hochland herauf. Dies gilt für die Hochlandgebiete am Rand jener aufgelösten, sanfteren Teile des Steilhanges über dem W. Khat und seinen Zuflüssen, und östlich des Oberlaufes des W. Qanūna, das von hier nach al-Qunfudha entwässert. So setzt sich vom Garnisonsmarkt al-Majārida am Eingang des W. Ghayl nach Osten eine dann mehr und mehr durch Häuser vom Hijāz-Subtypus unterbrochene Abfolge von derartigen Formen des einfachen Küstenstils fort, die bis knapp vor al-Namāṣ reicht (Abb. 68). ${ }^{347} \mathrm{Im}$ Gebiet der B. Shiḥr sind bis zu fünfzig dieser kleinen Wohnhäuser durch zwei Wehrtürme bewacht.

\footnotetext{
346 cf. auch Abdulfattah 1981: Abb. 20, der diese Hausform aber irrtümlicherweise dem Hijāāz und nicht dem Küstenstil zuordnet.

347 Aloshban 1987: 239.
} 
Was diese Form noch mit der Architektur des 'Asīr gemeinsam hat, sind das Steinmaterial und die Verbindung mit den hohen Wehrtürmen. Ansonsten entsprechen die Wohnhäuser aber jenen der Garnisonsmärkte in der Tihāma. Statt aus Ziegeln sind die leicht geneigten Mauern hier also aus glatt und regelmäßig behauenem Stein errichtet, und bilden ein- oder zweigeschoßige, niedrige Bauten. Sofern es sich um Ziegelbauten handelt, stellen sie eine direkte räumliche Extension des Küstenstils dar; Steinbauten dieser Art wären hingegen als Mischformen anzusprechen. Die Mauern sind fast durchwegs weiß verputzt, und die Ecken der Mauerkronen tragen dekorative Zinnen. Charakteristischerweise haben diese Häuser in der Regel keinerlei Schießscharten, sondern größere, verschließbare Fensteröffnungen.

Von allen Wohnbauten des 'Asīr sind die Mischformen des Küstenstils am wenigsten auf bewaffnete Konflikte eingerichtet, die gesamte Defensivfunktion wird in diesen Fällen von den in-towers und dorfnahen out-towers als vollspezialisierter architektonischer Form übernommen.

Dies stellt also die erwähnte regionale Ausnahme zur defensiven Hochbauweise des 'Asīr dar, von der hier nur die hohen Wehrtürme bewahrt sind. Die soziale Zusammensetzung der Bewohner dieser Mischformen bestätigt den angedeuteten historischen und wirtschaftlichen Hintergrund der Architektur des nördlichen Abschnittes. Es handelt sich zum einen um Gruppen von Handwerkern und Hirten von traditionell niedrigem, nicht-tribalem sozialen Status, die sich hier entlang einer politisch-militärisch gesicherten Verbindungsroute zu wohlhabenden Agrargebieten niedergelassen haben. Zum anderen sind die Bewohner aber auch tribale Angehörige der Banū 'l-Hajar, darunter Nachkommen ihrer ehemals halbnomadischen Untergruppen der Tihāma, aber auch Familien von ärmeren Bauern und einzelnen Kaufleuten aus dem Hochland. Insgesamt interpretiere ich diese einfachen und nahezu schutzlosen weißen Bauten als materialisierte Erscheinung von sozialen Verhältnissen, die auf der Grundlage einer wohlhabenden agrarischen Wirtschaft auch eine tribale Unterschicht hervorgebracht und von außen angezogen haben. In der Nähe der Wohnorte dieser tribalen Unterschicht haben sich Vertreter der Dienstleistungsgruppen niedergelassen. Schon die Mischformen zum Küstenstil weisen kaum Dekorierung auf, sieht man von den Eckzinnen (und dem weißen Verputz) ab. Die zweite Form von Wohnbauten im nördlichen Abschnitt ist ebenfalls äußerst spärlich dekoriert. Dies ist zugleich ihr wichtigster Unterschied zur üppiger dekorierten Steinarchitektur im Hauptteil des südlichen Hijāz. Ansonsten gleichen die defensiven Wohnbauten des Nordabschnittes weitgehend dem Subtypus des Bl. Ghāmid wa Zahrān. Ein- bis zweigeschoßige, selten dreigeschoßige, unverputzte Bauten aus roh behauenem Stein sind auch hier die Regel. Die mehrgeschoßigen Bauten haben bereits über der einfachen, tragenden Grundmauer im Obergeschoß die dekorierten Stützsäulen aus Holz ('ar'ar oder talḥ), die für den südlichen Hijāaz dann typisch sind. ${ }^{348}$ Nur die Bemalung mancher Mauerkronen und defensive Eckzinnen erinnern an die Wohnarchitektur der Hauptteile des 'Asīr im Süden. Auf den Oberhängen der isolierten, vorgelagerten Tihāma-Berge und im Gebiet des W. al-Ghayl und von al-Sumayd treten vereinzelt runde, ein- oder zweistöckige Steinbauten mit Flachdach (wie am J. Fayfā im Südwesten) auf, die auch hier auf enge Bezüge zu den 'ushash-Mischformen der Tihāma hinweisen. ${ }^{349}$

\footnotetext{
348 Thesiger 1947: 198.
}

349 Aloshban 1987: 251. 
Unter den Turmformen gehören einzelne Schachttürme bei al-Namāṣ zu den wenigen Bauten des nördlichen Abschnittes, die nicht um eine einfache Stützmauer errichtet sind. Auch einige der mehrstöckigen, aber nicht defensiven traditionellen Wohnbauten mancher Sāda-Familien in al-Namāṣ haben Innen- oder Zwischenschächte. ${ }^{350}$ Der reiche Schnitzdekor an den hölzernen Eingangstüren dieser Häuser verweist wiederum auf die typischen Merkmale der Architektur im südlichen Ḥijāz. ${ }^{351}$

Neben den Schachttürmen bei al-Namāṣ sind vier andere, tribale Turmformen im nördlichen Abschnitt unterschieden worden. Runde, niedrige Steintürme an den Ostabhängen (dawāyir) dienen den dortigen, halbnomadischen Gruppen als Markierungen und Bewachung ihrer Territorien; die hohen viereckigen out-towers (mashūr) im Gebiet des Hauptkammes dienen zum erwähnten Schutz der Siedlungen nach außen. Schließlich tragen in-towers die Bezeichnung „hụsn midā ${ }^{c}$ wa ḥarb“, was auf ihre defensive Funktion für Krieg und Fehde, aber auch auf ihre wirtschaftliche Bedeutung zur Lagerung von Vorräten verweist. Diese in-towers können bis zu $12 \mathrm{~m}$ Höhe erreichen und eine Dicke der Grundmauern von $1 \mathrm{~m}$ haben. Sie sind üblicherweise unbewohnt und Eigentum von Einzelhaushalten, aber auch von ganzen Gruppen, die sich dorthin in Zeiten des Konfliktes zurückziehen können. ${ }^{352}$ Diese „Fluchtburgen“ sind das erwähnte komplementäre Gegenstück zu den mangelnden Defensiveinrichtungen der Einzelhäuser. Das Miteinander von vielen, kaum defensiven und verstreuten Einzelhäusern mit wenigen dieser in-towers deutet an, daß größere Konflikte hier in rezenter Zeit eher die Ausnahme dargestellt haben dürften. Als Wohnform von Familien der tribalen Führungsschichte schließlich treten auch im Bl. al-Hajar jene weißen verputzten Wehrtürme mit vorspringendem Holzbalkon auf, die für Häuptlingsfamilien des südlichen Hijāaz traditionell üblich waren. ${ }^{353}$

In gewißer Weise sind also die tribalen Wehrtürme als Fluchtburgen in oder bei Streusiedlungen das einzige spezifische Merkmal der traditionellen Architektur im nördlichen Abschnitt des 'Asīr, das ich bisher feststellen konnte. Alle anderen Elemente oder Eigenschaften sind zum geringen Teil auch im südlichen Abschnitt vertreten (Schachttürme, Zinnen und Bemalung der Mauerkronen). Ältere, einfache Formen einfärbiger (brauner und roter) Binnenbemalung sah ich vereinzelt in Wohnhäusern der B. Shihr und Shumrān. Über Innenbemalung in dieser Region liegen mir ansonsten aber keine Angaben vor. Der Großteil der lokalen Architektur und ihrer Elemente repräsentiert entweder Kontinuität nach Norden hin, oder im Westen Misch- und Übergangsformen zur Tihāma (einfacher Küstenstil und Rundformen mit Flachdach). Diese eben nicht nur ökologisch bedingte Übergangssituation wird auf manchen Türmen durch eine spezifische Dekorierung mit weißem Zierstein gleichnishaft symbolisiert (Taf. XLVII). Diese Dekorform nimmt eine interessante Zwischenstellung ein, die zwischen den dominanten Formen des südlichen Hijā̄z und jenen im Gebiet der 'Asīr-Föderation liegt. Im Bilād Ghāmid wa Zahrān dominiert die Form eines mit der Spitze nach oben gerichteten, gleichschenkeligen Dreiecks als Steindekor auf den Turmbrüstungen. Für die Steindekoration der Architektur im Gebiet der 'Asīr-Föderation wurden andererseits die Kronen- und Rahmenfelder als typisch nachgewiesen, in denen Quadrate, waagrechte und senkrechte Linien vorherrschen

350 cf. auch ibid.: 430.

351 King 1976: 23.

352 Aloshban 1987: 249-251.

353 King 1976: 24; Gingrich 1983b: 104-106. 
und die schräge Gerade kaum vorkommt. Im nördlichen Abschnitt schließlich tritt an den Wehrtürmen der B. al-Hajar manchmal ein Dekor auf, der Elemente von beiden kombiniert: Zwischen parallele, senkrechte und waagrechte Linien sind Dreiecke gesetzt, deren Spitzen selten nach oben und häufiger auf die Seite gerichtet sind..$^{354}$

Die Sprache des Dekors expliziert damit, was die Architektur selbst implizit zum Ausdruck bringt. Die seitlichen Dreiecke zwischen den Linien trennen und verbinden die aufrechten Dreiecke im Nordwesten und die dominanten Vierecke im Südwesten. Der Dekor definiert die lokale Architektur als ausgesprochene Übergangsform zwischen 'Ası'r und Hijāz.

\section{Zusammenfassung zur Steinarchitektur des 'Asīr}

In Tab. 16 (S. 374) sind die Hauptergebnisse dieses Abschnittes zur Steinarchitektur des 'Asīr nochmals zusammengestellt worden. Die Architektur jeder der hier untersuchten Regionen (südwestliche Tihāma-Berge/J. Fayfā; westliche Tihāma-Berge/ J. Șalab; nördlicher bzw. südlicher Abschnitt des Nord-'Asīr) ist in einem der vier Felder (I-IV) von Tab. 16 nach gemeinsamen Gesichtspunkten aufgeschlüsselt, nämlich nach den Kriterien Siedlungsmuster, Wohnhäuser, Turmformen, Dekor und lokalen Sonderformen. Auf dieser Grundlage lassen sich in den Feldern I und III (also in der linken, senkrechten Spalte) die Bauformen der vorgelagerten Tihāma-Berge miteinander vergleichen, in den Feldern II und IV (rechte Spalte) jene des Nord-'Asīr, und in den Feldern III und IV (also in der unteren, waagrechten Spalte) die Bauformen des zentralen 'Asīr. Jenseits der materialbedingten Eigenschaften, die der Steinarchitektur als Variante defensiver Hochbauweise gemeinsam sind, weist sie unter allen Varianten des 'Asīr also die größten inneren Unterschiede auf.

Diese Abwandlungen treten nach allen fünf Vergleichskriterien auf - im Siedlungsmuster, nach Höhe und Grundriß der Wohnhäuser, bei den Turmformen und im Dekor. Per definitionem charakterisieren die lokalen Sonderformen diese Abwandlungen in Form von markanten, nur im jeweiligen Verbreitungsgebiet auftretenden Formen. Auf die Interdependenz von Siedlungsmuster, Wohnhaus- und Turmform ist kontinuierlich hingewiesen worden, diese Triade interagiert zugleich mit Geomorphologie und Klima, Sozialorganisation, Konfliktstruktur und rechtlich-politischen Verhältnissen. Im Zentrum der Analyse stand aber das Einzelwohnhaus, das ja auch im wirklichen Leben zentraler Bezugsort der Bevölkerung ist und demgemäß als entscheidendes Differenzierungselement heranzuziehen ist. Nichtsdestotrotz stellt die große Unterschiedlichkeit von Siedlungsmustern und besonders der Turmformen per se bereits eine deutliche Differenz der Steinarchitektur zu den beiden anderen Varianten des 'Asīr dar.

Zusätzlich zum Einzelwohnhaus als primäres kann der Dekor als sekundäres Differenzierungsmerkmal dienen, dem innerhalb der jeweiligen technischen Gegebenheiten sowie der sozialen und ökologisch-ökonomischen Rahmenbedingungen eine gewisse Eigenständigkeit zukommt. Bei Anwendung dieser methodischen Überlegungen ergibt sich erstens die Frage, ob die weitere Differenzierung der Variante überhaupt zu sinnvollen Ergebnissen führt oder nicht zur bloß formalen Fingerübung wird. Mir scheinen die vorliegenden Materialien ausreichende Belege dafür zu bieten, daß eine analytische Untergliederung

354 Aloshban 1987: $442 \mathrm{f}$. 
sinnvoll und möglich ist - wenn sie die primäre Abhängigkeit der Architektur von ihren materiellen und sozio-politischen Rahmenbedingungen positiv akzeptiert, und nicht von diesen künstlich isoliert. Das bedeutet aber, daß man die Ausgestaltung einer „Form“ nicht deswegen für ungeeignet zur Differenzierung erklären kann, weil in diese formale Ausgestaltung äußere Rahmenbedingungen und innere technische Zwänge einfließen. Vielmehr hat die formale Differenzierung eben dieses Einfließen äußerer Bedingungen und innerer Zwänge in die Analyse zu integrieren. Zweitens ergibt sich die Frage, ob die bisher getroffene Differenzierung nach geographisch-ökologischen Subregionen des 'Asīr ausreicht. Diese Frage ist eindeutig zu verneinen. Die geographisch-ökologischen Bedingungen haben uns zwar einen nützlichen ersten Überblick über die räumliche Verbreitung der Steinarchitektur geliefert und uns auf wichtige Teilaspekte der Abwandlung von Siedlungsmuster und Wohnhausformen hingwiesen. Die vorliegenden Materialien zeigen aber, daß die sozialanthropologische praktische Analyse weit darüber hinausgeht. Im wesentlichen ergibt die Anwendung des primären und sekundären Differenzierungsmerkmals auf die präsentierten Ergebnisse also folgende Resultate:

Die Wohnhäuser im Feld III und IV (Rijāl Almāc und Südabschnitt des Nord-'Asīr) weisen, wie schon in den betreffenden Abschnitten ausgeführt, wesentliche Übereinstimmungen auf - in beiden Fällen dominieren ausschließlich rechteckige Grundrisse und die defensive Hochbauweise; in-towers treten nicht auf. Innen- und Zwischenschachtbauten machen einen differierenden, aber vorhandenen Anteil der Wohnbauten aus. Bewohnbare, rechteckige Türme sind seltene strategische Einrichtungen, die aber gleichfalls nur in diesen beiden Feldern auftreten. Diese konstruktiven Gemeinsamkeiten der Wohnhäuser in Feld III und IV kommen im Unterschied zu den Eigenschaften der Wohnhäuser in den Feldern I und II (J. Fayfa und Nord-'Asīr) zugleich den generellen Eigenschaften des allgemeinen Subtypus am nächsten, welche auch die Pagoden- und Adobe-Varianten prägen. Daher sind die Architektur der westlichen Tihāma-Berge des 'Asīr (Rijāl Almac) und jene des fast benachbarten Südabschnittes des Nord-'Asīr entlang der Shifā (Nordgruppe der 'Asīr-Föderation und Subgruppe der Banū 'l-Hajar) als eine einheitliche Subvariante anzusehen - jene der Steinarchitektur des Zentral-'Asīr. Die Dekorierung verläuft dazu synchron und belegt, daß diese Bestimmung der Subvariante mehr ausdrückt als nur räumliche Nähe und technische Parallelen. Die Außenbemalung der Mauerkronen, vor allem aber der weiße Steindekor mit seinen Grundmotiven der Rahmen- und Kronenfelder aus senkrechten und waagrechten Linien stellen eine explizite Verbindung dieser beiden Formen von Architektur des Zentral- ${ }^{\circ}$ Asīr dar. Ihre gemeinsame Affinität zu den generellen konstruktiven Eigenschaften des Subtypus und der beiden anderen Varianten wird ebenfalls dekorativ expliziert, und zwar durch die hier regelmäßig gegebene bunte Innenbemalung der dīwāne. Der Steindekor verbindet also ebenso wie ihre konstruktiven Eigenschaften die Wohnhausarchitektur von Feld III mit jener von Feld IV zu einer einheitlichen Subvariante, und die bunte Innenbemalung, wie auch die konstruktiven Gemeinsamkeiten dieser Subvariante verbinden sie darüber hinaus noch mit den anderen beiden Varianten. Die örtlichen Unterschiede zwischen Feld III und IV gehen zum Teil auf ökologische Besonderheiten zurück (Höhenzonen der Bergmassive), zum Teil auf den Sonderstatus der politisch-rechtlichen Verfassung der Rijāl Alma ${ }^{c}$ und deren wirtschaftliche Grundlagen, und schließlich auf strategische Perfektionierung an bestimmten Orten (alSūda). Die „Streifentürme“ des zentralen Hochlandes sind ein lokales Pendant zur Abwesenheit der out-towers bei den Rijāl Almac. 
Trotz des rechtlich-politischen Sonderstatus der Rijāl Alma ${ }^{c}$ überwiegen also die Gemeinsamkeiten der Wohnarchitektur des Zentral-`Asīr eindeutig. Damit läßt sich diese als zentrale Subvariante klassifizieren. Hingegen ergibt die gemeinsame Position auf vorgelagerten, isolierten Tihāma-Bergen keine entscheidende konstruktiven und dekorativen Parallelen zwischen der Architektur der Rijāl Alma ' (Feld III) und jener der nordwestlichen Khawlān und ihrer Nachbargruppen im Südwesten (Feld I).

Die eine Gemeinsamkeit zwischen beiden Feldern ist eine Differenzierung von Siedlungsmuster und Geschoßanzahl gemäß der Höhenstufe. Aber davon abgesehen sind die Eigenschaften von Wohnarchitektur und Dekor am J. Fayfā und J. Salab dermaßen voneinander abgehoben, daß als Ergebnis dieses Vergleiches bereits von der Existenz einer eigenständigen Subvariante im äußersten Südwesten ausgegangen worden ist. Die niedrige Anzahl der Geschoße und damit korrespondierend die Abwesenheit von Innen- und Zwischenschachtbauten sowie das häufige Vorkommen von in-towers haben zwar zum Teil klimatische Ursachen, gehen aber auch auf eine andere innere Sozialstruktur zurück, in der intratribale Fehden eine weitaus größere Rolle spielen als bei den Rijāl Almac. Die Häufigkeit des runden Grundrisses ist eine von mehreren Sonderformen, die nur auf manchen anderen isolierten Tihāma-Bergen des nördlichen Abschnittes (Feld II) seltene Parallelen hat. Diese und andere ausgeprägte Sonderformen der Fayfa-Architektur von Feld I (Spiralenturm, Kegelturm mit oberer Außentreppe) sind auf die spezifische Vorgeschichte und die vergessene Herkunft der nordwestlichen Khawlān zurückgeführt worden. Diese architektonische Subvariante weicht nicht nur von jener des Zentral-'Asīr ab, sondern damit auch signifikant von den generellen Eigenschaften des Subtypus und der beiden anderen Varianten.

Die architektonische Subvariante der nordwestlichen Khawlān repräsentiert damit eine vom zentralen Muster abweichende, marginale und periphere Form. ${ }^{355}$ Sie hat ihre materielle Begleiterscheinung in der weitgehenden Abwesenheit solcher Bauten und Siedlungsmuster, die in den Feldern II, III und IV auf die kontinuierliche Existenz überregionaler Staatsmächte und die Auseinandersetzung mit ihnen zurückverweisen (insbesondere: Schachttürme, aber auch Bauten der Sāda). Nur das sporadische Vorkommen der bunten Innenbemalung überschreitet die periphere Form und verbindet sie mit dem gesamten Subtypus.

Feld I repräsentiert also eine „periphere“ Subvariante, Felder III und IV umfassen jene „zentrale“ Subvariante, die dem generellen Subtypus am nächsten steht, und Feld II schließlich beschreibt eine ausgesprochene Übergangs- und Mischform zwischen diesem Subtypus und jenem des südlichen Hijāāz (sowie dem Küstenstil). Die geringe Höhe der Wohnbauten dieses nördlichen Abschnittes hat primär agroklimatische Ursachen. Diese führt zur wichtigen architektonischen Differenz der Abwesenheit tragender Innenmauern und ihrer hier bereits häufigen Ersetzung durch hölzerne Stützsäulen. Die tiefliegenden, großen Streusiedlungen und die hier ins Hochland heraufreichenden Mischformen des einfachen Küstenstils sind jeweils als materielle Ausprägungen einer wohlhabenden, aber nach unten hin sozial differenzierten agrarischen Gesellschaftsstruktur identifiziert worden, die kontinuierlichem Staatseinfluß und Handelsverkehr mit der Küste ausgesetzt

355 Gingrich 1989: $100 \mathrm{f}$. 
war. Die Sonderform von Hawāla ist zum Schutz einer dieser Routen entwickelt worden und stellt eine Parallele zu al-Sūda in der „zentralen“ Subvariante dar.

Tab. 16: Vergleich der traditionellen Steinarchitektur des 'Asīr

\begin{tabular}{|c|c|c|}
\hline Steinarchitektur & $\begin{array}{l}\text { periphere Subvariante } \\
\text { Feld I }\end{array}$ & $\begin{array}{l}\text { transitorische Subvariante } \\
\text { Feld II }\end{array}$ \\
\hline Regionale Verbreitung & $\begin{array}{l}\text { südwestliche Tihāma-Berge des 'Asīr: } \\
\text { Nordwestgruppe der Khawlān b. } \\
\text { 'Amīr und Nachbargruppen (J. und } \\
\text { Ahl Fayfā) }\end{array}$ & $\begin{array}{l}\text { nördlicher Abschnitt des } \text { Nord-`Asīr }^{`} \\
\text { entlang der Shifā: Nordgruppen der } \\
\text { Banū l-Hajar und Nachbargruppen }\end{array}$ \\
\hline Siedlungsmuster & $\begin{array}{l}\text { untere Lagen: Einzelhöfe } \\
\text { obere Lagen: kleine Weiler }\end{array}$ & tiefgelegene, große Streusiedlungen \\
\hline Wohnhäuser (Höhe, Grundriß) & $\begin{array}{l}\text { untere Lagen: 3- bis 4geschoßig, } \\
\text { rechteckig obere Lagen: } \\
\text { lgeschoßig, rund-, rechteckig } \\
\text { 2geschoßig, rund-, rechteckig } \\
\text { 3geschoßig, rechteckig } \\
\text { kaum Innen- und Zwischenschacht- } \\
\text { bauten }\end{array}$ & $\begin{array}{l}\text { 1- bis 3-geschoßig, rechteckig } \\
\text { auf vorgelagerten Tihāma-Bergen: } \\
\text { auch rund } \\
\text { Mischformen zu Küstenstil und Subty- } \\
\text { pus des südlichen Hijāz } \\
\text { kaum Innen- und Zwischenschacht- } \\
\text { bauten }\end{array}$ \\
\hline Turmformen & $\begin{array}{l}\text { untere Lagen: hofnahe } \\
\text { obere Lagen: in-towers }\end{array}$ & $\begin{array}{l}\text { out-towers: runde dawāyir im Osten } \\
\text { viereckige mashūr } \\
\text { in-towers: husūun midāc wa harb - } \\
\text { Fluchtburgen } \\
\text { weiße hușūn mit Balkonen der triba- } \\
\text { len Oberschicht }\end{array}$ \\
\hline Dekor & $\begin{array}{l}\text { wenig bunte Innenbemalung } \\
\text { Steindekor: kaum vorhanden }\end{array}$ & $\begin{array}{l}\text { wenig bunte Innenbemalung } \\
\text { Steindekor: senk- und waagrechte Li- } \\
\text { nien mit seitwärts gerichtetem Drei- } \\
\text { eck }\end{array}$ \\
\hline \multirow[t]{3}{*}{ Lokale Sonderformen } & $\begin{array}{l}\text { sehr elaboriert: Spiralenturm, Kegel- } \\
\text { turm mit oberer Außentreppe, häufi- } \\
\text { ger: runder Grundriß; keine Schacht- } \\
\text { türme }\end{array}$ & Fluchtburgen, Hawāla, al-Namāṣ \\
\hline & \multicolumn{2}{|c|}{ zentrale Subvariante } \\
\hline & Feld III & Feld IV \\
\hline Regionale Verbreitung & $\begin{array}{l}\text { westliche Tihāma-Berge des 'Asīr: } \\
\text { Rijāl Alma', Nordwestgruppe der } \\
\text { 'Asīr-Föderation (J. und Ahl Șalab) }\end{array}$ & $\begin{array}{l}\text { südlicher Abschnitt des Nord-'Asīr } \\
\text { entlang der Shifā: Nordgruppe der } \\
\text { 'Asīr-Föderation und Südgruppe der } \\
\text { Banū 'l-Hajar }\end{array}$ \\
\hline Siedlungsmuster & $\begin{array}{l}\text { Einzelhöfe, als nahe beisammen ste- } \\
\text { hende riesige Streusiedlung (außer in } \\
\text { tiefen Lagen) }\end{array}$ & $\begin{array}{l}\text { isolierte Einzelhöfe, Streusiedlungen, } \\
\text { kompakte Dorfanlagen }\end{array}$ \\
\hline Wohnhäuser (Höhe, Grundriß) & $\begin{array}{l}\text { rechteckig, breit, } 3 \text { - bis } 4 \text { geschoßig } \\
\text { tribale Oberschicht: } 4 \text { geschoßig } \\
\text { zahlreiche Innen- und Zwischen- } \\
\text { schachtbauten }\end{array}$ & $\begin{array}{l}\text { rechteckig, } 3 \text { - bis } 4 \text { geschoßig, manch- } \\
\text { mal 5geschoßig } \\
\text { tribale Oberschicht: Innen- und Zwi- } \\
\text { schenschachtbauten }\end{array}$ \\
\hline Turmformen & $\begin{array}{l}\text { keine } \text { in-towers } \\
\text { wenige } \text { out-towers in niedrigen Lagen }\end{array}$ & $\begin{array}{l}\text { keine } \text { in-towers } \\
\text { out-towers: Streifentürme }\end{array}$ \\
\hline Dekor & $\begin{array}{l}\text { bunte Innenbemalung } \\
\text { weiße Bemalung von Mauerkronen } \\
\text { Steindekor: Rahmen- und Kronenfel- } \\
\text { der (waag- und senkrechte Linien) }\end{array}$ & $\begin{array}{l}\text { bunte Innenbemalung } \\
\text { weiße Bemalung von Mauerkronen } \\
\text { Steindekor: Rahmen- und Kronenfel- } \\
\text { der (waag- und senkrechte Linien) }\end{array}$ \\
\hline Lokale Sonderformen & $\begin{array}{l}\text { Sarha, ummauerte Abflüsse } \\
\text { Madīnat Rijāl Almac', rechteckige be- } \\
\text { wohnbare Türme in tiefen strategi- } \\
\text { schen Lagen }\end{array}$ & $\begin{array}{l}\text { al-Suda } \\
\text { bewohnbare, rechteckige Türme in } \\
\text { strategischen Lagen }\end{array}$ \\
\hline
\end{tabular}


Die hohen Fluchtburgen (ḥuṣūn midā’a wa ḥarb) geben diesem langgezogenen Verbreitungsgebiet allerdings auch eine gewiße eigenständige Note. Diese relative Eigenständigkeit unterstreicht der spärliche Dekor: Bunte Innenbemalung ist hier offenbar nicht gegeben, der weiße Steindekor hingegen kombiniert die dominanten Dreiecke des Hijāz mit den senkrechten und waagrechten Linien des Zentral-'Asīr.

Das erste Ergebnis unserer vergleichenden Analyse ist also die außerordentliche Heterogenität der Steinarchitektur des 'Asīr gegenüber der relativen Homogenität von Adobe- und Pagoden-Variante. Als zweites Ergebnis liegt nun die nähere Bestimmung dieser heterogenen Variante vor. Unterschieden werden können eine periphere, eine zentrale und eine transitorische Subvariante. Die zentrale Subvariante ist in sich ebenfalls nuanciert, aber dem gesamten Subtypus am nächsten. Die periphere Subvariante erweist sich nicht bloß als marginal zu dieser zentralen Subvariante der Steinarchitektur, sondern auch zu den übergreifenden Eigenschaften des gesamten Subtypus von defensiver Hochbauweise im 'Asìr und $W$. Najrān. Sie stellt aber keine Mischform dar, sondern repräsentiert eine eigenständige, abweichende Peripherie, die Hinweise auf den rezenten Charakter der Homogenisierungsprozesse im Hochland zurückzuspiegeln vermag. Demgegenüber repräsentiert im Nord-'Asīr die transitorische Subvariante ein Zwischenglied zwischen diesem Subtypus von Architektur im 'Asīr und W. Najrān und dem zweiten Subtypus im südlichen Hijāz.

Aufbauend auf diesen ersten beiden Ergebnissen kann nun drittens der Zusammenhang zwischen tribalen Territorien und der Verbreitung dieses Elementes materieller Kultur erneut thematisiert werden. Zunächst ist festzustellen, daß das langgestreckte Verbreitungsgebiet dieser Variante (Steinarchitektur) nicht mit den tribalen Territorien der Region übereinstimmt - ebensowenig, wie dies in den beiden anderen Fällen der Adobe- und Pagoden-Variante gegeben ist.

Allerdings existiert ein ausgeprägter Zusammenhang zwischen ihren drei Subvarianten und den jeweiligen tribalen Föderationsgebieten. Dieser Zusammenhang ist aus Tab. 17 ablesbar. Die Verbreitung der peripheren Subvariante deckt sich am deutlichsten, nämlich mit dem Gebiet der nordwestlichen Khawlān. Die zentrale Subvariante korrespondiert zu einem geringeren Grad mit den Nordwest-Territorien der 'Asīr-Föderation. Schließlich decken sich nur kleine agrarische Teilgebiete der Banū l-Hajar, die aber von einem Großteil dieser Föderationsbevölkerung besiedelt sind, mit der räumlichen Verteilung der transitorischen Subvariante. Die Korrespondenz zwischen architektonischem Verbreitungsgebiet und tribalem Territorium ist also bei der peripheren Subvariante am ausgeprägtesten und für die transitorische Subvariante am wenigsten gegeben.

Die Unterschiedlichkeit dieser relativen Korrespondenzen zwischen Subvarianten und tribalen Territorien scheint wenigstens teilweise einer unterschiedlichen äußeren Überformung durch historische Staatseinflüsse und deren Konsequenzen zu entsprechen. Diese Staatseinflüsse haben sich im Südwesten sehr rezent herausgebildet, während sie im Norden durch größere historische Kontinuität charakterisiert sind. Teilweise in Wechselwirkung mit diesen historischen Staatseinflüssen, und teilweise unabhängig davon dürften tribale Abspaltungen, strategische Expansionen und Bündnisschlüsse im semiariden Übergangsgebiet des Berglandes von Nord- wie von Südost-'Asīr für die dortige Ausgestaltung der tribalen Territorien verantwortlich gewesen sein: Dies betrifft die weiten Ausläufer von Stammesgebieten der Banū l-Hajar, Shahrān oder Qaḥtān nach Innerarabien und in die Tihāma, wo die defensive Hochbauweise des Hochlandes jeweils in andere Wohnformen übergeht. 
Tab. 17: Zusammenhang von Subvarianten der Steinarchitektur mit tribalen Föderationsterritorien im 'Asīr

\begin{tabular}{|l|l|l|l|}
\hline Architektonische Subvariante (Stein) & peripher & zentral & transitorisch \\
\hline $\begin{array}{l}\text { tribale Föderationsterritorien } \\
\text { Korrespondenz im sozialen Raum }\end{array}$ & $\begin{array}{l}\text { Nordwest-Khawlān } \\
\text { ausgeprägter } \\
(\text { partiell +) }\end{array}$ & $\begin{array}{l}\text { Nordwest- }{ }^{c} \text { Asīr } \\
\text { partiell vorhanden }\end{array}$ & $\begin{array}{l}\text { Banū 'l-Hajar } \\
\text { schwächer } \\
\text { (partiell -) }\end{array}$ \\
\hline
\end{tabular}

Ungeachtet dieser und möglicher anderer Bedingungsfaktoren kann jedenfalls die Existenz von mehr oder minder deutlichen Zusammenhängen zwischen tribalen Föderationsterritorien und der Verbreitung von Subvarianten für die Steinarchitektur des 'Asīr festgestellt werden.

Dieses dritte Ergebnis läßt sich nun mit jenem Befund vergleichen, der für die beiden anderen Varianten getroffen wurde. Für die Adobe-Bauten konnte klar ein nicht existierender Zusammenhang zwischen ihrer Verbreitung und den Dimensionen tribaler Territorien konstatiert werden: Letztere haben sich unabhängig entwickelt von der negativen Begrenzung für erstere durch klimatische und geomorphologische Faktoren. Innerhalb dieser Grenzen stellt die Adobe-Variante ein regionalkulturliches Element des Ost-'Asīr und W. Najrān dar, das inter- und cross-tribalen Charakter hat. Gleichwohl sind die seßhaften Yām (im Bereich des W. Najrān) und größere Gruppen der Qaḥtān, Rufayda und Shurayf (nordwestlich des W. Najrān) solche tribalen Verbände, deren seßhafte Hauptteile nicht nur zur Gänze im Gebiet der Adobe-Variante liegen, sondern die auch ihrerseits den Hauptteil der Gesamtbevölkerung im Gebiet dieser Variante ausmachen. Das regionalkulturliche Element der Adobe-Bauten umfaßt also die Gesamtheit der seßhaften Gebiete mehrerer, miteinander nicht immer föderativ verbundener Stämme. Rund um diese tribalen Kernbereiche gruppiert sind andere tribale Teilgebiete (Sinhāan, andere Qaḥtān, Shahrān), die ebenfalls in Adobe-Bauten leben.

Tribale Kerngebiete und Teile anderer tribaler Territorien sind im regionalkulturlichen Raum der Adobe-Bauten gruppiert, die darin ihrerseits nach konstruktiven Gesichtspunkten relativ homogen auftreten. Dieser inter- und cross-tribale Charakter des architektonischen Verbreitungsgebietes gilt für die Pagoden-Variante in noch stärkerem Maß. In der Pagoden-Zone sind die Territorien der B. Mālik ('Asīr) zur Gänze, jene der B. Mughayḍ zum größeren Teil gruppiert, und schließlich Teilgebiete von Shahrān sowie von Rufayda, Jārimah und B. Bishr (alle Qaḥțān).

Die homogene Verbreitung der Adobe- und Pagoden-Bauten in inter- und cross-tribalen Siedlungsräumen ist für diese beiden Varianten charakteristisch. Demgegenüber ist die dritte Variante der Steinarchitektur äußerst inhomogen in drei Subvarianten gegliedert, die aber mehr oder minder ausgeprägt mit Föderationsterritorien korrespondieren (Tab. 18).

Tab. 18: Differenzierung der Architektur-Varianten und tribaler Territorialität im 'Asīr

\begin{tabular}{|l|l|l|l|}
\hline Varianten & Adobe-Bauten & Pagoden-Bauten & Steinarchitektur \\
\hline $\begin{array}{l}\text { architektonische } \\
\text { Differenziertheit }\end{array}$ & homogen & relativ homogen & $\begin{array}{l}\text { inhomogen, drei } \\
\text { Subvarianten }\end{array}$ \\
\hline $\begin{array}{l}\text { Korrespondenz } \\
\text { mit tribalen Territorien }\end{array}$ & inter- und cross-tribal & inter- und cross-tribal & $\begin{array}{l} \pm \text { partielle Korrespon- } \\
\text { denz zu Subvarianten }\end{array}$ \\
\hline
\end{tabular}


Für diesen Unterschied der Korrespondenz von architektonischen Varianten mit tribalen Territorien habe ich im Fortgang der Untersuchung zwei Erklärungsmuster angeboten, die einander keineswegs ausschließen, sondern verstärken. Das sozio-ökologische Erklärungsmuster hat auf die negativen Begrenzungsfaktoren für die jeweilige Variante verwiesen und auf die sozialen Voraussetzungen, durch welche innerhalb dieser Begrenzung bestimmte architektonische Formen privilegiert werden. Das historisch-politische Erklärungsmuster hat darauf aufbauend eine Reihe von Indizien für relativ rezente Homogenisierungsprozesse der Architektur als Teil der tribalen Kultur gesammelt. Diese Homogenisierungsprozesse scheinen die traditionelle Architektur des Hochlandes (einschließlich der transitorischen Subvariante im Nord-'Asīr) im Ergebnis stärker durchdrungen zu haben als die zentrale und periphere Steinarchitektur im Westen und Südwesten. Die Plausibilität der vorgeschlagenen Erklärungsmuster werden künftige Forschungen erweisen; die angesprochenen empirischen Befunde sind jedoch nicht zu ignorieren: Die größere Homogenität der Adobe- und der Pagoden-Varianten in ihren Verbreitungsgebieten beziehen sich als regionalkulturliche Elemente jeweils auf inter- und cross-tribale Territorialität, die heterogene Aufgliederung der Steinarchitektur in Subvarianten korrespondiert mehr oder minder mit zusammenhängenden tribalen Föderationsgebieten.

Vor dem Hintergrund dieser drei Ergebnisse kann im letzten Schritt dieser Zusammenfassung die innere Logik des Dekors der Architekturvarianten sowie deren Bezug zur Verbreitung der Subvarianten und zur tribalen Territorialität nochmals erörtert werden. Wir lassen also für einen Moment unberücksichtigt, daß der Dekor bereits als sekundäres Differenzierungsmerkmal in die Bestimmung der Subvarianten eingeflossen ist. Die Subvarianten ergeben sich im Prinzip bereits durch die konstruktiven Merkmale des Wohnhauses, auch ohne Berücksichtigung des Dekors. Wir können die Sprache des Dekors also so rekapitulieren, als ob sie zunächst unabhängig von der Konstruktion der Subvarianten artikuliert würde.

Für den Dekor der Steinarchitektur verdeutlicht Tab. 16 dreierlei: Erstens ist die bunte Innenbemalung auch hier gegeben. Sie verbindet vor allem die zentrale Subvariante und in geringerem Maß auch die peripheren und transitorischen Subvarianten mit dem analogen Dekor des übrigen 'Asīr. Das seltenere Auftreten dieser Dekorform in der peripheren und der transitorischen Subvariante ist eine Parallele zum abgesetzten Status dieser beiden architektonischen Subvarianten gegenüber dem gesamten Subtypus. Neben diesem Element im wertgeschützten Inneren schränken Klima und Material zweitens die Dekorierung der Fassaden sehr ein. Am üppigsten fällt sie wiederum in der zentralen Subvariante aus, wo die Streifentürme und die Bemalung der Hauskanten zusätzliche Lokalformen zum dominanten Motiv der Kronen- und Rahmenfelder abgeben. In der transitorischen Subvariante expliziert die Bescheidenheit der Zinnen (auf den Mischformen zum Küstenstil) und der Steindekor mit seitwärts gerichtetem Dreieck den Status zwischen den beiden Subtypen des Hijāa und 'Asīr. In der peripheren Subvariante schließlich steht die weitgehende Abwesenheit von Steindekor im umgekehrten Verhältnis zur Bewahrung architektonischer Sonderformen. Daraus ergibt sich aber drittens, daß der Code des Steindekors synchron zur Architektur angelegt ist: Die Kronen- und Rahmenfelder treten etwa nicht in der transitorischen Subvariante auf, die seitwärts gerichteten Dreiecke kommen nicht in der peripheren Subvariante vor. In der Steinarchitektur des 'Asīr hat also jede Subvariante ihren eigenen dekorativen Aspekt in Stein, einschließlich eines „NullWertes " in der Peripherie. 
Der ästhetische Code des Steindekors akzentuiert hier also nochmals die mehr oder minder gegebene Korrespondenz von architektonischen Subvarianten mit jeweiliger tribaler Territorialität. In der zentralen Subvariante unterstreichen manche seiner Elemente zusammen mit jenen der Bemalung darüber hinaus die innere soziale Hierarchie. Und schließlich verbindet die Innenbemalung alle drei Subvarianten auf unterschiedlich ausgeprägte Weise mit dem gesamten Subtypus.

Damit aber formuliert der Steindekor als spezifische Symbolik dieser Subvarianten einen etwas anderen Code als die Verzierungen der beiden anderen Varianten. Die Schindelreihen der Pagoden-Bauten deklarieren ein singuläres Gesamtkunstwerk, in dem Architektur und Dekor verschmelzen. Dieses Gesamtkunstwerk variiert etwas nach Osten hin, von wo zusätzliche Elemente des Dekors der Adobe-Bauten sich mit jenem der Pagoden-Bauten verbinden. Das homogene architektonische Gesamtkunstwerk der PagodenBauten kennt also keinen von der Architektur abgesonderten variantenspezifischen Dekor, und nur graduelle Variationen nach Osten hin. Die etwas heterogenere architektonische Variante der Adobe-Bauten reicht ihrerseits mit diesem Teil ihres üppigen, weitgehend abgesonderten und variantenspezifischen Dekors über ihr eigenes Verbreitungsgebiet hinaus; in anderer Hinsicht betonen ihre Dekorformen wieder die soziale Hierarchie. Ihr Hauptaspekt aber liegt auf der Betonung lokaler Unterschiede zwischen nordwestlichen und südöstlichen Regionen ihres Verbreitungsgebietes. In dieser Hinsicht betont also der variantenspezifische Dekor lokale Unterschiede, welche die homogene architektonische Form dieser Variante nicht selbst zum Ausdruck bringt.

Durch die Innenbemalung sind alle drei Varianten (mit der Ausnahme im W. Najrān) über eine gesonderte Dekorform und parallel zu den konstruktiven Gemeinsamkeiten miteinander zu einem Subtypus verbunden. Die homogene Variante der Pagoden-Bauten hat ihren variantenspezifischen Dekor in ihre Architektur nahtlos integriert. Die AdobeVariante ist durch einen überbordenden Dekor gekennzeichnet, der zu einem Teil als Tarnung in die Defensivkonstruktion übergeht. Die Steinarchitektur schließlich hat in der peripheren Subvariante überhaupt keinen spezifischen Dekor, oder aber sie ist durch einen spärlichen, von der Architektur abgehobenen Dekor charakterisiert.

Unter den jeweiligen variantenspezifischen Dekorformen gehen jene der homogenen und integrierten Adobe-Komposition kaum auf soziale Hierarchien ein; jene der beiden anderen Varianten akzentuieren sie hingegen deutlich.

In diesem Gesamtspektrum der Vercodungen, welche die Dekorformen zueinander, zur Architektur der Varianten und zur sozialen Hierarchie einnehmen, wird nun auch ihr Verhältnis zum sozialen Raum deutlich: Die variantenspezifischen Dekorformen der Pagoden-Bauten sind in die Architektur integriert, die im Raum nur graduell variiert; daher entspricht die räumliche Verteilung dieser architektonischen Form jener ihres Dekors. Die konstruktiv relativ homogen im Raum verbeitete Adobe-Form wird durch einen Teil ihres Dekors hingegen zu Lokalformen gruppiert, wodurch Najrān vom Ost-'Asīr hervorgehoben wird: Hier untergliedert der variantenspezifische Dekor also das homogene Verbreitungsgebiet der architektonischen Variante auf asynchrone Weise.

Für die dritte Variante der Steinarchitektur jedoch kann nur in einem höchst abstrakten Sinn überhaupt von der Existenz eines variantenspezifischen Dekors gesprochen werden - in dem Sinn nämlich, daß Steindekor irgendeiner Art entweder vorkommt oder auch nicht. Der eigentliche Ort des Dekors sind aber die Subvarianten, mit der angesprochenen räumlichen Synchronität zwischen architektonischer Konstruktion und der jewei- 
ligen Ausgestaltung von Dekor. Die räumliche Inhomogenität der architektonischen Variante ist jener des Dekors analog.

Die Ergebnisse dieser Zusammenfassung führen also zu zwei Schlußfolgerungen: Erstens ist die Steinarchitektur des 'Asīr durch eine heterogene Gliederung in die peripheren, zentralen und transitorischen Subvarianten charakterisiert, die spärliche, abgehobene und synchrone Dekorformen aufweist. Die gemeinsame räumliche Verteilung dieser Subvarianten und synchronen Dekorformen korrespondiert mehr oder minder mit der Territorialität tribaler Föderationen und verweist damit expliziter als die beiden anderen Varianten auf die Grundlagen der traditionellen Gesellschaftsordnung im 'Asīr.

Geht man aber von den gemeinsamen Bestimmungen des Subtypus aus, von dem also, was für die defensive Hochbauweise des 'Asīr und W. Najrān generell charakteristisch ist, so zeigt sich: Die zentrale Subvariante nimmt in konstruktiver Hinsicht eine ähnliche Position ein wie die Adobe-und Pagoden-Varianten. Zentrale Subvariante der Steinarchitektur, Pagoden-Bauten und unter den Adobe-Bauten deren nordwestliche Gruppe sind als charakteristische Varianten der defensiven Hochbauweise anzusehen - sie bezeichnen die 'AsīrArchitektur im engeren Sinn. Nur durch den Dekor etwas davon abgesetzt ist die AdobeArchitektur des W. Najrān; deutlich durch Dekor wie auch konstruktive Merkmale weichen die periphere und die transitorische Subvariante der Steinarchitektur von der 'AsīrArchitektur im engeren Sinn ab (Karte 11).

Damit verweist die 'Asīr-Architektur im engeren Sinn, wie sie sich noch im letzten Drittel des 20. Jh. präsentiert hat, auf die alte Kulturgeschichte dieser Region, der ja auch ihre heutige administrative Gliederung größtenteils Rechnung trägt. In der Beschreibung al-Hamdān̄̄'s zählen das W. Najrān, das Bergland nordwestlich von Șa'da und die Gebiete nördlich des W. Tayya nicht mehr zum 'Asīr. ${ }^{356}$ Im späten 20. Jh. stimmt die regionale Verbreitung der traditionellen defensiven Hochbauweise des 'Asīr (im engeren Sinn) also weitgehend mit der mittelalterlichen Ausdehnung des 'Asīr überein.

In die Terminologie von Karte 11 übertragen, umfaßt der „südliche Subtypus“ (II), also die defensive Hochbauweise in 'Asīr und W. Najrān, daher

- die Adobe Variante (II A) mit ihren nordwestlichen (II A1) und südöstlichen (II A2) Verbreitungen;

- die Pagoden Variante (II B) und schließlich

- die Steinarchitektur (II C) mit ihrer zentralen Subvariante (II C1), der peripheren Subvariante (II C2) und der transitorischen Subvariante (II C3).

Unter diesen Varianten und Subvarianten machen II A1, II B und II C1 in Karte 11 die „traditionelle Architektur des 'Asīr im engeren Sinn“ aus.

\subsubsection{SÜDLICHER ḤIJĀZ: EIN- BIS DREISTÖCKIGE WOHNBAUTEN MIT IN-TOWERS (SUBTYPUS 2)}

\subsubsection{Verbreitung und tribale Territorialität}

Von allen Typen und Subtypen traditioneller Architektur im saudischen Südwesten, die in diesem Beitrag (zum Teil erstmals systematisch) behandelt werden, ist jener des südlichen Hijāz als einziger durch zwei frühere Arbeiten ${ }^{357}$ bereits ausführlich dokumen-

356 al-Hamdānī (Müller): 118.

357 Dostal 1983c: 13-20, I-III; Gingrich 1983b: 74-113, VIII-XI. 
tiert. Im vorliegenden Abschnitt wird es daher genügen, die Ergebnisse dieser früheren Studien zusammenzufassen und um einige noch unveröffentlichte Angaben zu ergänzen.

Die Wohnarchitektur des südlichen Ḥijāz ist als zweiter und „nordwestlicher" jener beiden Subtypen klassifiziert worden, in die sich die defensive Hochbauweise des saudischen Südwestens gliedern läßt. Diese architektonischen Formen weisen wiederum einige Gemeinsamkeiten auf, die sie zugleich von den Besonderheiten der Architektur des 'Asīr und W. Najrān unterscheiden.

Das Verbreitungsgebiet dieses Subtypus ist also das stark gegliederte, zerklüftete Bergland des südlichen Hijā̄z entlang von dessen Hauptkamm (al-Sarāt) oberhalb der Shi$f \vec{a}{ }^{2}$. Wiederum, wie schon im Nord-'Asīr, erstreckt sich dieses Verbreitungsgebiet wie ein langes Band von Nordwesten nach Südosten. Im Nordwesten endet es mit den abflachenden Hängen der Sarāt südlich von al-Ṭā'if; im Südwesten geht es bei Qiẓ̣āna oberhalb des W. Qanūna in den Nord-'Asīr über. Die Ostseite dieses bandartigen Verbreitungsgebietes ist mit den kurzen Ostabhängen der Sarāt identisch, die hier recht abrupt in die Steppenund Oasengebiete Innerarabiens übergehen, wo dann die Lehmbauweise der Najd-Architektur vorherrscht. Nach Westen hin setzt sich die Steinarchitektur des südlichen Hijijāz in den Steiltälern und am Fuß des Grabenrandes (al-Asdar) zunächst fort, wo daran die Mischformen der 'ushash-Architektur und vereinfachte Varianten des Küstenstils (etwa in al-Mukhwā') anschließen. Auch dieser Ostteil der Ḥijāz-Tihāma wird von einigen vorgelagerten, isolierten Bergstöcken überragt, die ähnlich wie jene der 'Asīr-Tihāma fruchtbare agrarische Siedlungsgebiete von Hochlandstämmen sind. Diese Tihāma-Berge (J. Shadā) sind zugleich der westlichste Rand des Verbreitungsgebietes der für den südlichen Ḥijāz typischen Wohnarchitektur.

Verwaltungsmäßig umfaßt das Gebiet die gesamte Provinz al-Bāḥa (vom innerarabischen Ostrand der Provinz mit seiner Najd-Architektur abgesehen), sowie kleine Teile des Südwestens der Provinz Mekka (südlich von al-Ṭā̄if und östlich von al-Qunfudha). Biljurshī und al-Bāḥa selbst sind die einzigen größeren, heute stadtähnlichen Marktorte; ansonsten dominiert hier aber das bäuerlich-tribale Bevölkerkungselement in einem Ausmaß, wie es im Südwesten Saudi Arabiens sonst nur im West-'Asīr gegeben ist. Die drei dominanten Föderationen des südlichen Ḥijāz sind Ghāmid, Zahrān und Thaqīf, deren jeweils relativ homogene Siedlungsgebiete in dieser Reihenfolge von Süden nach Norden ungefähr aneinander anschließen, zum Teil aber auch ineinander verzahnt sind.

Zu Ghāmid gehören auch halbnomadische Gruppen und Verbände ehemaliger Beduinen im östlichen Randgebiet des Najd (wie etwa die Rifā'a als Bewohner der bereits in Abschnitt 4 erörterten Najd-Bauten von al-'Aqīq), und auch Teile von Thaqiif siedeln in Oasen nordöstlich des eigentlichen Berglandes. Aber von diesen Gruppen von (semi-) Nomaden und Oasenbauern im Osten und Nordosten der Sarāt abgesehen, umfassen die Siedlungsgebiete und Territorien der Ghāmid und Thaqîf zum überwiegenden Teil, und jenes von Zahrān praktisch zur Gänze die Verbreitungszonen der Architektur des südlichen Ḥijāz und dessen bäuerliche Nutzungsgebiete.

Während die Territorien vieler Stämme des 'Asīr also weit nach Innerarabien oder in die hügelige Tihāma reichen (erinnert sei an die Gebiete der Shahrān, Qạhțān, der B. Mugayḍ oder der B. al-Hajar) so ist dies im südlichen Hijāz nicht, oder nicht in diesem Ausmaß der Fall: Hier stimmen die sozio-politische Territorialität der drei Stammesföderationen mit der räumlichen Ausdehnung der agrarisch nutzbaren Berggebiete sehr weitgehend überein. 
Dies unterstreicht nochmals die einleitenden Ausführungen zu diesem 5. Abschnitt, wonach die defensive Hochbauweise des Südwestens Saudi Arabiens primär eine Architektur von bergbäuerlichen Stammesgruppen ist. Nicht alle Stammesgruppen des Südwestens haben bergbäuerliche Landwirtschaft als Subsistenzgrundlage - als Beispiel dafür wurden bereits die semitribalen Verbände der hügeligen Tihāma und die ehemaligen Nomaden am Rande des Najd angeführt. Die Architektur dieser Gruppen aber war jeweils verschieden vom Typus der defensiven Hochbauweise.

Andererseits ist die Architektur jener nicht-tribalen Gruppen, die ebenfalls im Berggebiet leben, zwar manchmal auch von Hochbauten geprägt (wie die Häuser der Sāda in Madīnat Rijāl Almac), aber selbst wenn dies der Fall ist, so weist sie keine Defensiveinrichtungen auf - weder bei den nicht-tribalen Gruppen von hohem, noch bei jenen von niederem Status.

Die bergbäuerliche Subsistenzgrundlage ist also eine condition sine qua non für das Vorkommen defensiver Hochbauweise im saudischen Südwesten. Diese Bedingung ist zwar notwendig, aber nicht hinreichend; hinzu kommt als zweite Bedingung die Zugehörigkeit der Haushalte zu einer der tribalen Föderationen. Eine erste Besonderheit der Architektur des südlichen Hịjäz gegenüber jener des 'Asīr liegt in der Korrespondenz dieser beiden Rahmenbedingungen - nämlich darin, daß die räumliche Ausdehnung der ersten Bedingung (bergbäuerliche Subsistenzgrundlage) jener der zweiten Bedingung (tribale Territorialität) sehr weitgehend entspricht.

Eine zweite Besonderheit dieses architektonischen Subtypus liegt darin, daß sein Grundmaterial durchwegs Stein ist. Im Prinzip gelten für diesen Subtypus die gleichen materialspezifischen Bestimmungsmerkmale wie für die Bauten des West- und Nord-'Asīr: Die Mauern sind aus trocken verlegten Reihen von regelmäßig oder uneben geformten Steinblöcken errichtet, die Außenwände der Wohnhäuser weisen (hier auch wegen der geringeren Höhe als im 'Asīr) nur eine geringe Neigung auf (Abb. 69). Die Wände der Innenräume sind massiv verputzt, ansonsten ist die Ausstattung der Räume (im Unterschied zu jener der Lehmbauten) jedoch kärglich.

Während die architektonischen Varianten des Subtypus im 'Asīr und W. Najrān also wesentlich durch den jeweiligen materiellen Anteil von Stein o d e r Lehm am Baumaterial geprägt sind, ist ein hoher Steinanteil das durchgängige Grundmaterial des Subtypus im südlichen Hijāz. Die drei Varianten dieses Subtypus, die in der Folge zu erörtern sein werden, sind vielmehr von der Art des verwendeten Steines geprägt, sowie vom Anteil an Holzkonstruktionen.

Dies führt zu einem weiteren Merkmal der traditionellen Architektur im südlichen Hijāz, das allerdings keine Besonderheit darstellt, sondern in ähnlicher Form an der Steinarchitektur des 'Asīr aufgetreten ist: Die Verbreitungsgebiete der drei Hauptvarianten von Wohnarchitektur im südlichen Hijāz weisen eine ungefähre Entsprechung zu jenen Stammesgebieten von Ghāmid, Zahrān und Thaqīf auf, die im Bereich der Sarāt, von al-Asdar und der isolierten Tihāma-Berge liegen. Die räumliche Verteilung der drei Hauptvarianten steht also in einer teils partiellen, teils ausgeprägten Korrelation zu den Territorien der drei Föderationen. Dieses wichtige Ergebnis der Analyse des Subtypus nehmen wir aus dem Grund bereits hier vorweg, weil dadurch im Anschluß an die zusammenfassende Auswertung zur Architektur des 'Asīr die entsprechenden Gemeinsamkeiten deutlicher hervortreten: Da wie dort sind es diejenigen Formen von Steinarchitektur, die in den unzugänglichsten Stammesgebieten liegen, welche zugleich diese besonde- 
re Affinität zur tribalen Territorialität aufweisen. Die periphere und zentrale Subvariante der Steinarchitektur des 'Asīr und die drei Varianten von Steinarchitektur im südlichen Hijāz sind in ihrer räumlichen Verteilung also jeweils durch partielle oder ausgeprägte Korrespondenz zur Territorialität der entsprechenden tribalen Föderationen gekennzeichnet.

Damit kann festgehalten werden: Der Typus defensiver Hochbauweise im Südwesten Saudi Arabiens ist generell an tribale Verbände von Bergbauern gebunden, aber die beiden Subtypen dieser Bauweise treten nicht bei spezifischen Föderationen auf, sondern bei Gruppen solcher Föderationen oder Föderationsteilen, die in jeweils zusammenhängenden Naturräumen siedeln - dem südlichen Hijāāz, sowie im 'Asīr und W. Najrān. Zwei der drei Varianten des südöstlichen Subtypus weisen einen cross- und intertribalen, regionalkulturlichen Bezug zur Territorialität der Stämme auf, und die transitorische Form der dritten Varianz weist ebenfalls nur schwache Korrespondenzen zu den tribalen Gebieten auf. Hingegen besteht partielle oder ausgeprägte Korrespondenz dieser Art bei den drei Varianten des nordwestlichen Subtypus, und bei den zentralen und peripheren Subvarianten des West-'Asīr. Und eben diese Varianten und Subvarianten haben alle Stein als Grundmaterial. Die Bedingungen und Faktoren, die diesen ausgeprägten Zusammenhang zwischen bestimmten Varianten und Subvarianten der Steinarchitektur und der Territorialität von bestimmten tribalen Föderationen konstituieren, lassen sich als komplexe Zusammenhänge identifizieren:

Zunächst ergaben die ökologischen Bedingungen, daß die Steinarchitektur in jenen Regionen am zweckmäßigsten ist, welche am niederschlagreichsten sind. Zugleich sind diese Gebiete nicht nur besonders fruchtbar, sondern durch eine kleingekammerte und unzugängliche Gliederung ausgezeichnet. Dies wiederum hat den historischen Zugriff überregionaler Staatsmächte auf die betreffenden Gebiete erschwert, und zugleich die Abgesondertheit der Stämme voneinander gefördert. Diese resultiert in einer zugleich ökologisch-wirtschaftlich, wie auch militärisch-politisch relevanten, stärkeren Abgeschiedenheit und einer teils bewußt herbeigeführten Abschottung der betreffenden Stammesföderationen über längere Perioden ihrer Geschichte.

Stärkere Tendenzen zur Abgrenzung voneinander und etwas größere Möglichkeiten, um den vereinheitlichenden Staatseinfluß auf Distanz zu halten, sind also die sozialen und politischen Bedingungen in den betreffenden Stammesgebieten, welche die Herausbildung und Bewahrung von „Elementen tribaler Architekturstile“ gefördert zu haben scheinen. Hinzu kommen (eher im südlichen Hijāz als im West-'Asīr) die geologisch-technischen Besonderheiten des lokalen Steinmaterials, und schließlich die allgemeine technische Eigenschaft der Dauerhaftigkeit von Stein: Die Vergänglichkeit des Bauens in Lehm bei Adobe- und Pagoden-Bauten zwingt eher zur wechselseitigen Angleichung der Konstruktionstechniken. Hier stößt das jeweils ausgereifteste Detail auf ein stärkeres allgemeines Interesse daran, der Vergänglichkeit der Lehmbauten durch gezielte Verbesserung der Bau- und Reparaturtechniken entgegenzuwirken. Dieses technisch bedingte Interesse an der wechselseitigen Übernahme geeigneter Bauformen ist für die traditionelle Steinarchitektur in weit geringerem Maße notwendig, wo die Wohnhäuser in ihrer Grundsubstanz oft vier, fünf oder mehr Generationen überdauern können. Die Herausbildung und Bewahrung dieser „Elemente tribaler Architekturstile“ beruht also teilweise auch auf der paradoxen Tatsache, das das gemeinsame Baumaterial Stein die Unterschiede der lokalen Bautraditionen durch seine technischen Eigenschaften geradezu fördert. 


\subsubsection{Konstruktion und Raumnutzung}

Die Architektur des südlichen Hijāz ist somit in sozio-ökonomische Rahmenbedingungen eingebunden, in denen die räumlichen Dimensionen von bergbäuerlicher Subsistenz und tribaler Territorialität einander weitgehend entsprechen; sie hat durchwegs Stein als Grundmaterial, und sie tritt in drei Varianten auf, deren Verteilung wiederum eine (partielle oder ausgeprägte, aber nicht schwache) Korrespondenz zu den drei tribalen Föderationsgebieten aufweist.

Auf dieser Grundlage wenden wir uns nun den konstruktiven und räumlichen Nutzungsmerkmalen dieses Subtypus zu.

Die Wohnhäuser des südlichen Hijāz sind niedrigere Bauten als jene des 'Asīr und haben ein, zwei oder maximal drei Geschoße. Die kühleren und feuchteren Klimaverhältnisse bedingen, daß man hier größere Haushöhen meidet und solchen Bauten den Vorzug gibt, die eher in Hang- oder Bodennähe „kauern “ und dadurch innerhalb ihrer Steinmauern die Innentemperaturen besser speichern.

Die geringere Anzahl von Stockwerken (țābiq, pl. țawābiq) der Wohnhäuser ergibt aber zugleich defensive Nachteile für das Einzelhaus. Die beiden anderen Elemente jener defensiven „Triade“, die bereits für den 'Asīr diskutiert wurde, entlasten im südlichen Hiijāz deswegen systematisch die einzelnen Wohnhäuser: Kompakte „Frontsiedlungen “ mit in-towers sind hier die Regel.

Diese defensive Entlastung der Einzelhäuser erlaubt weiters, daß man auf den Schutz der Zugänge zwischen den Geschoßen weitgehend verzichtet. Die Zugänge zum einen, oder maximal zu den beiden Obergeschoßen erfolgen also in der Regel von außen durch die Fassade, über Außentreppen und hangseitige Türen. Auch die von kleinen, vorspringenden Regendächern geschützten Fensteröffnungen im zweiten oder dritten Geschoß sind relativ groß, aber stets durch Holzläden von innen verschließbar. Ebenerdige Bauten weisen hingegen nur selten Fensteröffnungen auf.

Die Fassaden der Wohnhäuser im südlichen Hijāz können also deshalb durchlässiger gestaltet sein, weil sie von den anderen beiden Elementen der Triade besser geschützt sind - nämlich von den nahen Mauern der Nachbarhäuser und von den überragenden $i n$ towers.

Die in-towers des südlichen Hijāz unterscheiden sich konstruktiv nicht von „ihren“ jeweiligen out-towers. Die Türme haben stets quadratischen Grundriß und mindestens drei Geschoße; die Turmwände sind deutlicher geneigt. Die Gestaltung der Innenaufgänge variiert; am häufigsten sind hochziehbare Leitern in Form einfacher Baumstämme, in welche Stufen eingekerbt sind (sullam, pl. salālim); ${ }^{358}$ manchmal können auch frei aus der Innenwand ragende Platten einen unsicheren Aufgang bilden. Die Türme im B. Zahrān haben bisweilen einfache Stiegenhäuser. Jedes Geschoß und insbesondere die Dachterrasse mit ummauerter Wehrbrüstung ist mit Schießscharten ausgestattet (burj, pl. burūj). Die Türme im südlichen Hịjāz sind damit das effektivste und spezialisierteste Element der Defensivarchitektur.

Türme mit rundem Grundriß treten im südlichen Hijāz kaum auf, sieht man von vereinzelten niedrigen Kegelstümpfen auf den vorgelagerten Bergstöcken ab, die ähnlich wie am J. Fayfa auf die benachbarte Tihāma verweisen (Abb. 91, 72). In der Sarāt des südli-

358 vgl. Schregle 1977: 762. 
chen Hijāz dominiert eindeutig der (statisch anspruchslosere) viereckige Turm, was das differenziertere architektonische know-how des südöstlichen Subtyps nochmals hervorhebt.

Die vielen rechteckigen in-towers inmitten von kompakten, nach außen durch die niedrigeren Häuserfronten fast abgeschlossenen Dorfsiedlungen sind also typisch für die Architektur des südlichen Hijāaz. Die architektonischen Defensivaufgaben sind zwischen Einzelhaus, Frontsiedlung und in-towers so aufgeteilt, daß dem Einzelhaus nur ein variabler, aber kleiner Anteil daran zukommt. Diese Aufteilung der Defensivfunktionen wird durch zusätzliche Eigenschaften gefördert. Die Dorfsiedlungen sind fast durchwegs in überhöhten Stellungen angelegt, also auf Kuppen, Bergrücken, im Steilhang oder auf Kämmen. Dies gleicht die niedrigen Haushöhen partiell aus und verschafft Überblick über Felder und Wege auf potentielle Feinde. Selbst am Fuß von al-Asdar, über deren Steilhänge aber ohnedies nur selten Angriffe zu erwarten sind, bevorzugt man kleine Anhöhen als Standorte über den Flußbetten (Abb. 71). Weiters sind die in-towers selten im Besitz eines einzelnen Haushaltes, und auch in diesen Fällen kann es jener des Dorfvorstehers oder eines lokalen Shaykh sein, der die Gemeinschaft repräsentiert und ihr auch seinen Turm zur Verfügung stellt. Im Normalfall aber sind die in-towers Eigentum mehrerer, miteinander verwandter Haushalte, eines Dorfviertels oder des ganzen Dorfes.

Die Entlastung des Einzelhauses und die Aufteilung der Defensivfunktionen über in-towers und Siedlungsanlage belastet also das soziale Kollektiv - die Dorfgemeinschaft durch die Siedlungsanlage, und zumindest Teile davon durch die gemeinsame Nutzung der in-towers. Diese Akzentuierung kollektiver dörflicher Defensivaufgaben mithilfe der Architektur ist nur dort möglich, wo auch die sozialen Voraussetzungen dafür gegeben sind: Die Bewohner kleinerer Weiler definieren sich häufig als patrilineare Nachfahren eines namentlich bekannten Ahnen, und größere Dorfanlagen setzen sich in der Regel aus lineage-quarters zusammen, in denen die Bauten der Haushalte, die einem Deszendenzverband angehören, zusammen jeweils ein derartiges Viertel mit eigenen in-towers bilden. Ausgeprägte und effektiv wirksame Prinzipien von Patrilokalität und Patrilinearität sind also im wesentlichen die soziale Grundlage für jene kollektive Aufteilung der architektonischen Defensivfunktionen im Dorf. Hier ist das einzelne Wohnhaus a priori kaum als „architektonische Waffe“ für offensive und defensive Zwecke gegen alle anderen Wohnhäuser ausgerichtet, wie in vielen Teilen des 'Asīr. Nord- und Zentralarabien liegen dem südlichen Hijāz auch in soziologischer Hinsicht näher: Die Defensivarchitektur akzentuiert hier eher die gemeinsamen Interessen lokaler, patrilinearer Deszendenzgruppen nach außen hin, und gibt ihnen eine nicht-vergängliche Form.

Unter diesen Bedingungen sind geschützte Stiegenhäuser im Inneren der Wohnbauten, wie sie aus dem 'Asīr bekannt sind, im südlichen Hijāz bloß eine seltene Ausnahme. Zwischen- und Innenschachtbauten kommen kaum vor: Die durchläßigen Fassaden gewährleisten ohnedies jene geringe Zahl von Außenzugängen, die Gebäude mit wenigen Geschoßen nur benötigen. Für Notfälle kann dies durch Luken und Leitern im Inneren ergänzt sein. Der an sich schon kleinere Druck der Hausmasse auf das Fundament wird durch die bevorzugte Abstützung im Hang (Abb. 72) noch zusätzlich verteilt. Die Verringerung und Verteilung des Drucks von oben, und die Einrichtung von Außenzugängen macht die „Kombinationslösungen“ im südlichen Hijāz also überflüssig. Einfache Binnen- 
mauern (rạ̣ḍa, pl. riḍạ̣̄) ohne Stiegen teilen nur das Erdgeschoß und damit die Stallungen (mit den Futterkrippen, madhwad) von den Geräteräumen, indem sie am Fels des Hanges ansetzen und das Gewicht der maximal zwei Obergeschoße tragen. Bei dreigeschoßigen Bauten kann diese Binnenmauer manchmal noch in das erste Obergeschoß hochgezogen sein.

Für die Überspannung der Räume ohne Bogen und Gewölbe, sondern mit Holzstämmen setzen diese einfachen Binnenmauern aber ebenso enge Grenzen wie im 'Asīr. Dementsprechend eng fällt der Spielraum für die Ausmaße des Grundrisses aus. Die dadurch bedingte Limitierung des Raumvolumens in einem Geschoß wird eben nicht durch die Errichtung vieler Geschoße in vertikaler Richtung ausgeglichen, wie im 'Asīr und im übrigen Südwestarabien, sondern durch die zahlreichen ebenfalls niedrigen An- und Zubauten in der Horizontale. Diese An- und Zubauten der verschiedenen Häuser sind durch eine Vielzahl von Elementen (wie hölzerne Verbindungsgänge, ‘aqd, und Gassenüberdachungen, jahwa) auch miteinander verbunden. Dies beschränkt die Räume zwischen den Dorfhäusern auf ein Mindestmaß - die typischen, schmalen Gassen der Dörfer im südlichen Hijiāz erlauben unerwünschten Eindringlingen kaum zu manövrieren. Enge zwischen den Häusern, und auch im Inneren der Wohnbauten ist also ein Charakteristikum der Architektur des südlichen Hijāaz. Die Limitierung des Binnenraumvolumens durch knappe Grundrisse und geringe Geschoßanzahl gleicht man einerseits durch die erwähnten An- und Zubauten aus, andererseits durch dünne Lattenwände, die im ganzen südlichen Hijāaz die Binnenräume ohne zusätzlichen Raumverlust abtrennen und zudem den Ausgleich der Binnentemperaturen erleichtern (rașș, pl. ruṣūṣ).

Für das eine (oder das letzte) Obergeschoß der Wohnhäuser ergibt sich aus der zusätzlichen Limitierung des Grundrisses durch die beschränkte Spannweite aber ein soziales Problem. In diesem Obergeschoß ist nämlich der mafraj (auch: majlis, majma ${ }^{c}$ ) unterzubringen, der nicht nur als Wohn- und Schlafraum groß zu sein, sondern auch den repräsentativen Zwecken der Gastfreundschaft zu dienen hat. Diese besonderen Raumanforderungen könnten nicht erfüllt werden, wenn die Binnenmauer auch noch durch diesen Raum hindurch hochgezogen wäre, um dann das Dach zu tragen. Dies würde das ohnedies schon begrenzte Raumangebot nochmals halbieren.

Die konstruktive Lösung dieses sozialen Problems gewährleisten nun jene hölzernen Stützsäulen (zāfir, pl. zaffār, auch: da'ma, pl. da $\left.{ }^{c} m a ̄ t\right)$, die das charakteristische Merkmal der architektonischen Innenausstattung im südlichen Ḥijāz darstellen (Abb. 75). ${ }^{359}$

Die hölzernen Stützsäulen überbrücken die Spannweiten von Dach und Zwischendekken, ohne daß die Räume deshalb durch Wände weiter unterteilt würden. Ökologische Voraussetzung dafür ist die üppige Baumbewachsung im südlichen Hijāz; die entscheidende konstruktive Bedingung ist die geringere Druckmasse: Die Stützsäulen haben oft nur die Dachterrasse zu tragen, maximal tragen sie im ersten noch ein darüberliegendes zweites Obergeschoß. In diesem Fall steht je eine Stützsäule des zweiten genau auf einer des ersten Obergeschoßes.

Geringe Geschoßanzahl und Außenzugänge statt Innenaufgang sind also die notwendigen technischen Begleitumstände dieses konstruktiven Charakteristikums der Wohnarchitektur des südlichen Hijāz. Auch in ebenerdigen Bauten, bei denen die Stallungen

359 Gingrich 1983b: 80, 92f., 94, 116, XI (Illustr. 23, 24). 
dann meist als direkter Anbau an die Wohnräume im Erdgeschoß angelegt sind, stützen Holzsäulen die Dachdecke im größten dieser Wohnräume. Hölzerne Stützsäulen sind im südlichen Hij̄äz ubiquitär, im 'Asīr und W. Najrān jedoch eine Rarität.

Die beschränkte Belastbarkeit der Holzsäulen verlangt wiederum, daß auch das Dachgewicht gering gehalten wird. Schwere steinerne Brüstungen oder gar Aufbauten (für Küche oder mafraj) auf Mauerkrone und Terrasse sind deshalb auf den Hausdächern des südlichen Hijāz äußerst selten. Das Dach wird an den Ecken mit Steinblöcken und über der mittleren Mauerkrone häufig mit Bienenstöcken erschwert. Neben der Imkerei dient das Dach darüber hinaus regelmäßig (wie auch im 'Asīr) als Standort der Sternen- und Mondbeobachtung für den Agrarkalender, und ebenso als häufigster Gebetsort: dafür ist in den Lehm der Dachmitte, über dem darunterstehenden Stützpfeiler, gewöhnlich eine flache Schieferplatte eingelassen - der Gebetsstein (mașalla Abb. 79). Auch wenn man früher vom Dach aus gelegentlich in liegender Haltung mit Schußwaffen verteidigen oder angreifen konnte, stellte dies nur eine untergeordnete, seltene Ergänzung zu den Hauptstandorten des Kampfes dar - nämlich jenen auf den Dächern der in-towers, und hinter den Schießscharten der Wohnhäuser und Türme.

Auch in den kämpferischen Zeiten der Vergangenheit waren die Hausdächer im südlichen Hijāz also eher Orte des Friedens - nämlich solche der zeitlichen Orientierung am Sternenhimmel, der pflegerischen Sorgfalt von Imkern, und der rituellen Einkehr im Gebet. Die unmittelbar technisch-konstruktive Grundlage dieser primär nicht-militärischen Nutzung der Hausdächer ist deren Abstützung durch die wenigen belastbaren Holzsäulen. Ermöglicht wird diese militärische Entlastung des Hausdaches durch die Anlage von in-towers und Front-Siedlungen. Wie ich am Schluß dieses Abschnittes noch ausführen werde, geht dies auch mit einer entsprechenden symbolischen Konnotation einher.

Im 'Asīr und W. Najrān hingegen kommen den Hausdächern ganz andere Funktionen zu: Dort erlauben massive Mauerkronen und Innenmauern, die bis zum Dach hochgezogen sind, die Anlage von Wehrbrüstungen und von Raumeinheiten auf der Dachterrasse. Die dadurch mögliche, regelmäßige Nutzung der Dachterrasse für offensiv-defensive Zwecke setzt am taktischen Vorteil der Höhe an; der Dachraum wird als mafraj oder Küche verwendet. Bienenstöcke werden im 'Asīr nicht am Dach gelagert (ohne Außenzugänge auf die Terrasse würden die Bienen dem Imker allzu leicht ins Hausinnere nachfolgen), gebetet wird selten am Dach (sondern in den gesonderten Gebetsräumen der Oberschicht oder außerhalb der Häuser), nur die Gestirne beobachtet man ebenfalls vom Dach aus. Die Hausdächer des 'Asīr sind also primär Orte der Wehrhaftigkeit, und danach auch solche der weiblichen Hauswirtschaft, der männlichen Gastfreundschaft und Ruhe, sowie des familiären Aufenthaltes. Pointiert läßt sich fomulieren: Während im 'Asīr am Hausdach gekämpft oder gekocht wird, züchtet man im südlichen Hijäz am Dach Bienen und betet.

Die Küche der 'Asīr-Wohnbauten befindet sich recht häufig am Dach. In den Wohnhäusern des Hijāz hingegen ist sie in der Regel direkt über oder (bei ebenerdigen Häusern) neben den Stallungen untergebracht. Dies verringert die Arbeitswege der Frauen, die sowohl die Stallfütterung und -tränke, als auch die Versorgung der Küche mit Wasser und Brennmaterial (Holz und Dung) überhaben. Zugleich bedingt dies aber schwierige Arbeitsbedingungen mit schlechter Entlüftung und wenig Licht. Der Mahlstein für das Getreide kann sich ebenfalls in der Küche (mațhan), in einem Nebenraum zum mafraj bei den Vorräten, oder unter einer Überdachung im Freien befinden. In hohen und feuchten Lagen sind Küche und mafraj mit einer offenen Herdstelle (malla) ausgestattet. 
Das knappe Raumangebot der Hijāz-Architektur bringt es überdies mit sich, daß eigene Wohnräume der Frauen hier eine ausgesprochene Seltenheit, und manchmal nur enge, dunkle Schlafkammern für die Eheleute oder die Frauen des Haushaltes eingerichtet worden sind. Diese Schlafkammern ('alīya, pl. 'aliyāt) sind in mehr als einstöckigen Wohnbauten „oben“; sie können in Verschlägen hinter dem mafraj liegen; bei den selteneren dreigeschoßigen Bauten sind sie etwas geräumiger und im obersten Stockwerk. In den rareren Fällen von polygynen Ehen wohlhabender Haushaltsvorstände gilt aber das Prinzip der Gleichbehandlung - hier muß der Ehemann jeder seiner Frauen und ihren Kindern einen eigenen Wohn- und Schlafraum zur Verfügung stellen. Dies bedeutet aber, daß im südlichen Hijāz die räumliche Geschlechtersegregation erst dort praktiziert wird, wo sie unbedingte rechtliche Pflicht ist. Monogame Familien hingegen haben, auch unter der reicheren tribalen Oberschicht, hier nur selten eigene Frauenräume.

Im 'Asīr und W. Najrān ist die räumliche Geschlechtersegregation in der Architektur der tribalen Oberschichten und der Sāda (auch bei monogamen Ehen) - wohl als Ergebnis stärkerer Anpassung dieser Schichten im Verlauf des 19. und 20. Jh. an städtisch-staatliche Einflüsse - sehr weitreichend gegeben, unter der einfachen tribalen Bevölkerung ist sie hingegen kaum verbreitet. Die geräumige und weitläufige Innengestaltung der Hochbauten des 'Asīr erlaubt ohnedies den Rückzug der Frauen in andere Teile des Hauses, wenn fremde Männer anwesend sind, aber auch dies ist nicht überall die Norm. Im südlichen Hijāz stellt sich die Situation diesbezüglich jedoch anders dar: Die soziale Segregation der Geschlechter wird hier in der tribalen Bevölkerungsmehrheit weitaus rigider praktiziert, insoferne das Meidungsgebot gegenüber fremden Personen des anderen Geschlechts durchgängig eingehalten wird. Aber die Enge der Wohnräume erlaubt in Meidungssituationen nur, daß die Frauen in die Küche, die Ställe oder ins Freie ausweichen.

Generell sind die Wohn-, Arbeits- und Lebensbedingungen der Frauen innerhalb dieser Wohnarchitektur also eingeschränkter und qualitativ deutlich minderwertiger als im 'Asīr. Ich meine freilich, daß nicht die Architektur selbst dafür die Ursache ist (nichts spräche etwa konstruktiv dagegen, die weiblichen Lebensräume architektonisch in horizontaler Richtung drastisch zu erweitern, was sie aber „exponieren“ würde und daher aus sozialen Gründen nicht der Fall ist), sondern daß vielmehr die Architektur in dieser Hinsicht einer vorgegebenen sozialen Tatsache Rechnung trägt und ihr erst rückwirkend dauerhafte Form verleiht. Die im Vergleich zum 'Asīr deutliche architektonische Abwertung weiblicher Arbeits- und Lebensräume verweist ebenfalls auf die im tribalen südlichen Hijāz weitaus stärker akzentuierten Prinzipien einer patrilinearen Verwandtschaftsordnung.

Zum mafraj haben Frauen und Mädchen des Haushaltes in der Regel nur dann Zugang, wenn dort keine fremden Männer anwesend sind. Grundsätzlich aber ist der größte Raum im Haus, in dem die markanten Holzsäulen die Decke stützen, der erste und wichtigste Aufenthaltsraum der männlichen, tribalen Mitglieder des Haushaltes.

Den Haushalten des südlichen Hijāz gehören allerdings manchmal auch nicht-tribale Mitglieder an. Im W. Najrān und Ost-'Asīr separiert die dortige Trennung zwischen 'ushash und Adobe-Bauten auch in räumlicher Hinsicht die ehemaligen Sklaven von den Freien. Im südlichen Hijāz hingegen leben die ehemaligen Sklaven (ähnlich wie in den Zwischenschachthäusern des West- und Zentral-'Asīr) in denselben Gebäudekomplexen mit ihren Herrn. Hier sind es nicht wenige, eher wohlhabende Familienverbände, bei denen sich derartige Spuren früherer „Haussklaverei“ finden. Diese früheren Sklaven leben ent- 
weder zu mehrt in einem ebenerdigen Zubau, oder sie haben bloß eine der fensterlosen Schlafkammern im Hauptgebäude zur Verfügung. Bei Familienmahlzeiten im mafraj können sie dort teilnehmen, bei Gastmählern teilen sie sich mit den Kindern die Aufgaben der Bewirtung.

Nur in den wenigen, großen Gehöften des südlichen Hijāz, in denen mehrere Einzelhäuser von verwandten, reichen Familien zu einem Geviert zusammengeschlossen sind, besteht genügend Raum für eine bessere Unterbringung auch der ehemaligen Sklaven. Auf derartigen Höfen sind polygyne Familien etwas häufiger, und auch die Frauen monogamer Ehen können hier fallweise separierte Wohnräume zugeteilt bekommen.

Ansonsten aber ist der mafraj mit hölzernen Stützsäulen eindeutig und überall der Raum der Männer, zu dem Frauen, Kinder und ehemalige Sklaven nur fallweise Zugang haben. Primär wird die hölzerne Stützsäule im mafraj daher mit den Männern des Haushaltes assoziiert.

Nach diesem generellen Überblick über Konstruktion und Raumnutzung des Subtypus kann nun zur Erörterung seiner drei Hauptvarianten und im Anschluß daran zu den Dekorformen übergegangen werden.

\subsubsection{Varianten}

Zu unterscheiden sind in der traditionellen Architektur des südlichen Ḥijāā von Südost nach Nordwest die drei Varianten der niedrigen Felsstein-Häuser (Ghāmid), der SchieferBauten (Zahrān) und der niedrigen Lattenwand-Häuser (Thaqīf).

\section{A. Niedrige Felsstein-Häuser (Biläd Ghämid)}

Der im Südteil des südlichen Hijā̄z in der Natur vorkommende, geeignetste Baustoff ist ein felsiger Stein von hohem spezifischem Gewicht und gelblicher Farbe (jabalīya, oder: hād). Er ist härter als die Bausteine der anderen beiden Varianten, und wird daher meist nur roh zubehauen.

Dies gibt den Mauern dieser Häuser ihr charakteristisches, grob gefügtes und helles Aussehen (Abb. 71). ${ }^{360}$ Die Massivität dieses Felssteins bedingt, daß die Mauern im Querschnitt meist nur aus einer Reihe von einzelnen Blöcken gebildet und etwas dünner sind als jene der zweiten Variante.

Dieser Felsstein ist zugleich für Naturräume mit niedrigem agrarischen Nutzungspotential am Süd- und Südostrand des südlichen Hijāz charakteristisch. In manchen Teilen reichen die semiariden Ausläufer der östlichen Steppe hier weiter bis an die Shifä’ heran als im übrigen Hijāz. In erster Linie ist dies das Siedlungsgebiet der Ghāmid, eines tribalen Großverbandes mit halbnomadischen und nomadischen Elementen im äußersten Osten, und einer ärmeren Bauernschaft in der Sarāt sowie in kleinen Randgruppen auch unterhalb der Shifā’

Die karge Subsistenzgrundlage vieler dieser bäuerlichen Familien bedingt also, daß auch ihre Wohnhäuser schlicht und niedrig sind. Meist handelt es sich um ebenerdige Bauten, nur manchmal ist auch ein Untergeschoß mit den Stallungen in den Hang errichtet. Die ebenerdige Anlage der Wohnhäuser bietet den Familien hier aber auch Vorteile.

360 Gingrich 1983b: IX (Illustr. 18). 
Die eingeschränkten Möglichkeiten des Feldbaues haben im Zentral- und Südteil des B. Ghāmid eine extensive Weidewirtschaft mit Kleinvieh auf den spärlich bewachsenen östlichen Hängen bedingt. (Sie bilden damit ein interagierendes, soziales und ökologisches Übergangsgebiet zur nomadischen und Oasenwirtschaft der östlichen Ghāmid am Rande des Najd.) Der dadurch gegebene hohe Anteil von Kleinvieh bei bäuerlichen Ghāmid-Haushalten verlangt größere Stallungen als im übrigen südlichen Hijāz. Diese Erweiterung der Stallungen ist zweckmäßigerweise horizontal und nicht vertikal angelegt. Lattenwände (țanșib, pl. țanāṣib) im Inneren teilen die Klein- von den Großviehstallungen, und manchmal auch die Wohnräume untereinander ab. Eigene Magazinräume wie in den reicheren Zahrān-Haushalten gibt es hier nicht. Eine weitere Besonderheit der Raumnutzung liegt darin, daß am Dach (bei Zugang vom Hang aus) oder auch im Wohnraum (bei ebenerdigen Bauten) das Getreide (außer Hirse) gedroschen werden kann. Landknappheit, der Mangel an ebenen Flächen und - bei Drusch im geschützten Wohnraum - die häufigen Winterregen bedingen diesen regionalen Sonderfall. Die niedrigen Wohnhäuser werden von hohen, klobigen Türmen über quadratischem Grundriß überragt, auf denen breite Aufsätze ruhen.

Die Massivität der Felssteinblöcke verhindert in der Regel auch, daß man den spröderen Quarz hier als Zierstein im Oberteil der Turm- und Hausfassaden einlegt; seine weiße Farbe würde zum Gelb des Grundmaterials auch kaum kontrastieren. Die Türme des B. Ghāmid sind damit die einzigen Varianten im tribalen Bergland des südwestlichen Saudi Arabiens, deren Fassaden ohne jeglichen Dekor ausgestattet sind. Gleichsam als Ersatz für den mangelnden Quarzdekor sind aber an den Kronen der Wohnhäuser wie auch im Nord-'Asīr Zinnen (sawma) angebracht, die keinerlei defensive Funktionen haben. Nur über Schießscharten und Fenstern der Wohnhäuser ist manchmal etwas Zierstein eingelegt. Ebenfalls auf den benachbarten Nord-'Asīr verweist das fallweise Auftreten bunter Innenwandmalereien, die von den Frauen verfertigt werden und hier ihr nördlichstes, sporadisches Verbreitungsgebiet haben. Der wichtigste Dekor in der Wohnarchitektur sind die Holzschnitzereien im Hausinneren und an den Stöcken und Flügeln der Fenster und Türen, deren Formen noch diskutiert werden. Im Gebiet um das Zentrum der Kunsttischler bei Biljurshī ist die Ausführung der Holzschnitzereien in Ghāmid-Haushalten abwechslungsreicher und vielgestaltiger als bei den anderen beiden Varianten.

\section{B. Zwei- bis dreigeschoßige Schieferbauten (Bilād Zahrān)}

Die Schieferbauten sind die charakteristischste Architekturvariante des südlichen Hijāz. Niedrige Steinbauten aus hellerem Material, die jenen des B. Ghāmid zumindest äuBerlich ähneln (sieht man vom Stützpfeiler im Inneren ab) gibt es vereinzelt auch im Westoder Nord-'Asīr und im zentralen wie südlichen jemenitischen Hochland überall dort, wo Steinbauten generell vorherrschen. Und andererseits kommen niedrige Lattenwand-Häuser gleichfalls nicht allein am Nordrand des südlichen Hijāz vor, sondern sporadisch auch im nördlichen Hijāz, wie auch in Inner- und Nordarabien.

Die Schieferbauten mit ihrem typischen, dunklen Grundmaterial, dem deutlich kontrastierenden weißen Quarzdekor, und ihren viereckigen, überragenden in-towers sind hingegen ein Spezifikum der traditionellen Wohnarchitektur dieser Region (Abb. 72). Was also die Pagoden-Bauten für den 'As̄̄r darstellen, das sind die Schieferbauten des Bl. Zahrān für den südlichen Hijāz - ein markantes Wahrzeichen und materielles Symbol der tribalen 
Regionalkultur. ${ }^{361}$ Das Verbreitungsgebiet dieser Schieferbauten deckt sich allerdings größtenteils mit den Territorien der Zahrān-Föderation, und ist daher primär für deren tribale Identität markant. Erst in zweiter Linie, und deutlich davon abgesetzt, können die Schieferbauten auch als Symbol der gesamten übrigen Bevölkerung und Kultur der Region angesprochen werden - insoferne diese sich nämlich damit identifiziert, und insoferne im Norden und Süden des südlichen Ḥijāz wie auch auf den vorgelagerten Tihāma-Bergen auch kleinere Randgruppen solcher tribaler Verbände in Schieferbauten leben, die selbst nicht den Zahrān angehören.

Der dunkle Schiefer (tuhl, auch: saḍ̄) ist ein an der Oberfläche natürlich vorkommendes Baumaterial, das besonders häufig im zerklüfteten Zentralteil der Sarāt des südlichen Hijāz auftritt. Seine plattenartige, weiche Konsistenz macht ihn zu einem gut transportierbaren und leicht bearbeitbaren Werkstoff, der noch dazu ein geringes spezifisches Gewicht hat. Ebenerdige Bauten sind im Bl. Zahrān nur für die ärmeren Haushalte typisch. Die Materialeigenschaften und das besonders feuchte Klima machen es möglich und zugleich sinnvoll, die Schieferbauten in der Regel als zwei- bis dreigeschoßige Wohnhäuser zu errichten. Der durchlässige Schiefer speichert nämlich zwischen seinen Platten etwas Feuchtigkeit, was für die Wohnräume im Erdgeschoß unangenehme Begleiterscheinungen für die Lebensqualität haben kann. Hingegen erlaubt die Anlage der Wohnräume im ersten und zweiten Obergeschoß, daß Stall-, Küchen- und Herdwärme in den nassen Wintermonaten die Innenwände von unten nach oben zunehmend trocken halten. Dreigeschoßige Schieferbauten haben manchmal den mafraj im Mittelgeschoß, wo er vom Hang aus oder talseitig über eine Treppe zugänglich ist; die Schlafräume (mit wenig dekorierten Stützpfeilern) liegen dann im Obergeschoß und sind nur vom mafraj aus über eine Leiter erreichbar. Von diesen Sonderfällen abgesehen, liegt der mafraj aber auch hier meistens im obersten Stockwerk, Küche und Schlafkammern sind je nach Grundriß im Erd- oder Mittelgeschoß untergebracht. Größere Gebäude mit länglichem Grundriß haben im Obergeschoß oft auch einen Speicherraum für Vorräte und Wertgegenstände (makhzan), unter dem die Schlafkojen der ehemaligen Sklaven liegen können, damit der makhzan auch nachts besonders geschützt bleibt.

Diese größeren, länglichen Bauten reicherer Haushalte verfügen fallweise auch über eigene Wehrtürme, die einzeln oder zu zweit an der Schmalseite des Längsbaus errichtet sind, was dem Gesamtkomplex ein kirchenähnliches Aussehen gibt. Derartige in-towers im Privatbesitz eines Einzelhauses haben nur wohlhabende Bauernfamilien des Bilād Zahrān als besondere Schutzvorrichtung erbauen lassen, sie treten ansonsten bei keiner anderen Variante auf (Abb. 99).

Nur durch ihren Rechtsstatus, aber nicht in konstruktiver Hinsicht unterscheiden sich diese „Privattürme“ von jenem Grundmuster, das den in- und out-towers des Bilād Zahrān grundsätzlich gemeinsam ist. Der Schiefer erlaubt nur den Zuschlag von entweder länglichen Blöcken oder von Schiefergeröll; runde Türme sind damit aber auch hier kaum zu errichten. Die viereckigen Türme haben vier bis sechs Geschoße. Türme auf Anhöhen, die das Dorf überblicken, können niedriger sein. Ihr Baumaterial erlaubt, daß Schiefertürme reichlicher als jene des Bilād Ghāmid mit Schießscharten ausgestattet sind, und daß sie insgesamt eine größere Grundrißfläche aufweisen (bis zu $7 \times 7 \mathrm{~m}$ Außenmauer). Während

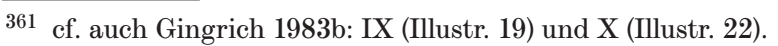


die kurzen, schweren Felssteinblöcke der Ghāmid-Türme eine größere Belastung ihrer geneigten Wände in deren Mitte verhindern, erlaubt die gute Verspannung der Schieferwände längere Turmseiten. Dies kann genutzt werden für größere Turmhöhen als in den beiden anderen Varianten. Der größere Grundriß erfordert dazu meist - als einziger architektonischer Form des südlichen Hijāz - eine tragende Binnenmauer ('ustwān), welche die Überspannung durch zahlreiche Zwischendecken abstützt und ein eigenes Treppenhaus trägt: Hölzerne Stützsäulen haben daher auch diese Türme nicht. Eine niedrige Eingangstür mit hoher Schwelle sowie Schießscharten (burj, pl. burūj) in jedem Geschoß runden die hohe Defensivkraft dieser Türme ab, die mit drei bis vier Mann pro Geschoß besetzt werden können. Hinzu kommen besondere Einrichtungen an der Terrasse der Schiefertürme.

Auf den Dächern ist immer eine massive Brüstung (jawl, pl. ajwāl; auch: rakn, pl. arkān oder hadda) errichtet, die über die eigentliche Mauerkrone hervorragt. Zwischen Mauerkrone und Unterseite der Brüstung sind nach unten gerichtet Schießscharten (kullab, pl. kulālib) ausgespart; an den Ecken der Brüstungskrone verleihen Zinnen (sīra) zusätzliche Deckung. An der Innenseite der Brüstung kann an einer oder mehreren Seiten eine Steinbank angebracht sein, die sowohl zum verbesserten Zielen wie auch zum Rasten dient: Die in- und out-towers müssen sich als einzige spezialisierte Defensiveinrichtung der lokalen Architektur auch für längerfristige Aufenthalte eignen. Auch im Obergeschoß können Lehmbänke sein, und in die vorspringende Brüstung sind öfters geschützte Latrinen (shāya) eingebaut - was an den Türmen des 'Asīr eine ausgesprochene Seltenheit darstellt. Diese shāya interpretiere ich als volkstümliche Spielart jener stabiler gearbeiteten Form, die sich an den noch zu behandelnden „weißen“ Türmen der tribalen Oberschicht befinden.

Weißer Quarz bildet den charakteristischen Dekorstein der Fassaden von Türmen und Wohnhäusern aus Schiefer - an den Wehrbrüstungen und Mauerkronen, über den Fenstern und Schießscharten. Trotz der Üppigkeit dieses spezifischen Steindekors an den Außenwänden kommt der Holzschnitzerei auch in dieser Variante größerer Stellenwert zu. Fensterläden und Fensterstöcke, Türen und Türstöcke, Wandverkleidungen und Stützpfeiler aus Holz können dekoriert und im Hausinneren auch bemalt sein, wobei Umfang und Ausmaß des Dekors von Reichtum und Status des Hausherren abhängen. Die im Bilād Zahrān verbreiteten Formen des Holzdekors, die im Schlußabschnitt ebenfalls noch zur Sprache kommen werden, sind aber einförmiger und facettenärmer als jene im Bl. Ghāmid, wo die Wanderhandwerker und reisenden Kunsttischler ihre Hauptwohnsitze haben.

Holz spielt auch bei zwei weiteren architektonischen Besonderheiten des Bl. Zahrān eine charakteristische Rolle - nämlich bei den erwähnten „weißen“ Türmen, und in der nach Norden hin zunehmenden Bedeutung von Lattenwänden und Balkonen.

„Weiße“ ḥuṣūn treten im gesamten Verbreitungsgebiet tribal-bäuerlicher Wohnarchitektur vom Nord-'Asīr bis zum Nordrand des südlichen Hijāz auf (Abb. 73). ${ }^{362}$ Allerdings sind sie im Bilād Zahrān, mit seiner hohen Bevölkerungsdichte und seiner Untergliederung in starke tribale Subgruppen häufiger als im Gebiet der Banū 'l-Hajar, Ghāmid oder Thaqîf. Diese Türme sind die Empfangs-, Beratungs- und manchmal auch Wohngebäude

362 ef. auch Gingrich 1983b: IX (Illustr. 17). 
der Shaykh's mancher Einzelstämme der genannten Föderationen. Sie befinden sich in jenen Dörfern, in denen die Deszendenzverbände der betreffenden Häuptlinge ihre Hauptwohnsitze haben (aber natürlich hat nicht jeder einzelne Häuptlingsverband einen derartigen Turm). Der jeweilige Häuptling hat darüber hinaus ein eigenes Wohnhaus im Dorf, in dem er und seine (meist polygyne) Familie normalerweise leben.

Der weiße hususn dient besonderen Anlässen, und nimmt eine zentrale Stelle im Ort ein, etwa auf einem Hügel. Der breite, viereckige und nicht sehr hohe (zwei- bis dreistöckige) Turm kann aus Ziegeln oder gut behauenem Schiefer errichtet sein und ist in jedem Fall auch außen weiß verputzt. Die Mauerkronen sind mit dachartigen Zier- und mit Eckzinnen aus Gips (um einen Holzkern, 'aswara) besetzt, Schießscharten weist ein solcher Bau nicht auf: Es handelt sich um einen nicht-defensiven Repräsentationsbau, dessen ganze Ausstattung wiederum darauf hinweist, daß sein Inhaber sich nicht selbst schützen muß, sondern vom ganzen Stamm geschützt wird.

Der Aufgang zu den Obergeschoßen erfolgt über ein Stiegenhaus, das mit Ziegeltreppen um eine oder zwischen zwei Binnenmauern hochführt. Eine kastenartige, seitlich aus der Wand ragende, hölzerne Latrine in einem der Obergeschoße zählt meist zur Grundausstattung dieser Türme, und in manchen Fällen auch eine hölzerne hervorragende Veranda oder ein offener, überdachter Balkon. Veranda und Balkon sind sorgfältig mit Holzschnitzereien verziert und tragen denselben Namen, den wir bereits im ersten Abschnitt bei der Diskussion der städtischen Architektur von al-Qunfudha und alȚā̉if begegnet sind - rawshān. Auf der Dachterrasse kann eine Regenwasserzisterne (über der tragenden Binnenwand und der Mauerkrone) eingerichtet sein; Wasserversorgung im Haus gibt es sonst in kaum einem traditionellen Wohnhaus des südlichen Ḥijāz.

Es handelt sich hierbei um einen spezialisierten, luxuriösen, nicht-defensiven Repräsentationsbau der ländlichen tribalen Oberschicht, in dem und mithilfe dessen lokale tribale Führungskräfte nicht bloß ihre eigenen, sondern zugleich die Interessen der ganzen tribalen Gruppe vertreten. Als „öffentliches“ Haus und gemeinsamer Ort der Gastfreundschaft stellt der weiße ḥuṣn damit eine unabhängige, entfernte Parallele zu den „Gästehäusern" des 19. Jh. in den zentralen kurdischen Gebieten dar. ${ }^{363}{ }^{2 m}$ 'Asīr sind die Wohnhäuser der tribalen Oberschicht Elaborierungen und Extensionen der tribalen, volkstümlichen Architektur - mit ihren komplexeren Stiegenhäusern und ritualisiert getrennten Innenräumen. Hier im südlichen Hijāz hingegen hat die tribale Oberschicht nicht komplexere Formen aus den durchschnittlichen Gebäuden heraus entwickelt, sondern eigene spezialisierte und separierte Hausformen: Sozial stehen sie „im Mittelpunkt“ der öffentlichen, gemeinsamen tribalen Interessen; aber architektonisch repräsentieren sie etwas anderes als den tribalen Baustil. Stützsäule, Stein- und Holzdekor fehlen hier. Ziegel und gezimmerter Baustein, der Verputz und der Mangel an defensiven Einrichtungen, Zisterne, Latrine und Balkon - all dies verweist klar auf städtische architektonische Einflüsse. Der historische Bezug zu den relativ nahen Zentren, vor allem zu al-Țā'if, hat hier gesonderte ländliche Extensionen der städtischen Architektur produziert.

So wenig der rawshān des weißen hụṣn ein verfeinertes Ergebnis der ländlichen Kunsttischlerei ist (sondern vielmehr ein vereinfachtes Ergebnis städtischen Handwerks-

363 Van Bruinessen 1989. 
einflusses darstellt), ebensowenig gehen die Holzelemente in der Architektur des nördlichen Bl. Zahrān auf die Wanderhandwerker des Bl. Ghāmid zurück.

Im nördlichen Grenzgebiet der Provinz al-Bāha zu jener von Mekka liegen die ZahrānGebiete von Daws und al-Qarā. Vergleichende Stichproben haben einen Anteil von Holzbalkonen bei $100 \%$ und von hölzernen Außenlattenwänden anstelle einzelner Außenmauern bei 60 \% ergeben (Abb. 74); hingegen lag er im südlichen Bl. Zahrān 1981 nur bei $6 \%$ und $3 \%$ der Wohnhäuser. Zu diesen Holzbalkonen (tarsīl, pl. tarāsil) und Lattenwänden (rașṣ, pl. ruṣuṣ), hinzu tritt ein veränderter Dekorstil mancher Schnitzereien an den Fensterstöcken. Diese Holzformen verweisen eindeutig auf die Eigenheiten der im Norden anschließenden dritten Variante von Wohnarchitektur im südlichen Hijāz, jener der Thaqīf.

\section{Niedrige Lattenwandhäuser (Thaq̄̃f)}

Die Nordabhänge des südlichen Hijāz flachen allmählich zu jener breiten Senke ab, die den Gesamtverlauf der Hijāz-Kette unterbricht und zwischen nördlichem und südlichen Hijāz einen natürlichen Durchlaß eröffnet - den Weg von Jidda am Roten Meer nach Mekka.

Inmitten dieser hügeligen Nordabhänge liegt al-Ṭā̉if als städtisches Zentrum mit seiner alten politischen, militärischen, kommerziellen und kulturellen Bedeutung für den gesamten südlichen Hijāz. Das ländliche Siedlungsgebiet im weiteren Umfeld von al-Ṭa if ist heute, wie bereits zu Zeiten des Propheten Muhammad, Territorium der Thaqīf. ${ }^{364}$

Nur in sehr eingeschränktem Maß gelten die Charakteristika des gesamten „nordwestlichen“ Subtypus von Architektur im südlichen Hijāz auch für diese dritte und letzte Variante. Schmucklose, ein- bis zweigeschoßige Hütten mit Flachdach gibt es auch in den benachbarten Teilen der Küstenebene, Innerarabiens und des nördlichen Hijāz, ebenso wie in Palästina, und auch die charakteristischen Lattenwände treten, wie schon erwähnt, sporadisch auch in der dortigen Architektur auf. Nur zwei Elemente der ThaqīfArchitektur verbinden sie eindeutiger mit jener des übrigen südlichen Hijāz als mit der anderer Nachbarregionen. Dies sind die Wehrtürme mit ihrem weißen Steindekor, und die dekorierten hölzernen Stützpfeiler im Hausinneren. ${ }^{365}$ Dies erlaubt, im konstruktiven und dekorativen Sinn die Lattenwandarchitektur als Variante des nordwestlichen Subtypus zu klassifizieren, dem aber in ökologischer und technischer Hinsicht bereits alle Merkmale einer Übergangsform zur Küste, vor allem aber nach Nord- und Innerarabien hin anhaften.

Die zerklüfteten, schroffen Talschaften und Bergkämme des südlichen Bl. Zahrān sind die eigentlichen Regenfanggebiete des südlichen Ḥijāz. Seine Nordabhänge hingegen werden nur von seitlichen Steigungsregen gestreift, sind aber in den trockeneren und heißeren Jahresabschnitten auch nach Norden und Osten hin exponiert. Dies erfordert andere Vorkehrungen zur Luftzirkulation als im Zentralteil des südlichen Hijāz. Ein, zwei und manchmal sogar drei ${ }^{366}$ Lattenwände sichern einen stärkeren Luft- und Temperaturaustausch zwischen dem Binnenklima der Häuser und dem Außenklima. Diese Latten sind

364 Balādhūrī 1966: 87.

365 Dostal 1983c: I-II (Illustr. 2, 4).

366 Dostal 1983c: 15-18. 
gerade, miteinander parallel verschnürte Hölzer und Bretter, die senkrecht in die Erde eingelassen und mit waagrecht fixierten Langhölzern zusätzlich stabilisiert werden. Außen- und Innenseite der Lattenwände können, müssen aber nicht mit Lehm und Gips abgedichtet, verputzt und stabilisiert sein. In jedem Fall ist zumindest eine Außenwand aus Stein errichtet und ebenso wie die Lattenwände entweder roh belassen oder verputzt. Unverputzte Außenlattenwände erlauben die Durchlüftung dort, wo der Wind nicht zuviel Staub und Sand mit sich bringt.

Zweigeschoßige Häuser sind aus statischen Gründen in den Hang hinein errichtet, wobei das Erdgeschoß mit einer unterteilenden Binnenmauer durchwegs aus Stein errichtet ist, und die Lattenaußenwände nur im Obergeschoß eingezogen sind. Latteninnenwände, die ja im Wohnbau des gesamten südlichen Hijāz üblich sind, werden in der Thaqîf-Architektur besonders häufig zur Abtrennung der Innenräume eingesetzt.

Die Außenlattenwände alleine können das Dachgewicht hier kaum tragen. Wo zwei derartige Wände miteinander ein Hausecke bilden, ist daher ein fester Baumpflock als Eckpfosten in den Boden gerammt, an dem die Lattenwände fixiert sind und auf dem das Dach ruht. Dennoch trägt der Stützpfeiler im Inneren des mafraj hier einen guten Teil des Dachgewichtes.

Zusätzlich zum auch hier mit Holzschnitzereien dekorierten Stützpfeiler in der Mitte ist der mafraj mit Lehmbänken an den Wänden und mit einer Herdstelle ausgestattet, wofür das Material beim Hausbau ohnedies bereitsteht.

Die Fassaden der Thaqīf-Häuser sind durch die Lattenwände noch durchlässiger und angreifbarer als es bei diesem Subtypus ohnedies schon gegeben ist. In vielen Fällen wird dies teilweise ausgeglichen durch eine Ummauerung mithilfe einer Stein- oder Lattenwand, die einen Vorhof vor dem Hauseingang bildet. Diese ansonsten im südlichen Hijāz seltenen Vorhöfe (hawsh) ${ }^{367}$ sind aufgrund dieser funktionalen Komplementarität zu den Außenlattenwänden hier recht häufig. Darüber hinaus stellen sie eine offensichtliche Parallele zu den Außenhöfen der räumlich anschließenden Najd-Architektur dar, und eventuell auch zu den weiter entfernt auftretenden 'arā'ish der 'ushash-Hütten in der Tihāma. Diese Vorhöfe gewähren auch die gleichen funktionalen und sozialen Möglichkeiten wie die erwähnten Parallelen. Ställe und Verschläge für Kleinvieh können separiert im Vorhof errichtet und eine Kochstelle kann dort im Freien angelegt sein; bei polygynen Haushalten sind die separierten Hütten oder Häuser der zusätzlichen Ehefrauen mit ihren Kindern auf den gemeinsamen Hof ausgerichtet, der damit auch erhöhte Mobilität und Arbeitsmöglichkeiten für die Frauen außerhalb der engen Lattenwandhäuser bietet.

Die Durchläßigkeit der Lattenwände und die Ausdehnung der Vorhöfe sind zwei der Gründe, weshalb die Häuser hier größere Abstände voneinander halten. Auch das landwirtschaftliche Terrain und die hohen in-towers erlauben, daß die Thaqîf-Dörfer eher als Streusiedlungen angelegt sind.

Die Auswertung osmanischer Archive oder der arabischen Quellen zur Stadtgeschichte von al-Ṭă if kann wohl erst Aufschluß darüber geben, inwieweit die noch bestehenden Wehrtürme der Thaqīf-Region auf städtische und staatliche Anstrengungen zurückzuführen sind, und inwieweit sie direktes Ergebnis baulicher Arbeit und Nutzung durch die örtliche tribale Bevölkerung darstellen. Bei einigen der wenigen, noch existierenden Wehr-

367 Für ein Beispiel aus al-Mandaq im Bilād Zahrān cf. Gingrich 1983b: 83f., 85. 
türme fällt jedenfalls ihr undekorierter, roher und schlecht gemauerter Zustand auf, was aber auch materialbedingt sein kann. Die Mehrheit der bestehenden Türme und „gekürzten" Turmreste ist hingegen gleichfalls aus Schiefer errichtet, den man fallweise auch von entferntesten Abbaustellen herantransportiert haben muß, um hier huṣūn von entsprechender Höhe errichten zu können. Diese $i n$ - und out-towers sind mit der gleichen Art von Quarzsteinmuster dekoriert, das für die Türme im übrigen südlichen Hijāaz typisch ist.

Lattenwände, Eckpfosten und Vorhöfe der Thaqīf-Architektur sind also besondere Elemente dieser Variante, die sie von den anderen beiden unterscheiden und auf die ökologische und soziale Nähe zu den Nachbargebieten an der Küste, in Innerarabien und im nördlichen Hijāz verweisen.

Unter denjenigen Elementen, welche der Thaqīf-Variante hingegen mit dem architektonischen Subtypus des südlichen Hijāz gemeinsam sind, ragen zwei heraus, die nicht primär ökologisch oder technisch bedingt sind: Dies sind die Dekorformen, also die Quarzsteinmuster an den Turmfassaden und im mafraj die Holzschnitzereien an den Stützsäulen.

\subsubsection{Dekorformen in der Architektur des südlichen Hijāz}

Die wesentlichen Dekorformen in der Architektur des südlichen Hijāaz sind der weiße Zierstein und die Holzschnitzereien. Die sporadisch auch im Süden gegebenen Innenbemalungen des mafraj im Bl. Ghāmid stellen hingegen bloß periphere Übergangsformen zum `Asīr dar; schmiedeeiserne Türringe schließlich sind seltene Statussysmbole.

Der weiße Zierstein ist ausschließlich außen an den Fassaden angebracht. Die Holzschnitzereien treten hingegen vorwiegend im Hausinneren auf, sie können in untergeordnetem Ausmaß aber auch außen bestimmte Fassadenteile (nämlich die holzbekleideten Öffnungen des Hauses nach außen und deren verschließbare Flügel) schmücken. Der weiBe Zierstein ist die häufigere Dekorierung der in- und out-towers; die Holzschnitzereien hingegen dekorieren in einem bei weitem überwiegenden Ausmaß die Wohnhäuser. Insoferne markiert das Verhältnis der beiden Dekorformen zueinander zwar nicht ausschließlich, aber doch sehr weitgehend die Beziehung von Außen zu Innen, und von friedlichem Wohnen zu wehrhafter Wachsamkeit im Zusammenhang mit dörflich-tribaler Architektur.

$\begin{array}{cc}\text { A } & \text { B } \\ \text { außen } & \text { innen } \\ \text { wehrhafte Wachsamkeit } & \text { friedliches Wohnen } \\ \text { Steindekor } & \text { Holzschnitzereien } \\ \text { Kampf } & \text { Gastfreundschaft } \\ \text { Dachbrüstungen } & \text { zentrale Holzelemente }\end{array}$

Vor dem Hintergrund dieses allgemeinen Beziehungsprinzips (A:B) ergeben sich beim Steindekor, dem wir uns zunächst zuwenden, zwei klar umgrenzbare Ausnahmen. In der Felssteinarchitektur des Bl. Ghāmid sind, wie erwähnt, die Wohntürme nicht mit Quarz dekoriert, der durch das größere Gewicht dieses Baumaterials zerstört werden würde; die Wohnhäuser und manche Türme tragen hier „ersatzweise“ Zinnen, an einigen Wohnhäusern ist Quarzstein bloß über den Schießscharten angebracht. Diese Abweichungen sind also primär materialbedingt - allerdings haben die lokalen Erbauer und Nutzer der Fels- 
steinarchitektur nach Ersatz für diese materialbedingte Aussparung des Quarzsteins gesucht, und sie im Zinnendekor des benachbarten Nord-`Asīr gefunden. Zinnendekor und bunte Innenmalerei am architektonischen Dekor der Bl. Ghāmid südlich von Biljurshī verweisen also gemeinsam auf den Nord-'Asīr, hingegen entsprechen die seltenen Quarzsteindekorierungen und die im Bl. Ghāmid besonders ausgeprägten Holzschnitzereien den allgemeinen Dekorformen des südlichen Hijāzz.

Die zweite, weniger häufige Ausnahme vom allgemein dekorativen Beziehungsprinzip (A:B) stellen jene Dörfer der Lattenwand-Architektur im Norden dar, die nicht, oder nicht mehr von in-towers beschützt werden, oder nur von undekorierten in-towers. Für diese kleine Teilmenge ist bereits der politisch-militärische Faktor als der vermutlich maßgebliche angeführt worden; die Mehrheit der traditionellen architektonischen Formen des Bl. Thaqī entspricht allerdings dem allgemeinen Beziehungsprinzip. Aus materialbedingten (südliches Bl. Ghāmid) und politisch-militärischen (nördliches Bl. Thaqīf) Gründen fehlt also der Steindekor (A) an den Turmfassaden (B) dieses norwestlichen Subtypus eher als die vorwiegend im Wohnhausinneren angebrachte Holzdekorierung (B).

Nach Erörterung dieser Ausnahmen kann nun der Steindekor selbst diskutiert werden. Das durchgängige Grundmotiv des Steindekors (naqsh) aus weißem Quarz (marw) ist im südlichen Hijāz ein gleichschenkeliges Dreieck (muthalatha), dessen Spitze nach oben zeigt. Das Dreieck kann entweder als Einzelmotiv isoliert auftreten, oder in Kombinationen. Als Einzelmotiv ist es über den Schießscharten der Türme und Wohnhäuser angebracht, also im Unter- und Mittelteil der Fassaden. Die Kombinationen wiederum sind ausschließlich im Oberteil der Fassaden zu finden, nämlich (selten) unterhalb der Mauerkronen von Wohnhäusern und (meistens) an den Wehrbrüstungen der Türme. Dort aber treten keine Einzelmotive, sondern nur horizontal gegliederte Kombinationen in Zeilenform auf, wobei ich fünf zunehmend komplexere Zeilenformen unterscheide (Taf. XLVIII). Diese fünf Zeilenformen belegen, daß das mit der Spitze nach unten „hängende“ Dreieck und die waagrechte, einfache oder doppelte Linie die ergänzenden Motive zum eigentlichen Grundmotiv sind, welches in jeder Kombination die Basis bildet - nämlich das ,aufrechte" Dreieck, das im Mittelteil der Fassade auch als Einzelmotiv, hier aber überall vervielfacht als Zeile auftritt.

Die fünf Steindekorzeilen repräsentieren nicht nur (von Zeile 1-5) zunehmende optische Komplexität, sondern zugleich zunehmenden Aufwand an Material und Arbeit.

Demgemäß symbolisieren die komplexeren Formen $(4,5)$ ein mehr an Wohlstand, was seinerseits einer von mehreren Indikatoren für sozialen Status ist. Diese Formen 4 und 5 dekorieren daher - sofern sie überhaupt gegeben sind - eher Brüstungen und Mauerkronen der Türfassaden, während die Seiten- und Hinterfassaden dann meist nur mit einer der einfacheren Formen (1-3) versehen sind. Auch die einfacheren Formen können die türseitigen Fassaden anderer Türme und Wohnhäuser dekorieren, deren Erbauer sich keinen höheren Dekoraufwand leisten wollen oder konnten. In diesen Fällen sind die Seiten- und Hinterfassaden entweder mit dem gleichen Muster oder überhaupt nicht dekoriert, wobei der letztgenannte Fall vorwiegend bei Wohnhäusern gegeben ist, bei denen aber der Steindekor schließlich auch ganz fehlen kann.

Diese Verteilung der Steindekorzeilen offenbart damit ein ähnliches Prinzip der Hierarchisierung nach zunehmender Komplexität, wie es bereits anhand der Zinnendekorierung auf den Adobe-Varianten des südöstlichen Subtypus für das W. Najrān demonstriert worden ist. Im nordwestlichen Subtypus werden überdies die Frontseiten privilegiert, 
aber auch hier steht größere Komplexität für höheren Status des „Hauses“ - also von „bayt“ im architektonischen wie im sozialen Sinn des Wortes. Im höchsten tribalen Statusrang eines Shaykh, den die Fassadenseiten von Turmarchitektur mit ihrem Dekor bezeichnen können, verschwinden die Quarzsteinzeilen allerdings; sie werden dann durch die urbanen Elemente des weißen ḥuṣn ersetzt.

Die dreieckigen Ziersteine sind damit ein regionales, tribales Dekorelement im südlichen Hijāz (mit besonderer Affinität zum Bl. Zahrān), das an der Außenseite der Architektur Wachsamkeit und Wehrhaftigkeit symbolisiert und darüber hinaus noch den sozialen Status des Bauherrn oder seiner Nachfahren anzeigt. Wie gezeigt, kontrastiert diese symbolische Form des aufrechten Dreiecks zu jener des Rechtecks im Zentral- ${ }^{c}$ Asīr und zu den Übergangsformen dazwischen.

Das Pendant zum Zierstein ist die Holzschnitzerei im Inneren. Während die Ziersteindekoration vom gleichen Bautrupp angelegt wird, der auch das Haus errichtet, werden die Holzdekorierungen zum überwiegenden Teil von jenen Wanderhandwerkern hergestellt, die in wenigen Produktionszentren des Bl. Ghāmid ansässig sind. Sie werden unter sozio-ökonomischen Gesichtspunkten an anderer Stelle von W. Dostal untersucht. ${ }^{368}$ Es genügt daher der Hinweis, daß das Synonym für einen dieser Kunsttischler oft „Makramī“ ist (jemand, der aus Dār al-Makārima bei Biljurshī im Bl. Ghāmid stammt), auch wenn heute bereits viele andere Stammesmitglieder der Region dieses Handwerk ausüben. Diese Wanderhandwerker führen Auftragsarbeiten im Nord-'As̄̄r, im südlichen Hijāz, und auf den vorgelagerten Tihāma-Bergen durch.

Die Stützpfeiler sind ein konstruktives Merkmal des gesamten Subtypus. Unter ihnen sind jene im mafraj fast immer dekoriert, jene außerhalb des mafraj hingegen fast nie. Nicht dekorierte Stützpfeiler im mafraj sieht man nur ganz selten in den Wohn- und Versammlungsräumen der traditionellen Bauten, nämlich bei den wenigen sehr armen tribalen Haushalten der Region. Unter den dekorierten Stützpfeilern ist wiederum nur eine verschwindende Minderheit nicht von den Wanderhandwerkern oder anderen Spezialisten dekoriert worden, sondern von Haushaltsangehörigen selbst: Dies ist an den abweichenden Motiven erkennbar, die Feldfrüchte oder auch Tierköpfe darstellen können; zumeist wird die Urheberschaft eines Vorfahren für derartigen Dekor auch von den Bewohnern erinnnert.

Die Dekorierung der Stützsäule hat vor allen anderen Holzelementen in jedem Haushalt Priorität. Bei entsprechendem Wohlstand sind als nächstes die Außenseite und der Türstock des Eingangstores dekoriert, danach andere Stützpfeiler im Inneren des Hauses, dann die Flügel und Stöcke der Fenster. Besonders wohlhabende Haushalte haben auch dekorierte Holzverkleidungen in ihrem mafraj an den Wänden anbringen lassen. Die Holzdekorelemente im Inneren des Hauses sind oft mit Kohlpech (qār, quṭān) bestrichen oder (erst bei neueren Ausführungen) bunt bemalt; für die etwas einfacher dekorierten Holzelemente an der Fassade verzichtet man darauf.

Aus diesen verschiedenen Erweiterungen der Holzdekorierung geht wiederum hervor, daß ihr variabler Anteil persönlichen Status und Reichtum der Haushaltsvorstände anzeigt. Das davon aber nahezu unabhängige, stets gegebene Element ist die Dekorierung des oder der Stützpfeiler im mafraj.

368 cf. auch Dostal 1983c: 51-57. 
Ein Pfeiler setzt sich stets aus dem Kapitell (falka) und der eigentlichen Säule (zāfir) zusammen; das Kapitell trägt die überspannenden Balken und ist selbst aus zwei oder mehr Teilen gezimmert. Vorder- und Hinterseite (wajba und janba) bilden jeweils parallele Ebenen, die Dekorflächen. Die beiden Schmalseiten (janbāya) sind gekrümmt und gewinkelt, und weniger spektakulär verziert.

Die Dekorierung kennt trotz gewisser, beschränkter Variationen der individuellen Ausführung eine Reihe von grundlegenden Gemeinsamkeiten. Die Motive sind meist als hervorragende, und seltener als vertiefte Reliefs gearbeitet. Von den Hauptmotiven sind Rand- und Zwischenleisten zu unterscheiden (Taf. XLIX). Die Dekorierung der Säulen und der anderen Holzelemente im Hausinneren ist dabei nicht grundsätzlich voneinander verschieden. Parallelität und Symmetrie sind die formalen Prinzipien der Gestaltung. Die parallelen Zwischenleisten untergliedern Kapitell- und Säulenfläche in horizontale bandartige Streifen, manchmal auch in zentrierte, senkrechte Felder mit Randleisten. Diese Felder und Streifen sind dann regelmäßig mit Hauptmotiven belegt. Unter diesen Hauptmotiven sind etwa zwei Drittel unabhängig von lokalen Traditionen und persönlicher Gestaltung im gesamten südlichen Hịjāz verbeitet. Dazu zählen das flache $\mathrm{X}$, das stehende und das liegende leere Karo, das gefüllte Karo, und einfache Blumenmotive (Taf. XLIX, Abb. 76 und 77). Die wichtigsten, heute geschnitzten Rand- und Zwischenleisten sind Linie, Treppen-, Wellen- und Zackenleiste.

Durch Interviews in Dār al-Makarīma konnte dieser regional relativ uniforme Anteil von Motiven als derjenige ermittelt werden, der sich in den letzten drei Generationen selbst auch kaum verändert hat, wenn auch die (1981/82) dreißig- bis vierzigjährigen Tischler zusätzlich einige neue Motive verwenden. Dies sind fast durchwegs kombinierte, komplexere Blumen- und Karomotive. Die in der letzten Generation konstatierbare Bereicherung und Ausgestaltung der Motive ist bemerkenswert: Sie belegt, daß der zunehmende Geldverkehr und die Öffnung der Region nach außen zunächst eher zu einem Anstieg der Nachfrage nach diesen Auftragsarbeiten und zu einer Integration neuer Stilelemente in den traditionellen Dekor geführt haben. Darüber hinaus dürfte dieser kleine, neuere Anteil an Motiven durch den Zustrom an Makramī-Tischlern in den 40er Jahren gefördert worden sein.

Die Kontinuität der traditionellen Hauptmotive wurde mir von Kunsttischlern, die um die siebzig Jahre alt waren, bestätigt. Da manche dekorierte Stützsäulen in alten Häusern auch datiert sind, konnten diese mündlichen Informationen mit den ältesten datierten Stützsäulen im südlichen Hijāz verglichen werden. Letztere stammten aus dem ersten Drittel des 19. Jh., die älteste aus al-Rușuba im Bl. Zahrān stammte aus dem Jahr 1249 H. (1833). Auf diesen alten Stützsäulen befanden sich zwar einige, heute beinahe vergessene Formen von Band- und Zwischenleisten, aber die Grundmotive entsprachen im wesentlichen den heute als „traditionell“ identifizierten X der Karozeile (Abb. 77, 78) und Blume.

Die Art des verwendeten Holzes scheint sich im Lauf der letzten 160 Jahre allerdings geändert zu haben. Während man in den letzten zwei Generationen talh, 'utm und 'ar'ar oder importierte Hölzer bevorzugt hat, scheint im 19. Jh. neben den drei letztgenannten der șidr sehr wichtig gewesen zu sein. Heute wird unter Berufung auf moralische Gebote, trotz nach wie vor großem șidr-Bestand, davon Abstand genommen, dieses Holz für die Dekorelemente zu nutzen. Davon abgesehen ergibt sich aber für den Holzdekor über 140 Jahre hinweg eine nachgewiesene Kontinuität, die von der Form der Stützsäulen bis in die Details der Motive reicht. 
Die erste Konsequenz aus diesem Ergebnis liegt darin, daß diese Tradition mindestens 100 Jahre älter ist als der Zeitpunkt der Ankunft (um 1940) der ersten Makramī-Tischler bei al-Bāhạ, wo „the Makramī carpenters had to adapt to the new cultural environment“" 369 Dieser soziale Strukturwandel unter den Tischlern fördert zusätzlich die erwähnten Veränderungen im verwendeten Dekor. Aber zugleich griffen die Makramī primär die Traditionen der älteren Muster auf, und paßten sich damit, wie Dostal bereits erkannt hat, der kulturellen Nachfragestruktur der ansässigen tribalen Bevölkerung an. Wer die Vorläufer dieser Handwerker-Spezialisten waren, die im 19. und frühen 20. Jh. die älteren Stützsäulen herstellten und dekorierten, konnte nicht mehr eindeutig eruiert werden. Am wahrscheinlichsten ist, daß sie tribale Bauernhandwerker der Ghāmid und Zahrān waren - so wie auch heute noch eine Minderheit unter den Tischlern und Steinarbeitern, von denen ein Teil mit den Makramī verschwägert ist.

Die zweite Konsequenz dieses Resultates ist also die Existenz einer „longue durée “ im Holzdekor, die sich unabhängig vom individuellen Talent der Tischler, von der persönlichen Nachfrage einzelner Bauherrn und sogar von der Herkunft der Handwerker als überlokale, kollektive, tribale Tradition einer ganzen Region erhalten hat. Dafür ist gezeigt worden, daß nicht das tradierte Wissen um Herstellungs- und Dekortechniken seitens der Tischler für die (konstante) Ausgestaltung der Dekorformen entscheidend war, sondern die tradierte Nachfrage durch tribale Auftraggeber.

Diese schließt notwendigerweise auch die longue durée einer Tradierung der Konzeption dieser Stützsäulen und ihres dekorativen und symbolischen Gehaltes ein: Aus dem Verhältnis (A:B) zum Steindekor wurde für den Holzdekor im Inneren, und damit für die Stützsäule als sein konstantes Zentralelement, die Konnotation des „friedlichen Wohnens“ im Gegensatz zur äußeren „wehrhaften Aufmerksamkeit“ bereits erschlossen. Im Schlußabschnitt soll dieses, aus der Analyse des Dekors gewonnene Teilergebnis mit der Analyse von sozialen Kontexten der architektonischen Räume im südlichen Hijāz verbunden, und mit den Dekorformen im 'Asīr verglichen werden.

\subsubsection{Zusammenfassung: Architektur-Dekor und Gesellschaft IM süDWestlichen BERGLAND}

In den einleitenden Abschnitten (5.1.) wurden die konstruktiven und technischen Gemeinsamkeiten und Besonderheiten des architektonischen Typus der defensiven Hochbauweise und seiner beiden Subtypen herausgearbeitet; in der Folge ist dies für jede Variante und Subvariante ausgeführt, im sozialen Zusammenhang erläutert und mit den jeweiligen Dekorformen kontrastiert worden. Der konstruktive und technische Aspekt dieser Untersuchung ist damit abgeschlossen. Offen geblieben ist noch die Zusammenfassung der Einzelergbnisse zum sozialen und symbolischen Gehalt der Außen- und Innendekorierung von traditioneller Architektur im südwestlichen Bergland Saudi Arabiens.

Konstruktiv und funktional gibt gerade die Defensiv-Architektur eine Gliederung der Dekorflächen primär in wehrhafte Außenseite und andererseits geschützte, lebensweltliche Innenseite vor. Dies ist der durch praktische Erfordernisse geprägte Kontext, in den die Dekorflächen dieses Architekturtypus eingebunden sind.

369 Dostal 1983c: 55; er gibt diesen Zeitpunkt für einen dieser Linienverbände mit den frühen 1940er Jahre an. 
Die Betonung des defensiven Aspektes hebt die Außenseiten der Bauten in sozialer und semantischer Hinsicht bei diesem Typus anders hervor als im Küstenstil, in der 'ushash-Architektur oder bei den Najd-Bauten. Wehrhafte Abschirmung und Herausforderung ist unter allen vier identifizierten Typen des saudischen Südwestens nur für die tribale Architektur des Berglandes das oberste Gestaltungsprinzip der Fassaden.

In zweiter Hinsicht geben die konstruktiven und funktionalen Eigenschaften dieses Typus aber auch eine Gliederung der äußeren und inneren Seiten in oben, im Zentrum oder unten gelegene Dekorflächen vor.

Diese zweite Gliederung ist nicht durchgängig vorhanden, weil ihr in manchen Regionen die „architektonische Arbeitsteilung“ zwischen hohen in-towers und ebenerdigen Wohnbauten entgegensteht (in den peripheren und transitorischen Subvarianten von Steinbau des südöstlichen Subtypus, und in den Thaqīf- und Ghāmid-Varianten des nordwestlichen Subtypus). Auch in dieser Minderheit von Ausnahmen ist durch die in-towers das Prinzip defensiver Hochbauweise zwar eingehalten, aber die Wohnbauten alleine lassen eine Gliederung in obere und untere Räume und Flächen dann eben kaum zu. In der Mehrheit der mehrgeschoßigen Wohnbauten hingegen, und bei allen tribalen in- und outtowers ist diese sekundäre Gliederung in untere, mittlere und obere Räume und Dekorflächen gegeben.

An den Außenseiten geben wiederum praktische Notwendigkeiten bestimmte dekorative Präferenzen gegenüber dieser Gliederung vor. Gerade der Dekor soll so angebracht sein, daß er gut sichtbar und nicht ständig der Gefahr von Beschädigungen ausgesetzt ist, sei es durch Fluten, durch das Vieh, durch Arbeitsverrichtungen oder durch Kampfhandlungen. Daher sind die unteren Außenseiten der defensiven Hochbauten in der Regel weniger dekoriert als die mittleren und oberen Partien. Wenn überhaupt, dann ist am unteren Teil der Außenfassade meist nur das Eingangstor geschmückt - mit Farbe an den Adobe- und Pagoden-Bauten, mit Quarzdekor bei den Steinbauten (über dem Torsturz), und mit Holzdekor (häufiger im südlichen Hijāzz und Nord-'Asīr). Ansonsten aber dominieren an den Außenseiten die mittleren und oberen Teile als Dekorflächen.

Im Inneren herrschen ähnliche praktische und lebensweltliche Notwendigkeiten vor: Das „fusion pattern “ impliziert, daß die Stallungen und Lagerräume für Geräte unten liegen und selbstverständlich undekoriert bleiben. Küche, Vorratsräume und Schlafzimmer sind nur zur Nutzung der Hausbewohner gedacht, und stets undekoriert. Für die inneren Räume und Flächen des Hauses gilt also zusätzlich, daß darunter nur jene als Dekorflächen ausgesucht werden, die auch hausfremden Personen zur friedlichen Nutzung angeboten werden können.

Erstens folgt daraus, daß die Innenräume der in- und out-towers nahezu immer undekoriert sind: Diese Räume werden zwar oft von mehreren Personen aus verschiedenen Haushalten genutzt, aber dann eben nicht friedlich, sondern wehrhaft. Der Innendekor betont also friedliche und kollektive, über den Einzelhaushalt hinausreichende soziale Aspekte. Diese sind per definitionem nie in den Wehrtürmen gegeben, sondern nur in den Wohnbauten. Und von den ebenerdigen Ausnahmen unter den Häusern abgesehen, sind diese friedlichen und kollektiven Aspekte stets in den mittleren oder oberen Geschoßen gegeben - also immer dort, wo der mafraj angelegt ist, eventuell auch der gesonderte mafraj der Frauen. Nur fallweise und ergänzend sind auch die Gänge, die im Hausinneren zum mafraj führen, mit Bemalung oder Schnitzdekor verziert - was aber selbst dann eher ein rezentes Phänomen ist. 
Außen sind die Mauerkronen, Fenster, Türen und Schießscharten die bevorzugten Dekorflächen, die in der Mitte und im Oberteil der Fassaden liegen, und auch im Inneren liegt der mafraj vorwiegend im Mittel- oder Oberteil und ist dort der nahezu einzige Ort des Dekors. Der untere Teil der Häuser und Türme ist außen selten, und innen nie dekoriert: Über zusammenfassende Bestätigung des Evidenten hinaus hat dieser erste Überblick ergeben, daß dem Dekor dieses Typus wesentliche Kontexte gemeinsam sind, die auf den praktischen, konstruktiven und funktionalen Eigenschaften der Architektur aufbauen und diese symbolisch überhöhen. Die Inhalte symbolischer Überhöhung grenzen diesen Typus zugleich von allen anderen Typen des saudischen Südwestens ab.

Mit Hilfe des Dekors der Außenseiten wenden sich die Bewohner des Einzelhauses in einer kollektiven, vielen gemeinsamen und verständlichen ästhetischen Sprache an anonyme Andere und Fremde. Die Botschaft dieser kollektiven ästhetischen Sprache ist durch die defensiven Kontexte der Fassaden weitgehend vorgegeben und auf die mittleren und oberen Partien konzentriert.

Der Innendekor wendet sich hingegen seitens der Hausbewohner ausschließlich an persönliche Besucher, und vermittelt durch den funktionalen Kontext seiner Räume friedlichen, kollektiven und gastfreundlichen Lebensalltag.

Dieses allgemeine Beziehungsmuster gilt für den gesamten Typus, und enthält damit eine grundlegende Gemeinsamkeit - nämlich jene von kollektivem, tribalen Status und tribaler Ehre. Außen wie innen repräsentiert der Dekor tribalen Status und Ehre in seinen Aspekten der Wehrhaftigkeit und der Gastfreundschaft, und zwar eher im oberen und mittleren als im unteren Teil der Bauten.

Diese Gemeinsamkeiten sind zwar abstrakt, aber wesentlich. Sie verbinden die defensive Hochbauweise mit Hilfe ihres Dekors, jenseits aller konstruktiven, technischen und ästhetischen Besonderheiten. Ungeachtet des persönlichen tribalen Status der einzelnen Bauherren grenzen diese abstrakten Gemeinsamkeiten des Dekors die tribale Architektur des Berglandes ab von jener der nicht-tribalen Gruppen und von den anderen drei Architektur-Typen des Südwestens.

Diese Art von Gemeinsamkeiten ist also verschieden von jenen Angleichungen der Dekorformen, die auf die Entwicklung des 19. Jh. oder auf reziproke technische Lernprozesse zurückgeführt worden sind, und sich jeweils nur auf bestimmte Regionen des Südwestens beziehen. Die allgemeine, abstrakte und normative Notwendigkeit, tribalen Status in der Architektur auf irgendeine gemeinverständliche Weise anzuzeigen, wird anderswo sichtbar: Etwa dort, wo der Felsstein die Ghāmid dazu zwingt, auf Quarzdekor zu verzichten, und sie stattdessen Lehmzinnen verwenden. Oder dort, wo die Ahl Fayfā in ihrem Gebiet keine Quarzvorkommen nutzen können, und stattdessen ihren Mauerkronen Eckzinnen aufsetzen.

Diese prinzipielle, abstrakte und normative Gemeinsamkeit macht den Dekor dieses Typus zum Bindeglied zwischen Architektur und Sozialstruktur, zwischen materieller Kultur und sozialen Verhältnissen. Erst auf der Grundlage dieser Gemeinsamkeit wird es sinnvoll, auch wesentliche Unterschiede im Dekor zusammenzufassen.

Für den Außendekor des südöstlichen Subtypus ist bereits auf sein Verhältnis zu den architektonischen Varianten und Subvarianten eingegangen worden: Der üppige, heterogene Dekor der Adobe-Variante reicht einerseits über die Verbeitung der Variante selbst hinaus, und andererseits untergliedert er sie, indem er das W. Najrān absetzt. Die relativ uniforme Dekorierung der Pagoden-Bauten ist integraler architektonischer Bestandteil dieser Va- 
riante und variiert mit dieser leicht zur Adobe-Variante hin. Und die Subvarianten der Steinbauten im 'Asīr werden in ihren Eigenheiten durch den Dekor synchron akzentuiert, wobei wiederum die peripherere und die transitorischen Subvarianten etwas abgesetzt sind.

Dieser Bezug von Dekor zu Architektur hat eine räumliche Dimension. Deren Verhältnis zu tribaler Territorialität wurde für die Adobe- und Pagoden-Varianten als cross- und intertribal klassifiziert, für die transitorische, zentrale und periphere Subvariante in Stein hingegen als schwache, partielle und ausgeprägte Korrespondenz.

Aus dieser Perspektive stellt die Außendekorierung des nordwestlichen Subtypus wiederum ein anderes Verhältnis her, das sich von allen Beziehungen zwischen architektonischen Varianten, Dekor und tribaler Territorialität im 'Asīr unterscheidet.

Im südlichen Hijāz herrschen partielle und ausgeprägte Korrespondenzen zwischen den drei architektonischen Varianten und der Territorialität der drei Föderationen vor. In dieser Hinsicht, die vom Dekor absieht, bestehen gewiße Ähnlichkeiten zur Variante der Steinbauweise im 'Asīr. Aber anders als im West- und Nord-'Asīr verläuft der Dekor hier nicht synchron zur mehr oder minder ausgeprägten Korrespondenz zwischen tribaler Territorialität und architektonischen Formen. Im südlichen Hijāz hat der Außendekor vielmehr inter- und crosstribalen Charakter, während die architektonischen Varianten selbst den tribalen Föderationsterritorien entsprechen. Oder anders ausgedrückt: Die Außen-, aber auch die Innendekorierung der Architektur im südlichen Ḥijāz hat eine ähnliche regionalkulturliche Verbreitung wie jene des Ost- und Zentral-'Asīr (cross- und intertribal), aber die architektonischen Varianten sind ähnlich verteilt wie jene des West-'Asīr (partielle oder ausgeprägte Korrespondenz).

Die charakteristischen Dekorformen an den Fassaden des südlichen Hijāz sind das Grundmotiv des „aufrechten“ Dreiecks, als Einzelmotiv oder in kombinierten Zeilenformen. Dieser Außendekor tritt durchwegs in der Schieferbau-Variante auf, aber nur an einem Teil der in-towers der Lattenwandarchitektur, und bloß sporadisch an der FelssteinVariante. Die dominanten Zinnen der Ghāmid-Bauten verweisen auf die Wohnbauten des Nord-'Asīr, während sich das dominante „aufrechte Dreieck“ des südlichen Hijāz absetzt vom „seitlichen Dreieck“, das sporadisch im Nord-'Asīr auftritt. Noch expliziter kontrastieren die horizontalen Dreiecksleisten des südlichen Hijā̄z zu den senkrechten Vierecksfeldern des Zentral-'Asīr. Auf der Grundlage der abstrakten dekorativen Gemeinsamkeiten von tribaler Ehre akzentuieren die konkreten Motive des Außendekors solchermaßen ebenbürtige Verschiedenheit - allerdings im südlichen Hijāz nicht von einzelnen, konkreten Föderationen, sondern wiederum als übergreifendes Prinzip. Tribale Ehre impliziert stets ebenbürtige Verschiedenheit.

Hierzu zählt auch der Aspekt der aktiven Herausforderung. Praktisch-militärisch gesehen ist es eigentlich disfunktional, dem Gegner das Zielen geradezu zu erleichtern, indem man die an sich schlecht sichtbaren, daher gut getarnten Schießscharten durch Quarzstein oder Ummalung markiert. Diese Markierung soll jedoch potentielle Gegner aufmerksam machen, bevor es überhaupt zum Kampf kommt. Sie ist Warnung und gebietet Respekt - mit einem Stolz, der auch die eigene militärische Exponierung in Kauf nimmt. Tribale Ehre mit ihren Aspekten der ebenbürtigen Verschiedenheit, der wehrhaften Aufmerksamkeit und stolzen Herausforderung sind also die impliziten, hauptsächlichen Inhalte der Außendekorierung.

Darüber hinaus sind noch weitere inhaltliche Aspekte in der Dekorierung der Außenfassaden vercodet. Sie sind durch die Ummalung oder Quarzdekorierung der Fenster- und Tür- 
öffnungen praktisch im gesamten Typus gegeben, und treten mit der modernen Abnahme gewaltsamer tribaler Konflikte noch deutlicher hervor als früher. Erstens signalisiert die Ummalung oder Quarzdekorierung von Fenstern und Toren Gastfreundschaft - gerade bei Adobe- und Steinbauten, deren Grundfarben sich aus der Ferne oft kaum von jener der Landschaft abhebt, wird dieser „einladende“ Aspekt von den Bewohnern sehr oft hervorgehoben.

Dies bezieht sich primär auf die hohen Fensteröffnungen, hinter denen auch der mafraj liegt, in dem Gäste empfangen werden, und auf das Tor, durch welches sie eintreten können. Damit findet sich ein wichtiges symbolisches Element der Innendekorierung auch an der Fassade, gemäß A:b::B:a. Als Ausformung der tribalen Ehre hat die Gastfreundschaft auch außen ihren selbstverständlichen, wenn auch untergeordneten Platz. Und schließlich ist noch auf die stereotypen, immer wieder geäußerten Mitteilungen zu verweisen, wonach sich eben diese Dekorierungen auch an nicht-menschliche Wesen wenden, nämlich an die jinn. ${ }^{370}$ Diese feinstofflichen Wesen, Dämonen oder Geister, deren Existenz der Qur'ān anerkennt, sollen durch die dekorativen Markierungen ferngehalten und abgewendet werden. Ihnen gelten die Dekorierungen an oder über allen Öffnungen der Fassaden ebenfalls - also an Schießscharten, Fenstern und Toren.

So wie geglaubt wird, daß die jinn durch die Öffnungen des Körpers in den Menschen fahren können, ebenso wird auch ihr Eindringen durch die Öffnungen des Hauses befürchtet. Der Dekor verwendet das „Haus“ als metaphorischen, sozialen und materiellen Körper, und trägt diesem Körper eine polysemische Sprache ein. Gemeint sind damit bestimmte Körper: Durchwegs repräsentiert die Außenseite jene Personen, die tribale Ehre mit ihren Aspekten der Herausforderung, Ebenbürtigkeit, Wehrhaftigkeit und Gastfreundschaft immer für Alle repräsentieren - für die Gruppe beiderlei Geschlechts und aller Altersgruppen: Dies sind die erwachsenen und älteren Männer.

Die Dekorsprache der Fassaden, vor allem ihrer Mittel- und Oberabschnitte, enthält damit, trotz aller und mithilfe aller regionalen Varianten des tribalen Berglandes, ein gemeinsames Ensemble von Grundbotschaften. Männliche Vertretung für die Ehre des Hauses und der Gruppe ist eine Grundbotschaft, die in den Aspekten der wehrhaften Aufmerksamkeit, der ebenbürtigen Verschiedenheit, der stolzen Herausforderung und der wohlwollenden Gastfreundschaft zum Ausdruck gebracht wird. Ubiquitär, auch in den konkreten Gestaltungsformen, wendet sich die zweite, untergeordnete Grundbotschaft hingegen nicht an Menschen, sondern an die jinn, deren schädliches Eindringen abzuwehren ist. Die Polysemie des Außendekors enthält damit einen dominanten Code der tribalen Ehre und einen untergeordneten Code der durch den Geisterglauben bedingten Abwehrmittel.

Mit diesem ersten Ergebnis können wir uns nun den sozialen Kontexten von zwei weiteren Bereichen zuwenden, nämlich dem Dach und dem mafraj. Die vorliegende Untersuchung hat bereits die funktionalen und dekorativen Unterschiede dokumentiert, die in diesen beiden Bereichen gegeben sind. Die funktionale Nutzung der Dächer im südöstlichen Subtypus unterscheidet sich von jener des Nordwestens; die dekorative Gestaltung des mafraj im südlichen Hijāz ist völlig verschieden von jener im 'Asīr, und jene im W. Najrān weicht wiederum von beiden etwas ab.

Sowohl im W. Najrān wie im 'Asīr ermöglichen die hochgezogenen, massiven Binnenmauern und Schächte eine große Belastbarkeit der Dächer, die dadurch befestigt und be-

370 cf. auch Serjeant 1949: 4-6; Henninger 1981b: 204-253; Gingrich 1995: 199-212. 
baut werden können. Aus diesem Grund ist das Dach des südöstlichen Subtypus als Ort der Wehrhaftigkeit und des Alltags bezeichnet worden, der wiederum entweder durch Küche oder mafraj geprägt ist und durch die Beobachtung der Sterne bloß ergänzt wird. Gebetet wird angesichts der Küche kaum, und vor dem mafraj selten. Am häufigsten wird im 'Asīr im Freien gebetet, aber außerhalb des Hauses. Im 'Asīr und W. Najrān ist der Gebetsort daher ein „getrennter Raum“, sei es als Gebetsplatz außerhalb, oder als Gebetsraum innerhalb der Wohnhäuser. Das Dach im 'Asīr und W. Najrān ist also in jedem Fall kein Ort des Gebetes; es ist vielmehr ein Ort des wehrhaften Alltags, mit entweder eher männlicher oder eher weiblicher sozialer Ausrichtung.

Das Dach im südlichen Hijāz ist ebenfalls nicht dekoriert (sieht man einmal hier wie dort von den Zinnen ab, die ja zugleich die Fassade krönen). Aber seine soziale Ausrichtung ist im südlichen Hijāz eine andere, wie bereits gezeigt worden ist. Die Dächer der Wohnhäuser sind als Orte der pflegerischen Sorgfalt von Imkern, der zeitlichen Orientierung am Sternenhimmel, der rituellen Einkehr im Gebet, und damit insgesamt primär als Orte des Friedens identifiziert worden (Abb. 79).

Diese beiden verschiedenen sozialen und funktionalen Zusammenhänge geben für die friedliche und kollektive Ausrichtung des mafraj zwei verschiedene Kontexte vor: Das, was sich normalerweise „über" dem Innendekor befindet, ist verschieden. Hingegen liegt „unterhalb“ der Räume mit Binnendekor in beiden Subtypen Ähnliches, nämlich die Stallungen und Gerätekammern - also die nicht-menschlichen Dinge und Sachen, welche dem Menschen untergeordnet sind und ihm dienen und nützen.

Wir sehen hier von den ebenerdigen Wohnhäusern des südlichen Hijāāz und des Westund Nord-'Asīr ab, und weiters von jenen Wohnhäusern im 'Asīr, bei denen der mafraj am Dach tatsächlich der einzige mafraj des Hauses ist. Der letztgenannte Fall ist ohnedies selten, da die Dachterrasse meist nicht groß genug dafür ist. Beschränken wir uns also auf die häufigsten Fälle von zwei- und mehrgeschoßigen tribalen Wohnhäusern im südwestlichen Bergland, die einen mafraj nicht am Dach angelegt haben, so lassen sich zwei verschiedene Kontexte des Innendekors herausarbeiten:

Tab. 19: Architektonische Kontexte der Innen-Dekorflächen

\begin{tabular}{|l|l|l|}
\hline $\begin{array}{l}\text { Soziale Kontexte des Innendekors } \\
\text { in mehrgeschoßigen Wohnhäusern }\end{array}$ & \multicolumn{1}{|c|}{$\begin{array}{c}\text { Nordwestlicher Subtypus } \\
\text { (südlicher Hijāz) }\end{array}$} & \multicolumn{1}{|c|}{$\begin{array}{c}\text { Südöstlicher Subtypus } \\
\text { ('Asīr) }\end{array}$} \\
\hline Getrennte Räume & Kampf: in-towers & Gebet: Gebetsräume, -plätze \\
\hline Dach & Frieden und Gebet; Imkerei & $\begin{array}{l}\text { Wehrhaftigkeit; männlicher } \\
\text { oder weiblicher Alltag }\end{array}$ \\
\hline Dekor des mafraj & $\begin{array}{l}\text { friedlich und kollektiv } \\
\text { dekorierter Stützpfeiler }\end{array}$ & $\begin{array}{l}\text { kollektiv } \\
\text { bunte Innenbemalung }\end{array}$ \\
\hline Erdgeschoß & \multicolumn{2}{|c|}{ Vieh und Geräte } \\
\hline
\end{tabular}

Die Gegebenheiten im W. Najrān entsprechen jenen des 'Asīr bis auf die markante Tatsache, daß der mafraj hier selten bunt, sondern meistens weiß ausgemalt ist, was durch parallele Gegebenheiten in Madīnat Rijāl unterstrichen wird, und im Zusammenhang mit dem lokalen Einfluß religiöser Staatskultur interpretierbar ist.

Ansonsten gilt: Sowohl der nordwestliche, wie auch der südöstliche Subtypus hat dem Erdgeschoß das Nützliche und Untergeordnete zugeordnet; „unten“ markiert hier eindeu- 
tig nicht nur die geringe praktische Höhe, sondern auch die niedrige, dekorarme symbolische Bewertung.

Das architektonische „Oben“ ist in beiden Subtypen hingegen symbolisch auf jeweils verschiedene Weise konstruiert. Das Dach im südlichen Hijāz hat den Ort von Gebet und Frieden in die Wohnarchitektur integriert, und den Ort des Kampfes auf die davon getrennten in-towers verlagert. Das Dach im 'Asīr hat hingegen umgekehrt den Ort des Gebetes in getrennte Räume verlagert, und den Ort des Kampfes in die Wohnarchitektur integriert. Daraus läßt sich für die Kontexte des Innendekors beider Subtypen in idealtypischer Kondensierung und Vereinfachung des bisher Dargelegten das folgende Schema abstrahieren:

Tab. 20: Kontexte der dekorierten, inneren Mitte

\begin{tabular}{|l|c|c|}
\hline Kontexte & Südlicher Hijāz & 'Asīr \\
\hline oben (Dach) & Gebet & $\begin{array}{c}\text { Mann oder Frau, } \\
\text { Kampf oder Küche }\end{array}$ \\
\hline Mitte (Innendekor) & $\begin{array}{c}\text { Säule im Zentrum } \\
\text { tribaler Status }\end{array}$ & $\begin{array}{c}\text { bunte Wände } \\
\text { friedich und kollektiv }\end{array}$ \\
\hline unten (Erdgeschoß) & \multicolumn{2}{|c|}{ Nützliches und Untergeordnetes } \\
\hline
\end{tabular}

Dieses Schema unterstreicht, daß die dekorierte Säule im südlichen Hijāz eine ähnliche Stellung einnimmt wie die bunte Innenbemalung im 'Asīr, insoferne beide den mafraj im Inneren dekorieren, der am häufigsten eine Mittelposition einnimmt, „über“ dem Nützlichen und „unter“ dem Dach. Beide Dekorformen akzentuieren grundsätzlich tribalen Status in seiner friedlichen, über den Einzelhaushalt hinausreichenden Dimension, die kollektiv ist und sich an persönlich Anwesende richtet. Die dekorierte Innensäule tritt in der Felsstein-, der Schiefer- und der Lattenwandvariante des nordwestlichen Subtypus auf, die Innenmalerei im Steinbau, in der Pagoden- und der Adobe-Variante des 'Asīr. Expliziter als jede andere Dekorierung vereinigen diese beiden Formen die Varianten ihrer jeweiligen Subtypen, und grenzen diese voneinander ab. Innenbemalung und dekorierte Stützsäule sind daher strukturell vergleichbar, aber dieser Vergleich ergibt Verschiedenes: Ihre sozialen Kontexte verleihen diesen beiden, für die zwei Subtypen charakteristischen Dekorformen auch unterschiedliche symbolische Vorgaben.

Für den mafraj des 'Asīr ist bereits gezeigt worden, daß er - von den Wohnhäusern der Oberschicht abgesehen - nur in sehr geringem Maße von räumlicher Meidung der Geschlechter geprägt ist. Dem entspricht auch, daß die Malereien selbst stets von den Frauen und Mädchen des Hauses hergestellt sind (Abb. 80). ${ }^{371}$ Diese weibliche Verbindung zu bunten Farben findet sich auch in der Tracht von Frauen in vielen Teilen des 'Asīr wieder. Die bunte Innenmalerei im mafraj des 'Asīr steht also für einen signifikanten weiblichen Anteil am öffentlichen Leben und in der Sozialstruktur, und dies korrespondiert mit der sozialen Ordnung des Daches, wo Mann und Frau durch die Wehrhaftigkeit tribaler Ehre geschützt sind.

Für die Wohnhäuser des südlichen Hijāz wurde andererseits demonstriert, daß sie eingebunden sind in kollektive Aufteilung der Defensivaufgaben auf patrilineare Deszen-

371 cf. auch Philby 1976: 113; Thesiger 1947: 195; Mauger 1993: 21. 
denzverbände, und daß ihr mafraj primär ein Ort der Männer ist. Die Säule steht hier zwischen dem übergeordneten Ort des Gebetes, des Friedens, der Bitte um göttlichen Segen, und dem untergeordneten Nützlichen, vielleicht auch dem Unreinen. In dieser deutlichen Hierarchie zwischen göttlichem Segen (oben) und Minderwertigem (unten) liegt der primär männliche Raum, genutzt durch Angehörige von Deszendenzverbänden, und gestützt von der dekorierten Säule. Ich interpretiere die dekorierte Holzsäule aus diesem sozialen Kontext heraus als Symbol der Patrilinien, die sich Gott unterordnen: sharaf (Ehre) steht unter baraka (Segen), aber dieses Konzept von sharaf privilegiert die männlichen Nachfahren.

Meine Interpretation setzt damit eine Überlegung fort, die Walter Dostal 1989 zur Entwicklung der Verwandtschaftssysteme innerhalb der Kulturgeschichte Südarabiens vorgelegt hat. ${ }^{372}$ Demnach entspricht die bunte Innenbemalung in den Wohnhäusern des 'Asīr einer größeren Bedeutung von kognatischen Verwandtschaftssystemen in der sozialen Entwicklung der südwestarabischen Hochländer.

Die dekorierte Stützsäule in den Wohnhäusern des südlichen Hïjäz repräsentiert hingegen die elaborierten Prinzipien patrilinearer Deszendenzordnungen in diesem Randbereich zu Inner- und Nordarabien. Möglicherweise enthält sie dabei auch Restbestände des altorientalischen Motivs des Weltenbaumes, der Himmel und Erde verbindet. ${ }^{373}$

\footnotetext{
372 Dostal 1989: 47-62.

373 Widengren 1951: passim.
} 